\title{
Struktur-Funktionsbeziehungen in den spleißosomalen Proteinen des U4/U6•U5 tri-snRNP
}

\author{
Dissertation \\ zur Erlangung des Doktorgrades \\ der Mathematisch-Naturwissenschaftlichen Fakultäten \\ der Georg-August-Universität zu Göttingen
}

vorgelegt von

Nina Müllers

aus Bagdad, Irak

Göttingen 2006 
D7

Referent:

Prof. Dr. R. Ficner

Korreferent:

Prof. Dr. O. Einsle

Tag der mündlichen Prüfung:

02.11.2006 


\section{Inhaltsverzeichnis}

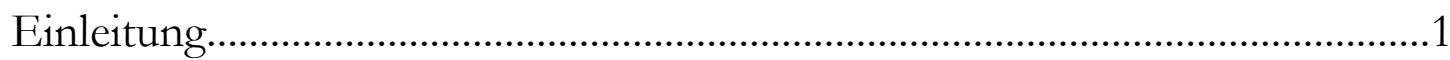

1.1 Einführung

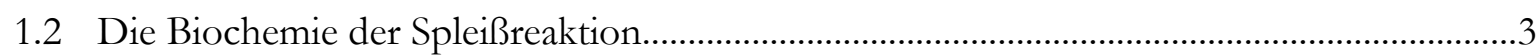

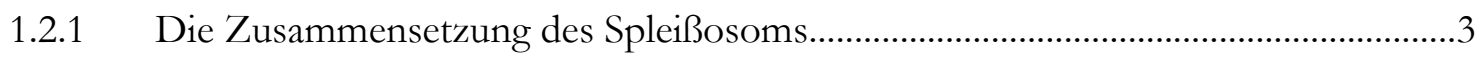

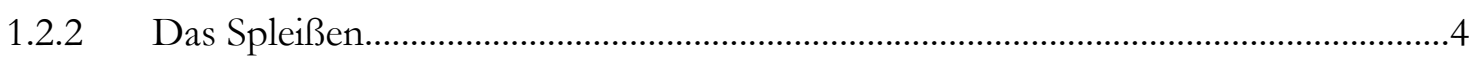

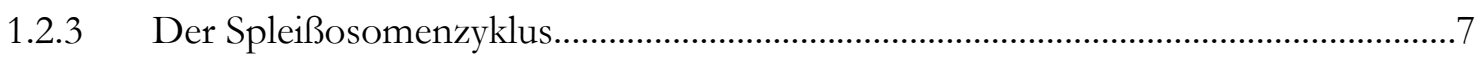

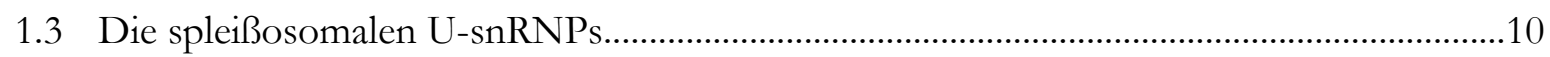

1.3.1 Die RNA-Komponenten des Spleißosoms - die U snRNAs....................................10

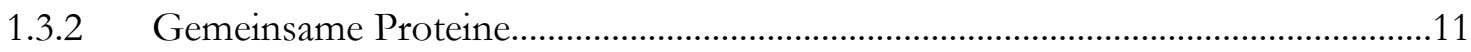

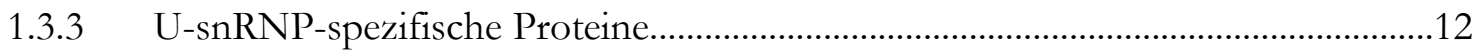

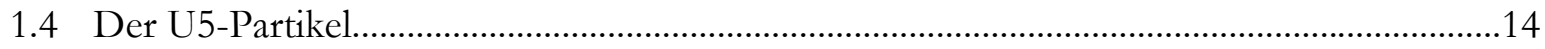

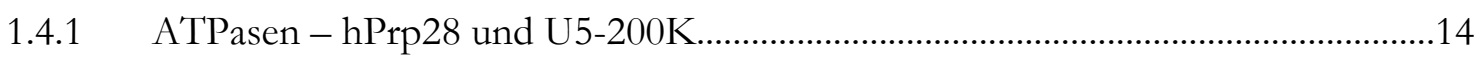

1.4.2 GTP-bindendes Protein - hSnu114 _..........................................................................16

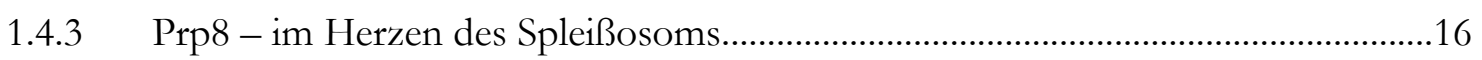

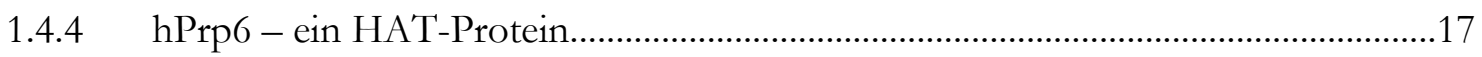

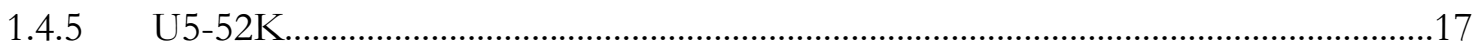

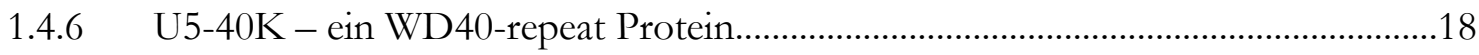

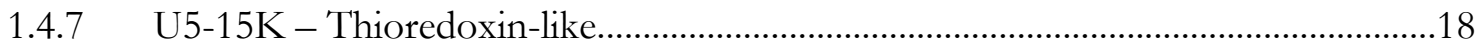

1.4.8 Die Bedeutung von U5-Proteinen im Spleißosom......................................................18

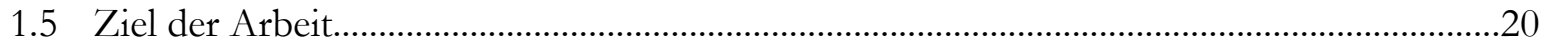

2 Material und Methoden................................................................................21

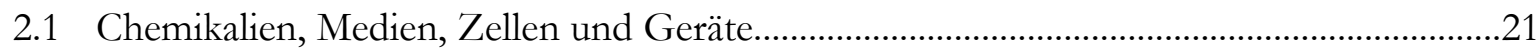

2.1.1 Chemikalien, Enzyme, Proteasen und Inhibitoren...................................................21 


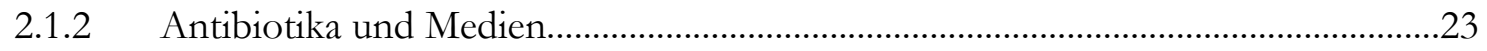

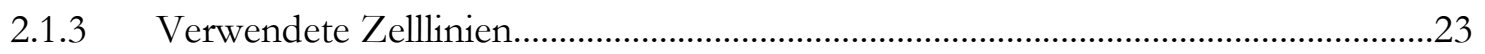

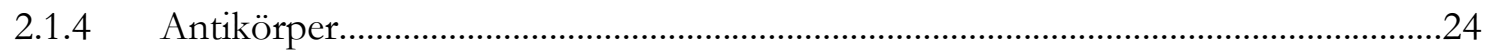

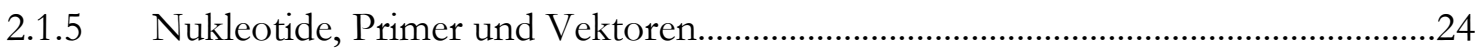

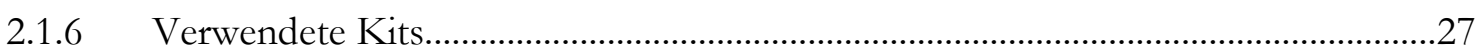

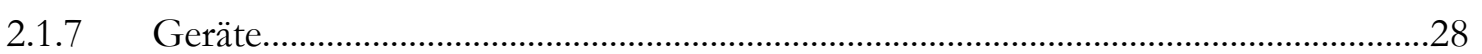

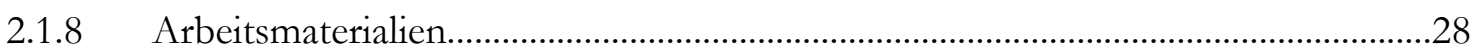

2.2 Allgemeine molekularbiologische Methoden..........................................................................

2.2.1 Bestimmung der Nukleinsäurekonzentration..................................................................

2.2.2 Extraktion und Fällung von Proteinen und Nukleinsäuren.........................................30

2.2.3 Agarosegelelktrophorese und Extraktion von DNA..................................................

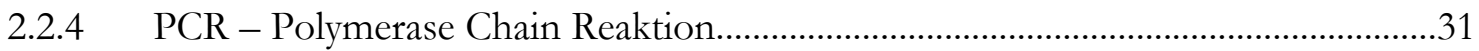

2.2.5 Enzymatischer Verdau und Ligation von Plasmiden und PCR-Fragmenten..........32

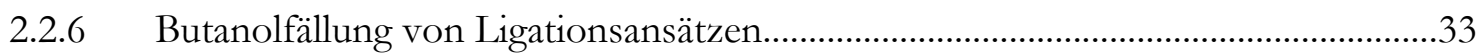

2.2.7 Transformation von Plasmiden in Bakterienzellen sowie deren Isolierung............33

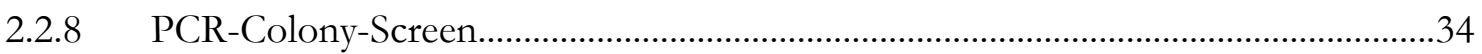

2.2.9 Herstellung kompetenter E. coli-Zellen für die Elektroporation...............................34

2.2.10 Herstellung kompetenter E. coli-Zellen für die Heat-Shock-Methode......................35

2.2.11 DNA-Sequenzierung und Analyse.............................................................................35

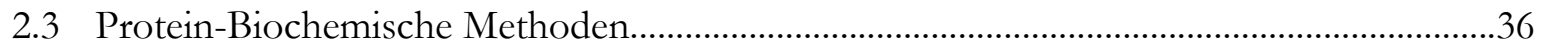

2.3.1 Diskontinuierliche SDS Polyacrylamid Gel Elektrophorese von Proteinen...........36

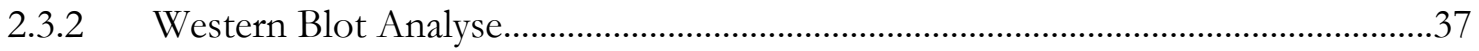

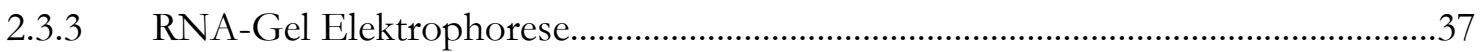

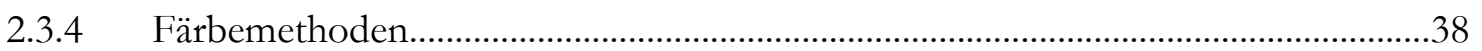

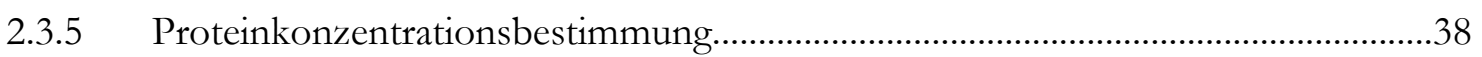

2.3.6 Konzentrierung von Proteinlösungen............................................................................ 
2.4 Expression und Reinigung von Fusionsproteinen in E. coli.......................................39

2.4.1 Analytische Expression von Fusions-Protein in E. coli................................................40

2.4.2 Präparative Expression von Fusions-Protein in E. coli.................................................40

2.4.3 Inclusion Body-Reinigung und Rückfaltung von Fusions-Protein............................40

2.4.4 Co-Expression von Fusionsproteinen in E. coli........................................................4

2.4.5 Aufschließen der Zellen mit Ultraschall.................................................................42

2.4.6 Proteinreinigung mit Ni-Affinitäts-Chromatographie............................................42

2.5 Expression und Reinigung von Snu114p in S. cerevisiae.........................................................4

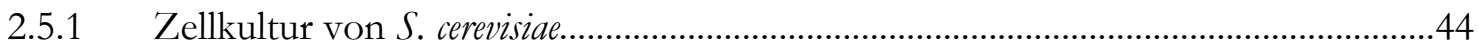

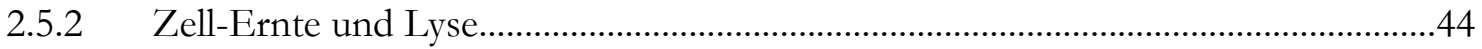

2.5.3 Reinigung von Snu114p mittels Ni-Affinitäts-Chromatographie...............................45

2.5.4 Reinigung mit IEX-Chromatographie (Q-Sepharose)................................................46

2.6 Insekten-Zellkultur und das Baculo-Virus Expressionssystem (BEVS) ..............................47

2.6.1 Transformation von pFASTBAC in E. coli DH10BAC und Überprüfung der positiven Klone

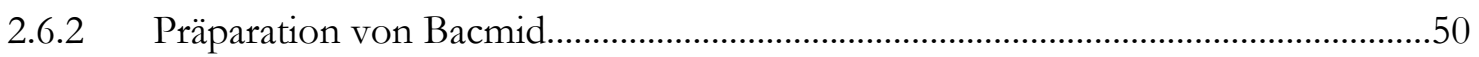

2.6.3 Transfektion von Insekten-Zellen...........................................................................

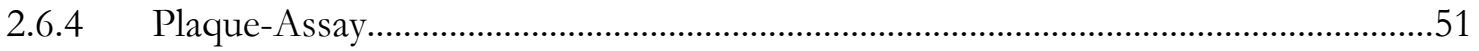

2.6.5 Mini-Expressions-Test...............................................................................................

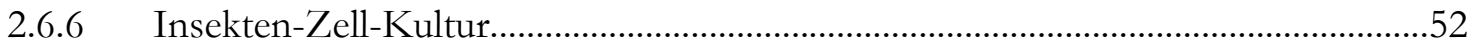

2.6.7 Generation von Cryo-Stocks und Kulturstart..............................................................52

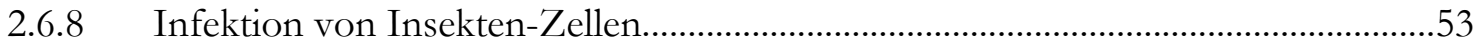

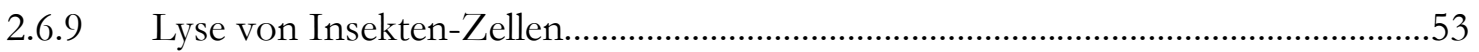

2.6.10 Reinigung mittels Ni-Affinitäts-Chromatographie.................................................53

2.6.11 Reinigung durch Size-Exclusion-Chromoatographie...............................................53

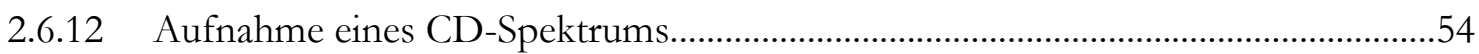


2.6.13 Kristallisation von rekombinantem hSnu114 . .54

2.7 Reinigung von Protein-Komplexen aus Kernextrakten. .55

2.7.1 Pelletierung von snRNP zur Anreicherung von U5-snRNP-Partikeln .55

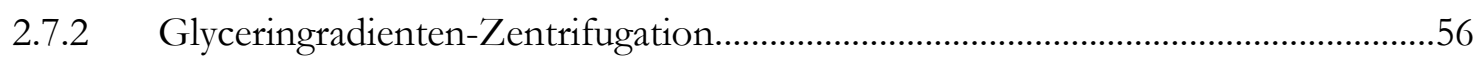

2.7.3 Repelletierung von komplexhaltigen Fraktionen.....................................................5

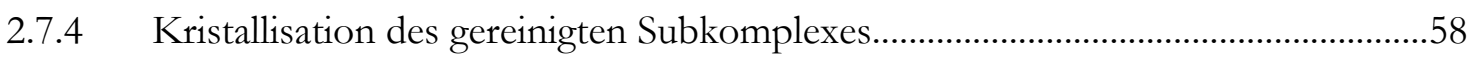

2.7.5 „Domain-Mapping“ durch limitierte Proteolyse..........................................................58

2.8 Bio-Informatische Methoden und verwendete Programme...................................................60

2.8.1 BLAST (Basic Local Alignment Search Tool) ............................................................60

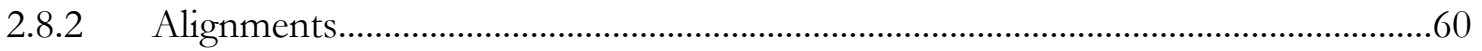

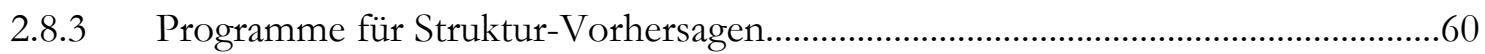

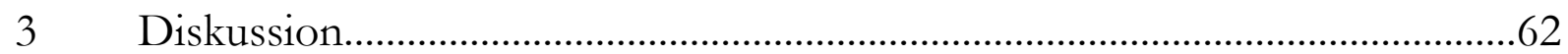

3.1 Gewinnung von rekombinantem hSnu114 in E. coli.......................................................62

3.1.1 Klonierung, Transformation, Expression und Rückfaltung von

GST-hSnu114.

3.1.2 Subklonierung von hSnu114 und Expressionstest......

3.1.3 1D NMR Spektrum eines Degradationsfragmentes der $\mathrm{N}$ terminalen aziden Domäne (Snu114p).

3.1.4 Zusammenfassung - Expression von rekombinantem Snu114p, hSnu114

und dessen Subdomänen in E. coli.

3.2 Limitierte Proteolyse des heterotetrameren Subkomplexes, Subklonierung und Coexpression.

3.2.1 Allgemeines zur limitierten Proteolyse. .69

3.2.2 Limiterten Proteolyse mit Trypsin und Gelfiltration des Subkomplexes. .69

3.2.3 Limitierte Proteolyse mit Asp-N. . .72 
3.2.4 Zusammenfassung der limitierten Proteolysen............................................................74

3.2.5 Subklonierung und Expression der zweiten Sec63-Domäne aus U5-200K............75

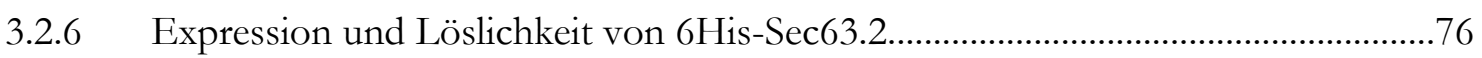

3.3 Coexpressionen verschiedener 6His-Prp8 und 6His-U5-200K Fragmente mit

GST-hSnu114. .77

3.3.1 Coexpression von GST-hSnu114 und 6His-Sec63.2 in E. coli.................................77

3.3.2 Coexpression von 6His-Prp8- und 6His-U5-200K-Fragmenten mit

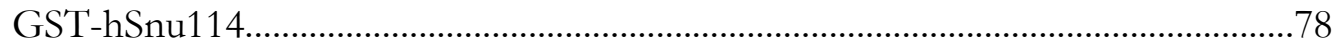

3.4 Expression von Domänen mit dem Duett-Vektor-System......................................................80

3.4.1 Untersuchung der einzelnen Domänen........................................................................

3.4.2 Löslichkeitstests von Domänen mit dem Duett-Vektor-System...............................81

3.4.3 Coexpressionen der Domänen im Duett-Vektor-System..........................................82

3.5 Untersuchung der „3' splice site high fidelity region“ (3'ss).................................................84

3.5.1 Expression, Inclusion Body-Reinigung und Rückfaltung von

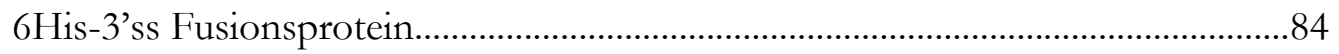

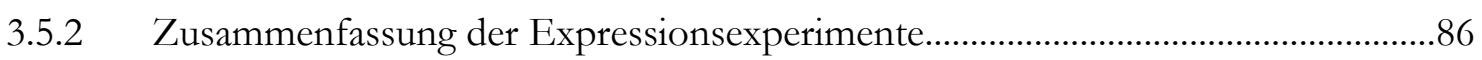

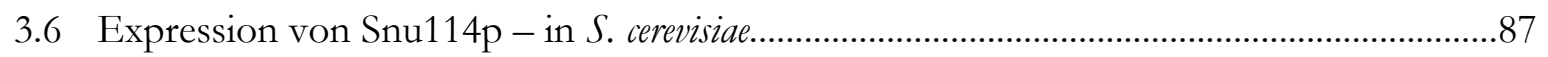

3.6.1 Expression und Reinigung des rekombinanten Proteins..........................................87

3.6.2 Zusammenfassung - Snu114p.................................................................................

3.7 Expression von hSnu114 durch das Baculo-Virus Expressions System (BEVS)................91

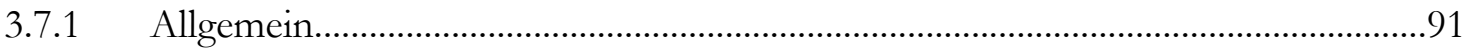

3.7.2 Generation der Klone und erste Expressionstests......................................................91

3.7.3 CD-Spektren von 8His-hSnu114 aus Insektenzellen...............................................94

3.7.4 Kristallisation von hSnu114 aus Insektenzellen......................................................

3.7.5 Zusammenfassung der Expression in Insektenzellen...............................................96

3.8 Reinigung nativer heterotetramer Komplexe und deren Kristallisation...............................97 
3.8.1 Konzentrationserhöhung des heterotetrameren Komplexes......................................98

3.8.2 Einfluß der $\mathrm{Mg}^{2+}$-Konzentration auf den heterotetrameren Komplex..................100

3.8.3 Guanidinium-Ionen als dissoziierendes Agens.......................................................100

3.8.4 Präparation aus Randfraktionen und U5-haltigen Fraktionen.................................101

3.8.5 Vergrößerung des Maßstabes bei der Reinigung für kristallisierbare Mengen.....103

3.8.6 Depletion von snRNPs aus der Komplex-Präparation durch eine zweite

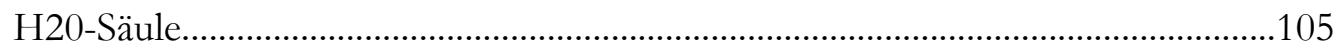

3.8.7 Dissoziation von Partikeln durch Behandlung mit RNAsen...................................107

3.8.8 Limitierte Proteolyse mit hochkonzentriertem Komplex.......................................109

3.8.9 Kristallisation des heterotetrameren Komplexes.......................................................111

3.8.10 Zusammenfassung - native Reinigung...............................................................111

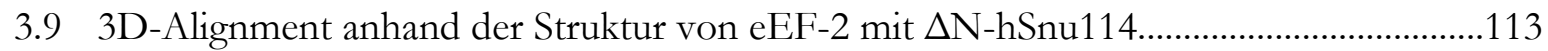

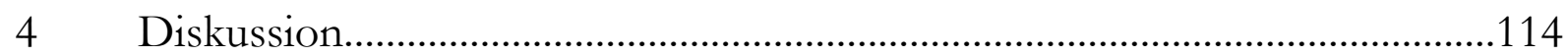

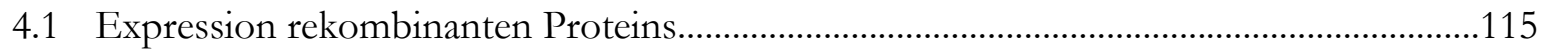

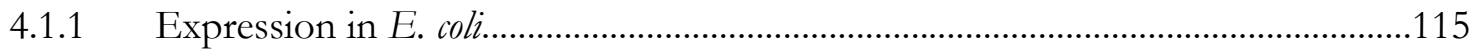

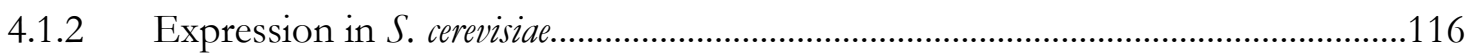

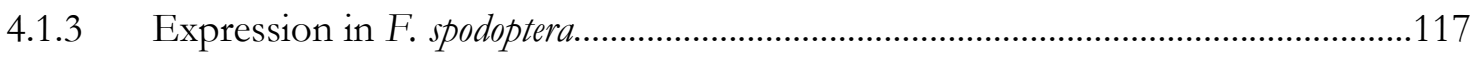

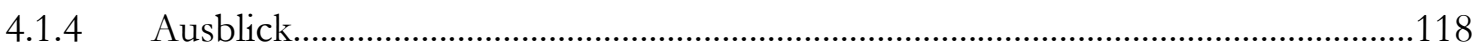

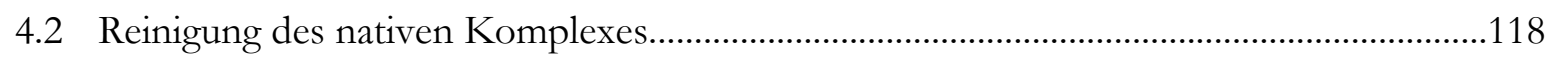

4.2.1 Anpassung des Maßstabes....................................................................................119

4.2.2 Verbesserung der Reinigung....................................................................................119

4.2.3 Kristallisationsexperimente der Proteinkomplexe.......................................................120

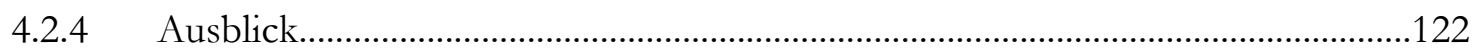

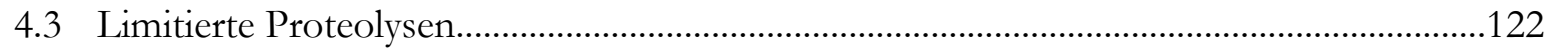

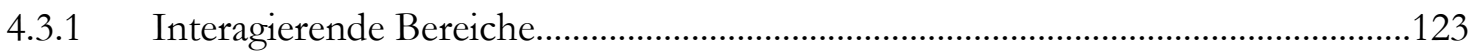




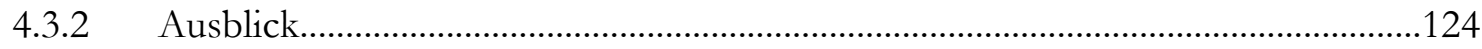

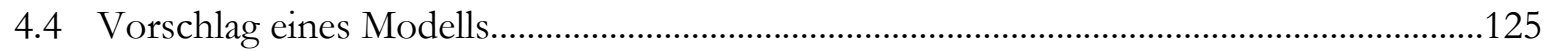

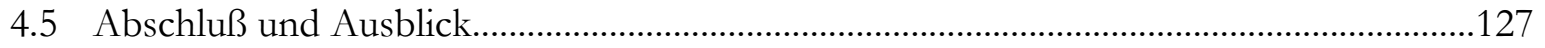

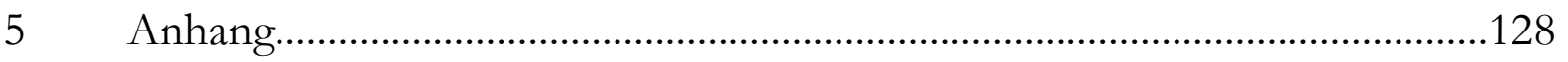

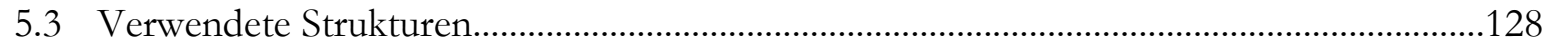

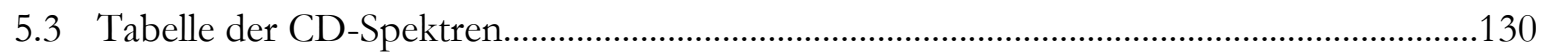

5.3 Verwendete Abkürzungen.................................................................................................132

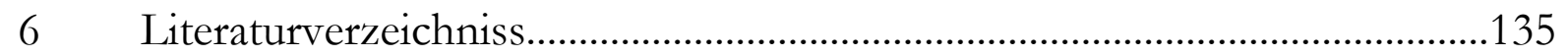




\section{Einleitung}

\subsection{Einführung}

Die vorliegende Arbeit beschreibt die Untersuchungen der spleißosomalen Proteine des U5 Partikels. Eine hoch aufgelöste Struktur des Spleißosoms ist immer noch ein Fernziel, da die Aufklärung des Spleißosoms aufgrund seiner hohen Dynamik und der heterogenen Zusammensetzung noch nicht möglich ist.

Warum ist die strukturelle Aufklärung interessant? Die Kenntnis des räumlichen Aufbaus der Reaktionszwischenprodukte, sowohl der zu spleißenden Prä-mRNA als auch der spleißosomalen Komponenten aus RNA und Protein, erhellt den Reaktionsmechanismus und gibt möglicherweise Hinweise auf die Entstehung des gesamten spleißosomalen Apparats.

Um die Prozesse in den modernen Zellen zu verstehen, muß man die Evolution der Zellen und so auch das Komplexerwerden der Prozesse in Betracht ziehen. Die Erbinformation wird mittels DNA gespeichert, bei Bedarf in RNA transkribiert und schließlich in Protein translatiert.

Ein Erklärungsversuch dieses komplexen Systems bietet die RNA-Welt Hypothese. Gemäß dieser Hypothese speicherten RNA-Moleküle die Erbinformation und hatten gleichzeitig katalytische Aktivität bei der Entstehung des Lebens. Im Laufe der Zellentwicklung von der Ur-Zelle bis zum heutigen Organismus übernahm die reaktionsinertere DNA die Aufgabe der Informationsspeicherung, und auf Grund ihrer größeren Vielseitigkeit - es gibt 20 verschiedene Aminosäuren, um Proteine mit enzymatischer Aktivität aufzubauen, und nur vier Nukleotide für RNA- bzw. DNAMoleküle - Proteine die der Reaktionskatalysation. Nichtsdestotrotz agiert RNA auch 
heute noch als Hauptkatalysator in grundlegenden Reaktionen der Zelle, so sind etwa die Translation und das Spleißen vermutlich RNA-basiert.

Ausgehend von der DNA wird eine mRNA (engl. messenger RNA) hergestellt, wobei die eukaryontische Gensequenz (das Primärtranskript, kurz Prä-mRNA), im Unterschied zur prokaryontischen, kodierende Sequenzbereiche (sogenannte Exons, expressed sequences) und nicht-kodierende Sequenzbereiche (sogenannte Introns, intervening sequences) aufweist.

Das Erkennen und Entfernen der Intronsequenzen erfolgt durch das RNASpleißen. Das Primärtranskript reift durch drei Schritte zur mRNA: Das 5'- und das 3'Ende des Primärtranskriptes werden jeweils modifiziert und die Introns werden entfernt. Anschließend katalysiert das Ribosom die Translation von mRNA in Proteinsequenz.

Wie oben angeführt, ist die eigentliche Spleißreaktion vermutlich RNA-vermittelt. Wozu braucht die höhere Zelle also so große proteinhaltige Komplexe, wie sie im Spleißosom vorkommen? Vermutlich wird die große Zahl der Proteinkomponenten benötigt, um die erforderliche hohe Genauigkeit der Spleißreaktion zu gewährleisten und gleichzeitig die feine Regulierbarkeit zu erhalten, die für einen komplexen Organismus notwendig ist. Beispielsweise werden gewebespezifische Spleißvarianten hergestellt, und man möchte eruieren ob und gegebenenfalls, wie die Proteinkomponenten zu dieser feinen Abstimmung beitragen.

Die strukturelle Untersuchung der spleißosomalen Proteine soll auf lange Sicht ihre Rolle während des Spleißens aufklären, also die genaue Aktion und gleichzeitig ihre Regulation. Während die Strukturaufklärung eine sehr komplexe Fragestellung darstellt, ist die Charakterisierung der Komponenten schon ein Fortschritt. Sie ermöglicht die Definition von strukturellen Einheiten und unterstützt letzten Endes die Strukturaufklärung. 
Auf den folgenden Seiten werden die Spleißreaktion und ihre Komponenten, soweit bekannt, vorgestellt. Dabei wird ein besonderer Fokus auf das U5-snRNP gelegt, welches den Gegenstand dieser Arbeit darstellt. Am Ende findet sich eine Zielsetzung der Arbeit.

\subsection{Die Biochemie der Spleißreaktion}

\subsubsection{Die Zusammensetzung des Spleißosoms}

Das Spleißosom setzt sich auf einer Prä-mRNA zusammen. Damit ein vollständiges Spleißosom entsteht, müssen fünf kernlokalisierte RibonukleoproteinPartikel, die U-snRNP-Partikel (engl. uridine-rich small nuclear ribonucleoprotein particles), und eine große Anzahl nicht-U-snRNP-assoziierter Spleißfaktoren miteinander interagieren und in einer festgelegten Reihenfolge auf der Prä-mRNA gebunden werden. In jedem U-snRNP-Partikel sind verschiedene Spleißfaktoren um eine, oder wie im Falle des U4/U6 di-snRNP-Partikels um zwei RNA-Moleküle organisiert, nach denen sich die Bezeichnung des einzelnen U-snRNP-Partikels richtet. Bei den Komponenten, die die snRNP-Partikel ausmachen, unterscheidet man zwischen einer RNA-Komponente und den Proteinkomponenten. Die RNA-Moleküle sind uridinreich und zeichnen sich durch hohe Stoffwechselstabilität und phylogenetische Konservierung aus. Die Proteinkomponenten oder Spleißfaktoren gliedern sich in die gemeinsamen Proteine, welche in allen Partikeln vorkommen, die partikelspezifischen Proteine, die sich durch ihre hohe Bindungsstabilität innerhalb des Partikels und ihre katalytischen Eigenschaften - Depletion eines Proteins führt zu einem Spleißstopp - auszeichnen, und schließlich die nicht-U-snRNP-assoziierten Spleißfaktoren, welche an der Assemblierung des Spleißosoms und der Katalyse beteiligt sind, sich allerdings nicht fest mit einem Partikel assoziieren. 


\subsubsection{Das Spleißen}

Der Reaktionsmechanismus des Spleißens besteht aus zwei nacheinander ablaufenden, stereospezifischen Transesterifizierungsreaktionen, die an den IntronExon-Grenzen erfolgen (Abbildung 1.1). Die Gesamtanzahl der Phosphordiesterbindungen bleibt im Edukt und in den Produkten gleich, also ist die Netto-Energiebilanz der Spleißreaktion ausgeglichen (Konarska et al., 1985; Lin et al., 1985). Allerdings verbrauchen die zahlreichen proteinkatalysierten Umlagerungen, die während der Bildung des Spleißosoms, dessen Aktivierung und den Neuordnungen innerhalb des Reaktionsverlaufs erfolgen, Energie. Die Gesamtenergiebilanz der Spleißreaktion fällt deswegen positiv, also energieverbrauchend aus. Im ersten Schritt wird die Prä-mRNA an der 5'-Spleißstelle (engl.: 5' splice site) geschnitten, sodaß das 5'liegende Exon 1 vom Intron getrennt wird. Dieser Schnitt erfolgt durch den nukleophilen Angriff der Ribose-2'-Hydroxylgruppe des hochkonservierten Verzweigungspunktadenosins im Intron auf das Phosphoratom der 3'-ständigen Phosphatgruppe des Exons 1. Das Adenosin ist eine der drei Komponenten, aus denen sich die 3'-Spleißstelle (engl.: 3' splice site, im Folgenden „3'-ss“) zusammensetzt. Neben dem Adenosin gehören noch der Polypyrimidintrakt und die eigentlichen 3'-ss, also die 3'-Seite des Exon 2 zu dieser 3'-Spleißstelle (Reed et al., 1989). Nach dem Angriff des Verzweigungspunktadenosin entsteht im Exon 1 eine freie 3'-Hydroxylgruppe, wohingegen das Intron-Exon-2-Molekül durch die gebildete 2',5'Phosphordiesterbindung in Form eines Lassos (engl.: lariat) vorliegt.

Der nukleophile Angriff des 3'-Hydroxylsauerstoffatoms am Exon 1 auf die 5'ständige Phosphatgruppe des Exons 2 (3'-ss) stellt den zweiten katalytischen Schritt dar. Dabei kommt es zu einer kovalenten Verknüpfung der beiden Exons (Ligation) und dem Entfernen des Introns, das zunächst weiter in der Form eines Lassos mit einer freien 
OH-Gruppe am 3'-Ende vorliegt, aber dann rasch abgebaut wird (zur Übersicht: (Burge et al., 1999; Moore und Sharp, 1993)).
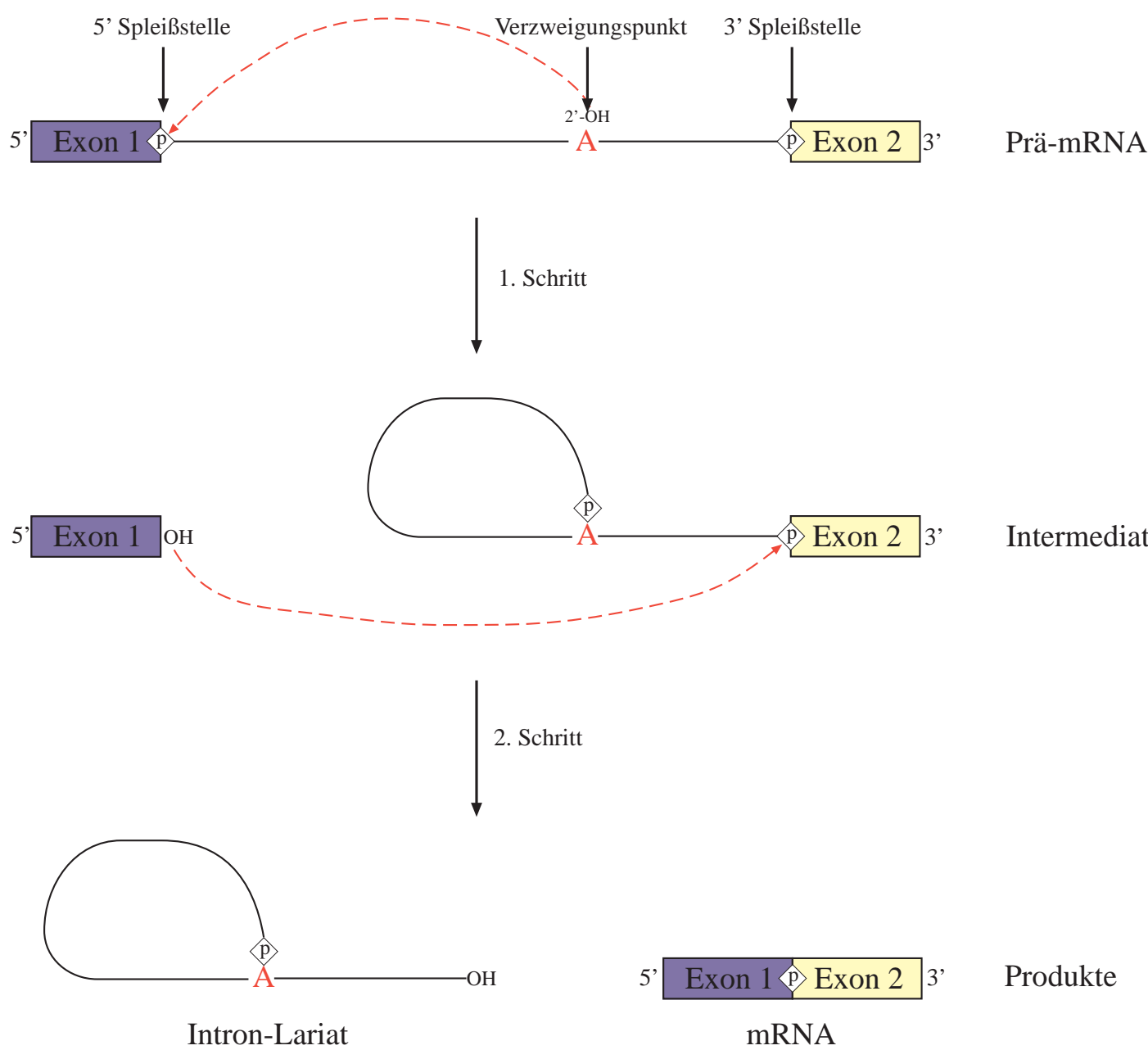

Abbildung 1.1: Schematische Darstellung der Spleißreaktion. Die nukleophilen Angriffe der 2'-Hydroxylgruppe des Verzweigungspunktadenosins auf die 5'-Spleißstelle (Schritt 1) und der 3'-Hydroxylgruppe des herausgeschnittenen Exons 1 auf die 3'-Spleißstelle (Schritt 2) sind durch gestrichelte Linien dargestellt.

Die Entdeckung der selbstspleißenden Introns (Kruger et al., 1982) unterstützt die Theorie, daß die reine Spleißreaktion RNA-katalysiert ist und die Proteinfaktoren für die Reaktion offenbar nicht obligatorisch sind. Diese Daten unterstreichen außerdem die RNA-Welt Hypothese. Ein weiterer interessanter Aspekt ist, daß sowohl die selbstspleißenden Typ II Introns als auch die vom Spleißosom prozessierten Introns ein Intron-Lariat bilden (Michel und Ferat, 1995; Cech et al., 1990). Das Vorhandensein 
gleicher Produkte deutet auf die katalytische Aktivität der snRNA-mRNA-Komplexe hin (Cech et al., 1990; Sharp et al., 1985; Sontheimer und Steitz, 1993; Strauss und Guthrie, 1991). Die Sequenz- und Strukturgemeinsamkeiten (beispielsweise das Intron-Lariat und Sequenzgemeinsamkeiten) für einen RNA-basierten Mechanismus sind bei snRNAs und selbstspleißenden Introns nicht groß genug, um die genaue Ableitung eines Mechanismus zuzulassen (Hausner et al., 1990; Michel und Ferat, 1995). Allerdings ist die Entstehung und der zugrundeliegende Reaktionsmechanismus durch die Reiche konserviert worden Die Aufklärung des Mechanismus und die strukturellen Voraussetzungen werden daher intensiv erforscht. Daß die katalytische Aktivität der snRNAs wahrscheinlich ist, wird durch die übereinstimmende Stereochemie der Spleißreaktionen (Maschhoff und Padgett, 1993; Moore und Sharp, 1993; Padgett et al., 1994) und durch die MetallionenKoordination (Sontheimer et al., 1999; Sontheimer et al., 1997) deutlich.

Ein Model der Interaktionen zwischen snRNAs und Prä-mRNA im katalytisch aktiven Spleißosom wurde durch Arbeiten von Madhani, Staley, Umen und Guthrie (Madhani und Guthrie, 1992; Staley und Guthrie, 1998; Umen und Guthrie, 1995) ermöglicht und bei Burge (Burge et al., 1999) diskutiert.

Eine strukturelle Aufklärung des Spleißosoms und seines katalytischen Zentrums auf atomarer Ebene ist wegen seiner Komplexität und Dynamik - zum Beispiel die Umorganisation des U5-Parikels während der Spleißosomenaktivierung (Makarov et al., 2002) - zur Zeit nicht möglich. Bis dahin bedeutet die Charakterisierung der katalytischen Untereinheiten, also sowohl der Partikel als auch der einzelnen Proteine, einen wesentlichen Schritt zum vollständigen Verständnis der Spleißreaktion. 


\subsubsection{Der Spleißosomenzyklus}

Der Vorgang des Spleißens umfaßt nicht nur die Bindung der einzelnen Partikel auf der Prä-mRNA und die Katalyse der Reaktion, sondern auch das Recycling der Partikel, wodurch sie für weitere Spleißreaktionen zur Verfügung stehen (Burge et al., 1999; Nilsen et al., 1998; Staley et al., 1998). Die bekannten Zustände des komplexen spleißosomalen Systems sind in Abbildung 1.2 dargestellt.

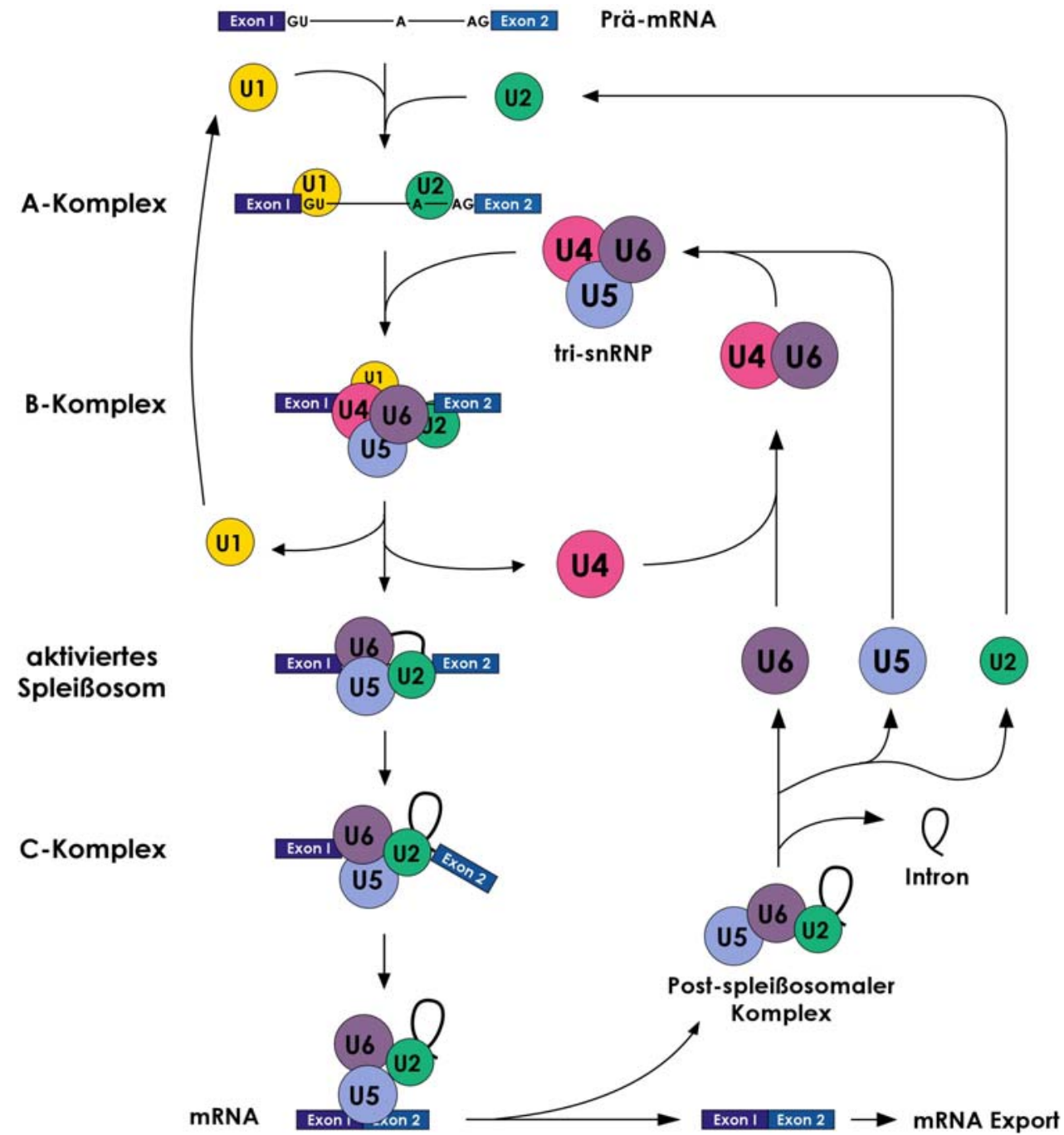

Abbildung 1.2 Schematische Darstellung der Spleißosomenassemblierung. Die Zusammensetzung des Spleißosoms auf der Prä-mRNA beginnt mit der Basenpaarung der U1-snRNA und der 5'-Spleißstelle. Anschließend bindet das U2-snRNP-Partikel an den Verzweigungspunkt (A-Komplex). Durch Integration des prä-assemblierten U4/U6•U5-tri-snRNP-Partikels entsteht der B-Komplex. Strukturelle Umwandlungen führen zum katalytisch aktiven Spleißosom, im Verlauf der Spleißreaktion werden U1 und U4 freigesetzt. Im Anschluß an den ersten Katalyseschritt der Spleißreaktion bleibt die Prä-mRNA im CKomplex mit dem Spleißosom assoziiert. Erst nach dem zweiten Schritt werden das Intron und die reife mRNA freigesetzt, und das Spleißosom zerfällt in seine Bestandteile, die somit für einen neuen Spleißzyklus zur Verfügung stehen (Staley und Guthrie, 1998). 
Der E-Komplex ist der erste isolierbare Komplex und besteht aus der Prä-mRNA und dem durch komplementäre Basenpaarung gebundenen U1-Partikel. Die Intronsequenz der 5'-Spleißstelle bindet das 5'-Ende der U1-snRNA (Reed und Palandjian 1997; Siliciano und Guthrie, 1988; Zhuang und Weiner, 1985). Anschließend wird der U2-Partikel energieabhängig gebunden, und man erhält den A-Komplex oder das Prä-Spleißosom (Reed und Palandjian, 1997).

Der U4/U6•U5-tri-snRNP bindet das Prä-Spleißosom als vorgefertigter Komplex, wodurch der B-Komplex, das präkatalytische Spleißosom, entsteht. Im weiteren Verlauf werden bestehende RNA-RNA-Interaktionen zwischen den U4- und U6-snRNAs unterbrochen und neue bilden sich zwischen U6-snRNA und der 5'Spleißstelle aus, wodurch das präkatalytische Spleißosom in das aktivierte Spleißosom (B -Komplex) überführt wird (Staley und Guthrie, 1998). Durch die weitreichenden konformellen Veränderungen verlassen U1 und U4 das Spleißosom (Lamond et al., 1988; Yean und Lin, 1991). Somit wird die katalytisch aktive Sequenz der U6-snRNA zur U2snRNA in das aktive Zentrum des Spleißosoms gerückt (Madhani und Guthrie, 1992; Sun und Manley, 1995; Wu und Manley, 1991). Nach der ersten Transesterifizierungsreaktion entsteht als Übergangsform der C-Komplex. Im Anschluß an die zweite Transesterifizierungsreaktion werden die reife mRNA und das IntronLariat freigesetzt.

In der Zelle kommt es dann zu einem Recycling der Partikel. Das heißt, die spleißosomalen Partikel nehmen an weiteren Spleißreaktionen teil, wobei der tri-snRNP Partikel sich hierarchisch assembliert (siehe auch die Dissertation von N. Schaffert). Die Protein-Komponenten aller Partikel werden in Tabelle 1.1 aufgelistet. In dieser Arbeit werden die dort genannten Namen für die humanen Proteine verwendet.

Zunächst wird der U4/U6-di-snRNP gebildet. Der erste Schritt ist die Bindung der 5'-Haarnadelschleife der U4-snRNA durch das U4/U6-15.5K-Protein. Das hPrp31- 
Protein wird gebunden und der $\mathrm{CypH}$-, hPrp4- und hPrp3-Subkomplex integriert (Nottrott et al., 1999; Nottrott et al., 2002). Im weiteren Verlauf wird das p110-Protein an die U6-snRNA gebunden, das zwar Bestandteil des U4/U6-di-snRNPs ist, allerdings bislang weder im tri-snRNP noch im Spleißosom gefunden werden konnte. Man nimmt daher an, daß es bei der Bildung des tri-snRNP-Partikels den Komplex verläßt (Bell et al., 2002; Makarova et al., 2002). Die Bindung zwischen U4/U6-di-snRNP und U5-Partikel könnte in der Interaktion des di-snRNP-spezifischen Protein hPrp31 und dem hPrp6 begründet sein. Dazu gibt es biochemische (Makarov et al., 2000) und Two Hybrid-Daten (Makarova et al., 2002), die diese Annahmen unterstützen. So stellt man sich die Bildung und die Bindung innerhalb des tri-snRNPs vor (Liu et al., 2006).

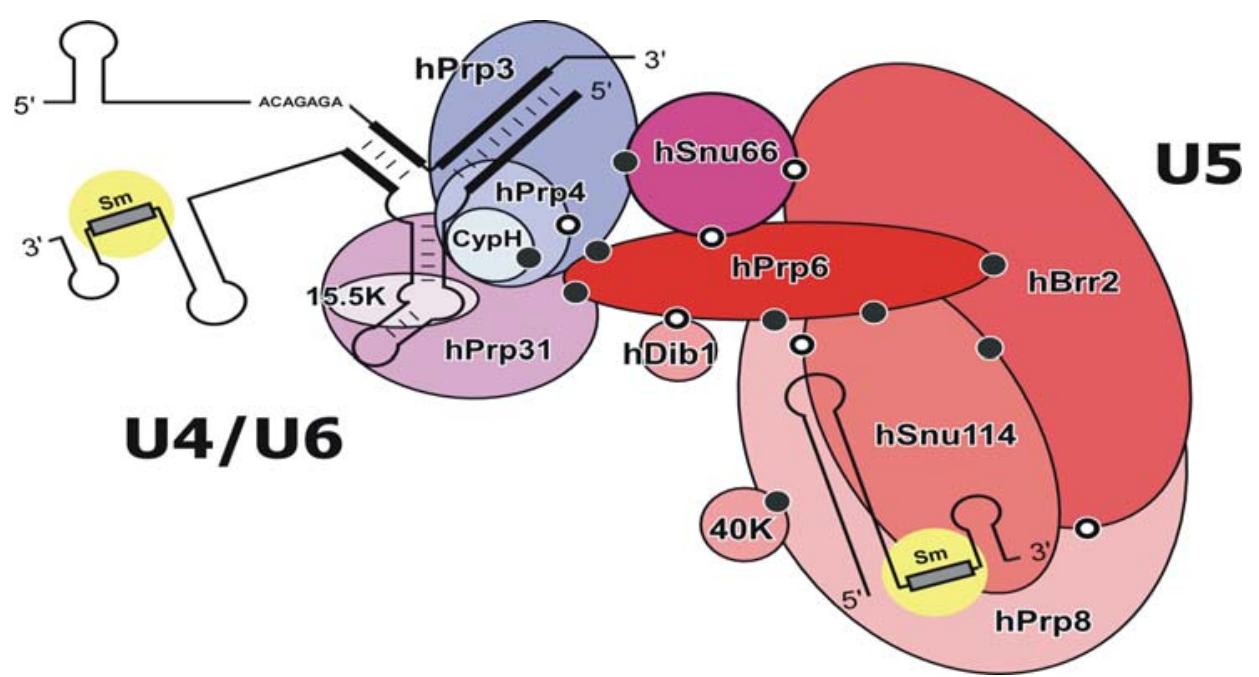

Abbildung 1.3: Der tri-snRNP - seine Zusammensetzung und Interaktionen aus Liu et al., 2006. Alle Punkte bezeichnen Protein-Protein-Interaktionen, die bei Liu et al. gezeigt werden konnten. Punkte in schwarz und weiß bezeichnen Interaktionen, die auch bei den Hefeorthologen gezeigt worden sind. $\mathrm{hBrr} 2$ ist $\mathrm{U} 5-200 \mathrm{~K}$. 


\subsection{Die spleißosomalen U-snRNPs}

\subsubsection{Die RNA-Komponenten des Spleißosoms - die U-snRNAs}

Aufgrund ihrer Sequenz lassen sich die fünf U-snRNAs U1, U2, U4, U5 und U6 unterscheiden, die in ihrer Länge zwischen 106 und 187 Nukleotiden variieren (Lamond et al., 1993a; Lamond et al., 1993b; Sharp et al., 1988). Diese snRNAs werden, außer U6, von RNA-Polymerase II transkribiert und besitzen eine 2'2'7-Trimethylguanosin-Kappe ( $\mathrm{m}_{3} \mathrm{G}$-Kappe) am 5'-Ende (Mattaj et al., 1986). Ein weiteres Charakteristikum für alle snRNAs mit Ausnahme von U6 ist die konservierte Sm-Bindungsstelle $\left(\mathrm{YAU}_{3-6} \mathrm{GY}\right.$; mit „Y“ für Purinbasen) (Branlant et al., 1982; Jarmolowski und Mattaj, 1993; Jones und Guthrie, 1990; Raker et al., 1999; Raker et al., 1996). Der Sonderfall U6-snRNA wird von RNA-Polymerase III transkribiert und besitzt ein $\gamma$-Monomethylphosphat am 5'-Ende (Kunkel et al., 1986; Reddy et al., 1987; Singh und Reddy, 1989). Außerdem werden viele für die Modulation der RNA-RNA-Interaktionen und in der Assemblierung der aktiven spleißosomalen Komponenten bedeutsame Nukleotide (Yu et al., 1998) postranskriptionell zu Pseudouridinen, 6-Methylguanosinen oder durch 2'-O-RiboseMethylierungen modifiziert (Massenet et al., 1998). Die U-snRNAs bilden komplexe Sekundärstrukturen aus, welche als Bindungsplattformen für die Proteinkomponenten dienen. Im Verlauf der Spleißreaktion bilden die U-snRNAs dynamische komplementäre Basenpaarungen mit dem Prä-mRNA-Substrat und untereinander aus, die sowohl für die Erkennung der Spleißstellen als auch die Katalyse der Spleißreaktion essentiell sind. In Abbildung 1.3 werden die humanen U-snRNAs im Überblick dargestellt. 

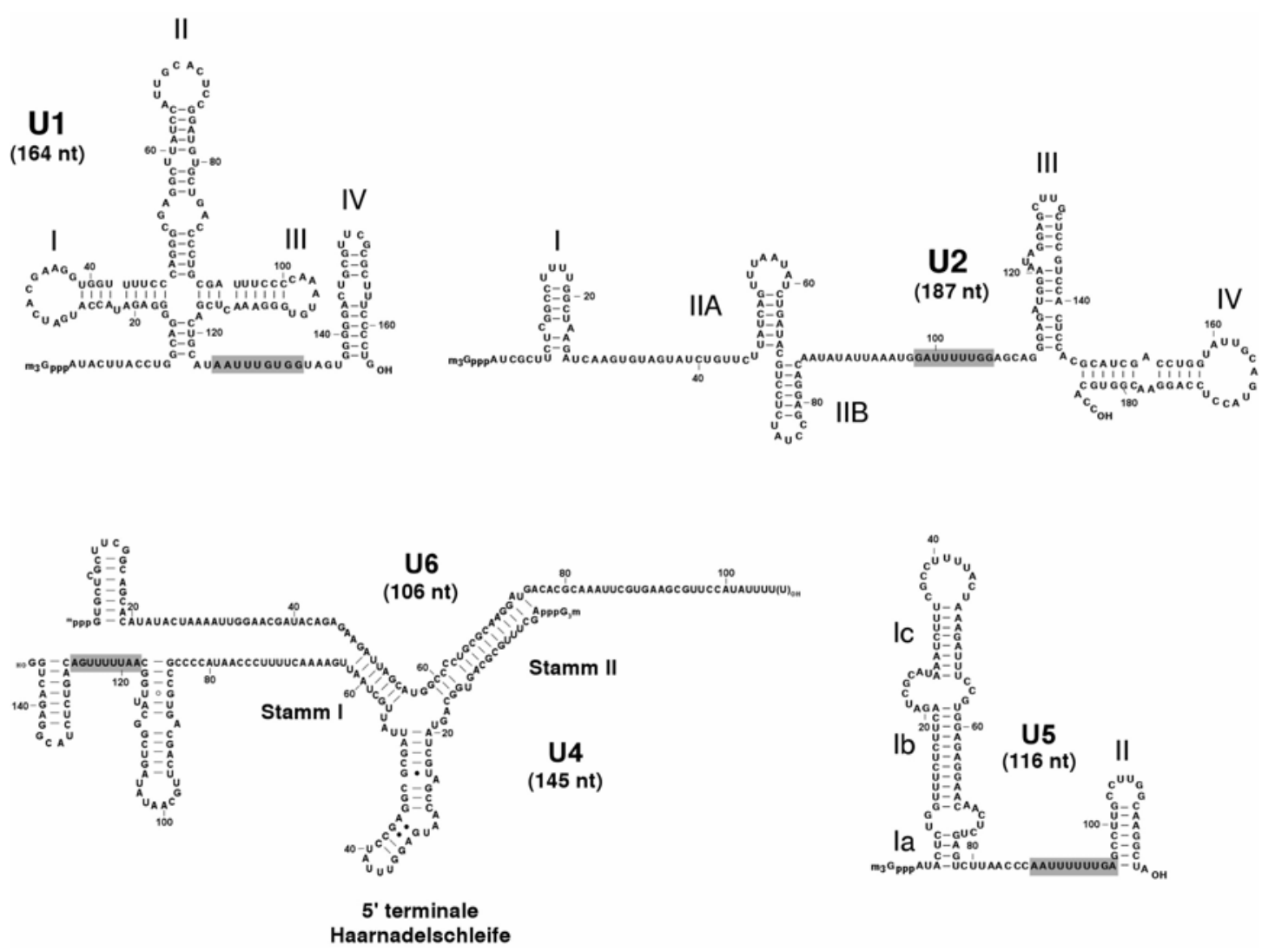

Abbildung 1.4: Primärsequenzen und postulierte Sekundärsequenzen der humanen U-snRNAs. Die Sequenzen der Sm-Bindungsstellen sind grau hinterlegt (nach Brow und Guthrie, 1988; Burge et al., 1999).

\subsubsection{Gemeinsame Proteine}

Wie bei der Vorstellung der snRNAs schon erwähnt, besitzen alle Partikel, mit Ausnahme des U6-snRNP, eine Sm-Bindungsstelle. Allen sieben Sm-Proteinen (B/B', wobei B' eine Spleißvariante von B darstellt, $D_{1}, D_{2}, D_{3}, E, F$ und G) ist das Sm-Motiv gemeinsam, durch welches sie sich auf der Sm-Bindungsstelle anlagern. Die Identifikation dieser Gruppe war möglich, weil Antiseren von Lupus erythematodesPatienten (Schmetterlingsflechte) mit Sm-Proteinen kreuzreagieren (Lerner et al., 1978). $\mathrm{D}_{1} / \mathrm{D}_{2}, \mathrm{E} / \mathrm{F} / \mathrm{G}$ und $\mathrm{B} / \mathrm{D}_{3}$, bzw. B'/ $\mathrm{D}_{3}$ bilden Subkomplexe, welche sich dann zu einer höheren Struktur ordnen. Die gebundenen Sm-Proteine an der snRNA nennen sich core-snRNP (Hermann et al.,. 1995; Raker et al., 1999; Raker et al., 1996). Die U6-snRNA bindet sieben Proteine, die aufgrund ihrer Ähnlichkeit Lsm-Proteine (engl. Like-Sm) 
genannt werden (Séraphin et al, 1995). Durch die strukturelle Aufklärung der

Subkomplexe $\mathrm{B} / \mathrm{D}_{3}$ und $\mathrm{D}_{1} / \mathrm{D}_{2}$ mittels Röntgenkristallographie konnte eine heteroheptamere Ringstruktur von Kambach et al. postuliert werden (Kambach et al., 1999).

\subsubsection{U-snRNP-spezifische Proteine}

Neben den Proteinen, die allen Partikeln gemeinsam sind, gibt es noch eine große Anzahl (etwa 200) partikelspezifischer Proteine (Zhou et al., 2002). Diese Proteine haben bestimmte Funktionen im spleißosomalen Zyklus. Zum Beispiel dienen sie der Erkennung der Prä-mRNA oder entwinden den U4/U6-RNA-Duplex (Will et al., 1997). Die Erkenntnisse aus biochemischen und massenspektrometrischen Studien bezüglich der Partikelzusammensetzung (Hartmuth et al., 2002; Jurica et al., 2002; Makarov et al., 2002; Rappsilber et al., 2002,) sind in Tabelle 1.1 zusammengefaßt (Kastner et al., 1998).

Die Proteine des U5-Partikels, werden in Abschnitt 1.4 genauer besprochen. 


\begin{tabular}{|c|c|c|c|c|c|c|c|c|}
\hline \multicolumn{3}{|c|}{ U snRNP Proteine } & $\begin{array}{l}\text { app. Mr } \\
\text { kDa }\end{array}$ & $\begin{array}{c}12 \mathrm{~S} \\
\mathrm{U} 1\end{array}$ & $\begin{array}{l}17 \mathrm{~S} \\
\mathrm{U} 2\end{array}$ & $\begin{array}{c}20 \mathrm{~S} \\
\text { U5 }\end{array}$ & $\begin{array}{c}135 \\
\text { U4/U6 }\end{array}$ & $\begin{array}{c}25 \mathrm{~S} \\
\text { U4/U6.U5 }\end{array}$ \\
\hline \multicolumn{2}{|c|}{$\begin{array}{c}\text { gemeinsame } \\
\text { Proteine }\end{array}$} & $\begin{array}{c}\text { B/B' } \\
\text { D3 } \\
\text { D2 } \\
\text { D1 } \\
\text { E } \\
F \\
G\end{array}$ & $\begin{array}{c}28 / 29 \\
18 \\
16.5 \\
16 \\
12 \\
11 \\
9\end{array}$ & $\begin{array}{l}0 \\
0 \\
0 \\
0 \\
0 \\
0 \\
0\end{array}$ & $\begin{array}{l}0 \\
\bigcirc \\
\bigcirc \\
\bigcirc \\
\bigcirc \\
\bigcirc \\
0\end{array}$ & $\begin{array}{l}0 \\
0 \\
0 \\
0 \\
0 \\
0 \\
0\end{array}$ & $\begin{array}{l}0 \\
0 \\
0 \\
0 \\
0 \\
0 \\
0\end{array}$ & $\begin{array}{l}0 \\
0 \\
0 \\
0 \\
0 \\
0 \\
0\end{array}$ \\
\hline \multirow{5}{*}{ 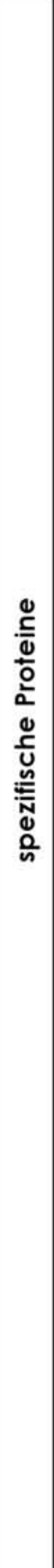 } & $\begin{array}{l}\text { U1 } \\
\text { snRNP }\end{array}$ & $\begin{array}{c}70 K \\
A \\
C\end{array}$ & $\begin{array}{l}70 \\
34 \\
22\end{array}$ & $\begin{array}{l}\bigcirc \\
\bigcirc \\
\bigcirc\end{array}$ & & & & \\
\hline & $\begin{array}{l}\text { U2 } \\
\text { snRNP }\end{array}$ & $\begin{array}{c}A^{\prime} \\
B^{\prime \prime} \\
\text { SF3a120 } \\
\text { SF3a666 } \\
\text { SF3a60 } \\
\text { SF3b155 } \\
\text { SF3b145 } \\
\text { SF3b130 } \\
\text { SF3b49 } \\
\text { SF3b 14a/p14 } \\
\text { SF3b14b } \\
\text { SF3b10 } \\
\text { hPrp5 } \\
\text { SR140 } \\
\text { CHERP } \\
\text { hPrp43 } \\
\text { SPF45 } \\
\text { SPF31 } \\
\text { SPF30 }\end{array}$ & $\begin{array}{c}31 \\
28.5 \\
120 \\
66 \\
60 \\
160 \\
150 \\
120 \\
53 \\
15 \\
15 \\
9 \\
140 \\
140 \\
130 \\
90 \\
50 \\
33 \\
31\end{array}$ & & $\begin{array}{l}0 \\
0 \\
0 \\
0 \\
0 \\
0 \\
0 \\
0 \\
0 \\
0 \\
0 \\
0 \\
0 \\
0 \\
0 \\
0 \\
0 \\
0 \\
0\end{array}$ & & & \\
\hline & $\begin{array}{l}\text { U5 } \\
\text { snRNP }\end{array}$ & $\begin{array}{c}\text { hPrp8 } \\
\text { U5-200K } \\
\text { hSnul114 } \\
\text { hPrp6 } \\
\text { hPrp28 } \\
\text { U5-52K } \\
\text { U5-40K } \\
\text { U5-15K } \\
\end{array}$ & $\begin{array}{l}220 \\
200 \\
116 \\
102 \\
100 \\
52 \\
40 \\
15 \\
\end{array}$ & & & $\begin{array}{l}0 \\
\bigcirc \\
\bigcirc \\
0 \\
0 \\
0 \\
\bigcirc \\
0 \\
\end{array}$ & & $\begin{array}{l}0 \\
0 \\
0 \\
0 \\
0 \\
0 \\
0 \\
0 \\
\end{array}$ \\
\hline & $\begin{array}{l}\text { U4/U6 } \\
\text { SnRNP }\end{array}$ & $\begin{array}{l}\text { hPrp3 } \\
\text { hPrp31 } \\
\text { hPrp4 } \\
\text { CypH } \\
\text { U4/U6-15.5K } \\
\text { Lsm2 } \\
\text { Lsm3 } \\
\text { Lsm4 } \\
\text { Lsm5 } \\
\text { Lsm6 } \\
\text { Lsm7 } \\
\text { Lsm8 } \\
\end{array}$ & $\begin{array}{c}90 \\
61 \\
60 \\
20 \\
15.5 \\
10 \\
15 \\
15 \\
10 \\
8 \\
13 \\
13 \\
\end{array}$ & & & & $\begin{array}{l}1 \\
1 \\
1 \\
1 \\
1 \\
0 \\
0 \\
0 \\
0 \\
0 \\
0 \\
0\end{array}$ & $\begin{array}{l}\text { (1) } \\
\text { (1) } \\
\text { (1) } \\
\text { (1) } \\
0\end{array}$ \\
\hline & $\begin{array}{l}\text { U4/U6.U5 } \\
\text { tri-snRNP }\end{array}$ & $\begin{array}{l}110 \mathrm{~K} \\
65 \mathrm{~K} \\
27 \mathrm{~K}\end{array}$ & $\begin{array}{c}110 \\
65 \\
27\end{array}$ & & & & & \\
\hline
\end{tabular}

Tabelle 1.1 Proteinzusammensetzung der humanen U-snRNP-Partikel (Kastner et al., 1998). 


\subsection{Der U5-Partikel}

Der U5-Partikel hat einen Sedimentationskoeffizienten von $20 \mathrm{~S}$ und ist der größte Partikel. Zusammen mit dem 13S U4/U6-di-snRNP bildet der U5-Partikel auf RNA-unabhängigem Wege den tri-snRNP, welcher mit etwa 30 spezifischen Proteinen die größte funktionelle Einheit des Spleißosoms bildet (Will und Lührmann, 2006).

Neben den partikelunspezifischen Sm-Proteinen gehören acht spezifische Proteine zum U5-Partikel. Sie werden nach ihren apparenten Molekulargewichten U515K, U5-40K, U5-52K, hPrp28, hPrp6, hSnu114, U5-200K und Prp8 genannt (Bach et al., 1989; Behrens und Lührmann, 1991). In Hefe wurde gezeigt, daß die Proteine mit einer Ausnahme (Snu40p) essentiell sind (Fabrizio et al., 1997; Lauber et al., 1996). Die ATPasen und die einzige bekannte GTPase sind vermutlich an den dynamischen Umstrukturierungen des Spleißosoms während dessen Aktivierung beteiligt (Will und Lührmann, 1997).

Der U5-Partikel hat einen salzstabilen Kern aus U5-40K, hSnu114 U5-200K und Prp8 der keine RNA gebunden hat (Achsel et al., 1998). Dieser Subkomplex ist durch seine Stabilität und seine starken intermolekularen Wechselwirkungen gekennzeichnet. Dazu wurden bereits Two-Hybrid- und in vitro-Affinitäts-Studien von Liu et al. (Liu et al., 2006) durchgeführt.

\subsubsection{ATPasen - hPrp28 und U5-200K}

Von den acht U5-spezifischen Proteinen gehören zwei, U5-200K und hPrp28, deren Hefehomologe Brr2p und Prp28p heißen, zur Familie der DEXD/H-Box ATPasen. Zur Aktivierung des Spleißosoms wird die Bindung der U1-snRNA an der 5'ss aufgelöst und U6 bindet, nachdem der U4/U6-Duplex ebenfalls gelöst wurde (Kim und Rossi, 1999; Raghunathan und Guthrie, 1998). Es konnte gezeigt werden, daß 
Prp28p für die Lösung der U1-snRNA von der 5'-ss verantwortlich ist (siehe dazu den Review (Staley und Guthrie, 1998)). Diese Konformationsänderung kann durch die Entwindung der Helix zwischen U1 und der 5'-ss vonstatten gehen, oder durch die Destabilisierung der U1C Bindung an die 5'-ss. Damit wäre Prp28p ein geeigneter Kandidat für eine RNPase. Prp28p ist essentiell in Hefe, kann aber deletiert werden, wenn U1C mutiert vorliegt (Staley und Guthrie, 1999).

Durch in vitro-Experimente konnte gezeigt werden, daß U5-200K in der Lage ist, RNA-Helices, wie den basengepaarten U4/U6-Duplex, zu entwinden (Bartels et al., 2002; Bartels et al., 2003; Fabrizio et al., 1997, Laggerbauer et al., 1998; Raghunathan und Guthrie, 1998; Xu et al., 1996). In Hefe konnte die ATP-abhängige Auftrennung des U4/U5•U6 tri-snRNP mit mutiertem Brr2p nicht nachgewiesen werden (Raghunathan und Guthrie, 1998).

Betrachtet man diese Ergebnisse, erscheint U5-200K als RNA entwindendes Motorprotein, welches die Freisetzung des U6-Partikels vor der Assoziation mit der 5'-ss und der Interaktion mit U2 katalysiert (Raghunathan et al., 1997).

Des weiteren besitz U5-200K zwei Sec63-Domänen, die den beiden ATPasen jeweils nachgeschaltet sind. Die Funktion der Sec63-Domänen ist nicht bekannt, dient aber möglicherweise der Proteinbindung an snRNP-Partikel (Ponting et al., 2000). Die zweite Sec63-Domäne interagiert mit den spleißosomalen Proteinen Prp16p und Snp1p (van Nues und Beggs, 2001).

Auch wenn die Aktivitäten der ATPasen klar definiert sind, ist doch ihre Fähigkeit zur konzertierten Aktion gering. Daher sind weitere Faktoren notwendig, die die genaue zeitliche und räumliche Abstimmung der ATPase-Aktivität regulieren. Diese Rolle könnte von hSnu114 und Prp8 übernommen werden. Diese Proteine werden im Folgenden besprochen. 


\subsubsection{GTP-bindendes Protein - hSnu114}

hSnu114 hat ein essentielles Hefeortholog namens Snu114p. Es konnte gezeigt werden, daß Snu114p homolog zu den Translations-Elongationsfaktoren EF-G, bzw. EF-2 ist und als putative GTPase (Fabrizio et al., 1997) an der Entwindung der U4/U6 Helix in der Spleißosomaktivierung beteiligt ist. Entweder wird U4/U6 durch direkte energieabhängige Wechselwirkung mit U5-200K entwunden, oder hSnu114 reguliert U5200K, welches die erforderliche, oben im Text diskutierte Funktion hat (Bartels et al., 2002; Bartels et al., 2003). Außerdem könnte hSnu114 nach dem ersten Spleißschritt die Exons für den zweiten Schritt ausrichten (Staley und Guthrie, 1998).

\subsubsection{Prp8 - im Herzen des Spleißosoms}

Prp8 wird als der Proteincofaktor im RNA-abhängigen katalytischen Zentrum des Spleißosoms diskutiert (Collins und Guthrie, 1999; Collins und Guthrie, 2000). Prp8p (aus Hefe) und Prp8 sind zu $62 \%$ identisch, was bei einem Protein mit mehr als 2300 Aminosäuren ob der Größe um so beachtlicher ist. Man hat bei Prp8pInteraktionen mit den U5- und U6-snRNAs und dem Prä-mRNA-Substrat in den Bereichen der Spleißstellen und des Verzweigungspunktes gefunden (Dix et al., 1998; Vidal et al., 1999; Wyatt et al., 1996).

Alle Untersuchungen weisen auf eine zentrale Rolle im katalytischen Zentrum des Spleißosoms: Dabei mag es sich um Konformationsänderungen, Aktivierung, Teilnahme als Cofaktor oder Regulator für die ATPase hPrp28 und U5-200K handeln.

Nach kürzlich veröffentlichten Studien können eine grobe Struktur der funktionellen Einheiten und einige Domänen für Prp8p postuliert werden (Boon et al., 2006; Grainger und Beggs, 2005). Durch bioinformatische Untersuchungen wurde eine MPN (Mpr-1, Pad-1. N-terminal Domäne, von Aminosäure 2173 bis 2310), eine RRM 
(engl. RNA recognition Motif von Aminosäure 1059 bis 1151) und ein mutmaßliches NLS (engl. nuclear localisation signal von Aminosäure 96 bis 156) gefunden. Außerdem konnten Grenzen für funktionelle Einheiten definiert werden. Diese Grenzen teilen das Protein bei Aminosäuren 394 bis 443, 770 und 2170-2179. Die letzte Grenze fällt mit der MPNDomäne zusammen und bestätigt sie.

\subsection{4 hPrp6 - ein HAT-Protein}

Dieses Protein besitzt $13 \underline{\text { H}}$ alf $\underline{A}$ Tetratrico peptide repeats, welche in RNAbindenden Proteinen gefunden wurden (Lamb et al., 1995; Preker et al., 1998), und ein Tetratrico peptide repeat Motif und hat ein Ortholog in Hefe (Prp6p). TPRs sind als Plattform für spezifische Protein-Protein-Interaktionen während der Bildung von makromolekularen Maschinen bekannt (D'Andrea und Regan, 2003; Scheufler et al., 2000) und bilden strukturell zwei antiparallele $\alpha$-Helices (Blatch und Lassle, 1999). Das hPrp6 ist durch diese Protein-Protein-Wechselwirkungen fest an U5 gebunden und vermittelt die Interaktion mit dem U4/U6-61K, wodurch der tri-snRNP entsteht. Diese Beziehung wurde durch Two Hybrid-Interaktionen nachgewiesen, da sich die biochemische Untersuchung als äußerst schwierig erwiesen hatte (Makarov et al., 2000; Makarova et al., 2002). Konsistent damit wird Prp6p in Hefe mit dem U4/U6 Partikel assoziiert gefunden, wobei diese Tatsache die Funktion des hPrp6 als Interaktionsvermittler zwischen U4/U6 und U5 unterstreicht.

\subsubsection{U5-52K}

Außer einer GYF-Domäne wurden keine Charakteristika des U5-52K gefunden. Es besitzt ein Ortholog in Hefe, das Snu40p oder Lin1p genannt wird. Dieses Protein ist 
das einzige bisher bekannte nicht essentielle spleißosomale Protein (Fabrizio et al., 1997; Jackson et al., 1988; Lauber et al., 1996; Reuter et al., 1999; Strauss und Guthrie, 1994).

\subsubsection{U5-40K - ein WD40-repeat Protein}

U5-40K bildet eine Ausnahme im U5 Partikel, denn es besitzt in Hefe kein bekanntes Ortholog (Gottschalk et al., 1999; Stevens und Abelson, 1999). Es besitzt WDrepeats (Neer et al., 1994), welche aus etwa 40 Aminosäuren bestehen und mit einem Tryptophan (W) und einem Aspartat (D) enden. Dieses Strukturmotiv wird in G-Proteinen und Effektormolekülen für die Signaltransduktion gefunden. WD-repeats bilden einen siebenblättrigen $\beta$-Propeller, der als Proteininteraktionsplattform dient (Branden und Tooze, 1991).

\subsubsection{U5-15K - Thioredoxin-like}

Die Struktur des U5-15K wurde gelöst und zeigt, daß U5-15K eine thioredoxinähnliche Struktur hat. Es hat eine nicht-kanonische Disulfidbrücke und zeigt keine Disulfidisomeraseaktivität. Durch seine hinzugekommenen 37 Aminosäuren - im Vergleich zum humanem Thioredoxin - stellt es einen weiteren Faktor für die ProteinProtein-Interaktionen dar (Reuter und Ficner, 1999; Reuter et al., 1999). Das Ortholog in Hefe heißt Dip1p.

\subsubsection{Die Bedeutung von U5-Proteinen im Spleißosom}

Die Bedeutung von U5 wird durch verschiedene Methoden untersucht und wird klarer. Durch phylogenetische Untersuchungen wurden ein neun invariante Nukleotide in einem elf Nukleotide umfassende Haarnadelschleife gefunden (Frank et al., 1994). Die

U5 Haarnadelschleife interagiert mit beiden Exonsequenzen (Newman et al., 1995; 
Newman und Norman, 1992; Sontheimer und Steitz, 1993; Wyatt et al., 1996). Die Bindung der U5-RNA an das 5' Exon erfolgt vor dem ersten Spleißschritt und bleibt während beider Spleißreaktionen erhalten. Man geht daher von einer Ankerfunktion von U5 für das 5' Exon aus. Das Zwischenprodukt aus der ersten Spleißreaktion wird dann in direkte Nachbarschaft des 3' Exons für den zweiten Reaktionsschritt gebracht (Newman und Norman, 1992; Sontheimer und Steitz, 1993). So gesehen wäre die U5Haarnadelschleife das Äquivalent der exonbindenden Haarnadelschleife ID3 in selbstschneidenden Typ II Introns (Michel und Ferat, 1995). Bei selbstschneidenden Introns wird die Bindung über komplementäre Basenpaarung erreicht, während die Bindung der U5-Haarnadelschleife alle Exonsequenzen erkennen können muß. Die Fragen, die sich stellen, sind also: i) Wie kann die Erkennung und Bindung von U5snRNP an eine prä-mRNA verbessert werden? ii) Wird diese Bindung durch den Proteinanteil bewirkt? iii) Wie wird U5 an die 5'-Exonsequenz gebunden, und wie werden dann die katalytisch relevanten Bereiche von U2 und U6 in eine direkte Nachbarschaft gebracht?

Von Prp8 ist bekannt, daß es an beide Exonsequenzen bindet und im katalytisch aktiven Spleißosom Kontakt zur 3' Spleißstelle ausbildet (Reyes et al., 1996). Prp8 wird als aktivierender Faktor für U5-200K und/oder hSnu114 diskutiert (Liu et al., 2006). U5200K und hSnu114 sind vermutlich die treibenden Kräfte bei der Aktivierung des Spleißosoms. Der genaue Ablauf ist nicht bekannt und würde durch strukturelle Aufklärung näher beschrieben werden können. Ein mögliches Modell ist die direkte Bindung an die RNA-Doppelhelix und deren enzymatisch katalysierte ATPverbrauchende Entwindung. Das zweite Modell sieht eine Helicase oder GTPase des aktiven Zentrums vor, welches nach der Hydrolyse eines Triphosphates einen „Power stroke" aussendet, welcher durch die einzelnen Komponenten weitergegeben wird und in 
der Entwindung resultiert (Liu et al., 2006; Will und Lührmann, 2001), woraufhin das Spleißosom aktiviert ist.

Wie bereits diskutiert, ist eine hochaufgelöste Struktur des Spleißosoms vor, während und nach den Transesterifizierungsreaktionen das Fernziel der strukturbiologischen Untersuchungen. Durch Cryo-EM können Daten bezüglich der Morphologie der U-snRNP-Komplexe gewonnen werden, allerdings ist die Identifikation der einzelnen Proteinkomponenten immer noch notwendig, da es sich bei den zu untersuchenden Proteinen um Komponenten mit enzymatischer Aktivität handelt, deren strukturelle Aufklärung in einem Komplex sehr hohe Anforderungen an die Homogenität des Partikels und dessen Zustands stellt. Der U5-Partikel ist von großem Interesse, weil durch ihn wichtige Faktoren zum katalytischen Zentrum gebracht werden. Auch beim Vergleich zwischen dem majoren, oben beschriebenen Spleißosom und dem minoren, U12-abhängigen Spleißosom, fällt auf, daß der einzige beiden Spleißosomen gemeinsame Partikel der U5-Partikel ist. Das unterstreicht die Wichtigkeit der Charakterisierung des Partikels, bzw. seiner Proteine.

\subsection{Ziel der Arbeit}

In dieser Arbeit sollten die Proteine des U5-Partikels weiter untersucht und charakterisiert werden, um die Kenntnis der Abläufe zu vertiefen, unter denen es zur Ausbildung des katalytischen Zentrums kommt. Daher sollten stabile Subkomplexe des U5-Partikels isoliert, charakterisiert und nach Möglichkeit auch röntgenkristallographisch untersucht werden. Gleichzeitig soll die Expression, Reinigung und die Untersuchung der Funktionalität der gewünschten Proteine, bzw. deren Domänen, weitere Möglichkeiten eröffnen. Eine weitere Strategie ist die Gewinnung nativer Subkomplexe 
in ausreichender Menge und von höchstmöglicher Güte für die Durchführung von Kristallisationsversuchen. 


\section{Material und Methoden}

\subsection{Chemikalien, Medien, Zellen und Geräte}

\subsubsection{Chemikalien, Enzyme, Proteasen und Inhibitoren}

Alle übrigen, hier nicht aufgeführten Standardchemikalien, organischen Substanzen sowie Lösungsmittel (Reinheitsgrad p.a.) wurden von Applichem (Darmstadt), Merck (Darmstadt), Roth (Karlsruhe), Serva (Heidelberg) oder Fluka (Schweiz) bezogen

Acrylamidlösungen, gebrauchsfertig Ammoniumperoxodisulfat (APS)

N, N, N', N'-Tetramethylethylendiamin (TEMED)

Agarose

Ampicillin

Bacto-Agar

Bradford Reagenz

Bromphenolblau

Chloramphenicol

Coomassie Brilliant Blau R/G250

N'N-Dimethyldodecylamin-N-oxide (30 \% LDAO)

Dimethylsulphat (DMS)

Dimethylsulfoxid (DMSO)

Dithiothreitol (DT')

DNA Molekulargewichtsmarker (III, VI)

Dodecylsulfat Natriumsalz (SDS)

Dulbecco's Mod. Eagle Medium (DMEM)

EDTA Dinatriumsalz Dihydrat

Ethanol

Ethidiumbromidlösung $(10 \mathrm{mg} / \mathrm{ml})$

Essigsäure

Fötales Kälberserum (FCS)

Glutathion, reduziert

Glycin

Glycogen

Glyzerin

Guanidinium Hydrochlorid

Harnstoff

Hepes (N-2-Hydroxyethylpiperazin-N-2-ethansulfonsäure)

Imidazol

Isopropyl- $\beta$-D-thiogalactosid (IPTG)

Kaliumchlorid

Kaliumphosphat

LB-Agar Medium

LB-Medium

Lipofektin

Lysozym

Magermilchpulver, instant
National Diagnostics Atlanta

Merck (Darmstadt)

Sigma, Deisenhofen

Invitrogen, Karlsruhe

Sigma, Deisenhofen

Difco Laboratories, USA

Biorad, München

Merck, Darmstadt

Boehringer, Mannheim

Serva, Heidelberg

Fluka, Schweiz

Fluka, Schweiz

Roth, Karlsruhe

Roth, Karlsruhe

Boehringer, Mannheim

Merck, Darmstadt

Invitrogen, Groningen

Merck, Darmstadt

Merck, Darmstadt

Boehringer, Mannheim

Merck, Darmstadt

GibcoBRL, Karlsruhe

Sigma-Aldrich, Steinheim

Merck, Darmstadt

Invitrogen, Groningen

Merck, Darmstadt

Fluka, Schweiz

Roth, Karlsruhe

Calbiochem, USA

Merck, Darmstadt

Sigma-Aldrich, Steinheim

Roth, Karlsruhe

Sigma, Deisenhofen

Q-Biogene, USA

Q-Biogene, USA

GibcoBRL, Karlsruhe

Boehringer, Mannheim

De-Vau-Ge, Lüneburg 
Magnesium Chlorid

2-Mercaptoethanol

Methanol

Natriumacetat

Natriumchlorid

Natriumcitrat

Natriumthiosulphat

NDSB-256[3-(1-Pyridino)-1-Propan Sulphat]

Neutralrot Lösung

Polyethylenglycol 240-8000

Phenol

PMSF (Phenylmethysulfonylfluorid)

Roti-Phenol

Roti-Phenol/Chloroform

Precision Proteinstandard Marker

PVDF-Membran

Silbernitrat

Sodium dodecyl sulphate (SDS)

N,N,N',N'-Tetramethylethylendiamin (TEMED)

Triton X-100

Tris-(hydroxymethylen)aminomethan (Tris)

Trypsin-EDTA

Tween-20

X-Gal (5-Bromo-4-Chloro-3-Indolyl- $\beta$-D-Galactopyranosid)

Xylencyanol FF
Merck Eurolab, Hannover

Roth, Karlsruhe

Merck, Darmstadt

Sigma, Deisenhofen

Roth, Karlsruhe

Roth, Karlsruhe

Merck Eurolab, Hannover

Calbiochem, USA

Sigma-Aldrich, Steinheim

Merck, Eurolab, Hannover

Roth, Karlsruhe

Boehringer, Mannheim

Roth, Karlsruhe

Roth, Karlsruhe

BioRad, München

Amersham Biosciences, Freiburg

Merck Eurolab, Hannover

Merck Eurolab, Hannover

Sigma-Aldrich, Steinheim

Sigma-Aldrich, Steinheim

Roth, Karlsruhe

GibcoBRL, Karlsruhe

Calbiochem, Darmstadt

Clontech, Heidelberg

Fluka, Schweiz

Restriktions Endonukleasen, Ligase, die dazugehörigen Puffer wurden von NEW ENGLAND BIOLABS, Frankfurt a.M., verwendet. Pfu DNA Polymerase $(2.5 \mathrm{U} / \mu \mathrm{l})$ von Stratagene, Heidelberg, und Taq Polymerase von Promega, USA.

Pefa-Bloc von Biomol, Hamburg, und Complete EDTA-free ${ }^{\text {TM }}$ Tabletten von Roche, Mannheim wurden neben den einzelnen Inhibitoren verwendet.

Aprotinin

Benzamidin

Chymostatin

LEupeptin

Pepstatin A

Phenylmethylsulfonylfluorid (PMSF)
Serva, Heidelberg

Serva, Heidelberg

Serva, Heidelberg

Serva, Heidelberg

Serva, Heidelberg

Roche, Mannhein verwendet.

Aminopeptidase I

Carboxypeptidase Y

Chymotrypsin

Endoproteinase Arg-C

Endoproteinase Asp-N

Endoproteinase Glu-C

Endoproteinase Lys-C

Leucin Aminopeptidase

Papain

Protease X (Thermolysin)

Trypsin
Sigma-Aldrich, Steinheim Sigma-Aldrich, Steinheim

Roche, Mannheim

Sigma-Aldrich, Steinheim Sigma-Aldrich, Steinheim Sigma-Aldrich, Steinheim Sigma-Aldrich, Steinheim Sigma-Aldrich, Steinheim Sigma-Aldrich, Steinheim Sigma-Aldrich, Steinheim Sigma-Aldrich, Steinheim 


\subsubsection{Antibiotika und Medien}

Antibiotika für die Zellkultur

Ampicillin

Chloramphenicol

Fungizone

Gentamicin

Kanamycin

Streptomycin

Tetracyclin

Zeocin

Medien für Escherichia coli

SOC-Medium

SOB-Medium

LB-Medium

LB-Agar

Medien für Saccharomyces cerevisiae

YP-Medium

YPD-Medium

Medien für Spodoptera frugiperda

Ex-Cell 420

2xGrace's Insect Media
Sigma-Aldrich, Steinheim

Boehringer, Mannheim

GibcoBRL, Karlsruhe

Sigma-Aldrich, Steinheim

Boehringer, Mannheim

Merck Eurolab, Hannover

IBA, Göttingen

Invitrogen, Groningen

Qbiogene, Eschwege

Qbiogene, Eschwege

Qbiogene, Eschwege

Qbiogene, Eschwege

Bio101, USA

YP-Medium mit 2\% steriler Glucose

JRH Bioscience, UK

Invitrogene, Groningen

\subsubsection{Verwendete Zelllinien}

Verwendete Escherichia coli Stämme

BL21 (DE3) pLys

BL21 (DE3) pLys, pRIL

BL21 (DE3) pLys, Rosetta

BW23473

DH5 $\alpha$

DH10BAC

DH10MultiBac

DH10MultiBac ${ }^{\mathrm{Cre}}$

HB101

XL-1 Blue

Der für die Expression von Snu114p verwendete Hefestamm

YPF39 MAT, trp1- $\Delta 1$, his3- $\Delta$, ura3-52, lys2-801, ade2-101, snu114 $\Delta:: H I S$ B-P

(TRP1-pRS424-GPD1/SNU114 6 his N-Term., ARS, CEN) 
Sf9

Verwendete Spodoptera frugiperda Stämme

Sf21

Der verwendete HeLa-Stamm

HeLa S3
Invitrogen, USA

Invitrogene, USA

GBF, Braunschweig

\title{
2.1.4 Antikörper
}

\author{
$\alpha 116 \mathrm{~K}$ (Stan) \\ $\alpha 200 \mathrm{~K}$ (Rob) \\ $\alpha 40 \mathrm{~K}$ (Paul) \\ $\alpha \mathrm{GST}$ \\ $\alpha 6 \mathrm{His}$ \\ $\alpha$ Snu114p (Camillo) \\ $\alpha$ Ziege-POX \\ $\alpha$ Maus-ALP \\ $\alpha$ Kaninchen-POX \\ $\alpha$ Kaninchen-ALP
}

\author{
Kaninchen, 1:10000 \\ Kaninchen, 1:10000 \\ Kaninchen, 1:20000 \\ Ziege, 1:2000, Pharmacia \\ Maus, 1:4000, Quiagen \\ Kaninchen, 1:2000 \\ 1:10000 \\ $1: 10000$ \\ $1: 10000$ \\ $1: 10000$
}

\subsubsection{Nukleotide, Primer und Vektoren}

\author{
Verwendete Nukleotide \\ Desoxynukleotid-5'-Triphosphate, 100 mM, (dATP, dCTP, dGTP, dTTP) Amersham Pharmacia, \\ Nukleotid-5'-Triphosphate (ATP, CTP, GTP, UTP)
Freiburg
Amersham Pharmacia, \\ Freiburg
}

Verwendete Primer

Die Duett-Vektoren von Novagene haben keine Protease-Schnittstelle. Deshalb wurde eine TEVSchnittstelle durch die Integration der Nukleotidsequenz im Klonierungsprimer umgangen. In der folgenden Tabelle werden die verwendeten Primer aufgelistet. Die Restriktionsschnittstelle wird in der Sequenz unterstrichen dargestellt.

Name des Primers

$\rightarrow \quad$ Sequenz

116K_aa126_BamHI (für 1 und 2) $\quad \rightarrow \quad$ cgc gga tcc gag ctc atc aga aat gtg acc

116K_aa450_XhoI (für 1) $<\quad$ ccg ctc gag tca ctc at ctt ggg ctt ggc gcc c

116K_aa578_XhoI (für 2) $\quad<\quad$ ccg ctc gag tca tcg gaa aat ctg agc ctc ctc att gc

116K_aa584_BamHI (für 3) $\rightarrow \quad$ cgc gga tcc acc aca tct gtt atc aag att gct gtg

116K_aa660_BamHI (für 4) $><\quad$ cgc gga tcc gtt gtc acg ttt tgt gag acg gt

116K_aa920_XhoI (für 3 und $\overline{4}$ ) $<\quad$ ccg ctc gag tca gcg gat gac aat gct ctt gtc cag

Diese Primer sind für die Subklonierung der Domänen von hSnu114 mit GST-tag in pGEX-6p-1 verwendet worden

116K_pGex_fo (BamHI) gcg ata gga tcc atg gat acc gac tta tat gat gag

116K_pGex_re (Not I) gga tgg $\operatorname{cgg} \operatorname{ccg} c$ tca cat ggg gta att gag cac

Mit diesen Primern wurde ein volllängen Klon in pGEX-6P-1 generiert

200s1_bamHI_fo

200s1_ecoRI_re

cgc gga tcc atg gaa ctg ggc cgt ata gcc agc cac tac

cag gaattc atc gac agg cag ctg ggt ctc aca ag

Diese Primer erkennen die erste Sec63-Domäne des hBrr2 und ermöglichen deren Subklonierung in pGEX-6p-1

200s1_NcoI_fo

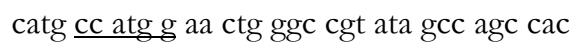


200s1_Acc65I_re

gctt ggtacc atc gac agg cag ctg ggt ctc aca ag

Mit diesen Primern kann man die o.g. Domäne in die M-serie subklonieren

200s2_bamHI_fo

200s2_ecoRI_re

cgc gga tcc atg aac cta ggc atg atc gec gec tac

Diese Primer sind für die zweite Sec63 Domäne und deren Klonierung pGEX-6P-1

200s2_NcoI_fo

200s2_Acc65I_re

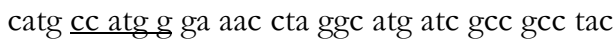

Mit diesen Primern kann man die o.g. Domäne in die M-serie subklonieren

S-tag: 220rrm_BglII_fo

S-tag: 220rrm_XhoI_re

S-tag: 220rrmTEV_XhoI_re

His-tag: 220rrm_BamHI_fo

His-tag: 220rrmTEV_BamHI_fo

His-tag: 220rrm_NotI_re

S-tag: 220MPN_BglII_fo

S-tag: 220MPN_XhoI_re

S-tag: 220MPNTEV_XhoI_re

His-tag: 220MPN_BamHI_fo

His-tag: 220MPNTEV_BamHI_fo

His-tag: 220MPN_NotI_re

S-tag: 220-1BglII_fo

S-tag: 220-1_XhoI_re

S-tag: 220-1TEV_XhoI_re

His-tag: 220-1_AscI_fo

His-tag: 220-1TEV_AscI_fo

His-tag: 220-1_NotI_re

S-tag: 200Helic_NdeI_fo

S-tag: 200Helic_XhoI_re

S-tag: 200HelicTEV_XhoI_re

His-tag: 200Helic_BamHI_fo

His-tag: 200Helic'TEV_BamHI_fo

His-tag: 200Helic_NotI_re

S-tag: 116KntdNdeI_fo

S-tag: 116Kntd_XhoI_re

S-tag: 116KntdTEV_XhoI_

His-tag: 116Kntd_BamHI_fo

His-tag: 116KntdTEV_BamHI_fo

His-tag: 116Kntd_NotI_re

S-tag: 116KctdNdeI_fo

S-tag: 116Kctd_XhoI_re

S-tag: 116KctdTEV_XhoI_re

His-tag: 116Kctd_BamHI_fo

His-tag: 116KctdTEV_BamHI_fo

His-tag: 116Kctd_NotI_re

gga a gat ctc aag tgg tgt caa ggc atc aat aac c ggc ctc gag gec ata ata ctg cac tat gaa tga gg ggc ctc gag acc ttg tac ata acc ggt ttc gec ata ata ctg cac tat gaa tga gg

cgc g gat cc a aag tgg tot caa ggc atc aat aac c

$\operatorname{cgc}$ g gat cc a gaa acc ggt tat gta caa ggt aag tgg tot caa ggc atc aat aac c

ataagaat geggccgc tta gcc ata ata ctg cac tat gaa tga gg

gga a gat ctc ggc tac acc tac atc ctt ccc aag

ggc ctc gag gec act agg ggt cag ctt gta gg

ggc ctc gag acc ttg tac ata acc ggt ttc gec act agg ggt cag ctt gta gg

cgc g gat cc a ggc tac acc tac atc ctt ccc aag

cgc g gat cc a gaa acc ggt tat gta caa ggt ggc tac acc tac atc ctt ccc aag

ataagaat gcggecgc tta gcc act agg ggt cag ctt gta gg gga a gat ct $\mathrm{c}$ atg gec gga gtg ttt cct tat cga $\mathrm{g}$ ggc ctc gag ggg ctc cac aaa ctc cgg gag

ggc ctc gag acc ttg tac ata acc ggt ttc ggg ctc cac aaa ctc cgg gag

$\operatorname{cgc} \operatorname{ggcgcgc} c$ tg gcc gga gtg ttt cct tat cga gg

$\operatorname{cgc} \operatorname{ggcgcgc} c$ tg gaa acc ggt tat gta caa ggt gcc gga gtg ttt cct tat cga gg

ataagaat geggccgc tta ggg ctc cac aaa ctc cgg gag

ggaattc cat atg atc cag acc cag gtg ttt aac act $g$

ggc ctc gag ctc ata taa gaa ctt ctt gaa gaa atc c

ggc ctc gag acc ttg tac ata acc ggt ttc ctc ata taa gaa ctt ctt gaa gaa atc $c$

cgc g gat cc a atc cag acc cag gtg ttt aac act $g$

$\operatorname{cgc}$ g gat cc a gaa acc ggt tat gta caa ggt atc cag acc cag gtg ttt aac act $g$

ataagaat gcggecgc tta ctc ata taa gaa ctt ctt gaa gaa atc c

ggaattc cat atg gtg tat gag atg gat ttc ttg gcg

ggc ctc gag ttc got tat ggt tgc tgt ctt cac

ggc ctc gag acc ttg tac ata acc ggt ttc ttc ggt tat ggt tge tgt ctt cac

cgc g gat cc a gtg tat gag atg gat ttc ttg gcg

cgc g gat cc a gaa acc ggt tat gta caa ggt gtg tat gag atg gat ttc ttg gcg

ataagaat gcggccgc tta ttc ggt tat ggt tgc tot ctt cac ggaattc cat atg aca tct gtt atc aag att gct gtg gag ggc ctc gag atc atc gaa gaa ttt gct gat get cac

ggc ctc gag acc ttg tac ata acc ggt ttc atc atc gaa gaa ttt get gat get cac

cgc g gat cc a aca tct gtt atc aag att get gtg gag

$\operatorname{cgc}$ g gat cc a gaa acc ggt tat gta caa ggt aca tct gtt atc aag att get gtg gag

ataagaat geggecgc tta atc atc gaa gaa ttt get gat get cac

Von allen identifizierbaren Domänen, bzw. solchen Bereichen, von denen Interaktionen bekanntwaren, 
wurden zwei Klone in pRSF (mit und ohne TEV-Erkennungsstelle vor dem nach dem HisTag) und zwei Klone in pCDF (mit und ohne TEV-Erkennungsstelle vor dem S-Tag) generiert.

116K_pBAC_fo (BamHI)

$\triangle \mathrm{N}-116 \mathrm{~K} \_$pFASTBAC_fo (aa120, BamHI)

gcg ata gga tcc cat atg gat acc gac tta tat gat gag

116K_pGex_re $\left(\right.$ Not I) $=116 \mathrm{~K} \_$pBAC_re gcg ata gga tcc ctg atg gat aac tca gag ct gga tg g $\operatorname{cgg} \operatorname{ccg} c$ tca cat ggg gta att gag cac

Mit diesen Primern wurden ein volllängen Klon und eine Deletionsmutante, der die ersten 123 Aminosäuren fehlen, in pFASTBAC generiert.

Tabelle 3.1: Verwendete Primer - außer den MultiBac Primern

Alle U5-spezifischen Proteine werden in den MultiBac Vektor pUCDM kloniert, um den Partikel im Insektenzellsystem vollständig zu rekonstruieren. Die U5 Proteine wurden dazu paarweise in ein Multiplicationsmodul kloniert. Diese Module können mit den integrierten Genen ausgeschnitten und in ein weiteres Modul, welches bereits zwei Gene enthält, inseriert werden. Das bedeutet, daß verschiedene Gene miteinander kombiniert werden können, bzw. eine große Anzahl Gene gemeinsam exprimiert werden können. In der folgenden Tabelle werden die miteinander kombinierten Gene und ihre Position im Multipliciationsmodul dargestellt. Außerdem wurden Doppelstopp-Codons eingefügt, um die Translationstermination zu gewährleisten.

\begin{tabular}{|c|c|c|}
\hline \multirow[t]{2}{*}{ Gen } & $200 K$ & $102 K$ \\
\hline & MCS1: fo: SmaI; re: NheI & MCS2: fo:SalI; re:XbaI \\
\hline \multirow[t]{6}{*}{ Primer } & TCCCCCGGGATGGCGGATGTAACCGCCC & ACGCGTCGACATGAACAAGAAGAAG \\
\hline & G 200_BAC1_SmaI_fo & AAACCG 102_Bac2_SalI_fo \\
\hline & & CTAGTCTAGATTATCAGAAGGTGTTC \\
\hline & CTAGGCTAGCTTATCAATCTGAATCACTG & TTGATGCG 102_Bac2_XbaI__ mit \\
\hline & TCTGTC 200_BAC1_NheI_re mit & Doppelstop \\
\hline & Doppelstop & \\
\hline \multirow[t]{2}{*}{ Gen } & $220 \mathrm{~K}$ & $116 K$ \\
\hline & MCS1: fo:XhoI; re:NheI & MCS2: fo:BamHI; re:XbaI \\
\hline \multirow[t]{6}{*}{ Primer } & CCGCTCGAGATGGCCGGAGTGTTTCCTT & CGCGGATCCTATGGATACCGACTTAT \\
\hline & ATCG 220_Bac1_XhoI_fo & $\begin{array}{l}\text { ATGATGAGTTTGG 116_Bac2_BamHI_fo } \\
(1 \mathrm{bp} \text { eingefügt, um ein kryptisches }\end{array}$ \\
\hline & ctagctagcTTATCAGGCATACAGGTCCTCCC & Startcodon auszuschließen) \\
\hline & GATC 220_Bac1_NheI_re mit & CTAGTCTAGATTATCÁcatggggtaattgagcac \\
\hline & Doppelstop & 116_Bac2_XbaI_re mit \\
\hline & & Doppelstop \\
\hline \multirow[t]{2}{*}{ Gen } & $100 \mathrm{~K}$ & $40 \mathrm{~K}$ \\
\hline & MCS2: fo: BamHI; re: XbaI & MCS1: fo:SmaI; re: XhoI \\
\hline \multirow[t]{6}{*}{ Primer } & CGCGGATCCCATGGCAGGAGAGCTGGC & TCCCCCGGGATGATAGATCAGCAGAA \\
\hline & 100_Bac2_BamHI_fo(1 bp eingefügt, & GCG 40_Bac1_SmaI_fo \\
\hline & um ein kryptisches Startcodon auszuschließen) & CCGCTCGAGTTATCĀCTGAATCTCTCC \\
\hline & CTAGTCTAGATTATCAGGCAAAGATGGT & CATATAC 40_Bac1_XhoI_ \\
\hline & CTCTTC 100_Bac2_XbaI_re re mit & mit Doppelstop \\
\hline & Doppelstop & \\
\hline \multirow[t]{2}{*}{ Gen } & $15 \mathrm{~K}$ & \\
\hline & MCS2: fo:StuI; re: $\mathrm{XbaI}$ & \\
\hline Primer & AAAAGGCCTTatgtcgtacatgctcccgc & \\
\hline & 15KB2_StuI_fo(1 bp eingefügt, & \\
\hline
\end{tabular}




\section{kryptisches Startcodon auszuschließen) \\ CTAGTCTAGAT'TATCAgtagcggtacttggtgg \\ 15_B2_XbaI_re re mit Doppelstop}

Tabelle 3.2: Primer für die Klonierung in das MultiBac-System

Alle für die Sequenzierung verwendeten Primer wurden von S. Liu freundlicherweise zur Verfügung gestellt.

\section{Escherichia coli-Vektoren}

pGEX-6P-1

M-Serie

Duett-Vektoren

Sacharomyces cerevisiae-Vektoren

pRS424-GPD1/SNU114

Spodoptera frugiperda-Vektoren

pFBDM

PUCDM

pUCDM-YFP

pBADZ-HisCre

pFASTBAC

\subsubsection{Verwendete Kits}

Anions and Cations Suites

Blot Strip Kit

Classics and Classics lite

Crystal Screen I + II

Cryo Screen I + II

ECL Western Blot Detection Kit

FoldIt Screen ${ }^{\mathrm{TM}}$

GFX Purification Kit

Heavy Atoms Screen

$\mathrm{Mb}$ class I and II

MPD suite

Natrix Screen

$\left(\mathrm{NH}_{4}\right)_{2} \mathrm{SO}_{4}$ screen

Nucleix Suite

$\mathrm{pH}$ clear I and II

Salt Rx Screen

Qiagen Plasmid Midi/Maxi Kit

Qiagen Gel Extraction Kit

QIAprep Spin Miniprep Kit

QIAquick PCR Purification Kit
Amersham PharmaciaBiotech, Munich EMBL, Heidelberg

Novagene, Darmstadt

Shuttle-vector with snu114p cloned via KpnI/SacI, GPD1Promotor,

N-terminal 6 xhis-tag, ARS, CEN; TPR1(Dr. P. Fabrizio)

GentamicinR, AmpicillinR, ETH Zürich ChloramphenicolR, ETH Zürich ChloramphenicolR, ETH Zürich ZeozinR, ETH Zürich Invitrogene, USA
Nextal-Qiagen, Hilden

Amersham Biosciences, Freiburg

Nextal-Qiagen, Hilden

Hampton Research, USA

Hampton Research, USA

Amersham Pharmacia Biotech

Hampton Research, USA

Amersham Biosciences, Freiburg

Hampton Reasearch, USA

Nextal-Qiagen, Hilden

Nextal-Qiagen, Hilden

Hampton Research, USA

Nextal-Qiagen, Hilden

Nextal-Qiagen, Hilden

Nextal-Qiagen, Hilden

Hampton Research, USA

Qiagen, Düsseldorf

Qiagen, Düsseldorf

Qiagen, Düsseldorf

Qiagen, Düsseldorf 


\subsubsection{Geräte}

Äkta explorer/prime/purifier and columns

Autoklav

Biofuge, pico

Biofuge, fresco

Casy, Cellcounter

CD-Spectrometer

Dampfsterilisatoren, Varioklav

French press

Geldokumentationsanlage

Gelelektrophoreseapparaturen

Geltrockner Modell 583

Gradient Master 106

Heizblock Dri-Block DB-3

Hochspannungstransformatoren

Incubation shaker Multitron

NanoDrop Robot

Peristaltische Pumpe P-1

$\mathrm{pH}$-Meter

Röntgenfilm X-Omat

Röntgenfilm Biomax

SMART-System

Sonifier (Branson 250D)

Sorvall S100-AT

Sorvall RC 5B Zentrifuge

Sorvall GSA-Rotor

Sorvall GS3-Rotor

Sorvall HB-4 Rotor

Sorvall SS-34 Rotor

Spinnerflaschen und Cellroll

SW28 Rotor

Speed Vac Concentrator 5301

Spektrophotometer Ultrospec 3000 pro

UV-Lampen 254, 312, $366 \mathrm{~nm}$

Vortex

\subsubsection{Arbeitsmaterialien}

Amicon Concentrators

Cryo-Röhrchen

Dounce Homogenisator

Einmalpipetten

Kassetten zur Filmexposition

Multischalen (24 Well)

Nesco-/ Parafilm

Nylonmembran, PVDF-Membran

Objektträger

Protein A Sepharose CL-4B

Protran Nitrozellulose Membran

Pipetten (verstellbar)

Qiabrane-Nylon Membran

Reaktionsgefäße $(0.5 \mathrm{ml}, 1.5 \mathrm{ml}, 2 \mathrm{ml})$

Reaktionsgefäße $(5 \mathrm{ml}, 15 \mathrm{ml}, 50 \mathrm{ml})$

Röntgenfilme Biomax MR

Sterilfilter $0.2 \mu \mathrm{m}, 0.45 \mu \mathrm{m}$

24-Well Platten
Amersham Biosciences, Freiburg

Tecnomara, Schweiz

Heraeus, Hanau

Heraeus, Hanau

Schaerfe System, Reutlingen

Jasco, Hamburg

$\mathrm{H}+\mathrm{P}$ Labortechnik, Oberschleißheim

IUL, Bad Godesberg

Bio-Rad, München

Bio-Rad, München; Institutswerkstatt

Bio-Rad, München

BioComp Instruments, Canada

Techne, UK

Bio-Rad, München

Infors, Schweiz

Zinsser Analytic, Cartesian, USA

Pharmacia, Freiburg

Mettler, Toledo

Kodak, USA

Kodak, USA

Amersham Biosciences, Freiburg

Heinemann Labortechnik

Kendro, USA

Kendro, USA

Kendro, USA

Kendro, USA

Kendro, USA

Kendro, USA

TecNoMara, Schweiz

Beckman, USA

Eppendorf, Hamburg

Biorad, München

Bachofer, Reutlingen

Janke und Kunkel
Millipore, USA

Nunc, Dänemark

Wheaton, USA

Nunc, Wiesbaden

Kodak, USA

Nunc, Wiesbaden

Roth, Karlsruhe

Amersham Pharmacia Biotech

Menzel-Gläser, Marienfeld

Amersham Pharmacia Biotech

Schleicher \& Schüll, Dassel

Gilson Medical

Qiagen, Düsseldorf

Eppendorf, Hamburg

Greiner

Kodak, USA

Millipore, Frankreich

Nunc, Wiesbaden 
Whatman 3MM Papier

Whatman Paper, UK

Zellschaber, $25 \mathrm{~cm}$

Sarstedt, Nuembrecht 


\subsection{Allgemeine molekularbiologische Methoden}

\subsubsection{Bestimmung der Nukleinsäurekonzentration}

Für die Bestimmung der Konzentration von DNA wurde die optische Dichte (OD oder $A_{260}$ Einheiten) der entsprechenden verdünnten wässrigen Lösung bei $260 \mathrm{~nm}$ gegen Wasser als Referenz an einem Photometer der Firma Biorad gemessen. Als Messzelle diente eine Quarzküvette mit einem Volumen von $150 \mu \mathrm{l}$ und einer optischen Länge von $1 \mathrm{~cm}$. Der Optischen Dichte von 1 entspricht $33 \mu \mathrm{g} / \mathrm{ml}$ einzesträngiger oder $50 \mu \mathrm{g} / \mathrm{ml}$ doppelsträngiger DNA (Sambrook et al., 1989)

\subsubsection{Extraktion und Fällung von Proteinen und}

\section{Nukleinsäuren}

Die Trennung von Proteinen und Nukleinsäuren erfolgt durch die Extraktion wässriger Lösungen in PCA, einem organischen Lösungsmittel bestehend aus Phenol, Chloroform und Isoamylalkohol (25:24:1), gepuffert in TE pH 7.5. Die Probe wird mit demselben Volumen PCA versetzt und geschüttelt. Nach einer anschließenden zehn minütigen Zentrifugation bei $13000 \mathrm{rpm}$ und Raumtemperatur wird die obere, wässrige Phase in ein neues Reaktionsgefäß überführt und mit 1/10 V 3 M Natriumacetat pH 5.2 und $2.5 \mathrm{~V} 96 \%(\mathrm{v} / \mathrm{v})$ Ethanol versetzt und für $1 \mathrm{~h}$ bei $-20{ }^{\circ} \mathrm{C}$ gefällt. Die untere, organische Phase enthält die Proteine, welche mit $5 \mathrm{~V}$ kaltem Aceton bei $-80{ }^{\circ} \mathrm{C}$ für $1 \mathrm{~h}$ gefällt werden. Nach einer anschließenden Zentrifugation werden die gefällten Proben mit $80 \% \quad(\mathrm{v} / \mathrm{v})$ Ethanol gewaschen, nochmals sedimentiert und in einer Vakuumzentrifuge getrocknet. 


\subsubsection{Agarosegelelktrophorese und Extraktion von DNA}

Geschnittene Plasmide, PCR-Produkte und Fragmente von Restriktionsreaktionen wurden nach Standardprotokollen (Sambrook et al., 1989) hergestellt und analysiert. Dazu wurden Agarosegele hergestellt, die je nach Größe des zu analysierenden Fragmentes zwischen 1 und $3 \%$ Agarose (w/v) in $1 \times$ TBE-Puffer enthielten. Die Gellösung wurde mit Ethidiumbromid (Endkonzentration: $0.5 \mu \mathrm{g} / \mathrm{ml}$ ) versetzt. Ethidiumbromid dient der Visualisierung von DNA im UV-Licht (365 nm). Die Probe wurde in DNA-Probenpuffer aufgenommen und bei 60-170 V in 1 x TBE-Puffer elektrophoretisch getrennt.

Um die DNA aus der Agarose zu extrahieren, wurde nach der Identifikation der Bande unter dem UV-Licht diese ausgeschnitten und nach Herstellerangaben aus der Gelmatrix gewonnen. Die Elution erfolgte in TE Puffer (siehe 3.2.2).

$\begin{array}{ll}\text { 10 x TBE-Puffer pH 7.5 } & \text { 89 M Borsäure } \\ & 0.89 \mathrm{M} \text { Tris } \\ & 25 \mathrm{mM} \text { EDTA } \\ & \mathrm{pH} 8.3 \\ & 1 \times \mathrm{TBE} \\ & 1-3 \%(\mathrm{w} / \mathrm{v}) \text { Agarose } \\ & 0.5 \mu \mathrm{g} / \mathrm{ml} \text { Ethidiumbromid } \\ & 1 \times \mathrm{TBE} \\ & 0.05 \%(\mathrm{w} / \mathrm{v}) \text { Etthidiumbromid } \\ & \\ \text { Kammerpuffer: } & 30 \%(\mathrm{v} / \mathrm{v}) \text { Glycerin } \\ & 0.25 \%(\mathrm{w} / \mathrm{v}) \text { Bromphenolblau } \\ & 0.25 \%(\mathrm{w} / \mathrm{v}) \text { Xylencyanol }\end{array}$

\subsubsection{PCR - Polymerase Chain Reaktion}

Mittels der PCR kann durch ein stabiles in vitro System DNA vervielfacht werden (Mullis and Faloona, 1987). Durch die Verwendung genspezifischer, synthetischer Oligonukleotide (sog. Primer) wird eine bestimmte DNA Sequenz amplifiziert. Ein typischer Ansatz setzte sich wie folgt zusammen: 


$\begin{array}{ll}5 \mu \mathrm{l} & 10 \times \text { PCR Puffer } \\ 5 \mu \mathrm{l} & \text { dNTP Mix (je } 2.5 \mathrm{mM} \text { dATP, dCTP, dGTP und dTTP) } \\ 100 \mathrm{ng} & \text { Plasmid-DNA } \\ 10 \mu \mathrm{l} & \text { Primer A }(10 \mathrm{pM}) \\ 10 \mu \mathrm{l} & \text { Primer B }(10 \mathrm{pM}) \\ 5 \mu \mathrm{l} & \text { DMSO } \\ 1-4 \mu \mathrm{l} & \mathrm{MgCl}_{2}(25 \mathrm{mM}) \\ 1 \mu \mathrm{l} & \text { Pfu Polymerase } \\ & \mathrm{ddH}_{2} \mathrm{O} \text { ad } 50 \mu \mathrm{l}\end{array}$

Schritt 1 (Auseinanderschmelzen der DNA-Doppelstränge): $\quad 3$ min $\quad 95{ }^{\circ} \mathrm{C}$

Schritt 2 (Denaturierungsschritt): $\quad 1 \mathrm{~min} \quad 95^{\circ} \mathrm{C}$

Schritt 3 (Anlagern der Primer): $\quad 30 \mathrm{sec} \quad 55^{\circ} \mathrm{C}$

Schritt 4 (Primer Extension): $\quad 7 \mathrm{~min} \quad 72^{\circ} \mathrm{C}$

Schritt 5 (Auffüllen der Lücken und Reaktionsstop): $\quad 10 \mathrm{~min} \quad 72^{\circ} \mathrm{C}$

Schritte 2 bis 4 werden 25-30 x wiederholt. Pfu-Polymerase synthetisiert $1 \mathrm{~kb}$ in ca. 2 min. Ein 3,5 kb großes Gen oder Fragment wird in 7 min vollständig synthetisiert. Die Tag-Polymerase ist doppelt so schnell und benötigt daher nur die 3,5 min.

\subsubsection{Enzymatischer Verdau und Ligation von Plasmiden}

\section{und PCR-Fragmenten}

Die Restriktionsreaktionen wurden mit den geeigneten Enzymen nach Standardprotokollen (Sambrook et al., 1989) und laut der Herstellerangaben durchgeführt. Anschließend wurden die Reaktionen durch ein Agarosegel (siehe 3.2.3) analysiert, bzw. extrahiert. Die Ligation der Fragment in Vektoren mit passenden Enden erfolgt über Nacht bei $16{ }^{\circ} \mathrm{C}$ mit T4-DNA-Ligase.

Restriktionsreaktionen wurden nach folgendem Muster angesetzt:

$\mathrm{x} \mu \mathrm{l}$
$5 \mu \mathrm{l}$
$5 \mu \mathrm{l}$
$2 \mu \mathrm{l}$
$2 \mu \mathrm{l}$

$\mathrm{x} \mu \mathrm{l}$

$\mathrm{x} \mu \mathrm{l}$

$2 \mu 1$

$1 \mu \mathrm{l}$

$\mathrm{x} \mu \mathrm{l}$
DNA $(5 \mu \mathrm{g})$

$10 \mathrm{x}$ Puffer (Für Enzyme A und B)

$10 \times$ BSA

Enzyme A $(20000 \mathrm{U} / \mathrm{ml})$

Enzyme B (20000 U/ml)

$\mathrm{dd}_{2} \mathrm{O}$ ad $50 \mu \mathrm{l}$

Die Ligationen wurden mit einem Verhältnis 1:10 (Plasmid: Insert) angesetzt.

$$
\begin{aligned}
& \text { Plasmid } \\
& \text { Insert } \\
& 10 \text { x Ligationspuffer } \\
& \text { T4-DNA-Ligase } \\
& \text { ad } 20 \mu \mathrm{ldd} \mathrm{H}_{2} \mathrm{O}
\end{aligned}
$$




\subsubsection{Butanolfällung von Ligationsansätzen}

Die Butanolfällung von Ligationen wurde als Standardprozedur vor der Transformation in Bakterien verwendet. Der Ligationsansatz wird mit zehn Volumen Butanol und 1/10 des Volumen Glycogen $(10 \mathrm{mg} / \mathrm{ml})$ versetzt. Die DNA präzipiert und wird durch eine 20 minütige Zentrifugation in einer Tischzentrifuge sedimentiert. Der Überstand wird verworfen und das Pellet wird mit $100 \mu \mathrm{l} 80 \%$ Ethanol gewaschen und ein weiteres Mal für 10 min sedimentiert. Nachdem der Überstand verworfen wurde und das Pellet getrocknet ist, wird es in TE oder $\mathrm{ddH}_{2} \mathrm{O}$ aufgenommen.

\subsubsection{Transformation von Plasmiden in Bakterienzellen}

\section{sowie deren Isolierung}

Escherichia coli-Zellen werden nach Standardmethoden beschrieben in Hanahan et al. (Hanahan et al., 1985) transformiert. Um Plasmide zu amplifizieren, wurde der Stamm

XL1 Blue verwendet. Für Proteinexpression wurden B121 (DE3)-Stämme verwendet. Ligationen wurden grundsätzlich nach einer Butanolfällung (siehe 3.2.6) durch Elektroporation transformiert, Plasmide wurden auch durch die Heat-Shock-Methode transformiert. Die Isolierung von DNA aus Bakterienzellen erfolgte unter Verwendung der geeigneten Kits (siehe 3.1.6) und nach Angaben der Hersteller (Quiagen Mini- und Maxi-Prep).

\section{Heat-Shock-Methode}

Ein 200 $\mu$ l Aliquot kompetenter Bakterien wird auf Eis aufgetaut und mit DNA gemischt. Nach einer 30 minütigen Inkubation werden die Zellen für $90 \mathrm{sec}$ bei $42^{\circ} \mathrm{C}$ inkubiert und rasch wieder auf Eis gekühlt. Nach der Zugabe von $800 \mu \mathrm{l}$ SOC-Medium werden die Zellen bei $37^{\circ} \mathrm{C}$ bebrühtet und anschließend in Medium mit dem geeigneten Selektionsmarker überführt.

\section{Elektroporation}

Das Aliquot Zellen $(50 \mu \mathrm{l})$ wird $10 \mathrm{~min}$ mit DNA auf Eis inkubiert und in eine Elektroporationsküvette überführt. Die Zellen werden mit $2.5 \mathrm{kV}$ für $0.5 \mathrm{sec}$ elektroporiert und sofort in $2 \mathrm{ml}$ SOC-Medium aufgenommen. und bei $37^{\circ} \mathrm{C}$ inkubiert. Anschließend werden positive Transformanten durch Kultur mit einem Selektrionsmarkers ausgewählt. 


\subsubsection{PCR-Colony-Screen}

Mit diesem Protokoll können große Zahlen von Transformanten untersucht werden. In einem Arbeitsschritt wird eine Masterplatte angefertigt, eine Mini-Prep angesetzt und eine analytische PCR durchgeführt, sodaß man nach der Auswertung der PCR sofort DNA der positiven Klone gewinnen kann und ein Platte für die Dauerlagerung vorhanden ist.

\section{PCR-Reaktion}

$5 \mu \mathrm{lddH} \mathrm{H}_{2} \mathrm{O}$ werden in 28 numeriert PCR-Reaktionsgefäße vorgelegt, wobei man eine positiv Kontrolle (mit Ausgangs-DNA) und eine negativ Kontrolle (ohne Zellen und ohne DNA) anlegt. Mit einem sterilen Zahnstocher wird ein Transformant gepickt und das PCR-Gefäß getipt. Mit demselben Zahnstocher wird das korrespondierende Areal auf der Master-Platte angeimpft und die Mini-Prep.

$\mathrm{Zu}$ den $5 \mu \mathrm{l}$ der Vorlage werden $15 \mu \mathrm{l}$ PCR-Pre-Mix hinzugefügt. Das PCR-Programm, welches zur Generierung des DNA-Fragments verwendet wurde, wird der Polymerase entsprechend modifiziert und durchgeführt. Anschließend werden alle Ansätze mit einem Agarose-Gel analysiert.

$1 \mathrm{x}$ Pre mix

$\begin{array}{ll}2 \mu \mathrm{l} & 10 \times \text { Taq Puffer } \\ 1 \mu \mathrm{l} & \mathrm{MgCl}_{2}(25 \mathrm{mM}) \\ 1 \mu \mathrm{l} & \text { Primer A }(10 \mathrm{pM}) \\ 1 \mu \mathrm{l} & \text { Primer B }(10 \mathrm{pM}) \\ 1 \mu \mathrm{l} & \text { dNTPs }(\text { je } 2.5 \mathrm{mM}) \\ 0,2 \mu \mathrm{l} & \text { Taq polymerase }(3 \mathrm{U} / \mu \mathrm{l}) \\ 8,8 \mu \mathrm{l} & \mathrm{H}_{2} \mathrm{O}\end{array}$

\section{Master-Platte}

Eine Platte mit den geeigneten Selektionsmarkern wird 28 Areale unterteilt. Nach dem Animpfen wird die Platte für $12 \mathrm{~h}$ bei $37^{\circ} \mathrm{C}$ bebrühtet und anschließend für bis zu 3 Monaten bei $4{ }^{\circ} \mathrm{C}$ gelagert.

\section{Mini-Prep Ansatz}

28 Reaktionsgefäße werden mit 2-5 ml Medium, welches das Antibiotikum zur Selektion beinhaltet, vorbereitet. Die Mini-Preps werden ebenfalls für $12 \mathrm{~h}$ bei $37^{\circ} \mathrm{C}$ inkubiert. Anschließend wird laut Herstellerangaben eine Plasmid-Präparation durchgeführt.

\subsubsection{Herstellung kompetenter $E$. coli-Zellen für die}

\section{Elektroporation}

Eine Bakterienkultur des gewünschten Stammes wird in 0.51 Medium bis zu einer optischen Dichte von 0.4-0.6 wachsen gelassen und anschließend bei 4000 x g für 15 min sedimentiert. Das resultierende Pellet wird zweimal mit $300 \mathrm{ml}$ eisgekühltem, 
sterilem ddH $\mathrm{H}_{2} \mathrm{O}$, einmal mit $200 \mathrm{ml}$ und einmal mit $50 \mathrm{ml}$ sterilem $10 \%$ Glycerin gewaschen, bevor das Zellpellet in $4 \mathrm{ml} 10 \%$ Glycerin aufgenommen und aliquotiert wird. Die Zellen werden in flüssigem Stickstoff schockgefroren und bei $-80{ }^{\circ} \mathrm{C}$ gelagert.

\subsubsection{Herstellung kompetenter E. coli-Zellen für die}

\section{Heat-Shock-Methode}

Nachdem die Kultur eine Dichte von 0.4-0.6 $\mathrm{OD}_{600}$ hat, wird sie für $10 \mathrm{~min}$ auf Eis gekühlt und anschließend bei $4000 \mathrm{xg}$ bei $4{ }^{\circ} \mathrm{C}$ für 15 min sedimentiert. Das Pellet wird in $250 \mathrm{ml}$ eiskaltem TB-Puffer resuspendiert und ein weiteres Mal sedimentiert. Anschließend wird das Pellet in TB-Puffer aufgenommen, der $7 \%$ DMSO enthält. Die Zellen werden aliquotiert und in flüssigem Stickstoff schockgefroren und bei $-80{ }^{\circ} \mathrm{C}$ gelagert.

TB-Puffer:

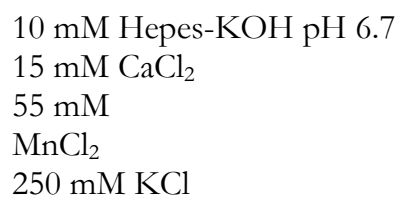

Alle Komponenten außer dem $\mathrm{MnCl}_{2}$ werden gemischt und der $\mathrm{pH}$ wird eingestellt. Anschließend wird das $\mathrm{MnCl}_{2}$ hinzugefügt und die Lösung wird steril filtriert.

\subsubsection{DNA-Sequenzierung und Analyse}

Die Reaktion und alle dazugehörigen Schritte wurden von Gordon Dowe, Abteilung Jaeckle ausgeführt. Ein Ansatz bestand aus einem Endvolumen von $12 \mu \mathrm{lmit}$ 300 ng DNA (bei Plasmiden bis 8 kb Größe) oder 500 ng (bei Plasmiden von 8 bis $12 \mathrm{~kb}$ Größe) und 10 pMol Primer. Die Sequenzen wurden mit VectorNTI und DNAstar analysiert. 


\subsection{Protein-Biochemische Methoden}

\subsubsection{Diskontinuierliche SDS Polyacrylamid Gel}

\section{Elektrophorese von Proteinen}

Die analytische Auftrennung von Proteinen in denaturierenden SDSPolyacrylamid-Gelen (SDS-PAGE) erfolgte primär in Abhängigkeit von der molekularen Masse des jeweiligen Proteins (Laemmli, 1970; Weber et al., 1972). Je nach Größe der zu untersuchenden Proteine wurden unterschiedliche Konzentrationen an Polyacrylamid (meist 10 bzw. 13\%) verwendet. Die aufbereiteten Proteine wurden durch 10-minütiges Schütteln in $10 \mu$ Proteinprobenpuffer resuspendiert, 5 min bei $95^{\circ} \mathrm{C}$ denaturiert und in die Geltaschen geladen. Die Proben wurden bei 15-25 mA im Sammelgel fokussiert und anschließend bei 30-45 mA aufgetrennt. Die Elektrophorese wurde beendet, wenn der Farbstoff den unteren Rand der Glasplatte erreicht hatte (Bromphenolblau zeigt ein Laufverhalten wie ein Peptid von ca. 4 kDa Größe). Die Proteine konnten anschließend mit Coomassie Brilliant Blau oder Silber gefärbt werden.

\begin{tabular}{|c|c|c|c|}
\hline \multicolumn{2}{|c|}{ Sammelgel } & \multicolumn{2}{|c|}{$4 \times$ Trenngel-Puffer } \\
\hline $\begin{array}{l}\text { Puffer } \\
125 \mathrm{mM}\end{array}$ & Tris $\mathrm{HCl}$ pH 6.8 & $375 \mathrm{mM}$ & Tris $\mathrm{HCl} \mathrm{pH} 8.8$ \\
\hline $0.1 \%$ & SDS & $0.1 \%$ & SDS \\
\hline ad 0.51 & $\mathrm{H}_{2} \mathrm{O}$ & ad 11 & $\mathrm{H}_{2} \mathrm{O}$ \\
\hline
\end{tabular}

Sammelgel 5\%

$\begin{array}{lllll} & 12 \mathrm{ml} & 15 \mathrm{ml} & 20 \mathrm{ml} & 25 \mathrm{ml} \\ 4 \times \text { Puffer } & 3 \mathrm{ml} & 3.75 \mathrm{ml} & \text { four ml } & 6.3 \mathrm{ml} \\ \text { PAA-30 } & 2 \mathrm{ml} & 2.5 \mathrm{ml} & 3.3 \mathrm{ml} & 4.2 \mathrm{ml} \\ \mathrm{H}_{2} \mathrm{O} & 7 \mathrm{ml} & 8.75 \mathrm{ml} & 12.7 \mathrm{ml} & 14.5 \mathrm{ml} \\ 10 \% \text { APS } & 80 \mu \mathrm{l} & 100 \mu \mathrm{l} & 133.3 \mu \mathrm{l} & 166.7 \mu \mathrm{l} \\ \text { TEMED } & 8 \mu \mathrm{l} & 10 \mu \mathrm{l} & 13.3 \mu \mathrm{l} & 16.7 \mu \mathrm{l}\end{array}$

Trenngel $50 \mathrm{ml}$

$\begin{array}{lllll} & 10 \% & 12 \% & 15 \% & 17 \% \\ 4 \times \text { Puffer } & 12.5 \mathrm{ml} & 12.5 \mathrm{ml} & 12.5 \mathrm{ml} & 12.5 \mathrm{ml} \\ \text { PAA-30 } & 16.7 \mathrm{ml} & 20 \mathrm{ml} & 25 \mathrm{ml} & 28.3 \mathrm{ml} \\ \mathrm{H}_{2} \mathrm{O} & 20.8 \mathrm{ml} & 12.5 \mathrm{ml} & 12.5 \mathrm{ml} & 9.2 \mathrm{ml} \\ 10 \% \text { APS } & 166.7 \mu \mathrm{l} & 166.7 \mu \mathrm{l} & 166.7 \mu \mathrm{l} & 166.7 \mu \mathrm{l}\end{array}$


TEMED

$166.7 \mu \mathrm{l}$

$166.7 \mu \mathrm{l}$

$166.7 \mu 1$

$166.7 \mu 1$

Trenngel $30 \mathrm{ml}$

$\begin{array}{lllll} & 10 \% & 12 \% & 15 \% & 17 \% \\ 4 \times \text { Puffer } & 7.5 \mathrm{ml} & 7.5 \mathrm{ml} & 7.5 \mathrm{ml} & 7.5 \mathrm{ml} \\ \text { PAA-30 } & 10 \mathrm{ml} & 12 \mathrm{ml} & 15 \mathrm{ml} & 17 \mathrm{ml} \\ \mathrm{H}_{2} \mathrm{O} & 12.5 \mathrm{ml} & 10.5 \mathrm{ml} & 7.5 \mathrm{ml} & 5.5 \mathrm{ml} \\ 10 \% \text { APS } & 100 \mu \mathrm{l} & 100 \mu \mathrm{l} & 100 \mu \mathrm{l} & 100 \mu \mathrm{l} \\ \text { TEMED } & 100 \mu \mathrm{l} & 100 \mu \mathrm{l} & 100 \mu \mathrm{l} & 100 \mu \mathrm{l}\end{array}$

Trenngel $20 \mathrm{ml}$

$\begin{array}{lllll} & 10 \% & 12 \% & 15 \% & 17 \% \\ 4 \times \text { Puffer } & 5 \mathrm{ml} & 5 \mathrm{ml} & 5 \mathrm{ml} & 5 \mathrm{ml} \\ \text { PAA-30 } & 6.6 \mathrm{ml} & 8 \mathrm{ml} & 10 \mathrm{ml} & 11.3 \mathrm{ml} \\ \mathrm{H}_{2} \mathrm{O} & 8 . f \circ u \mathrm{ml} & 7 \mathrm{ml} & 5 \mathrm{ml} & 3.7 \mathrm{ml} \\ 10 \% \text { APS } & 66 \mu \mathrm{l} & 66 \mu \mathrm{l} & 66 \mu \mathrm{l} & 66 \mu \mathrm{l} \\ \text { TEMED } & 66 \mu \mathrm{l} & 66 \mu \mathrm{l} & 66 \mu \mathrm{l} & 66 \mu \mathrm{l}\end{array}$

\subsubsection{Western Blot Analyse}

Der Blot wurde von einem Polyacrylamid-Gel auf PVDF- oder Nitrocellulosemembran nach Standardprotokoll im Semi-dry-Verfahren durchgeführt. Die spezifische Nachweis von Proteinen erfolgte durch Antikörper, bzw. Antiseren (s.h. 3.1.4). Die Blots wurden mit TBS-T-Puffer, der $5 \%(\mathrm{w} / \mathrm{v})$ Magermilchpulver enhält, blockiert. Alle Antikörper-Reaktionen wurden mit TBS-T bei Raumtemperatur durchgeführt. Die anschließende Nachweisreaktion mit Horse-Radish Peroxidase (HRP) oder Alkalischer Phosphatase $(A L P)$ wurde nach Standardprotokollen durchgeführt.

Puffer T:

$48 \mathrm{mM}$ Tris $\mathrm{NaOH}$ pH 8.5

$39 \mathrm{mM}$ Glycin

$0.0375 \%$ SDS

TBS-T-Puffer:

$20 \mathrm{mM}$ Tris $\mathrm{NaOH}$ pH 7.5

$150 \mathrm{mM} \mathrm{NaC}$

$0.1 \%$ Tween 20

\subsubsection{RNA-Gel Elektrophorese}

Ähnlich der diskontinuierlichen Polyacrylamid Gel Elektrophorese können auch RNA-Moleküle ihrer Größe nach aufgetrennt werden. Die Elektrophorese erfolgt bei 
$50 \mathrm{~mA}$ für $2 \mathrm{~h}$. Ein Gel ist $1 \mathrm{~mm}$ dick und wird nach der Trennung in 1 x TBE-Puffer mit $0.5 \%$ Ethidiumbromid inkubiert, um die RNA-Moleküle im UV-Licht sichtbar zu machen.

$10 \%$ RNA-Gel:

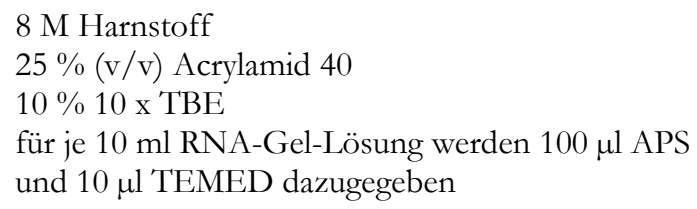

\subsubsection{Färbemethoden}

Die Proteine wurden mittels Coomassie Brilliant Blau (Auflösungsgrenze: $1 \mu \mathrm{g}$ pro Bande) angefärbt oder nach der von Blum et al. (Blum et al., 1987) beschriebenen Methode silbergefärbt (Auflösungsgrenze bis zu 5 ng pro Bande). Anschließend wurden die Gele auf Whatmann Papier oder zwischen Zellulose getrocknet.

\subsubsection{Proteinkonzentrationsbestimmung}

Die Konzentrationsbestimmung von Proteinen in wässriger Lösung erfolgte mit Hilfe des Bradford Assays. 5 bis $20 \mu$ Protein-Lösung wurden in $800 \mu$ 1:5 (Bradford Reagenz: $\left.\mathrm{ddH}_{2} \mathrm{O}\right)$ Bradford-Lösung aufgenommen. Anschließend wurde die Extinktion bei einer Wellenlänge von $595 \mathrm{~nm}$ mit einem Photometer bestimmt. Als Referenz diente eine BSA-Standardkurve, anhand der die Konzentration der Proteine abgelesen werden konnte.

\subsubsection{Konzentrierung von Proteinlösungen}

$\mathrm{Da}$ in den meisten Fällen die Konzentration von Protein-Lösungen für kristallographische Experimente nicht ausreicht, werden die Lösungen ankonzentriert. Die Konzentratoren (von Millipore und Vivascience) werden zu diesem Zweck fünfmal mit $\mathrm{ddH}_{2} \mathrm{O}$ und dann mit dem Puffer der Wahl gewaschen. Um die Adhäsion von 
Zielprotein an der Membran zu minimieren, wurde die Membran vorblockiert. Entweder wurden Fraktionen mit sehr geringen Konzentrationen des Zielproteins oder eine BSALösung durch eine Zentrifugation als Blockiermittel benutzt. Anschließend wurde die Lösung mit dem Zielprotein ankonzentriert. Die Konzentratoren wurden laut Herstellerangaben benutzt und sowohl die ankonzentrierte Lösung als auch der Durchfluß wurden analysiert.

\title{
2.4 Expression und Reinigung von Fusionsproteinen in E. coli
}

Die in dieser Studie verwendeten Fusionsproteine wurden in B121 (DE3) E. coliStämme exprimiert. Nach einer Transformation wurden die Zellen auf Agar-Platten mit den nötigen Selektionsmarkern über Nacht bei $37^{\circ} \mathrm{C}$ wachsen gelassen und so positiv selektiert. Vorkulturen wurden am nächsten Tag in 5-50 ml LB-Medium angesetzt und ebenfalls über Nacht bei $37^{\circ} \mathrm{C}$ im Schüttler angezogen. Diese Vorkultur wurde dann 1:50 oder 1:100 im Kulturmedium verdünnt, bei 16 bis $37^{\circ} \mathrm{C} \mathrm{zu}$ einer bestimmten optischen Dichte gezogen und dann mit IPTG induziert. Die IPTG-Endkonzentration und der Induktionszeitpunkt bieten Möglichkeiten zur Optimierung. Zu bestimmten Zeitpunkten wurde die $\mathrm{OD}_{600}$ der Kultur gemessen und eine Probe für die Gel-Analyse wurde genommen.

LB-Medium:

\author{
$1 \%(\mathrm{w} / \mathrm{v})$ Bacto-Trypton \\ $0.5 \%$ (w/v) Hefe-Extrakt \\ $1 \%(\mathrm{w} / \mathrm{v})$ Natriumchlorid \\ $1,5 \%(\mathrm{w} / \mathrm{v})$ Bacto-Agar (nur für Plattenmedium)
}




\subsubsection{Analytische Expression von Fusions-Protein in E. coli}

Die analytische Expression kann in kleinen Volumen (25-100 ml) durchgeführt werden. Wie in 3.4 erwähnt, werden Faktoren wie Kulturtemperatur, Induktionszeitpunkt, IPTG-Endkonzentration und die Dauer der Induktion getestet.

\subsubsection{Präparative Expression von Fusions-Protein in E. coli}

Nachdem Bedingungen für die maximale Ausbeute löslichen Fusions-Proteins gefunden wurden, wird die Expression mit 61 wiederholt. Dazu werden grundsätzlich Schikane-Flaschen verwendet. Nachdem die Zellen geerntet wurden, werden sie entweder als Pellets in flüssigem Stickstoff gefroren und bei $-20{ }^{\circ} \mathrm{C}$ gelagert, oder direkt aufgeschlossen.

\subsubsection{Inclusion Body-Reinigung und Rückfaltung von Fusions-Protein}

Inclusion Bodies können bei der Überexpression von Fusions-Proteinen in einem prokaryontischen Organismus entstehen und sind Aggregate des Fusionsproteins. Man kann die Aggregate durch ein nicht-ionisches Detergenz reinigen und erhält in den meisten Fällen sehr sauberes Protein.

Die geernteten Zellen werden in $1 / 100$ des Kulturvolumens Puffer S aufgenommen und mit einem Ultraschall-Gerät aufgeschlossen (2 min Sonifizierungszeit, $30 \%$ Amplitude, $0.5 \mathrm{sec}$ Pulse, $2 \mathrm{sec}$ Pause, in einem Wasser-Eis-Bad). Die aufgeschlossenen Zellen werden in einem SA-2300 Rotor bei $17000 \mathrm{rpm}$ und $4{ }^{\circ} \mathrm{C}$ für 30 min sedimentiert. Der Überstand wird verworfen und das Pellet in $5 \mathrm{ml}$ Puffer P

aufgenommen und $20 \mathrm{x}$ mit einem Dounce Homogenisator homogenisiert. Die 
Zentrifugation und das Homogenisieren wird insgesamt dreimal wiederholt. Das Pellet von der letzten Sedimentation wird in Puffer D aufgenommen und für den FoldIt ${ }^{\mathrm{TM}}$ Screen wird eine Proteinkonzentration von $20 \mathrm{mg} / \mathrm{ml}$ eingestellt. Dieser Screen beinhaltet 16 verschiedene Bedingungen, welche die Protein-Konzentration, Wahl des Detergenz und Anwesenheit von reduzierendem Agenz abdeckt. Im Anschluß an die Rückfaltung werden die Ansätze für $30 \mathrm{~min}$ in einer Tischzentrifuge bei $13000 \mathrm{rpm}$ sedimentiert und durch SDS-PAGE analysiert. Vielversprechende Bedingungen, also diejenigen mit löslichem Protein, werden durch analytische Gelfiltrationsläufe weiteruntersucht.

$\begin{array}{ll}\text { Puffer S (Sonifikation): } & 10 \mathrm{mM} \text { Tris } \mathrm{HCl} \mathrm{pH} 7.0 \\ & 75 \mathrm{mM} \mathrm{NaCl} \\ & 1 \mathrm{mM} \mathrm{BME} \\ & 0.5 \%(\mathrm{v} / \mathrm{v}) \mathrm{NP}-40 \\ & 10 \mathrm{mM} \text { Tris HCl pH } 7.0 \\ & 100 \mathrm{mM} \mathrm{NaCl} \\ & 1 \mathrm{mM} \mathrm{BME} \\ & 0.5 \%(\mathrm{v} / \mathrm{v}) \mathrm{LDAO} \\ & 10 \mathrm{mM} \text { Tris HCl pH } 7.0 \\ & 100 \mathrm{mM} \mathrm{NaCl} \\ \text { Puffer D (Denaturation): } & 1 \mathrm{mM} \mathrm{BME} \\ & 6 \mathrm{M} \mathrm{Gunaidinium} \mathrm{Hydrochlorid} \\ & 10 \mathrm{mM} \mathrm{Tris} \mathrm{HCl} \mathrm{pH} 7.0 \\ & 75 \mathrm{mM} \mathrm{NaCl} \\ \text { Gelfiltrationspuffer: } & 1 \mathrm{mM} \mathrm{BME}\end{array}$

\subsubsection{Co-Expression von Fusionsproteinen in E. coli}

Novagene hat ein Vektorsystem konstruiert mit dem man bis zu acht verschiedene Ziel-Gene gleichzeitig exprimieren kann. Das ist unter dem Aspekt interessant, daß die Wechselwirkung der co-exprimierten Proteine ihre Löslichkeit positiv beeinflußt. Da es schon erste Daten bezüglich der Interaktionen der U5-spezifischen Proteine gab, sollten diese mutmaßlichen Interaktionen durch Co-Expressionen bestätigt 
und die interagierenden Domänen weiter eingegrenzt werden.

\subsubsection{Aufschließen der Zellen mit Ultraschall}

Üblicherweise werden E. coli-Zellen nach Überexpressionen mit einem Sonifier von Branson aufgeschlossen. Die Gefäße werden in Eis-Wasser gekühlt, um die Erwärmung der Lösung zu minimieren. Dazu werden die üblichen Parameter bezüglich der Amplitude und der Pulsdauer angewandt.

\subsubsection{Proteinreinigung mit Ni-Affinitäts-Chromatographie}

Das Zellpellet wird in $\mathrm{W}_{0}$-Puffer aufgeschlämmt und mit Proteaseinhibitoren versetzt. Nach dem Aufschluß werden Zelltrümmer von der löslichen Fraktion durch eine 45 minütige Sedimentation bei $17000 \mathrm{rpm}$ und $4{ }^{\circ} \mathrm{C}$ im SA-300 Rotor abgetrennt. In der Zwischenzeit wird Ni-NTA-Agarose äquilibriert. Dazu wird das frisch aufgeschlämmte Material mit dem zehnfachen Volumen $\mathrm{W}_{0}$-Puffer versetzt und $1 \mathrm{~min}$ bei 3000 rpm sedimentiert. Die Ni-NTA-Agarose wird mit dem löslichen Protein für $1 \mathrm{~h}$ bei $4{ }^{\circ} \mathrm{C}$ auf einem Roller inkubiert. Diese Lösung wird anschließend mittels einer Polyprep-Säule in „Durchfluß“ und „säulen-gebundenes Protein“ getrennt. Die so entstandene Säule wird mit einem zehnfachen Bett-Volumen $\mathrm{W}_{1^{-}}, \mathrm{W}_{2^{-}}$und $\mathrm{W}_{3^{-}}$Puffer gewaschen. Die Elutionen bestehen nur aus der Hälfte des Bett-Volumens.

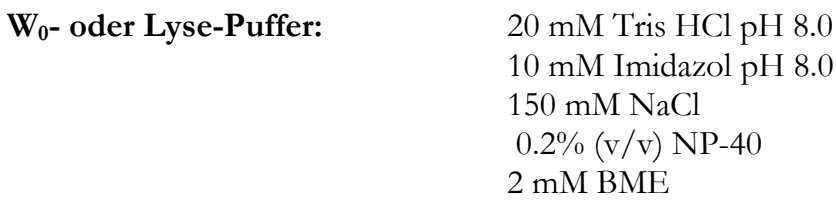

Für je $20 \mathrm{ml}$ Puffer wird eine Tablette Complete EDTA-free zugegeben.

\begin{tabular}{|c|c|}
\hline$W_{1}$-Puffer: & $\begin{array}{l}20 \mathrm{mM} \text { Tris } \mathrm{HCl} \mathrm{pH} 8.0 \\
10 \mathrm{mM} \text { Imidazol } \\
150 \mathrm{mM} \mathrm{NaCl} \\
2 \mathrm{mM} \mathrm{BME}\end{array}$ \\
\hline $\mathbf{W}_{2}$-Puffer: & $20 \mathrm{mM}$ Tris $\mathrm{HCl} \mathrm{pH} 8.0$ \\
\hline
\end{tabular}


$10 \mathrm{mM}$ Imidazol

$1 \mathrm{M} \mathrm{NaCl}$

$2 \mathrm{mM} \mathrm{BME}$

$W_{3}$-Puffer:

$20 \mathrm{mM}$ Tris $\mathrm{HCl}$ pH 8.0

$50 \mathrm{mM}$ Imidazol

$150 \mathrm{mM} \mathrm{NaCl}$

$2 \mathrm{mM}$ BME

Elutions-Puffer:

$10 \mathrm{mM}$ Tris $\mathrm{HCl} \mathrm{pH} 7.0$

$300 \mathrm{mM}$ Imidazol

$150 \mathrm{mM} \mathrm{NaCl}$

$2 \mathrm{mM} \mathrm{BME}$ 


\subsection{Expression und Reinigung von Snu114p in \\ S. cerevisiae}

\subsubsection{Zellkultur von $S$. cerevisiae}

Hefe wird auf YPD-Agar Platten oder Medium gezogen. Um Kontamination durch Prokaryonten entgegen zu wirken, werden $12.5 \mathrm{mg}$ Chloramphenicol/1 Kulturmedium zugegeben. Für eine Vorkultur werden $15 \mathrm{ml}$ YPD-Medium mit einigen Zellen einer frischen Platte angeimpft und bei $30^{\circ} \mathrm{C}$ auf einem Schüttler für mindestens $12 \mathrm{~h}$ angezogen. Nachdem die optische Dichte dieser Kultur bestimmt worden ist, wird die Hauptkultur mit 7.5 OD pro Liter angeimpft und in Kolben ohne Schikanen bei $30{ }^{\circ} \mathrm{C}$ in einem Schüttler gezogen. Mit dem Erreichen von OD 3.5 wurde die Kultur geerntet.

\subsubsection{Zell-Ernte und Lyse}

Die Zellen werden in einem SLC-6000 Rotor mit $4000 \mathrm{x}$ g bei $4{ }^{\circ} \mathrm{C}$ für $15 \mathrm{~min}$

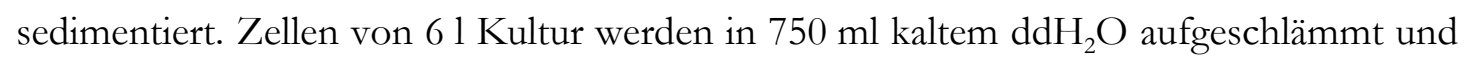
erneut sedimentiert. Diese Pellets werden erneut in kaltem $\mathrm{ddH}_{2} \mathrm{O}$ aufgeschlämmt und in $50 \mathrm{ml}$ Greiner-Röhrchen sedimentiert. Das Zell-Pellet wird ohne Überstand in flüssigem Stickstoff schockgefroren, auch wenn die Reinigung im Anschluß fortgesetzt wird. Während die Zellen auf Eis auftauen wird ein Volumenäquivalent des Pellets in Puffer L hinzugefügt. Die French Press wird 30 min gekühlt und durch Durchgänge mit $\mathrm{ddH}_{2} \mathrm{O}$, $0.5 \mathrm{M} \mathrm{NaOH}$-Lösung, dd $\mathrm{H}_{2} \mathrm{O}$, Ethanol, $\mathrm{ddH}_{2} \mathrm{O}$ und $20 \mathrm{ml}$ Puffer L vorbereitet. Die Zellen werden bei $1.5 \mathrm{kbar}$ aufgeschlossen und immer auf Eis gehalten. Im Anschluß an den Aufschluß werden Zelltrümmer, Lipide und DNA von den löslichen Proteinen durch eine Sedimentation bei $17000 \mathrm{rpm}$ und $4{ }^{\circ} \mathrm{C}$ für $45 \mathrm{~min}$ abgetrennt. 
Währenddessen werden 4 ml Ni-NTA-Agarose in Binde-Puffer äqulibriert.

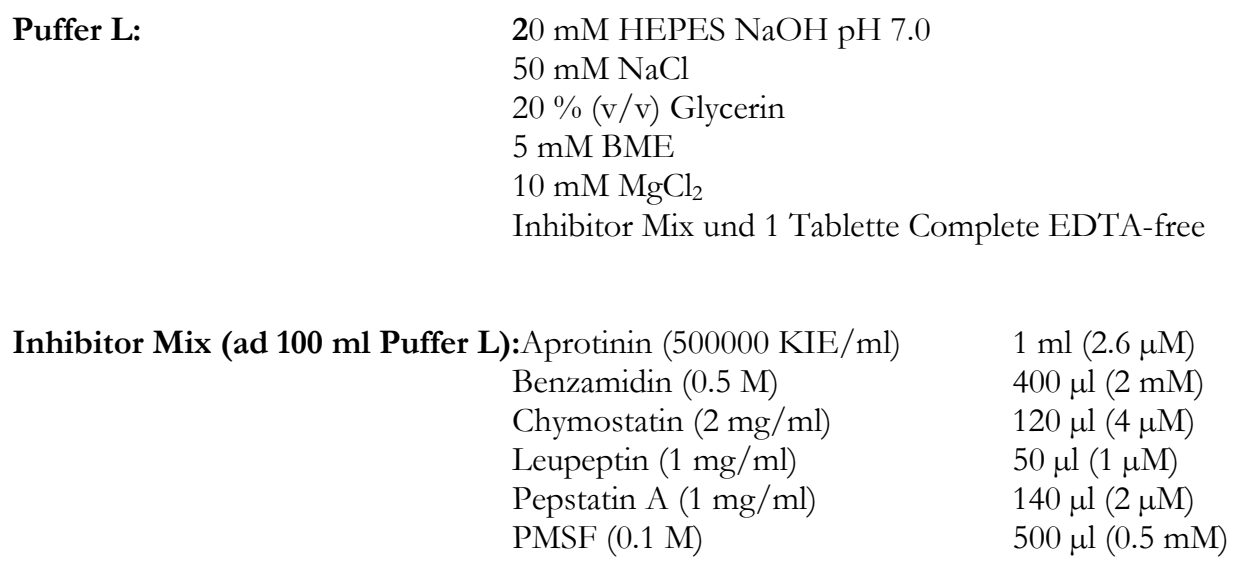

\subsubsection{Reinigung von Snu114p mittels Ni-Affinitäts-}

\section{Chromatographie}

Das zentrifugierte Lysat der Hefe-Zellen besteht aus einer Schicht Fettsäuren, dem wässrigen Teil, einer Schicht DNA und den Zelltrümmern am Grund des Gefäßes. Durch vorsichtiges Abnehmen trennt man die wässrige Phase von den Fettsäuren und der dem festen Sediment ab. Die wässrige Phase, welche das überexprimierte Protein enthält wird mit der äqulibrierten Ni-NTA-Agarose bei $4{ }^{\circ} \mathrm{C}$ auf einem Roller für $1 \mathrm{~h}$ inkubiert. Nach dem Durchfluß einer Polyprep-Säule wird die Säule mit je $50 \mathrm{ml}$ der $4{ }^{\circ} \mathrm{C}$ kalten Wasch-Puffer gewaschen. Die Elutionen werden in fünf mal $2 \mathrm{ml}$ Schritten gesammelt.

\begin{tabular}{|c|c|}
\hline Binde-Puffer: & $\begin{array}{l}20 \mathrm{mM} \text { HEPES NaOH pH } 7.0 \\
500 \mathrm{mM} \mathrm{NaCl} \\
5 \mathrm{mM} \text { Imidazol pH } 7.0 \\
5 \mathrm{mM} \text { BME } \\
1 \text { Tablette Complete EDTA-free } / 20 \mathrm{ml}\end{array}$ \\
\hline Wasch-Puffer I: & $\begin{array}{l}20 \mathrm{mM} \text { HEPES NaOH pH } 7.0 \\
500 \mathrm{mM} \mathrm{NaCl} \\
10 \mathrm{mM} \text { Imidazol pH } 7.0 \\
5 \mathrm{mM} \mathrm{BME}\end{array}$ \\
\hline Wasch-Puffer II: & $\begin{array}{l}20 \mathrm{mM} \text { HEPES NaOH pH } 7.0 \\
300 \mathrm{mM} \mathrm{NaCl} \\
10 \mathrm{mM} \text { Imidazol pH } 7.0 \\
5 \mathrm{mM} \text { BME }\end{array}$ \\
\hline Wasch-Puffer III: & 20 mM HEPES NaOH pH 7.0 \\
\hline
\end{tabular}




\begin{tabular}{|c|c|}
\hline & $\begin{array}{l}100 \mathrm{mM} \mathrm{NaCl} \\
10 \mathrm{mM} \text { Imidazol pH } 7.0 \\
5 \text { mM BME }\end{array}$ \\
\hline Elutions-Puffer I: & $\begin{array}{l}20 \mathrm{mM} \text { HEPES NaOH pH } 7.0 \\
100 \mathrm{mM} \mathrm{NaCl} \\
50 \mathrm{mM} \text { Imidazol pH } 7.0 \\
5 \mathrm{mM} \text { BME }\end{array}$ \\
\hline Elutions-Puffer II: & $\begin{array}{l}20 \mathrm{mM} \text { HEPES NaOH pH } 7.0 \\
100 \mathrm{mM} \mathrm{NaCl} \\
100 \mathrm{mM} \text { Imidazol pH } 7.0 \\
5 \mathrm{mM} \mathrm{BME}\end{array}$ \\
\hline Elutions-Puffer III: & $\begin{array}{l}20 \mathrm{mM} \text { HEPES NaOH pH } 7.0 \\
100 \mathrm{mM} \mathrm{NaCl} \\
150 \mathrm{mM} \text { Imidazol pH } 7.0 \\
5 \mathrm{mM} \mathrm{BME}\end{array}$ \\
\hline Elutions-Puffer IV: & $\begin{array}{l}20 \mathrm{mM} \text { HEPES NaOH pH } 7.0 \\
100 \mathrm{mM} \mathrm{NaCl} \\
200 \mathrm{mM} \text { Imidazol pH } 7.0 \\
5 \mathrm{mM} \mathrm{BME}\end{array}$ \\
\hline Elutions-Puffer V: & $\begin{array}{l}20 \mathrm{mM} \text { HEPES NaOH pH } 7.0 \\
100 \mathrm{mM} \mathrm{NaCl} \\
250 \mathrm{mM} \text { Imidazol pH } 7.0 \\
5 \mathrm{mM} \mathrm{BME}\end{array}$ \\
\hline
\end{tabular}

\subsubsection{Reinigung mit IEX-Chromatographie (Q-Sepharose)}

Die Elutionen von der Ni-Affinitäts-Reinigung wurden auf $150 \mathrm{mM}$ Salz verdünnt. Diese Lösung wurde dann auf eine Q-Sepharose-Säule gespült, welche bereits in zehn Säulen Volumen (engl. Column Volumes, CV) Puffer A äqulibriert wurde. Eluiert wurde durch einen sog. „Step“-Gradienten, indem 30 \% Puffer B nach 30 CV gefolgt von einem kurzen Plateau, $50 \%$ nach weiteren 15 CV, $80 \%$ nach $10 \mathrm{CV}$ und $100 \%$ nach $5 \mathrm{CV}$ erreicht wurde. Die Fraktionen werden durch ein analytisches Gel und einen anschließenden Western Blot analysiert (3.2.2). 


\subsection{Insekten-Zellkultur und das Baculo-Virus}

\section{Expressionssystem (BEVS)}

Zur rekombinanten Expression von hSnu114 wurde ein von Joop van den Heuvel (GBF, Braunschweig) modifizierter pFASTBAC-HT verwendet. In jüngster Zeit wurden die Klonierungsarbeiten für das MultiBac System aufgenommen.

Generell ist zur Insekten-Zell-Kultur sagen, daß es sich um ein robustes System handelt, welches im Unterschied zum Hefe-System alle posttranslationalen Modifikationen durchführt und verhältnismäßig leicht zu manipulieren ist, weshalb man es den humanen Zell-Systemen vorzieht. Baculo-Viren sind die prominentesten Insekten-infizierenden Viren. Sie sind Stabförmig (engl.: rod-shaped) und enthalten doppelsträngige, zirkuläre, supercoiled DNA. Ein weiterer Vorteil besteht darin, daß sie nur einen Effekt auf Insekten-Zellen haben, daß heißt in einer S1-Zellkultur neben andern humanen Zelllinien verwendet werden können, ohne das die Viren Einfluß auf diese haben. Wild-Typ Baculo-Viren haben sowohl eine lytische als auch eine latente Phase. Die Virus-Replikation untergliedert sich in drei Phasen mit folgenden Charakteristika:

In der frühen Phase (engl. early phase, virus synthesis phase) beginn der Virus sich zu replizieren. Dazu adhäriert der Virus an der Wirtszelle, penetriert die Zellwand, streift die Hülle $a b$ und beginnt innerhalb der ersten halben Stunde die frühen viralen Gene zu exprimieren und die Genexpression des Wirtes abzuschalten.

Die späte Phase (engl. late phase, viral structural phase) beginnt $6 \mathrm{~h}$ nach der Infektion. Die Wirtszelle exprimiert virale Proteine und DNA. Extra-zellulärer Virus (EV) wird produziert, und die maximale Abgabe von Virus-Partikeln erfolgt 18 bis $36 \mathrm{~h}$ nach der Infektion.

Die sehr späte Phase (engl. very late phase, viral occlusion protein phase) wird durch die 
Expression von Polyhedrin- und p10-Genen gekennzeichnet. Sogenannte Einschlußkörper (engl.: Occlusion Bodies) werden gebildet, und die Lyse der Wirtszelle beginnt (GibcoBRL).

Der Unterschied zwischen in vivo- und in vitro-Infektion ist, daß das PolyhedrinGen durch das rekombinante Gen ersetzt wird. Da das Virus-Genom zu groß ist, um es durch PCR zu amplifizieren, verwendet man site-specific Transposons. Dieses befindet sich auf einem Plasmid, welches eine Multiple Cloning Site (MCS) besitzt und in E. coli vermehrt werden kann (Invitrogen, 2002). Die so zur Expression gebrachten Proteine sind meist vollständig modifiziert. hSnu114 wurde als Vollängenkonstrukt mit 8His-Tag kloniert. Nach der Sequenzierung wurde von der Testexpression eine massenspektrographische Analyse durchgeführt, welche in der Bestätigung des Konstrukts endete.

Das Expressionssystem, welches von Berger et al. (Berger et al., 2004) etabliert und freundlicherweise zur Verfügung gestellt wurde ermöglicht die heterologe Expression mehrerer Gene, bzw. Domänen. Dieses System bietet die vielversprechende Aussicht, die U5-spezifischen Proteine gemeinsam als funktionelle Einheit zu exprimieren.

Abbildung 2.1 gibt einen schematischen Überblick von der Generation des Plasmids bis zur Proteinexpression in Flüssigkultur. 


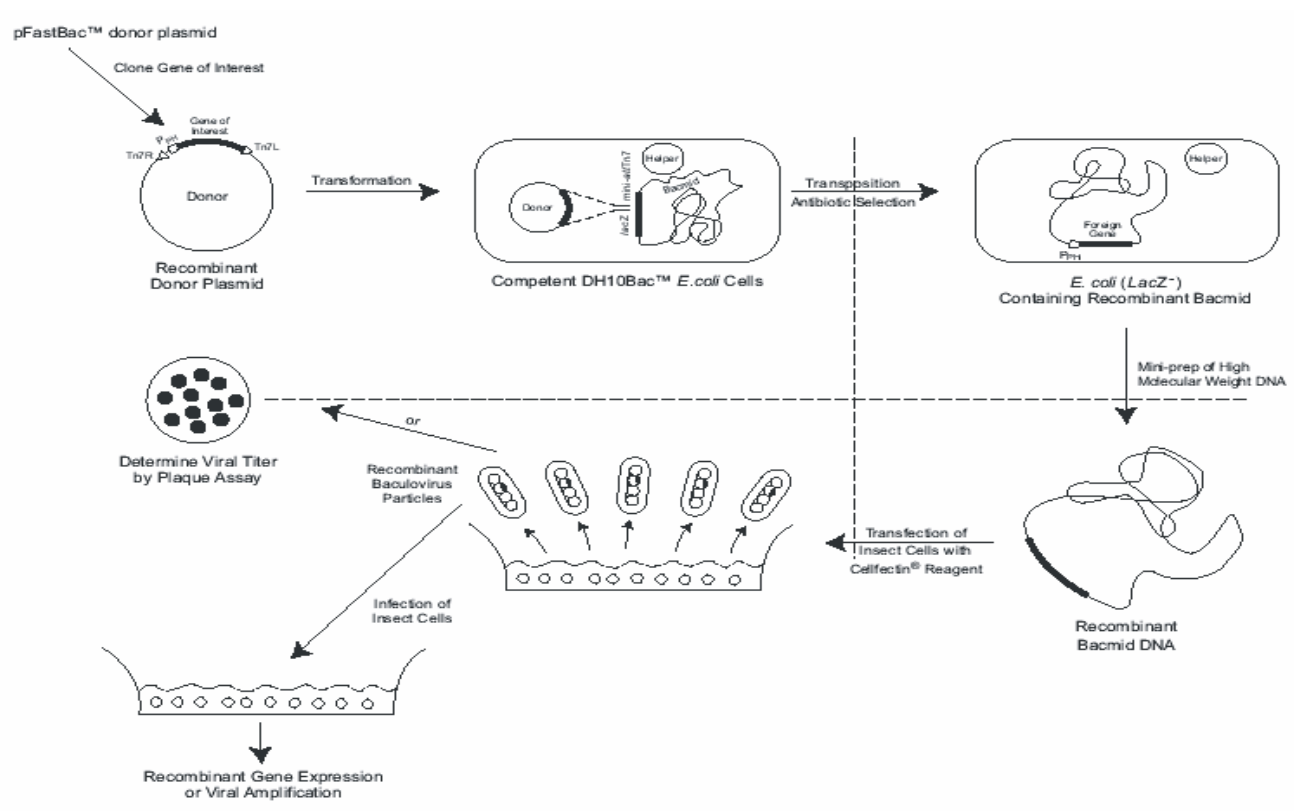

Abbildung 2.1: Schematische Darstellung von Generation des Plasmids, des Bacmids, bishin zur Transfektion. (Invitrogen, 2002)

\subsubsection{Transformation von pFASTBAC in $E$. coli DH10BAC}

\section{und Überprüfung der positiven Klone}

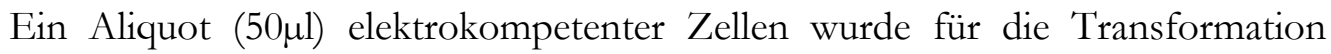
eingesetzt (siehe 2.2.7). Nach der Elektroporation werden die Zellen in Medium bei $37^{\circ} \mathrm{C}$ für mindestens $4 \mathrm{~h}$ geschüttelt. Je eine Hälfte des Ansatzes wird auf Platten A und B verteilt, wobei B die Transformationskontrolle ist. Positive Transformanten werden auf Platte A identifiziert (die positiven Klone sind weiß) und mindestens dreimal erneut auf Platte A ausgestrichen. Von den so identifizierten Klonen werden PCR-Reaktionen (wie im PCR-Kolonie-Screen beschrieben, 3.2.8) mit den Klonierungsprimern durchgeführt. Bei Auftreten einer klaren Bande hat die Rekombination mit einem das Zielgen enthaltenden Mini-Transposon stattgefunden.

Platten A:

LB-Agar

Kanamycin $(50 \mu \mathrm{g} / \mathrm{ml})$

Gentamicin $(7 \mathrm{mg} / \mathrm{ml})$

Tetracyclin $(10 \mu \mathrm{g} / \mathrm{ml})$

X-Gal $(100 \mu \mathrm{g} / \mathrm{ml})$ 


$\begin{array}{ll} & \text { IPTG }(40 \mu \mathrm{g} / \mathrm{ml}) \\ \text { Platten B: } & \text { Platten A } \\ & \text { Ampicillin }(100 \mu / \mathrm{ml})\end{array}$

\subsubsection{Präparation von Bacmid}

Der Klon der Wahl wird in $200 \mathrm{ml}$ LB-Medium gezogen, und eine Plasmid-MidiPrep wird den Herstellerangaben folgend durchgeführt. Nachdem die gewonnene DNA in $70 \%(\mathrm{v} / \mathrm{v})$ Ethanol gewaschen wurde, wird sie durch eine Inkubation in $70 \%(\mathrm{v} / \mathrm{v})$ Ethanol bei $4{ }^{\circ} \mathrm{C}$ für mindestens eine Woche entsalzt. Nachdem die DNA sedimentiert wurde, wird sie in $\mathrm{ddH}_{2} \mathrm{O}$ aufgenommen und für die Sequenzierung, bzw. anschließend für die Transfektion eingesetzt.

\subsubsection{Transfektion von Insekten-Zellen}

Eine Transfektion wird in drei von sechs Vertiefungen einer 6-Well-Plate durchgeführt. Jeder Well wird mit $1 * 10^{6}$ Zellen einer logarithmisch wachsenden Adhäsionskultur von Sf21-Zellen angesät. Nach der Adhäsion werden die Zellen zweimal mit Medium ohne Antibiotika gewaschen. Währenddessen wird 100 ng Bacmid in $50 \mu \mathrm{l}$ $\mathrm{ddH}_{2} \mathrm{O}$ in ein Reaktionsgefäß vorgelegt. Pro Transfektion werden $5.5 \mu$ Lipofectin mit

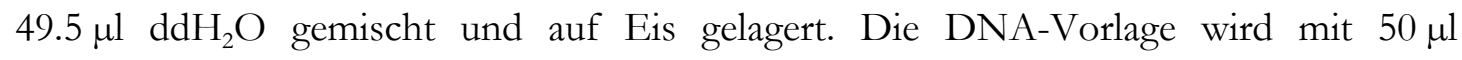
Lipofectin- $\mathrm{ddH}_{2} \mathrm{O}-$ Mischung versetzt, gemischt und $15 \mathrm{~min}$ auf Eis gelagert. Das Medium wird von den Zellen entfernt und $2 \mathrm{ml}$ frisches Medium werden in jeden Well gegeben. Der DNA-Lipofektin-Komplex wird in das Medium getropft. Die Platten werden $5 \mathrm{~h}$ bei $27^{\circ} \mathrm{C}$ gelagert. Anschließend wird der Überstand entfernt und $2 \mathrm{ml}$ antibiotikahaltiges Medium werden zu den Zellen gegeben. Das Medium (der Kulturüberstand, bzw. Ur-Virus) wird nach drei Tagen abgenommen, aufbewahrt und durch $2 \mathrm{ml}$ frisches Medium ersetzt. Nach weiteren zwei Tagen wird der Kulturüberstand 
erneut gesammelt und mit dem zuvor Gesammelten vereinigt. Der Titer des Ur-Virus wird mittels eines Plaque-Assays ermittelt.

\title{
2.6.4 Plaque-Assay
}

Die Zellen werden mit einer Dichte von $1 * 10^{6}$ pro Well einer 6-Well-Platte ausgesät und bis zur Adhärenz inkubiert. Der Ur-Virus wird in Medium üblicherweise auf $1: 10^{4}, 1: 10^{5}$ und $1: 10^{6}$ verdünnt. Das Medium wird entfernt, und $250 \mu \mathrm{l}$ einer VirusVerdünnung werden pro Well vom Rand aus auf die Zellen gegeben. Nach einer Inkubationszeit von $1 \mathrm{~h}$ bei $27^{\circ} \mathrm{C}$ werden $7 \mathrm{ml}$ der (auf $30^{\circ} \mathrm{C}$ abgekühlten) lmp-Agarose mit $7 \mathrm{ml} 2 \times$ Graces' Insect Medium und $70 \mu \mathrm{l}$ DEAE-Dextran gemischt und $2 \mathrm{ml}$ pro Well auf die Zellschicht pipettiert. Nachdem die Agarose fest geworden ist, wird die Platte eine Woche lang bei $27^{\circ} \mathrm{C}$ über Kopf inkubiert. Die Neutralrot-Lösung wird 1:7 mit Medium verdünnt, und $500 \mu \mathrm{l}$ werden pro Well für $3 \mathrm{~h}$ inkubiert. Neutralrot färbt nur lebende Zellen. Da, wo ein Virus-Partikel eine Plaque geformt hat (d.h. Zellen lysiert hat) bleibt der Agar ungefärbt, während die Umgebung aus lebenden Zellen rot gefärbt sind. Die Plaques werden gezählt und der Titer ergibt sich aus folgender Rechnung:

$$
\text { Anzahl der Plaques } * 4 * \text { Verdünnungs-Faktor }=\mathrm{x}[\mathrm{pfu} / \mathrm{ml}]
$$

Benötigtes Material:

\author{
logarithmisch wachsende Sf21 Adhäsions-Kultur \\ Ex-Cell 420 Medium, $27^{\circ} \mathrm{C}$ \\ 2 x Grace's Insect Medium \\ DEAE-Dextran $50 \mathrm{mg} / \mathrm{ml}$ in PBS \\ $3 \%$ lmp-Agarose \\ 6-Well-Platten für die Zellkultur \\ sterile Reaktionsgefäße, $1.5 \mathrm{ml}, 50 \mathrm{ml}$ \\ $0.5 \%$ sterile Neutralrot-Lösung
}

\subsubsection{Mini-Expressions-Test}

Dieser Test kann simultan mit dem Plaque-Assay durchgeführt werden. Eine logarithmisch wachsende Sf9 Kultur wird mit $1 * 10^{6}$ Zellen pro Well ausgesät und bis zur 
Adhärenz inkubiert. Das Medium wird entfernt und $2 \mathrm{ml}$ frisches Medium mit Virus im Verhältnis 1:5, 1:10 und 1:15 wird auf die Zellen gegeben. Nach einer Wachstumszeit von bis zu vier Tagen bei $27^{\circ} \mathrm{C}$ werden die Zellen und eine Negativkontrolle mittels eines Zell-Schabers geerntet, in SDS-Proben-Puffer aufgenommen, auf $95{ }^{\circ} \mathrm{C}$ erhitzt und auf ein analytisches Gel geladen. Das Gel wird geblottet und der Blot mit einem geeigneten Antikörper untersucht.

\subsubsection{Insekten-Zell-Kultur}

Sf21-Zellen werden in Gewebezellkulturflaschen bis zu einer Konfluenz von $95 \%$ wachsen gelassen, mit einem Zellschaber abgelöst und mit dem CASY-CellCounter gezählt. Die Kultur wird mit $5 * 10^{5}$ Zellen/ml weitergeführt.

Sf9-Zellen werden in Spinner-Flaschen gezogen. Die Dichte sollte $1 * 10^{7}$ Zellen $/ \mathrm{ml}$ nicht übersteigen und beim Ansähen etwa $1 * 10^{5}$ Zellen $/ \mathrm{ml}$ betragen.

\subsubsection{Generation von Cryo-Stocks und Kulturstart}

Um eine gesunde logarithmisch wachsende Kultur zu haben, muß man zum frühstmöglichen Zeitpunkt Zellen für einen Neustart der Kultur wegfrieren. Das geschieht indem man von einer nach optischer Kontrolle gesunden Kultur Aliquots mit $1 * 10^{7}$ Zellen/ml anfertigt und diese in antibiotikafreiem Medium, welches $10 \%$ DMSO enthält, aufschlämmt, fraktioniert und mittels eines kontinuierlichen Temperaturgradienten auf $-80{ }^{\circ} \mathrm{C}$ friert. Diese Zell-Stocks werden anschließend in flüssigen Stickstoff überführt. Der Kulturstart beginnt durch rasches Auftauen eines der eben genannten Aliquots. Sobald die Suspension flüssig ist, wird sie im zehnfachen Volumen Medium verdünnt, sedimentiert und zum Ansähen in frischem Medium aufgenommen. 


\subsubsection{Infektion von Insekten-Zellen}

Um rekombinantes Protein zu erhalten, werden Sf9-Zellen mit Virus infiziert. Zur Produktion von Protein, wählt man eine MOI (engl. multiplicity of infection) von 2 bis 10, d.h. 2 bis 10 Virus-Partikel werden pro Zelle in die Kultur gegeben. Die Dauer der Infektion ist optimierbar. Im Falle von 8His-hSnu114 resultierte eine relativ kurze Infektion von drei Tagen in der größten Menge undegradierten Proteins.

\subsubsection{Lyse von Insekten-Zellen}

Die Zellen werden nach der Sedimentation bei $800 \mathrm{rpm}$ bei $4{ }^{\circ} \mathrm{C}$ für $15 \mathrm{~min}$ in einem Lyse-Puffer Volumen aufgenommen, welches viermal so groß ist wie das Pelletvolumen. Diese Zell-Suspension wird für 45 min auf Eis inkubiert. Da in dem Lyse-Puffer kein Salz enthalten ist, platzen die Zellen durch osmotischen Druck. Im Anschluß wird die Suspension bei $17000 \mathrm{rpm}$ und $4{ }^{\circ} \mathrm{C}$ für $45 \mathrm{~min}$ sedimentiert.

$\begin{array}{ll}\text { Lyse-Puffer: } & 20 \mathrm{mM} \text { Tris } \mathrm{HCl} \mathrm{pH} 7.5 \\ & 0,5 \%(\mathrm{v} / \mathrm{v}) \text { Tween } 20 \\ & 0.5 \mathrm{mM} \text { Leupeptin }\end{array}$

\subsubsection{Reinigung mittels Ni-Affinitäts-Chromatographie}

Die Reinigung wird durchgeführt wie in 2.4.6 beschrieben. Allerdings beträgt der pH 7.5. 0.5 mM GTP werden den Puffern hinzugefügt.

\subsubsection{Reinigung durch Size-Exclusion-}

\section{Chromoatographie}

Durch diesen Chromatographie-Schritt wird die Probe zum einen von 
Kontaminaten abgetrennt, welche ein vom Zielprotein verschiedenes Molekulargewicht haben, und zum anderen in einen salzarmen Puffer gebracht, der für die Kristallisation von Nöten ist. Im Falle des Fusions-Proteins aus Insekten-Zellen, wurde ein SMARTSystem verwendet um die geringen Proteinmengen zu handhaben. Der verwendete Puffer setzt sich wie folgt zusammen:

$\begin{array}{ll}\text { Gelfiltrations-Puffer: } & 10 \mathrm{mM} \mathrm{HEPES} \mathrm{KOH} \mathrm{pH} \mathrm{7.0} \\ & 100 \mathrm{mM} \mathrm{KCl} \\ & 5 \mathrm{mM} \mathrm{MgCl} \\ & 2 \mathrm{mM} \mathrm{DTT} \\ & 0.5 \mathrm{mM} \mathrm{GTP}\end{array}$

\subsubsection{Aufnahme eines CD-Spektrums}

Die Proteinkonzentration und Molarität wird mit dem Biopolymer Calculator (http://paris.chem.yale.edu/extinct.html) bestimmt. Circular Dichroismus (CD) ist die Absorbtionsdifferenz zwischen rechts und links polarisiertem Licht bei einer bestimmten Wellenlänge. Ein CD-Spektrum dient der Beantwortung der Frage, ob ein rekombinantes Protein gefaltet ist oder nicht. Minima bei 202 und $210 \mathrm{~nm}$ sprechen für $\alpha$-helikale Anteile. Bei der Aufnahme einer Schmelzkurve von einem gefalteten Protein aus mehreren Domänen, erkennt man anhand der sigmoiden Kurve die Disintegration von Domänen und später von Sekundär-Strukturelementen.

$$
\begin{array}{ll}
\text { CD-Puffer: } & 20 \mathrm{mM} \mathrm{Pi} \text { pH } 7.8 \\
& 50 \mathrm{mM} \mathrm{NaCl} \\
& (1 \mathrm{mM} \mathrm{GTP})
\end{array}
$$

\subsubsection{Kristallisation von rekombinantem hSnu114}

Das rekombinante Protein wurde nach der Gelfiltration auf $2 \mathrm{mg} / \mathrm{ml}$ ankonzentriert. Mit dem Nano Drop-Roboter konnten zwei Kristallisationsscreens angefertigt werden: Der Index- und der PEG/ $\left(\mathrm{NH}_{4}\right)_{2} \mathrm{SO}_{4}$-Screen wurden durchgeführt und bei $4{ }^{\circ} \mathrm{C}$ gelagert. 


\subsection{Reinigung von Protein-Komplexen aus}

\section{Kernextrakten}

SnRNP-Partikel können aus HeLa-Kernextrakten (gereinigt nach Dignam et al. (Dignam et al., 1983)) durch Verwendung eines monoklonalen Antikörpers (sogenannten H20-Antikörper) gegen die $m_{3}$ G-Kappe schonend gereinigt werden (Bach et al., 1989; Behrens et al., 1993; Bochnig et al., 1987; Bringmann and Lührmann, 1986; Bringmann et al., 1983). Die anschließende Trennung in die einzelnen Partikel (12S U1, 17S U2, 20 S U5 und 25S U4/U6•U5) erfolgt durch die Wahl der Pufferbedingungen der Dichtegradienten-Zentrifugation.

Der Subkomplex, bestehend aus hPrp8, U5-200K, hSnu114 und U5-40K, wird durch NaSCN-haltigen Puffer aus dem angereicherten U5-snRNP gelöst. NaSCN bildet in wässrigen Lösungen ein großes, weiches Anion, welches positiv geladene Bereiche auf den Oberflächen von Proteinen bedeckt und so die Präparation von Subkomplexen ermöglicht.

\subsubsection{Pelletierung von snRNP zur Anreicherung von U5- snRNP-Partikeln}

Um ausreichende Partikelmengen für die Kristallisation zu erhalten, wurden große Volumen U5-haltiger Fraktionen (Randfraktionen) differentiell pelletiert. Die Randfraktionen beinhalten größtenteils U1- und U5- Partikel, wobei ein Ziel ist, U1 möglichst früh und vollständig abzutrennen. Dazu wurde die differentielle Zentrifugation etabliert. Diese macht sich zunutze, daß der größere U5-Partikel schneller im Gradienten wandert und also schneller am Grunde des Gefäßes ankommt, während U1 durch ein Glycerinkissen abgebremst wird. In 647.5-Zentrifugationsgefäßen wurden $53 \mathrm{ml}$ des 
Randfraktionen-Pools mit $5 \mathrm{ml}$ Kissen-Lösung unterschichtet und einer Sedimentation bei $45000 \mathrm{rpm}$ bei $4{ }^{\circ} \mathrm{C}$ für $14 \mathrm{~h}$ unterworfen. Nach der Sedimentation wird der Überstand in drei Schritten abgenommen. Die oberen $35 \mathrm{ml}$ enthalten nur noch Spuren von snRNP-Partikeln und werden verworfen. Die nächste Fraktion umfaßt $15 \mathrm{ml}$ und enthält vor allem disintegrierte Partikel. Die letzte, $8 \mathrm{ml}$ große Fraktion besteht aus angereichertem U1-snRNP in der Glycerin-haltigen Kissen-Lösung. Das klare Pellet am Grund des Gefäßes besteht größtenteils aus U5 Partikeln und hat eine bräunlich-rote Färbung. Dieses Pellet wird durch zweistündige Lagerung auf Eis in R400-Puffer gelöst und in desintegriert. Diese Lösung heißt in den folgenden Schritten „R400-Pool“. Vom Ausgangsmaterial, den Fraktionen und dem R400-Pool werden Proben für ein analytisches Gel genommen.

\begin{tabular}{|c|c|}
\hline Kissen: & $\begin{array}{l}20 \mathrm{mM} \text { Hepes KOH pH } 7.9 \\
75 \mathrm{mM} \mathrm{NaCl} \\
20 \text { (v/v) Glycerin } \\
0.5 \mathrm{mM} \text { DTT }\end{array}$ \\
\hline R400-Puffer: & $\begin{array}{l}20 \mathrm{mM} \text { Hepes } \mathrm{KOH} \mathrm{pH} 7.9 \\
1.5-7.5 \mathrm{mM} \mathrm{MgCl} \\
400 \mathrm{mM} \mathrm{NaSCN} \\
0.5 \mathrm{mM} \text { DTT }\end{array}$ \\
\hline
\end{tabular}

Alle Lösungen werden vor Gebrauch sterilfiltriert und auf $4{ }^{\circ} \mathrm{C}$ temperiert.

\subsubsection{Glyceringradienten-Zentrifugation}

Nach einer breit angelegten Optimierung wurden folgende Bedingungen für die großvolumige Reinigung zugrunde gelegt: Der Glyceringehalt steigt von oben nach unten von 10 auf $30 \%$, wohingegen die NaSCN-Konzentration von 300 mM oben zu $200 \mathrm{mM}$ abnimmt. Diese Bedingung sollte möglichst viel Subkomplex während des Wanderns im Gradienten intakt halten, wobei die Dissoziation vom Core-snRNP im oberen Teil des Gradienten so vollständig wie möglich erfolgen sollte. Die Gradientenlösungen werden als doppeltkonzentrierte Lösungen angesetzt und dann mit Glycerin und $\mathrm{ddH}_{2} \mathrm{O}$ zur Gebrauchslösung verdünnt und sterilfiltriert. Die 10 \%-ige Glycerin-Lösung wird bis zur 
Hälfte des Zentrifugationsgefäßes eingefüllt und mit der 30\%-igen Lösung unterschichtet. Der Gradient wird mit Hilfe des „Gradient Master 106“ gemischt und mindestens $2 \mathrm{~h}$ bei $4{ }^{\circ} \mathrm{C}$ gelagert. Nach Abnahme von $2 \mathrm{ml}$ werden $2 \mathrm{ml}$ des R400-Pool aufgetragen, ohne den Gradienten zu verwirbeln. Die Sedimentation erfolgte im S630Rotor bei $30000 \mathrm{rpm}$ und $4{ }^{\circ} \mathrm{C}$ für $28 \mathrm{~h}$. Im Anschluß wurden die Gradienten mit einem Fraktionssammler in $1.5 \mathrm{ml}$ Schritten von unten nach oben abgenommen. Das UVChromatogram wurde durch Konzentrationsbestimmungen und ein analytisches Gel bestätigt. Wenn die Fraktionen gegen einen hellen Hintergrund gehalten werden, kann man anhand der bräunlich-roten Färbung die Fraktionen mit dem gewünschten Subkomplex eingrenzen.

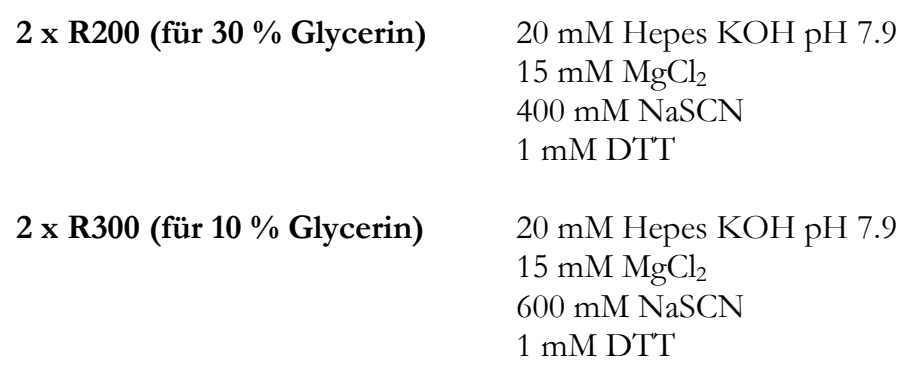

Alle Lösungen werden vor Gebrauch sterilfiltriert und auf $4{ }^{\circ} \mathrm{C}$ temperiert.

\subsubsection{Repelletierung von komplexhaltigen Fraktionen}

Gradientenfraktionen mit möglichst wenig Kontamination durch U1 wie wurden vereinigt und einer Pelletierung, wie unter 2.7.1 beschrieben, unterworfen. Die Repelletierung wurde der Konzentrierung mit Konzentratoren vorgezogen, da der Salzund Glyceringehalt bei den ankonzentrierten Gradientenfraktionen für Kristallisationsexperimente zu hoch gewesen ist. Bei der Dialyse waren die Verluste durch unspezifische Adhäsionen an die Dialysemembran ebenfalls hoch und die Konzentration der Proteinlösung verringerte sich durch die Volumenzunahme. Durch die darauf folgende Konzentrierung wären weitere Verluste entstanden. Aus diesen Gründen wurde der Subkomplex repelletiert und in speziellem Puffer aufgenommen. Die 
Repelletierung hatte sich schon als Methode der Wahl herausgestellt und resultierte den EM-Daten zu folge in homogenem Material (Diskussion M. Golas, N. Fischer und B. Kastner). Das Pellet wird in R200spec durch Lagerung von bis zu $4 \mathrm{~h}$ auf Eis gelöst. Durch eine Sedimentation bei $13000 \mathrm{rpm}$ und $4^{\circ} \mathrm{C}$ für $5 \mathrm{~min}$ in einer Tischzentrifuge werden Aggregate abgetrennt. Die Konzentration wurde, nachdem große Mengen Protein-Aggregate abgetrennt wurden, durch den Gebrauch eines $500 \mu$ l-Konzentrators (Millipore, $10000 \mathrm{MWCO}$ ) auf $7 \mathrm{mg} / \mathrm{ml}$ erhöht.

$\begin{array}{ll}\text { R200spec: } & 10 \mathrm{mM} \mathrm{Hepes} \mathrm{KOH} \mathrm{pH} 7.9 \\ & 50 \mathrm{mM} \mathrm{NaCl} \\ & 200 \mathrm{mM} \mathrm{NaSCN} \\ & 0.5 \mathrm{mM} \mathrm{DTT}\end{array}$

\subsubsection{Kristallisation des gereinigten Subkomplexes}

Der gereinigte Subkomplex wurde in den folgenden Screens bei 4 und $21{ }^{\circ} \mathrm{C}$ eingesetzt: Anions, Cations, Classics, Classics lite, Cryos, Mb class I und II, MPD suite, $\left(\mathrm{NH}_{4}\right)_{2} \mathrm{SO}_{4}$, Nucleix, pH Clear I und II. Die Screens wurden von nicht eingefrorenem Komplex gefertigt.

\subsection{5 „Domain-Mapping durch limitierte Proteolyse}

Interagierende Domänen innerhalb des Subkomplexes sollten durch limitierte Proteolysen mit anschließenden analytischen Gelfiltrationsläufen untersucht werden. Verschiedene Proteasen mit mehreren Inkubationslängen wurden untersucht, um im besten Fall ähnliche Fragmente und Zusammensetzungen durch verschiedene Proteasen zu generieren. Die anschließende Gelfiltration (der Puffer ist weiter unten beschrieben) gibt Aufschluß darüber, ob die stabilen Fragmente gemeinsam durch die Gel-Matrix wandern, also noch interagieren. Entstandene Domänen wurden durch Massenspektrometrie analysiert. In der folgenden Tabelle sind die verwendeten 
Proteasen zusammengefaßt.

\begin{tabular}{|c|c|c|c|c|}
\hline Name & $\begin{array}{l}\text { Verdünnung und } \\
\text { Inkubationsdauer }\end{array}$ & MW & Buffer $_{\text {opt }}$ & $\mathrm{T}_{\mathrm{opt}}$ \\
\hline Aminopeptidase I & $\begin{array}{c}\min 100 \mathrm{U} / \mathrm{mg} \\
\text { Protein } \\
\text { 30, 60, } 90 \mathrm{~min}\end{array}$ & $33 \mathrm{kDa}$ & $\begin{array}{c}20 \mathrm{mM} \text { Tricin pH } \\
8,0,0,05 \% \mathrm{BSA}\end{array}$ & $37^{\circ} \mathrm{C}$ \\
\hline Carboxypeptidase Y & $\begin{array}{c}1: 25 \\
2,9,20 \mathrm{~min}\end{array}$ & $61 \mathrm{kDa}$ & $\mathrm{pH} 5,5-6,5$ & $35^{\circ} \mathrm{C}$ \\
\hline Chymotrypsin & $\begin{array}{c}1: 100 \\
30,60,90 \mathrm{~min}\end{array}$ & $25 \mathrm{kDa}$ & $\begin{array}{l}100 \mathrm{mM} \text { Tris } 7,9- \\
9,0,10 \mathrm{mM} \mathrm{CaCl}_{2}\end{array}$ & $25^{\circ} \mathrm{C}$ \\
\hline Endoprot Arg-C & $\begin{array}{c}1: 200 \\
30,60,90 \mathrm{~min}\end{array}$ & no data & no data & $37^{\circ} \mathrm{C}$ \\
\hline Endoprot Asp-N & $\begin{array}{c}1: 100 \\
30,60,90 \mathrm{~min}\end{array}$ & $27 \mathrm{kDa}$ & $\begin{array}{c}10 \text { mM Tris } \sim 8,0 \\
\text { w/o EDTA }\end{array}$ & $37^{\circ} \mathrm{C}$ \\
\hline Endoprot Glu-C & $\begin{array}{c}1: 100 \\
30,60,90 \mathrm{~min}\end{array}$ & $30 \mathrm{kDa}$ & $\begin{array}{c}25 \mathrm{mM}_{\left(\mathrm{NH}_{4}\right)_{2} \mathrm{CO}_{3}} \\
\mathrm{pH} \sim 7,8\end{array}$ & $25^{\circ} \mathrm{C}$ \\
\hline Endoprot Lys-C & $\begin{array}{c}1: 100 \\
30,60,90 \mathrm{~min}\end{array}$ & $36 \mathrm{kDa}$ & $\begin{array}{c}10 \mathrm{mM} \text { Tris } 7,0-9,0 \\
1 \mathrm{mM} \text { EDTA }\end{array}$ & $37^{\circ} \mathrm{C}$ \\
\hline Leucin Aminopep & $\begin{array}{c}1: 100 \\
30,60,90 \mathrm{~min}\end{array}$ & no data & no data & $37^{\circ} \mathrm{C}$ \\
\hline Papin & $\begin{array}{c}1: 100 \\
30,60,90 \mathrm{~min}\end{array}$ & $21 \mathrm{kDa}$ & $\mathrm{pH} 6,0-7,0$ & $25^{\circ} \mathrm{C}$ \\
\hline $\begin{array}{c}\text { Protease X } \\
\text { (Thermolysin) }\end{array}$ & $\begin{array}{c}1: 100 \\
30,60,90 \mathrm{~min}\end{array}$ & no data & no data & $37^{\circ} \mathrm{C}$ \\
\hline Trypsin & $\begin{array}{c}1: 100 \\
30,60,90 \mathrm{~min}\end{array}$ & $25 \mathrm{kDa}$ & $\begin{array}{c}\text { in the delivered } \\
\text { buffer }\end{array}$ & $37^{\circ} \mathrm{C}$ \\
\hline
\end{tabular}

Tabelle 2.2: Die verwendeten Proteasen. Des weiteren enthält die Tabelle ihre Optima, Eigenschaften und die gewählten Verdünnungen. Arg-C benötigt zur Reaktionsinitiation $1 \mathrm{mM} \mathrm{CaCl}_{2}$, 5 mM DT'T, 0.5 mM EDTA in $10 \mathrm{mM}$ Tris $\mathrm{NaOH}$ pH 1.9.

Gelfiltration R200 (10 \% Glycerin) 20 mM Hepes KOH pH 7.9

$$
\begin{aligned}
& 75 \mathrm{mM} \mathrm{NaCl} \\
& 200 \mathrm{mM} \mathrm{NaSCN} \\
& 1 \mathrm{mM} \mathrm{DTT} \\
& 13 \%(\mathrm{v} / \mathrm{v}) \text { Glycerin }
\end{aligned}
$$




\subsection{Bio-Informatische Methoden und verwendete}

\section{Programme}

\subsubsection{BLAST (Basic Local Alignment Search Tool)}

Für erste Hinweise von Domänengrenzen und/oder höher geordnete Regionen werden die Sequenzen der Proteine Standard-BLASTs des „National Center of Biotechnology Information NCBI“" unterzogen (http://www.ncbi.nlm.nih.gov/entrez/).

\subsubsection{Alignments}

Sequenzvergleiche für Proteine wurden mit VectorNTI Version 8.0 von Informax durchgeführt. DNA-Alignments und Analyse der Erkennungssequenzen von Restriktionsenzymen wurden mit VectorNTI und Seybuilder von DNAstar erstellt.

\subsubsection{Programme für Struktur-Vorhersagen}

Für die Ermittlung von Domänen wurde der ExPASy Proteomics Server (http://us.expasy.org/prosite) verwendet.

Die Wahrscheinlichkeit, mit der eine Sequenz für eine geordnete Domäne kodiert wird mit PONDR (http://www.pondr.com/2daypage.html) berechnet.

FoldIndex ${ }^{\odot}$ ist ein hilfreiches Programm, um gefaltete von ungefalteten Regionen zu unterscheiden (http://bip.weizmann.ac.il/fldbin/findex).

$\begin{array}{llll}\text { Desweiteren } & \text { wurde } & \text { Sürukurvorhersagen }\end{array}$ (http://bioinf.cs.ucl.ac.uk/psipred/pdiform.html) und um Motive in einer Proteinsequenz zu identifizieren: http://myhitsisb-sib.ch/cgi-bin/motif scan verwendet. Die Rückfaltungsdatenbank wurde unter http://refold.med.monash.edu.au/ verwendet. Außerdem wurden Programme zur Steuerung von dem Cartesian Nanodrop 
Roboter (AXSYS), oder der ÄKTA-Systeme (Unicorn), die Jasco Software for CD

Spectrometrie, sowie WindowsNT und Office Programme, Endnote, und Biorads Documentations Programm verwendet. 


\section{Ergebnisse}

Im U5-snRNP bilden Prp8, U5-200K, hSnu114 und U5-40K einen heterotetrameren Subkomplex. Dieser Subkomplex ist der Gegenstand der vorliegenden Arbeit.

Um eine große Anzahl Kristallisationsversuche durchzuführen, mußten ausreichende Mengen Protein präpariert werden. Während der Arbeit wurden zwei Strategien verfolgt: Zum einen sollten rekombinante Proteine, domänenweise oder als volllängen Konstrukte, mit verschiedenen Tags hergestellt und zur Kristallisation gebracht werden. Zum anderen Subkomplexe des U5 snRNP-Partikels gereinigt, kristallisiert und außerdem die interagierenden Domänen der einzelnen Proteine untersucht werden.

\subsection{Gewinnung von rekombinantem hSnu114 in $E$. coli}

\subsubsection{Klonierung, Transformation, Expression und Rückfaltung von GST-hSnu114}

Zunächst wurde hSnu114 in pGEX-6P-1 kloniert. Nach der bioinformatischen Analyse wurden Primer entworfen, welche die Schnittstellen für BamHI und NotI enthielten. pGEX-6P-1 wurde gewählt, weil dieser Vektor eine vergleichsweise große MCS (engl., Multiple Cloning Site) besitzt, vielfach bewährt ist und die Affinitätsreinigung mit dem GST-Tag in sehr sauberem Protein resultiert. Die PCR wurde mit PfuPolymerase durchgeführt, um von deren Proof-Reading Aktivität zu profitieren. Trotzdem wurden die Klone sequenziert. Das Konstrukt wurde daraufhin in den Expressionsstamm Bl21 (DE3) ROSETTA transformiert. Der ROSETTA-Stamm wurde gewählt, weil er tRNAs für seltene Codons besitzt und so die vollständige Translation 
eines eukaryonten Genes in einem prokaryonten Wirt wahrscheinlicher ist, bzw. reibungsloser erfolgt. Die Expression wurde unter verschiedenen Bedingungen getestet. So wurde die Temperatur zwischen 37 und $16{ }^{\circ} \mathrm{C}$ variiert, da eine niedrigere Temperatur einen positiven Einfluß auf die Expressionsrate und so auf die Faltungswahrscheinlichkeit eines eukaryonten Proteins haben kann. Die Induktion ist ebenfalls zwischen $\mathrm{OD}_{600} 0.5$ bis 1.8 getestet worden, sowie die Endkonzentration des Induktors, welche zwischen 1 und $0.1 \mathrm{mM}$ lag. Die Zugabe von $2 \%$ (v/v) Ethanol oder 2-Propanol zum Zeitpunkt der Induktion wurde ebenfalls untersucht. Im folgenden Beispiel wurde eine Schüttelkultur bei $\mathrm{OD}_{600} 0.5 \mathrm{mit} 125 \mathrm{nM}$ IPTG induziert (das entspricht einem Achtel der üblichen IPTG Konzentration). Man erkennt deutlich die Expression des Zielproteins.

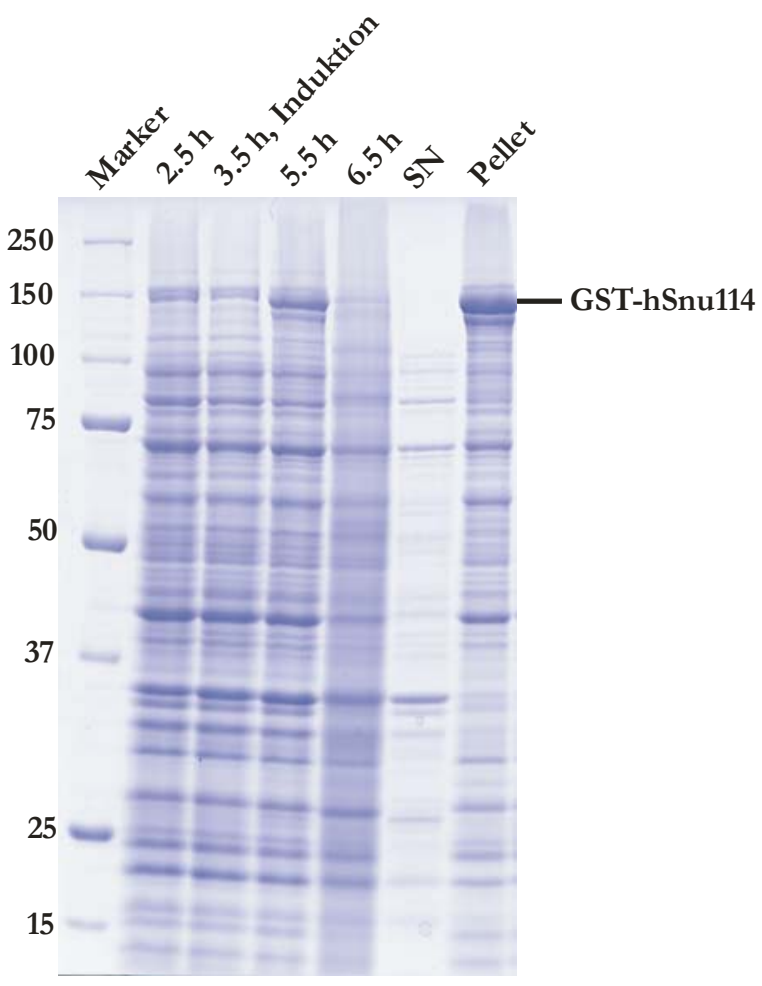

Abbildung 3.1: Expression von GST-hSnu114 in B121 (DE3) ROSETTA bei $25^{\circ} \mathrm{C}$. Induktion bei OD600 0.5 nach 3.5 h. Ernte der Zellen nach weiteren $3 \mathrm{~h}$ und Lyse durch Sonifizierung. Der lösliche Überstand (SN) und das Sediment (Pellet) sind ebenfalls auf dem Gel zu sehen. Die Expression des Zielproteins erkennt man an einer Bande bei $150 \mathrm{kDa}$, was dem Molekulargewicht des Zielproteins mit GST-Tag entspricht. 
GST-hSnu114 ist induzierbar, was man am Sichtbar werden der Zielbande erkennt. Leider ist nach dem Zellaufschluß und Zentrifugation das Zielprotein im Sediment.

Als nächstes wurden Inclusion Bodies (IBs) gereinigt, um reines Protein für weitere Tests zur Verfügung zu haben. Daran wurde eine Rückfaltung angeschlossen, welche in löslichem Protein resultierte. Mit dieser Probe wurde eine Affinitätsreinigung durchgeführt.

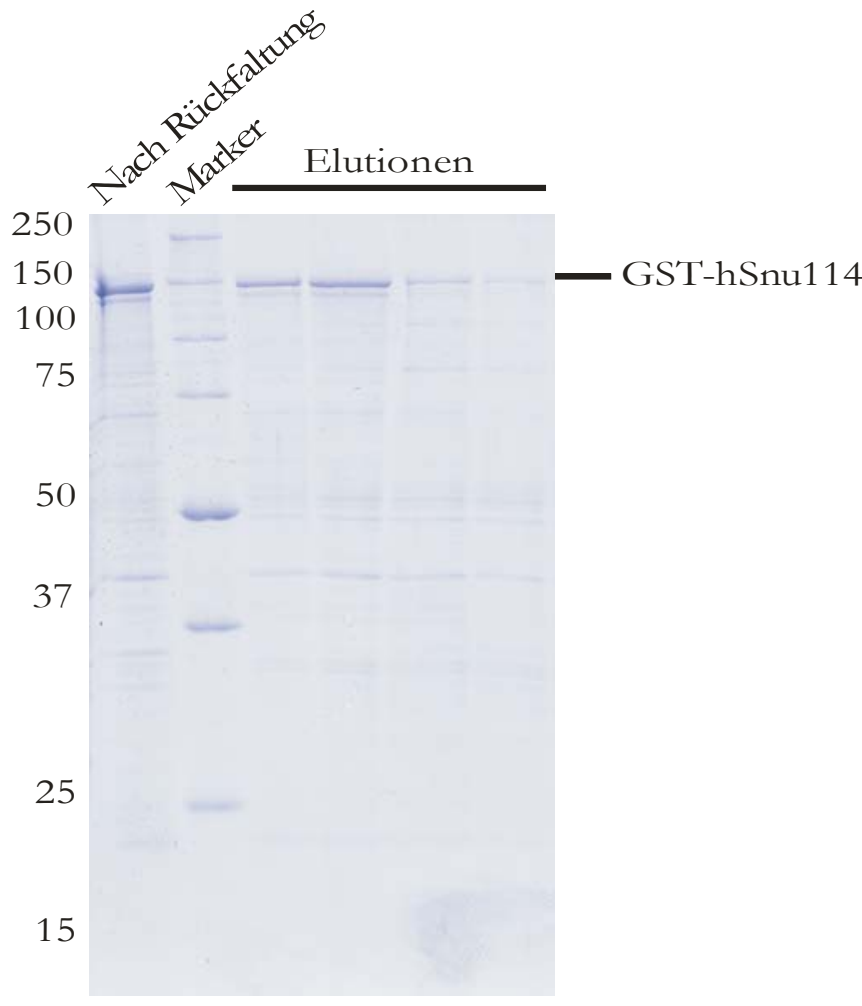

Abbildung 3.2: GST-hSnu114 nach Rückfaltung im Eluat der Glutathion-Affinitätssäule. Das Protein läßt sich durch die IB-Reinigung und die Rückfaltung in Lösung bringen. Die Zielbande erscheint auch im Eluat von der Affinitätssäule.

GST-hSnu114 läßt sich aus Inclusion Bodies reinigen und man kann nach der Rückfaltung eine Affinitätssäule anschließen, von der sich das Zielprotein eluieren läßt. Durch den Verdau mit der spezifischen Protease (Prescission ${ }^{\mathrm{TM}}$ ) fällt hSnu114 aus, nur der GST-Tag bleibt in Lösung. Der GST-Tag hat für die Löslichkeit gesorgt, weil er in seine native Form, eine $25 \mathrm{kDa}$ große, $\alpha$-helikale, globuläre Domäne, zurückgekehrt ist, 
was auf hSnu114 nicht zu trifft. Die Größe und der vorwiegende $\beta$-Faltblattanteil des Proteins machen eine Rückfaltung unwahrscheinlich. Nachdem der GST-Tag, abgetrennt wurde, interagierten die $\beta$-Faltblätter verschiedener Proteine, bzw. nicht benachbart liegende, miteinander und führten zur vollständigen Präzipitation des Zielproteins.

\subsubsection{Subklonierung von hSnu114 und Expressionstest}

Die Domänengrenzen für diese Klonierung wurden anhand eines 3D-Abgleichs mit bekannten Strukturen von G-Proteinen erstellt. Dazu wurden folgende Einträge der PDB verwendet: 1ELO, 1DAR, 1EFG und 2EFG. Darüber hinaus angewandte bioinformatische Analysen verbessern das Design derart, daß Sekundärstrukturelemente wie $\alpha$-Helices und $\beta$-Faltblätter bei den subklonierten Domänen intakt blieben.

Es wurden vier Domänen entworfen, deren Anordnung, Bestandteile und kalkulierte Größe in Abbildung 3.3 dargestellt werden.

A

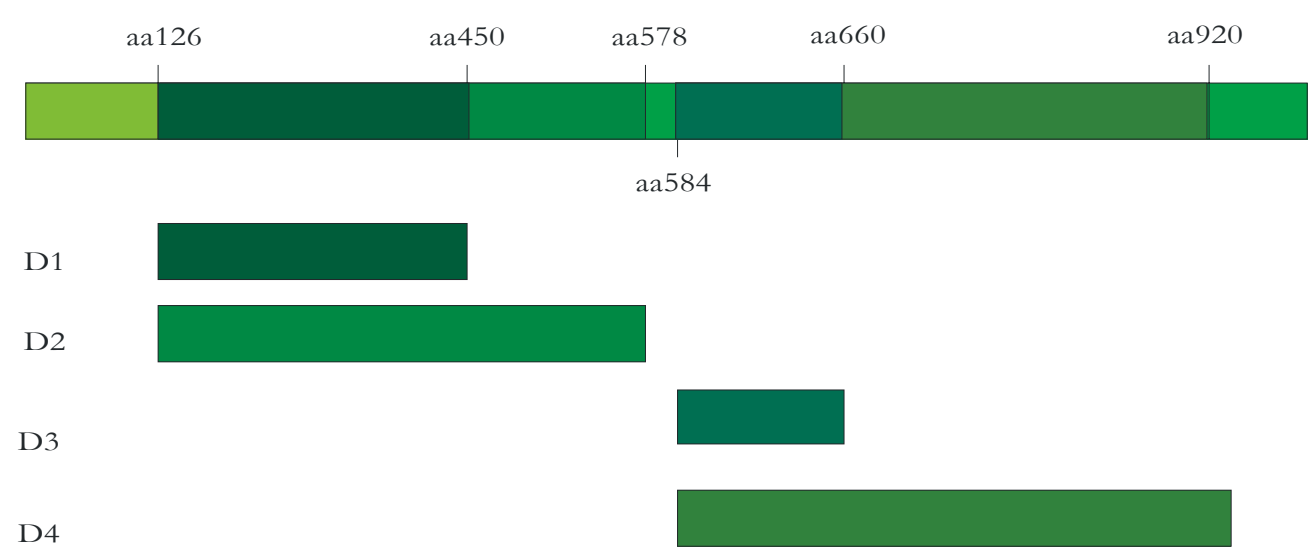

B

\begin{tabular}{|l|c|c|}
\hline Name & Domänengrenzen & Kalkulierte Größe \\
\hline hSNu114 & 1 bis 955 & $110 \mathrm{kDa}$ \\
\hline D1 & 126 bis 450 & $37 \mathrm{kDa}$ \\
\hline
\end{tabular}




\begin{tabular}{|c|c|c|}
\hline D2 & 126 bis 578 & $51 \mathrm{kDa}$ \\
\hline D3 & 584 bis 660 & $10 \mathrm{kDa}$ \\
\hline D4 & 584 bis 920 & $37 \mathrm{kDa}$ \\
\hline
\end{tabular}

Abbildung 3.3 und Tabelle 3.1: Schematische Darstellung der Subklonierung von hSnu114.

Die Domänen wurden in pGEX-6P-1 kloniert und auf Expression und lösliches Protein untersucht. In allen Subklonierungen außer D2 wurde kein lösliches Protein gefunden. Die Domäne D2 ließ sich nicht von dem GST-Tag abverdauen und präzipitierte.

Die Subdomäne D4 entspricht einem Fragment, welches bei den massenspektrometrischen Analysen der limitierten Proteolysen gefunden wurde.

\subsubsection{D NMR Spektrum eines Degradationsfragmentes der N-terminalen aziden Domäne (Snu114p)}

Bei der Reinigung eines Fusionsproteins bestehend aus einem N-Terminalen, GST-Tag und einem Snu114p-Fragment von $70 \mathrm{kDa}$ Größe, entstand ein Degradationsfragment. Dieses Degradationsfragment war löslich und etwa $50 \mathrm{kDa}$ groß. Die Reinigung des Fusionsproteins erfolgte zunächst ohne proteolytische Spaltung von Tag und Zielprotein, daher kann man davon ausgehen, daß es sich um die ersten $25 \mathrm{kDa}$ des Proteins handelt, da der GST-Tag selbst etwa $25 \mathrm{kDa}$ groß ist. Der reine NTerminus, der durch seine hohe Azidität (IP 3.8) auffällt und eine besondere Funktion für das GTP-bindende Protein Snu114p haben muß, da es sich durch diese Domäne von EF-2 unterscheidet, ist $22 \mathrm{kDa}$ groß. Es handelt sich um ein äußerst interessantes Ziel für die strukturelle Aufklärung, da die Domäne eine bislang unbekannte Struktur und Funktion hat. Um weitere Schritte zu planen, wurde ein 1D-Spektrum in der medizinischen NMR, Göttingen, aufgenommen. 
Das Fragment wurde gewählt, da es sich bei Expressionen als stabiles, präparierbares Ziel erwiesen hat. Die Klonierung wurde von U. Reidt durchgeführt.

1D-Spektrum des aziden N-Terminus von hSnu114

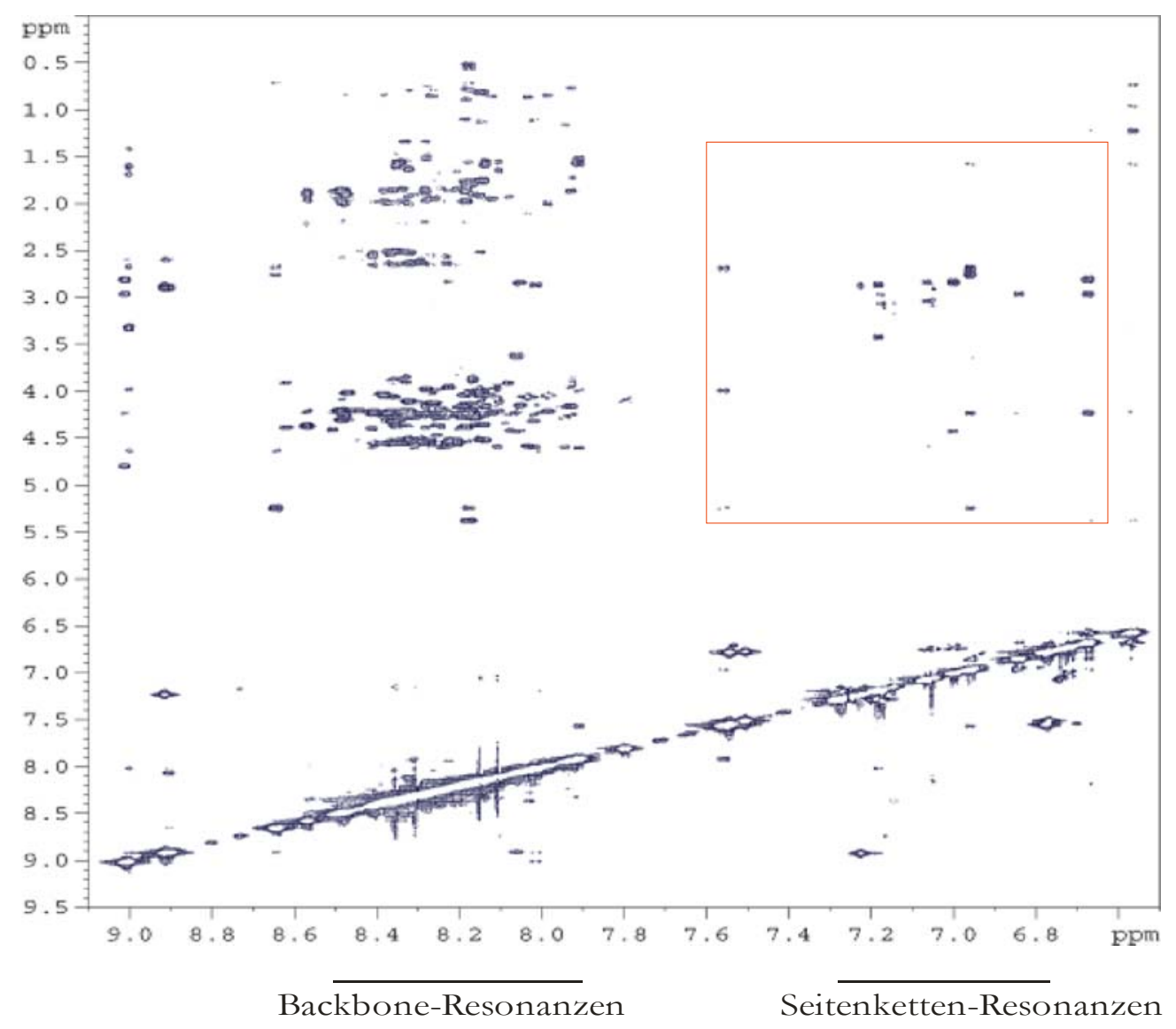

Abbildung 3.4: 1D-NMR-Spektrum des aziden N-Terminus von Snu114p. Es gibt zwei aussagekräftige Bereiche, in dem einen erkennt man die Resonanzen für das Rückrat des Proteins und in dem zweiten weisen Signale auf Seitenketten hin. In diesem Fall sind die Resonanzen für die Seitenketten schwach und deuten auf ein ungefaltets Protein hin.

Abbildung 3.4 zeigt ein 1D-NMR-Spektrum des aziden N-Terminus von Snu114p. Die geringe Signaldichte in dem Bereich der Seitenketten deutet auf ein wenig gefaltetes Proteinfragment hin. Die gute Löslichkeit kann in der geringen Größe und der hohen Azidität begründet liegen. Das Fragment wurde nicht weiter untersucht. 


\subsubsection{Zusammenfassung - Expression von rekombinantem Snu114p,} hSnu114 und dessen Subdomänen in E. coli

Die einfache Expression der spleißosomalen Proteine aus $H$. sapiens und $S$. cerevisiae (siehe oben im Text), bzw. deren Fragmente, ist in E. coli nicht erfolgversprechend. Nötige Modifikationen für Löslichkeit und native Faltung werden nicht gemacht, oder es fehlen Membranen, bzw. Chaperone als Faltungsmediatoren.

Darum sollten aus nativem, humanem heterotetrameren Komplex interagierende Domänen charakterisiert werden, welche für eine Coexpression geeignet sind. Dabei bestand zu dem Zeitpunkt als das Projekt begonnen wurde das Problem, daß noch keinerlei Aussagen über die Domänenstruktur von Prp8 gemacht werden konnten. 


\subsection{Limitierte Proteolyse des heterotetrameren}

\section{Subkomplexes, Subklonierung und Coexpression}

\subsubsection{Allgemeines zur limitierten Proteolyse}

Die limitierte Proteolyse ist eine elegante Methode, um eng miteinander interagierende Proteinbereiche von solchen Teilen zu unterscheiden, die eine andere Funktion, als die Bindung haben. Bereiche, die nicht durch inter- oder intramolekulare Wechselwirkungen geschützt sind, werden von Proteasen mit einer höheren Wahrscheinlichkeit verdaut und dissoziieren von dem Kernbereich des Partikels. Die zentralen, interagierenden Domänen des U5-snRNP sollten charakterisiert werden. Dazu wurde der heterotetramere Subkomplex aus Prp8, U5-200K, hSnu114 und U5-40K gereinigt und verschiedenen analytischen Verdauen ausgesetzt.

\subsubsection{Limiterten Proteolyse mit Trypsin und Gelfiltration des Subkomplexes}

Die Proteolyse mit Trypsin wurde durch Variation des Verhältnisses, der Dauer und der Temperatur optimiert. Die im Gel erscheinenden stabilen Fragmente sollten im Anschluß an die Proteolyse auf comigrierende Fragmente untersucht werden. Das heißt der Komplex wird proteolysiert und durch Gelfiltration werden Fragmente der Größe nach getrennt. Findet man im Analysegel Fragmente unterschiedlicher Größe, die zum selben Zeitpunkt von der Säule eluieren, interagieren die Fragmente miteinander (ihre jeweiligen Molekulargewichte haben sich addiert). Die im Analysegel erhaltenen comigrierenden Fragmente werden durch Massenspektrometrie identifiziert. 


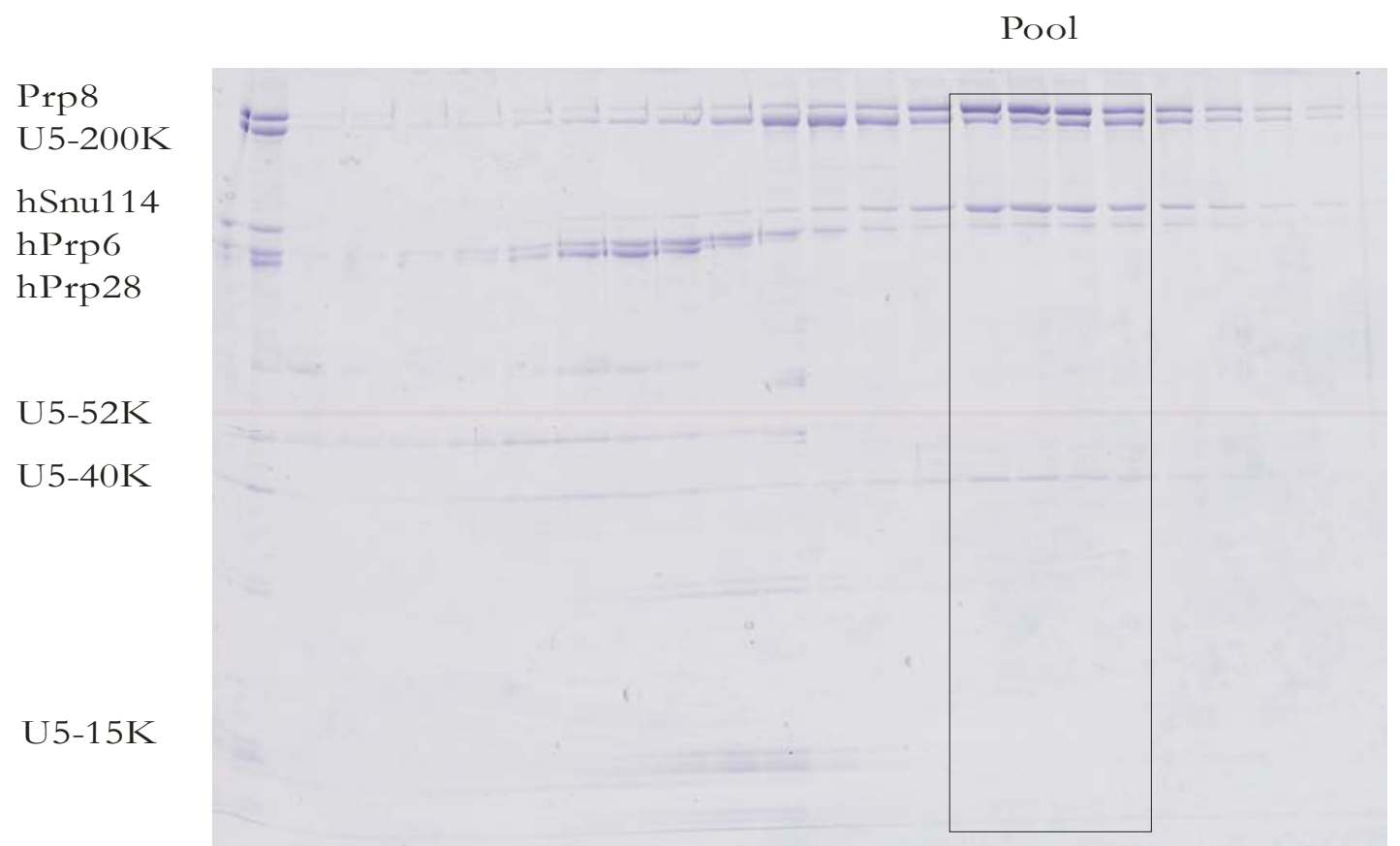

Abbildung 3.5: Ursprüngliche Präparation des Subkomplexes nach C. Bartels. Ganz links wurde ein Aliquot des Ausgangsmaterials aufgetragen. Dabei handelt es sich um U5-haltige Fraktionen von der H20-Säule. Die Trennung von den Core-Proteinen ist befriedigend, wenn auch eine Kontamination mit hPrp6 und ein ausdiffundieren von U5-200K unvermeidlich ist. Die Konzentration ist nicht hoch genug, um möglicherweise reassoziierte Patikel zu sehen.

Der Subkomplex wurde nach dem Standardprotokoll (nach C. Bartels und T. Achsel) präpariert und die Fraktionen vereinigt. Anschließend wurde die Konzentration durch Ultrafiltration erhöht und der Komplex mit Trypsin (1:100, Trypsin:Subkomplex) bei $37 \mathrm{C}$ für $2 \mathrm{~h}$ ohne Schütteln verdaut. Um die Gelfiltration durchführen zu können, mußte dem Gelfiltrationspuffer neben Thiocyanat auch ein 10\%iger Anteil Glycerin beigemengt werden. In allen Versuchen ohne Hochsalz und Glycerin adhärierte das Protein an der Säulenmatrix. 


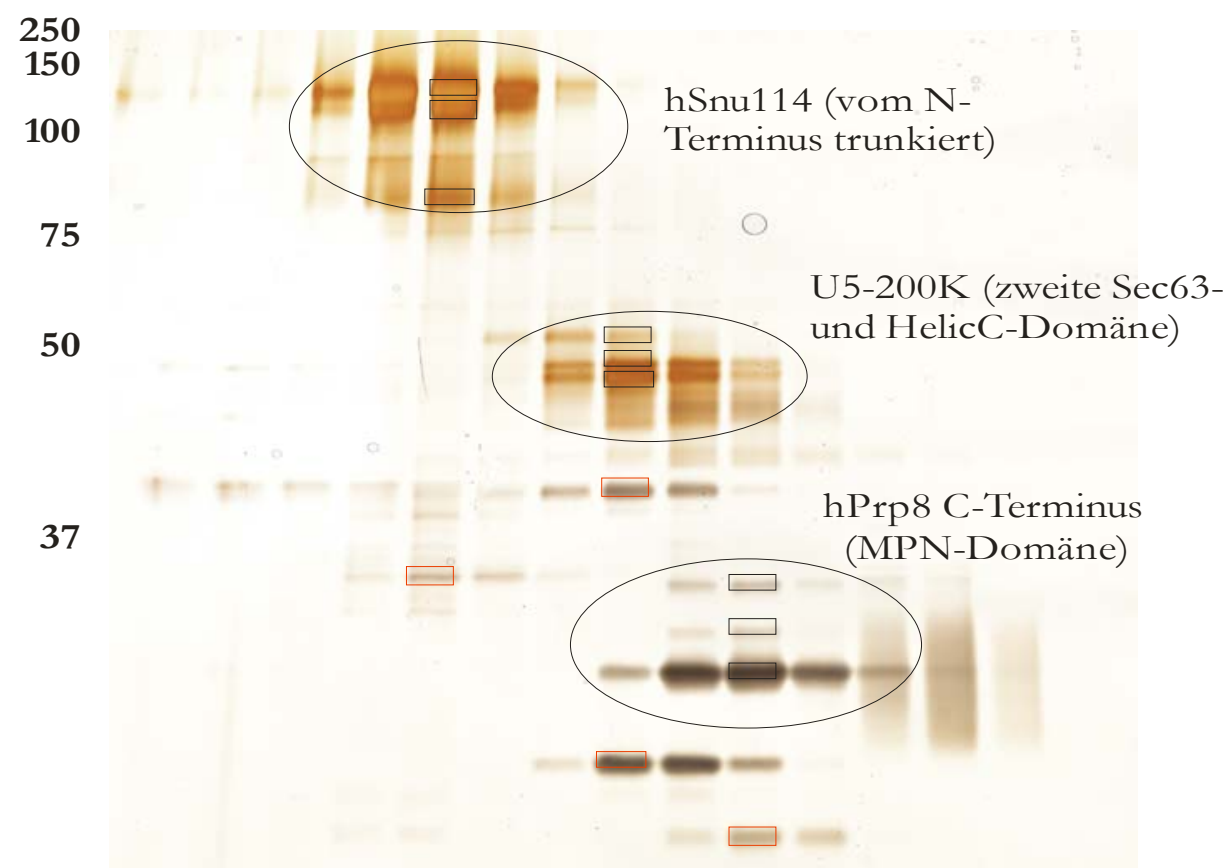

15

Abbildung 3.6: Gel des Subkomplexes in der Gelfiltration nach der limitierten Proteolyse mit Trypsin. Die Kästchen markieren Banden, welche analysiert worden sind. Die rot markierten haben keine Daten ergeben. Die Banden in den schwarzen Kästchen oben links ergaben hSnu114 ohne den NTerminus in verschiedenen Degradationsstufen. Im mittleren Komplex wurde der C-Terminus mit der zweiten Sec63- und Teilen der zweiten Helikase-Domäne von U5-200K gefunden. Der untere Bereich lieferte Daten aus dem C-Terminus von Prp8.

Die Fragmente, die zum selben Zeitpunkt eluieren sind Degradationsprodukte eines Proteins. Die Blasen markieren die Fragmente, die aufgrund ihrer Migrationseigenschaften und Färbung im Gel identisch zu seien scheinen. Die Ergebnisse bezügliche der stabilen Fragmente, sollten durch deren Reproduktion mit einem anderen Enzym bestätigt werden.

Das kürzeste Fragment von hSnu114 beginnt bei aa570 bis zum Stop. Die längeren beinhalten alle G-Domänen.

Das Fragment von U5-200K beginnt in der zweiten DEAD-Box-Domäne, bzw. zu Beginn der zweiten Sec63-Domäne und schließt den C-Terminus mit ein. 
Die geschützte Region von Prp8 umfaßt die MPN-Domäne, bzw. besteht aus der bei Boon et al. (Boon et al., 2006) als Domäne IV bezeichnetem Fragment.

\subsubsection{Limitierte Proteolyse mit Asp-N}

Die Wahl des Enzyms für den präparativen Verdau fiel auf Asp-N. Zuvor wurde ein breites Spektrum kommerziell erhältlicher Proteasen untersucht, wobei Asp-N das klarste Muster ergeben hat und eine spezifische Schnittstelle hat. Das Protokoll ist unter 2.7.5 im Material und Methoden Teil ausführlich beschrieben worden. Asp-N schneidet N-Terminal zu Asparaginen. Der Subkomplex wurde bei $37^{\circ} \mathrm{C}$ mit einem Verhältnis von 1:20 (Asp-N:Subkomplex) für $2 \mathrm{~h}$ ohne Schütteln inkubiert. Anschließend wurde die Probe in Probenpuffer aufgenommen, erhitzt und nach der Hitzeinaktivierung des Enzyms, auf ein Gel aufgetragen. Das Gel wurde geblottet und die Banden durch N-terminale Sequenzierung analysiert. 
A

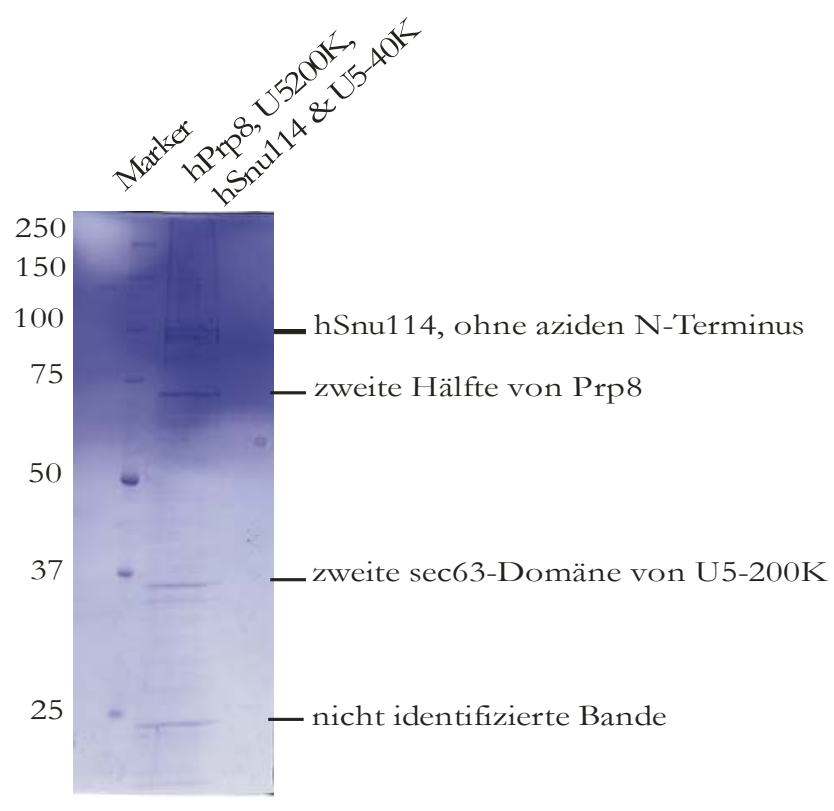

B

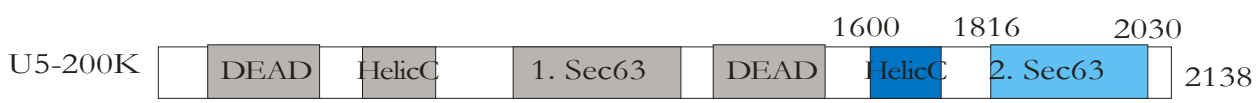

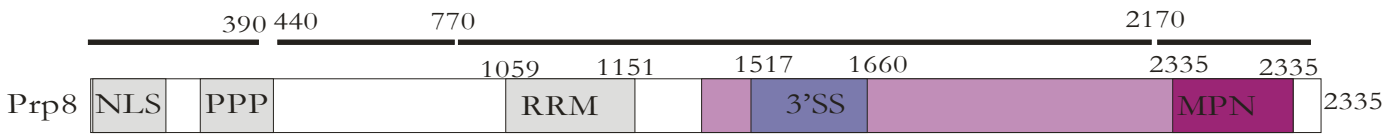

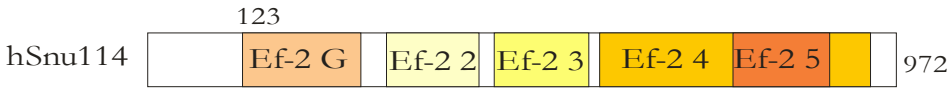

Abbildung 3.7: Limitierte Proteolyse des heterotetrameren Subkomplexes. (A) Das Gel zeigt die Fragmente, die durch die Protelyse mit Asp-N entstanden sind. (B) Im Schema sieht man durch farbige Darstellung die gefundenen Fragmente, in grau sind bekannte Domänen verzeichnet, die nicht nachgewiesen werden konnten. Der Balken über Prp8 indiziert die bei Boon et al. (Boon et al., 2006 ) gefundenen möglichen Sektionen für Domänen.

Das hSnu114 und Prp8 einen salzstabilen Komplex bilden, wurde in von Achsel et al. (Achsel et al., 1998) gezeigt. Dafür spricht auch eine vermutlich vorhandene Interaktionsfläche der beiden Proteine, da sie vor proteolytischer Spaltung geschützt sind. Die gefundene Domäne aus U5-200K hat keine bekannte Funktion im spleißosom, man vermutet regulatorische Eigenschaften der Sec63-Domänen im sekretorischen Vesikeltransport (Ponting et al., 2000). Weil das Signal dieser Domäne klar war, wurde sie nach bioinformatischen Analysen subkloniert. 


\subsubsection{Zusammenfassung der limitierten Proteolysen}

Die limitierten Proteolysen ergeben eine minimale Interaktionsplattform für den Subkomplex bestehend aus hSnu114 ohne dessen aziden N-Terminus und den CTermini von Prp8 und U5-200K. Die bekannten, bzw. definierbaren Domänen in diesem Bereich sind die Sec63- bei U5-200K und die MPN-Domäne bei Prp8.

\begin{tabular}{|l|l|l|}
\hline & Trypsin 1:100 & Asp-N 1:20 \\
\hline hSnu114 & aa124-972 & aa124-972 \\
& aa570-972 (D4) & \\
\hline U5-200K & aa1750-2136 & aa1810-1030 (Sec63.2) \\
\hline Prp8 & aa1200-2335 (DIII-DIV ohne & aa1990-2335 (DIV, MPN) \\
& RRM) & \\
\hline
\end{tabular}

Tabelle 3.2: Aufstellung der minimalen Interaktionsplattform, des heterotetrameren U5 Subkomplexes. Zur verdeutlichung siehe Abbildung $3.4 \mathrm{~B}$. 


\subsubsection{Subklonierung und Expression der zweiten Sec63-Domäne aus}

\section{U5-200K}

Mittels der N-terminalen Sequenzierung konnte der Anfang präzise auf Aminosäure 1810 und das Ende der Domäne aufgrund der beobachteten Größe auf Aminosäure 2030 eingegrenzt werden. Nach bioinformatischen Analysen wurde die Domäne von Aminosäure 1813 bis 2014 definiert. Diese Domäne wurde mit den Enzymen Acc65I und NcoI in die M-Serie kloniert. In S. Lius Dissertation wird die Wechselwirkung dieses Bereichs mit hPrp6 beschrieben.

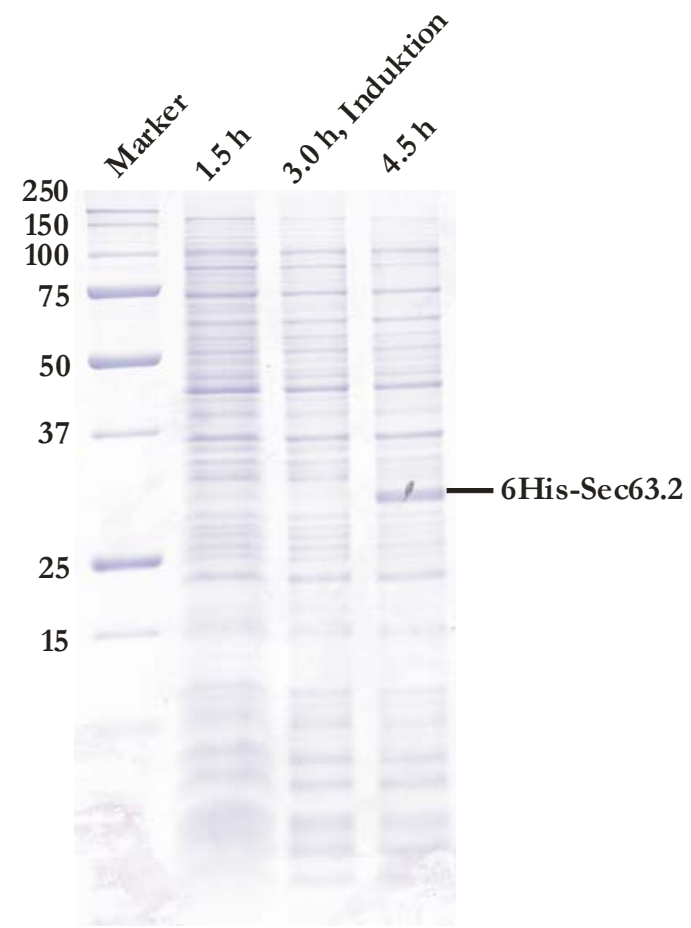

Abbildung 3.8: Analyse der Expression von 6His-Sec63.2. Das Konstrukt war nach seiner Sequenzierung in B121 (DE3) ROSETTA transformiert worden und in einem Volumen von $100 \mathrm{ml}$ LBMedium angezogen und bei $30^{\circ} \mathrm{C}$ bei $\mathrm{OD}_{600} 0.5 \mathrm{mit} 1 \mathrm{mM}$ IPTG (Endkonzentration) induziert worden.

Mittels Massenspektrometrie wurde die markierte Bande als 6His-Sec63.2 bestätigt. 


\subsubsection{Expression und Löslichkeit von 6His-Sec63.2}

Da kein lösliches Protein gewonnen werden konnte (Daten nicht gezeigt) wurde die Expression bei einer niedrigeren Temperatur wiederholt. Die Kultur wurde erst bei $\mathrm{OD}_{600} 1.0$ mit $0.5 \mathrm{mM}$ IPTG (Endkonzentration) induziert, wobei gleichzeitig $2 \%(\mathrm{v} / \mathrm{v})$ Ethanol zur Verbesserung der Löslichkeit hinzugegeben wurden. Anschließend wurde eine Affinitätsreinigung durchgeführt.

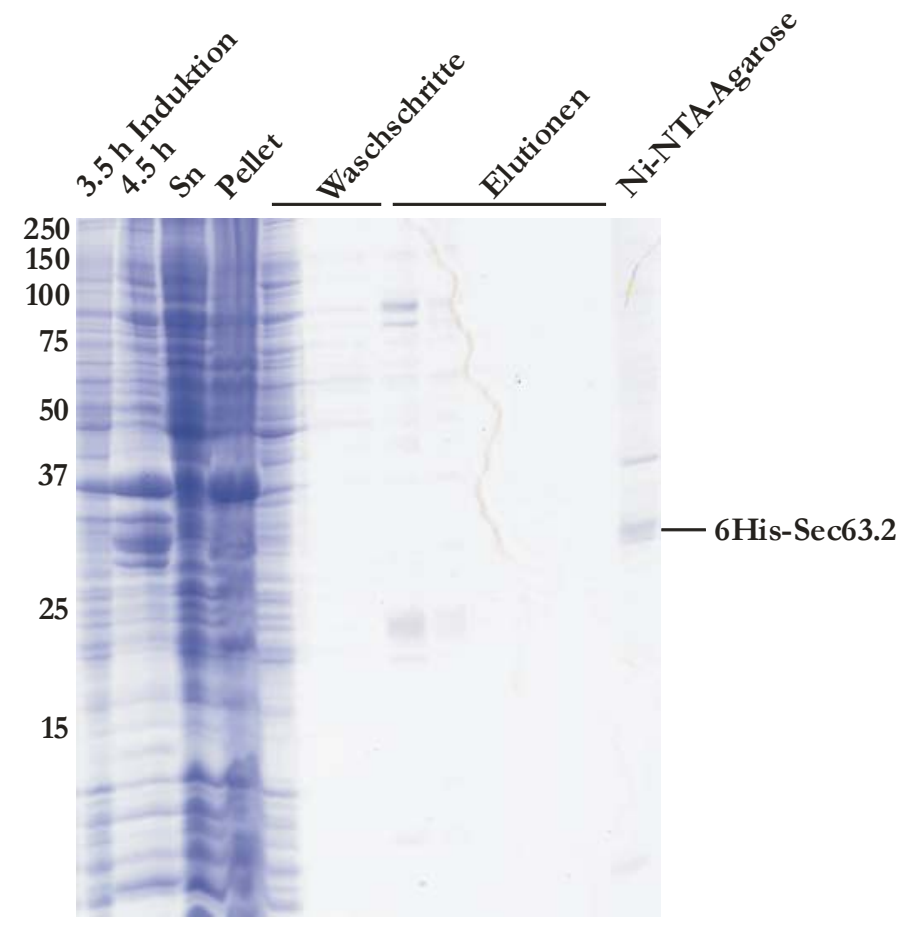

Abbildung 3.9: Induktion und Reinigung von 6His-Sec63.2. Die Bande erscheint trotz der relativ kurzen Induktionsdauer. Man erkennt weder in den Waschschritten noch in den Elutionen eine Bande die dem Zielprotein entspricht. Allein in der Spur in der die Agarose analysiert wird, gibt es ein Signal vom Zielprotein.

Allein ist die Domäne nicht löslich. Da das einzige Signal von der analysierten Affinitäts-Agarose stammt, klebt der Teil des Proteins, der löslich ist an der Säulenmatrix, und ist aller Wahrscheinlichkeit nach nicht gefaltet. 


\subsection{Coexpressionen verschiedener 6His-Prp8 und 6His-U5-}

\section{K Fragmente mit GST-hSnu114}

\subsubsection{Coexpression von GST-hSnu114 und 6His-Sec63.2 in E. coli}

In 3.2.1 wurde die Interaktion zwischen hSnu114 und der zweiten Sec63-

Domäne gefunden. Die Klonierung in verschiedene Vektorsysteme mit unterschiedlichen Transkriptionsstarts (engl. Origins of Replication) und Selektionsmarkern, sollten für die Coexpression der möglicherweise direkt miteinander interagierenden Domänen verwendet werden. Um diese Annahme zu prüfen, wurden die beiden Konstrukte in B121 (DE3) ROSETTA transformiert. Ein Klon, der beide Vektoren trägt, ist in der Lage auf Platten mit beiden Selektionsmarkern zu wachsen. Ein solcher Klon wurde in Flüssigkultur bei $25^{\circ} \mathrm{C}$ überführt und induziert. In dem Analyse-Gel waren keine spezifischen Signale zu sehen, deshalb wurde die Reinigung blind durchgeführt. Nach dem Zellaufschluß und der Sedimentation wurde das Lysat halbiert und eine Hälfte mit Glutathion-, die andere Hälfte mit Ni-NTA-Sepharose inkubiert. Nach der jeweiligen Reinigung sollte im Falle, daß nur die Expression verbessert wurde, je ein Zielprotein, und im Falle der erwarteten Wechselwirkung, Signale für beide Proteine in beiden Reinigungen zu sehen sein. 


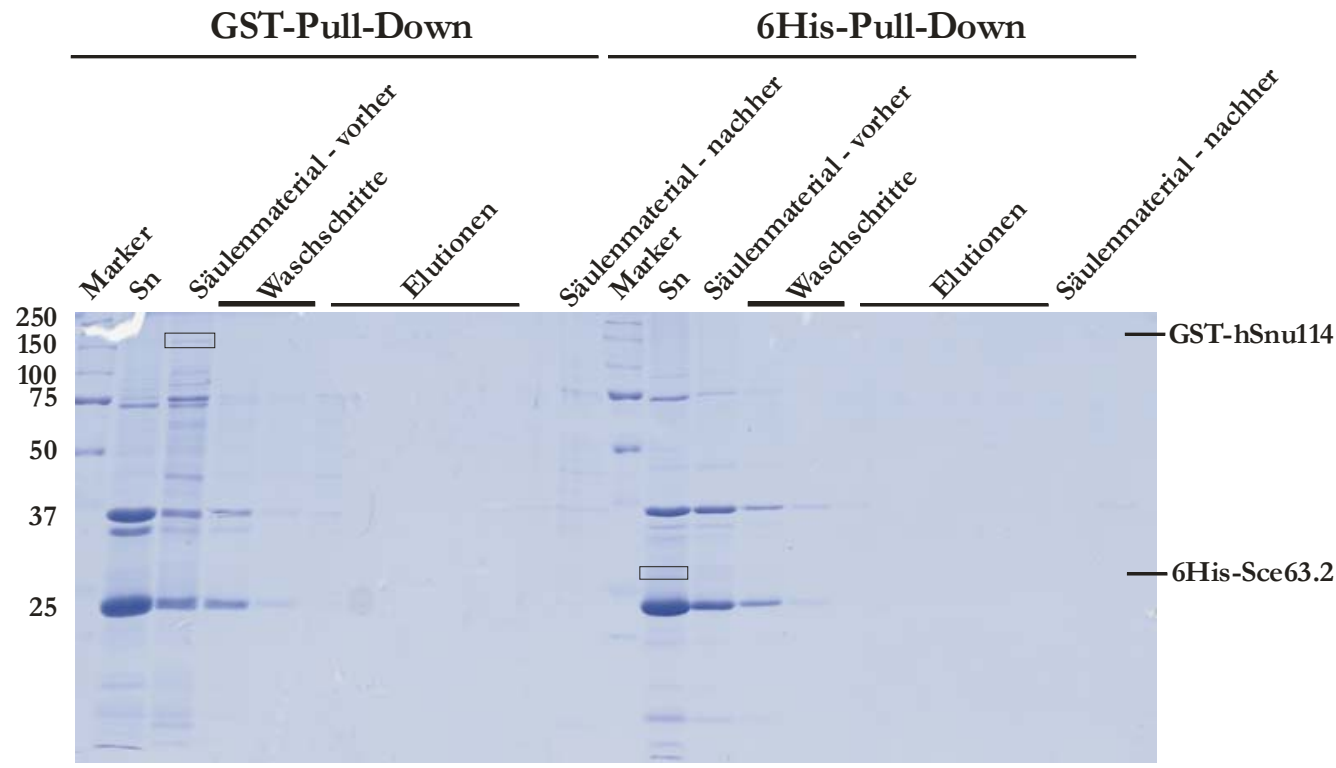

Abbildung 3.10: Reinigung der Coexprimierten Fusionsproteine GST-hSnu114 und 6His-Sec63.2. Man erkennt im Säulenmaterial des GST-Pull-Down vor der Reinigung eine Doppelbande, mit der Größe von GST-hSnu114, allerdings in keinem Eluat. Auch ist die 6His-Sec63.2-Domäne nicht zu detektieren. Im 6His-Pull-Down kann man im löslichen Überstand (SN) eine zarte Bande mit der größe des 6His-Sec63.2 Fusionsprotein erkennen. Auch hier ist kein Ziel-Protein in den Elutionen detektierbar, wohl aber starke Kontaminationen durch Chaperone des prokaryonten Wirts.

Da nur minimale Proteinmengen auf dem Säulenmaterial, bzw. im Überstand detektierbar und die Kontaminationen sehr groß waren, sollte der Versuch interagierende Domänen zu finden auf eine breitere Basis gestellt werden.

\subsubsection{Coexpression von 6His-Prp8- und 6His-U5-200K-Fragmenten mit GST-hSnu114}

Die Fragmente wurden von S. Liu während seiner Dissertation generiert und freundlicherweise zur Verfügung gestellt. Alle fünf U5-200K Fragmente und alle sechs Prp8 Fragmente, jeweils mit einem N-terminalen 6His-Tag im pET28a Vektor, wurden mit GST-hSnu114 in Bl21 (DE3) ROSETTA cotransformiert und in $50 \mathrm{ml}$ LB-Medium bei $24^{\circ} \mathrm{C}$ gezogen. Es wurde bei $\mathrm{OD}_{600} 1.0$ mit $0.5 \mathrm{mM}$ IPTG (Endkonzentration) für $1 \mathrm{~h}$ induziert. Diese kurze Induktionszeit sollte der Bildung von Inclusion Bodies entgegenwirken und die Toxizität der Fusionsproteine für den Wirtsorganismus 
minimieren. In der folgenden Abbildung werden die Coexpressionen und die verwendeten Fragmente (außer GST-hSnu114) dargestellt.

A

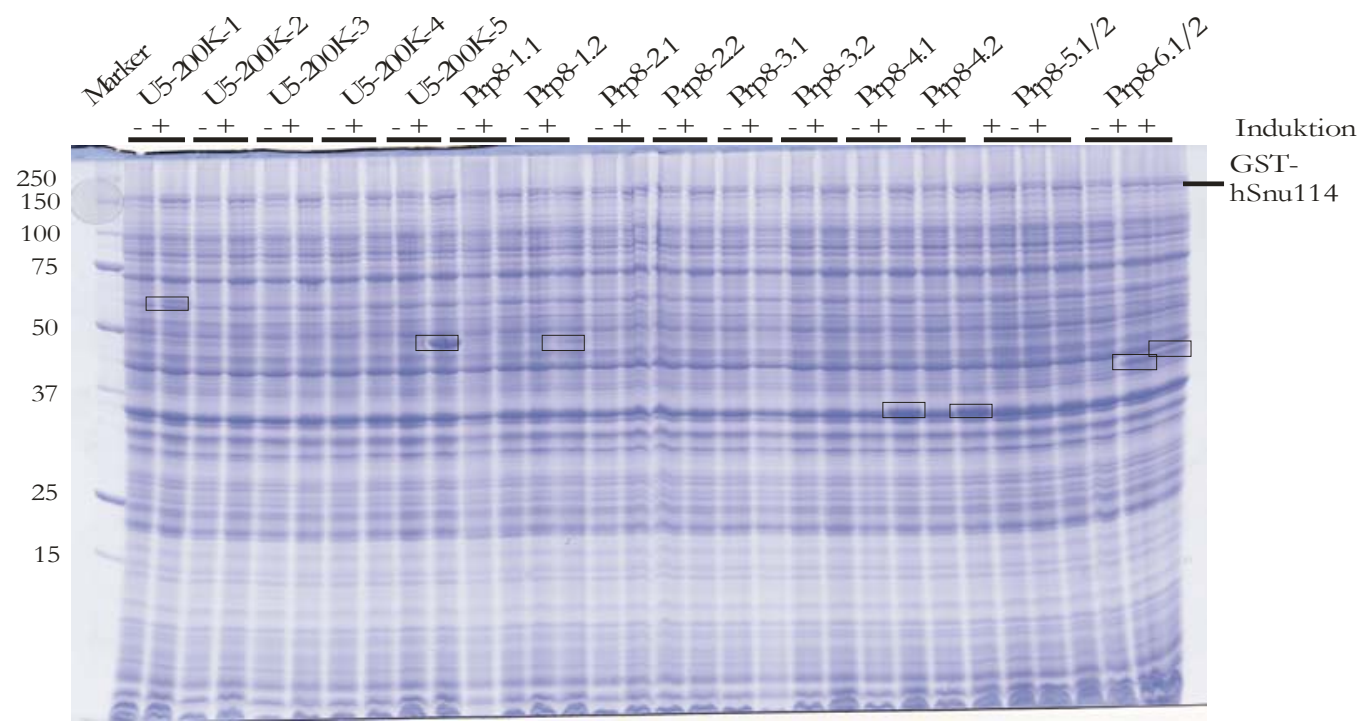

B

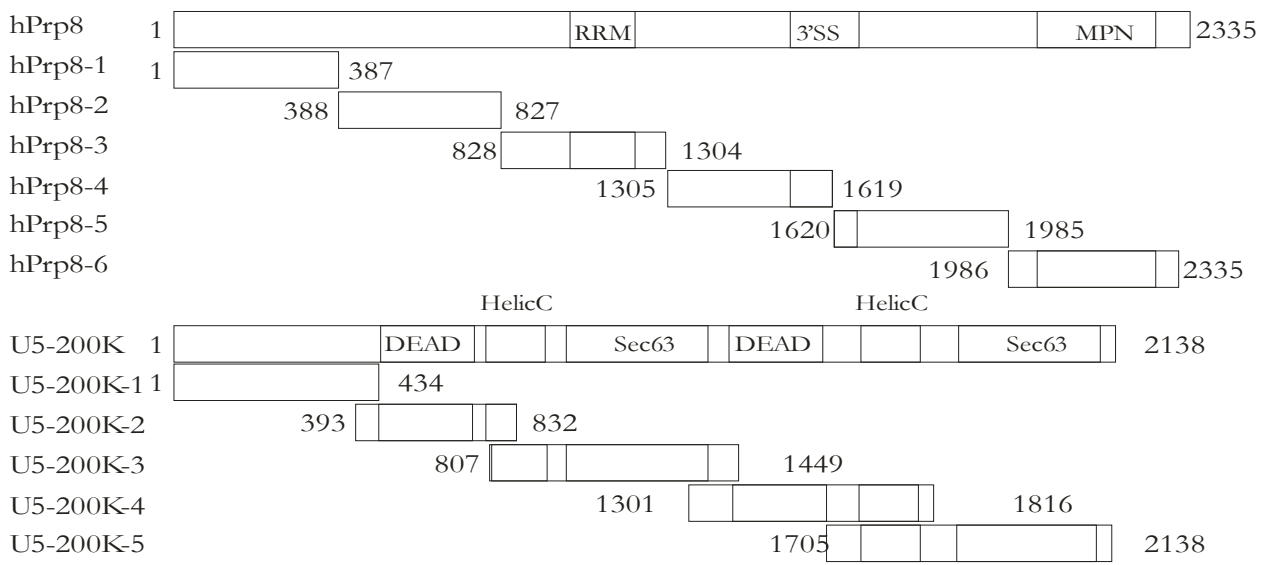

Abbildung 3.11: Hier werden in der Übersicht alle Coexpressionen gezeigt (A) und die Lage der Fragmente und der Domänen schematisch dargestellt (B). Man erkennt in allen induzierten Proben, daß GST-hSnu114 exprimiert wird. Die Banden der co-exprimierten Proteine sind nur in wenigen Fällen (Banden mit Kasten) erkennbar.

Alle Kulturen wurden auf lösliches Protein untersucht. Keine Kombination hat die Löslichkeit der Fusionsproteine erhöht. 


\subsection{Expression von Domänen mit dem Duett-Vektor-System}

Ein letzter Ansatz für Coexpressionen bot das Duett-Vektor-System. Dieses System ist konstruiert worden, um bis zu acht Gene miteinander zu kombinieren. Die Replikationsstarts sind aufeinander abgestimmt und außerdem gehören sowohl Vektoren mit großer (engl. high copy) als auch mit kleiner (engl. low copy) Kopienzahl zu dem System. Man hat also theoretisch die Möglichkeit ein Protein im Überschuß zu produzieren, indem man dessen Gen in einen high copy-Vektor kloniert. Umgekehrt bietet ein low copyVektor die Möglichkeit, zum Beispiel bei cytotoxischen Proteinen, das Zielprotein in vergleichsweise kleinen Mengen zu bilden. Von Grainger und Beggs (Grainger und Beggs, 2005) ist eine Studie bezüglich des Hefe Prp8p Proteins erschienen. Darin werden erstmals mögliche Domänen beschrieben. Diese sind nach bioinformatischen Analysen in das Duett-Vektor-System kloniert worden. Die von S. Liu gewonnen 2-Hybrid-Daten sind ebenfalls in die Konstruktion der subklonierten Domänen geflossen. Wie schon in Abbildung 3.7 dargestellt, sind folgende Konstrukte mit N-terminalem S-Tag und 6HisTag, sowohl mit Proteaseschnittstelle, als auch ohne, generiert worden:

\begin{tabular}{|l|c|c|}
\hline Name der Domäne & Domänengrenzen & Kalkulierte Molekulargewichte \\
\hline Prp8-RRM & 954 bis 1046 & $12 \mathrm{kDa}$ \\
\hline Prp8-MPN & 2100 bis 2234 & $17 \mathrm{kDa}$ \\
\hline Prp8-3'ss & 1300 bis 1588 & $32 \mathrm{kDa}$ \\
\hline Prp8-1 & 36 bis 386 & $44 \mathrm{kDa}$ \\
\hline U5-200K-HelicC & 1331 bis 1720 & $51 \mathrm{kDa}$ \\
\hline hSnu114-NTD & 112 bis 567 & $59 \mathrm{kDa}$ \\
\hline hSnu114-CTD & 584 bis 955 & $58 \mathrm{kDa}$ \\
\hline
\end{tabular}

Tabelle 3.3: Die klonierten Fragmente und ihre kalkulierten Molekulargewichte.

\subsubsection{Untersuchung der einzelnen Domänen}

Die Expression der Fragmente wurde zunächst einzeln in ROSETTA-Zellen untersucht. Die Kulturen wurden bei einer $\mathrm{OD}_{600} 0,9$ mit $1 \mathrm{mM}$ IPTG (Endkonzentration) induziert und nach $2.5 \mathrm{~h}$ geerntet. 


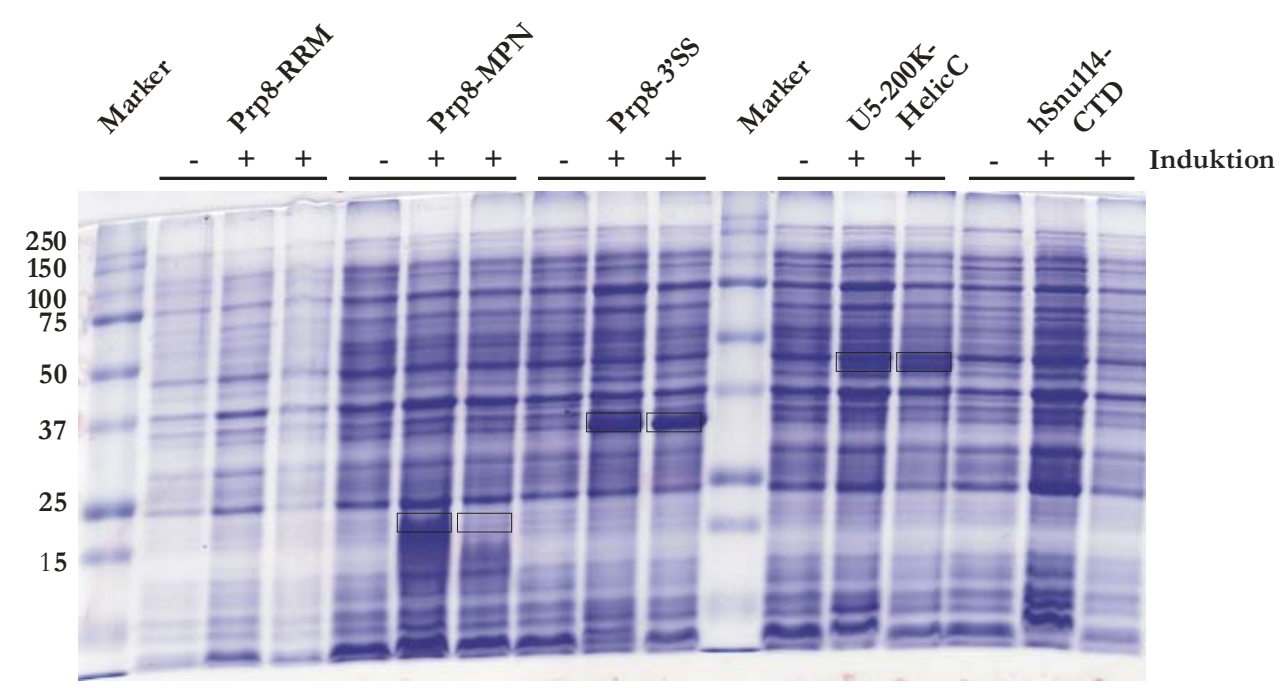

Abbildung 3.12: Einzelne Expression der RRM-, MPN-, 3'SS, HelicC- und der CTD-Domänen. Die jeweils erste Spur entspricht OD600 0.9. Die zweite Spur 1 h und die dritte 2 h Kultur nach Induktion.

Die Prp8-RRM konnte nie in einer Expression gewonnen werden. Die Prp8MPN wird zwar gebildet, unterliegt einer starken Degradation. Die Prp8-3'SS scheint ein stabiles, exprimierbares Fragment zu sein. Diese Aussage läßt sich auch für U5-200KHelicC machen, wohingegen die CTD von hSnu114 nicht exprimiert worden ist. Es wurden Löslichkeitstests für alle Domänen durchgeführt.

\subsubsection{Löslichkeitstests von Domänen mit dem Duett-Vektor-System}

Die Löslichkeitstests wurden protokollgemäß durchgeführt und repräsentative Schritte auf einem Gel analysiert (Abbildung 3.13). 


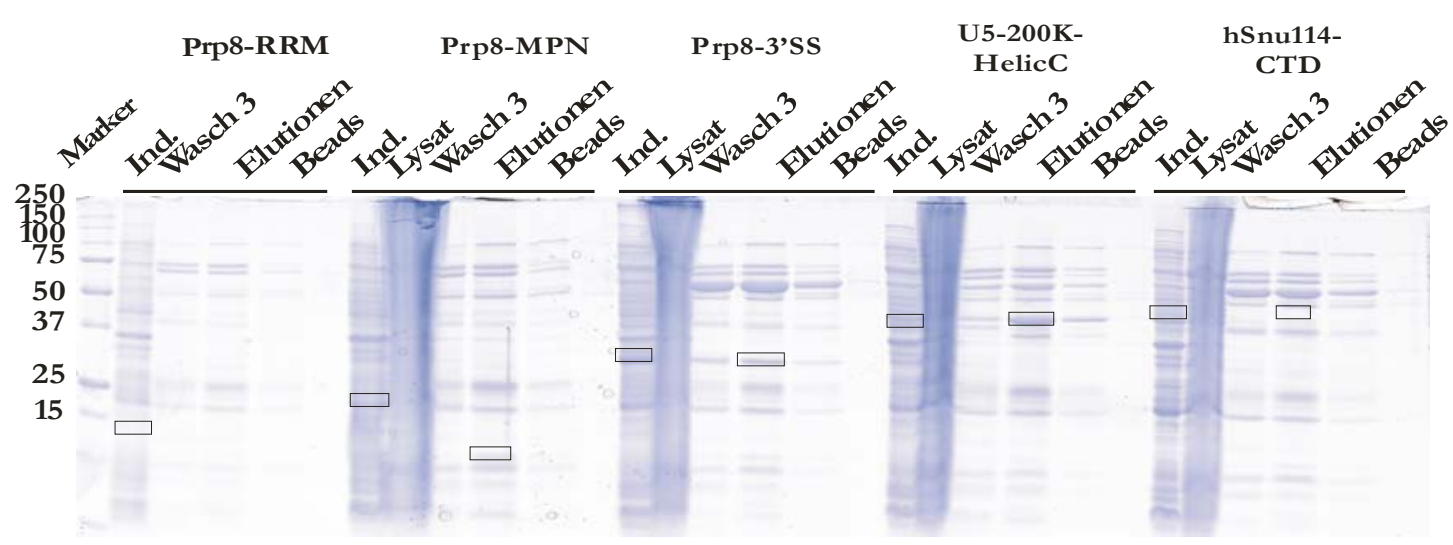

Abbildung 3.13: Löslichkeitstest der Domänen im Duett-Vektor-System. Die Analyse der Elutionen zeigt in einigen Fällen das Aufkommen von Zielbanden. Diese wurde mit massenspektrometrischen Methoden untersucht und bestätigt.

Die Prp8-RRM konnte nicht isoliert werden. Die Prp8-MPN wurde nur als stark degradiertes Fragment gefunden, wie sich aus dem Größenunterschied der markierten Banden ersehen läßt. Wie man bei allen Analysen sehen kann, sind die Kontaminationen sehr stark. Die Banden deuten auf prokaryonte Chaperone hin. Die Chaperone konnten nur durch ATP-haltige Waschschritte bei $37^{\circ} \mathrm{C}$ reduziert werden. Dieser Sachverhalt deutet auf ungefaltetes Protein hin. Der prokaryonte Wirt ist nicht in der Lage das humane Protein in seiner nativen Faltung zu exprimieren und zu modifizieren. Darum sind die Teile des Zielproteins, welche in Lösung isoliert werden können, mit so großen Mengen Chaperonen eng assoziiert. Reinigt man über den Affinitätsschritt das Zielprotein, reichert man gleichzeitig auch die Chaperone an.

\subsubsection{Coexpressionen der Domänen im Duett-Vektor-System}

Die Coexpressionsexperimente standen auf dem Fundament der Daten von S. Liu, den Daten aus den limitierten Proteolysen und den jüngsten veröffentlichten Ergebnissen von Boon et al. und Grainger und Beggs (Boon et al., 2006; Grainger und Beggs, 2005). Die Coexpressionen sollten die Faltung ermöglichen indem die Domänen 
miteinander interagieren. Die folgende Tabelle faßt die vermuteten Interaktionen und die dafür nötigen Domänen zusammen.

\begin{tabular}{|c|c|c|c|c|c|c|}
\hline & $\begin{array}{l}\text { Prp8.6 = } \\
\text { MPN }\end{array}$ & Prp8.1 & $\begin{array}{l}\text { U5-200.4 = } \\
\text { HelicC }\end{array}$ & $\begin{array}{l}\text { hSnu114.3 = } \\
\text { CTD }\end{array}$ & $\begin{array}{l}\text { hSnu114.2 = } \\
\text { NTD }\end{array}$ & \\
\hline $\begin{array}{l}\text { Prp8.6 = } \\
\text { MPN }\end{array}$ & & & + & + & + & \\
\hline Prp8.1 & & & + & & + & \\
\hline $\begin{array}{l}\text { U5-200.4= } \\
\text { HelicC }\end{array}$ & + & + & & + & + & \\
\hline $\begin{array}{l}\text { hSnu114.3 = } \\
\text { CTD }\end{array}$ & + & & + & & & \\
\hline $\begin{array}{l}\text { hSnu114.2 = } \\
\text { NTD }\end{array}$ & + & + & + & & & \\
\hline $\operatorname{Prp} 8.3=\mathrm{RRM}$ & & & & & & $\begin{array}{l}\text { RNA-Oligo } \\
\text { (U4, U6 oder } \\
\text { 5'ss) }\end{array}$ \\
\hline $\operatorname{Prp} 8.4=3$ 'ss & & & & & & $\begin{array}{l}\text { 3'ss- } \\
\text { Erkennungs- } \\
\text { motiv }\end{array}$ \\
\hline
\end{tabular}

Tabelle 3.4: Zusammenfassung der erwarteten Interaktionen mit den näher definierten Domänen.

Jede Kombination mit bekannten Interaktionen wurde in B121 (DE3) ROSETTA Zellen transformiert und positive Klone durch selektive Wachstumsbedingungen identifiziert. Die $500 \mathrm{ml}$ Kulturen wurden bei $16{ }^{\circ} \mathrm{C}$ gezogen und bei $\mathrm{OD}_{600} 0.7$ für weitere $3 \mathrm{~h}$ induziert. Lyse und Reinigung wurden nach dem im Methodenteil beschriebenen Standardprotokoll durchgeführt.

Sollten die vermuteten Interaktionen auch proteinbiochemisch vorhanden sein, sollte die Reinigung durch die Nickel-Affinitätschromatographie, also der Reinigung eines Partners, auch der interagierende Partner angereichert werden. Unter keiner der untersuchten Bedingungen konnte lösliches Fusionsprotein gewonnen werden. 


\subsection{Untersuchung der „3' splice site high fidelity region“} (3'ss)

\subsubsection{Expression, Inclusion Body-Reinigung und Rückfaltung von 6His-3'ss Fusionsprotein}

Die 3'ss bot ein weiteres Ziel für Expression und Reinigung. Durch Sequenzvergleiche ist die hohe Konservierung deutlich geworden. Die Exprimierbarkeit ist in Abbildung 3.12 gut zu sehen. Die Versuche die Domäne unter milden Bedingungen $\mathrm{zu}$ exprimieren und $\mathrm{zu}$ reinigen schlugen fehl. Deshalb wurde im Anschluß an eine vergleichsweise harsche Expression eine Inclusion Body (IB) Reinigung durchgeführt. Diese Reinigung führt nach nur einem Reinigungsschritt zu reinem Protein. Ein weiterer Vorteil dieser Reinigung ist, daß Chaperone die Präparation nicht verunreinigen.

Nach der Reinigung des Proteins aus Inclusion Bodies wurde untersucht, ob sich natives Protein durch Rückfaltung gewinnen läßt. Dazu wurde der FoldIt ${ }^{\mathrm{TM}}$-Screen von Hampton Research verwendet und die Herstellerangaben befolgt. 


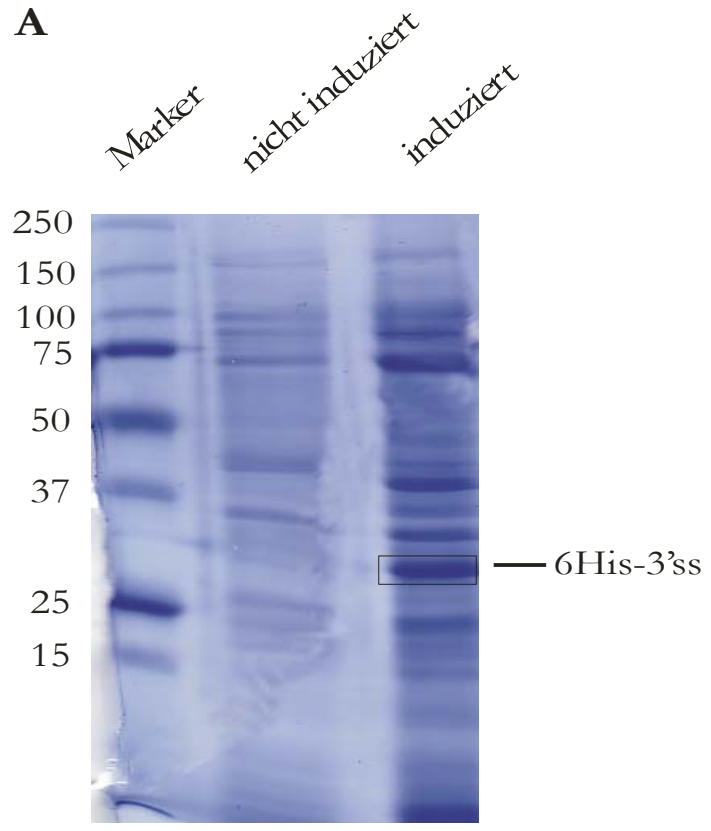

B

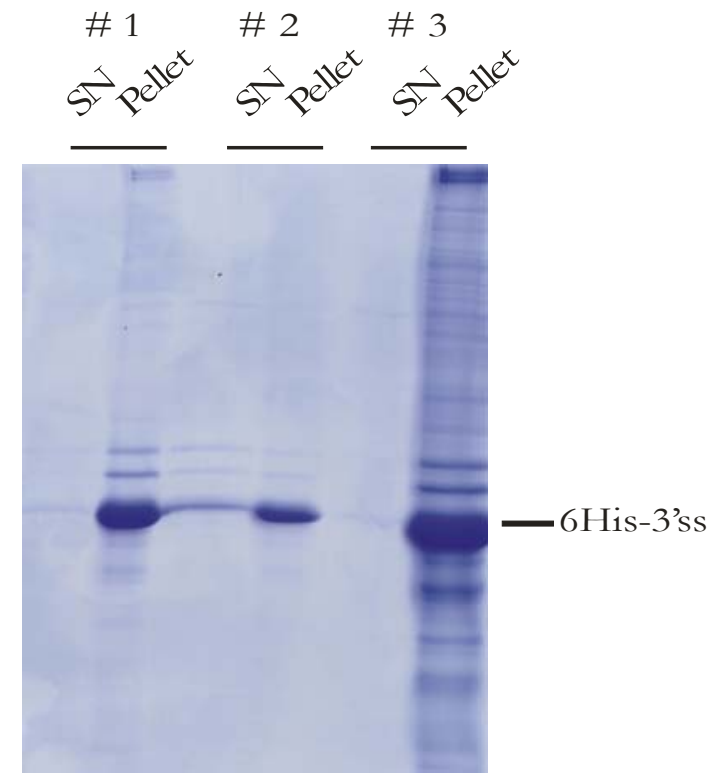

C

\begin{tabular}{|c|c|c|c|c|c|c|c|}
\hline & Puffer & Salz & $\begin{array}{l}\text { PEG } \\
3350\end{array}$ & $\begin{array}{l}\text { Gua- } \\
\mathrm{HCl}\end{array}$ & $\begin{array}{l}\text { Kationen/ } \\
\text { Chelatoren }\end{array}$ & $\begin{array}{l}\text { Polare/ } \\
\text { unpolare } \\
\text { Additive }\end{array}$ & $\begin{array}{l}\text { Protein } \\
\text { Konz. } \\
(\mathrm{mg} / \mathrm{ml})\end{array}$ \\
\hline$\# 1$ & $\begin{array}{l}55 \mathrm{mM} \\
\text { MES } \\
\text { pH } 6.5\end{array}$ & $\begin{array}{l}10.56 \mathrm{mM} \\
\mathrm{NaCl}, \\
0.44 \mathrm{mM} \\
\mathrm{KCl}\end{array}$ & $\begin{array}{l}0,055 \\
(\% \mathrm{w} / \mathrm{v})\end{array}$ & $\begin{array}{l}550 \mathrm{~m} \\
M\end{array}$ & $\begin{array}{l}1.1 \mathrm{mM} \\
\text { EDTA }\end{array}$ & $\begin{array}{l}440 \mathrm{mM} \\
\text { Succrose, } \\
550 \mathrm{mM} \\
\text { L-Arg }\end{array}$ & 0.1 \\
\hline$\# 2$ & $\begin{array}{l}55 \mathrm{mM} \\
\text { Tris } \\
\text { pH } 8.2\end{array}$ & $\begin{array}{l}264 \mathrm{mM} \\
\mathrm{NaCl}, \\
11 \mathrm{mM} \\
\mathrm{KCl}\end{array}$ & 0 & 0 & $\begin{array}{l}2.2 \mathrm{mM} \\
\mathrm{MgCl}, \\
2.2 \mathrm{mM} \\
\mathrm{CaCl}\end{array}$ & $\begin{array}{l}440 \mathrm{mM} \\
\text { Succrose, } \\
550 \mathrm{mM} \\
\text { L-Arg }\end{array}$ & 0.1 \\
\hline$\# 3$ & $\begin{array}{l}55 \mathrm{mM} \\
\text { MES } \\
\text { pH } 6.5\end{array}$ & $\begin{array}{l}264 \mathrm{mM} \\
\mathrm{NaCl}, \\
11 \mathrm{mM} \\
\mathrm{KCl}\end{array}$ & 0 & 0 & $\begin{array}{l}2.2 \mathrm{mM} \\
\mathrm{MgCl}, \\
2.2 \mathrm{mM} \\
\mathrm{CaCl}\end{array}$ & $\begin{array}{l}440 \mathrm{mM} \\
\text { Succrose, }\end{array}$ & 1.0 \\
\hline
\end{tabular}

Abbildung 3.14 und Tabelle 3.5: Beispiele für die Rückfaltung von 6His-3'ss und deren Bedingungen. In (A) kann man eine deutliche Induktionsbande erkennen. In (B) sind drei Bedingungen des FoldItTM-Screens exemplarisch dargestellt. In \#1 kann man in der löslichen Fraktion einen geringen Anteil Protein erkennen, welcher in \#2 - in Anbetracht des Verhältnisses von löslichem zu unlöslichem Protein - noch größer erscheint. In \#3 erkennt man keiner lösliches Protein. In der Tabelle 3 unter (C) sind die Bedingungen des Screens aufgeführt.

Die 6His-3'ss läßt sich als stabiles Fragment exprimieren. Es gibt Bedingungen, unter denen es Anteile löslichen Proteins gibt. Dieses lösliche Protein ist nicht in seiner nativen Form, da es bei Gelfiltrationen (oder engl., size exclusion chromatography) im Ausschlußvolumen der Säule eluierte. Wenn ein Proteinfragment mit dem errechneten 
und apparenten Molekulargewicht von $32 \mathrm{kDa}$ im Ausschlußvolumen einer Gelfiltrationssäule eluiert, ist das Protein aggregiert.

\subsubsection{Zusammenfassung der Expressionsexperimente}

Die Versuche lösliches Protein durch Expressionen und Coexpression in E. coli zu erhalten, standen auf einem breiten Fundament. Die Suche nach exprimierbaren Domänen ist durch bioinformatische Analysen und bereits veröffentlichte Forschungsergebnisse gestützt worden. Die Expression von Proteinen, die viele Domänen haben und hoch modifiziert sind, ist in E. coli noch nicht für alle Zielproteine möglich. Bei den Proteinen, die in dieser Arbeit untersucht worden sind, wurde nur ungefaltetes Protein gewonnen. Im Falle der Expressionen der einzelnen Domänen sind unter milden Bedingungen Spuren von löslichem rekombinanten Protein gewonnen worden. Diese Mengen Protein sind allerdings durch die Kontamination mit Chaperonen für die Kristallisation nicht geeignet. 


\subsection{Expression von Snu114p - in Saccharomyces cerevisiae}

\subsubsection{Expression und Reinigung des rekombinanten Proteins}

Bei dem Hefestamm YPF39 wurde das chromosomale SNU114 ausgeschaltet und durch ein Plasmid ersetzt, welches durchschnittlich 100 mal pro Zelle vorhanden ist. Das bedeutet, daß ein Überschuß rekombinantes mit 6His-Tag versehenes Protein von den Zellen produziert wird. Um ausreichende Mengen Protein für die Kristallisation zu erlangen, wurden 161 Kulturvolumen verwendet. In Abbildung 3.15 (A) ist nicht ersichtlich, ob das leiterartigen Bandenmuster Kontaminationen entspricht, oder ob es sich um Degradationsprodukte handelt. Der Western Blot (B) der mit einem Antikörper gegen Snu114p durchgeführt wurde, zeigt schon im Zelllysat viele leiterartige Signale. Diese Signale und die leiterartigen Banden in allen anderen Fraktionen deuteten auf eine starke Degradation des Zielproteins hin. 
A

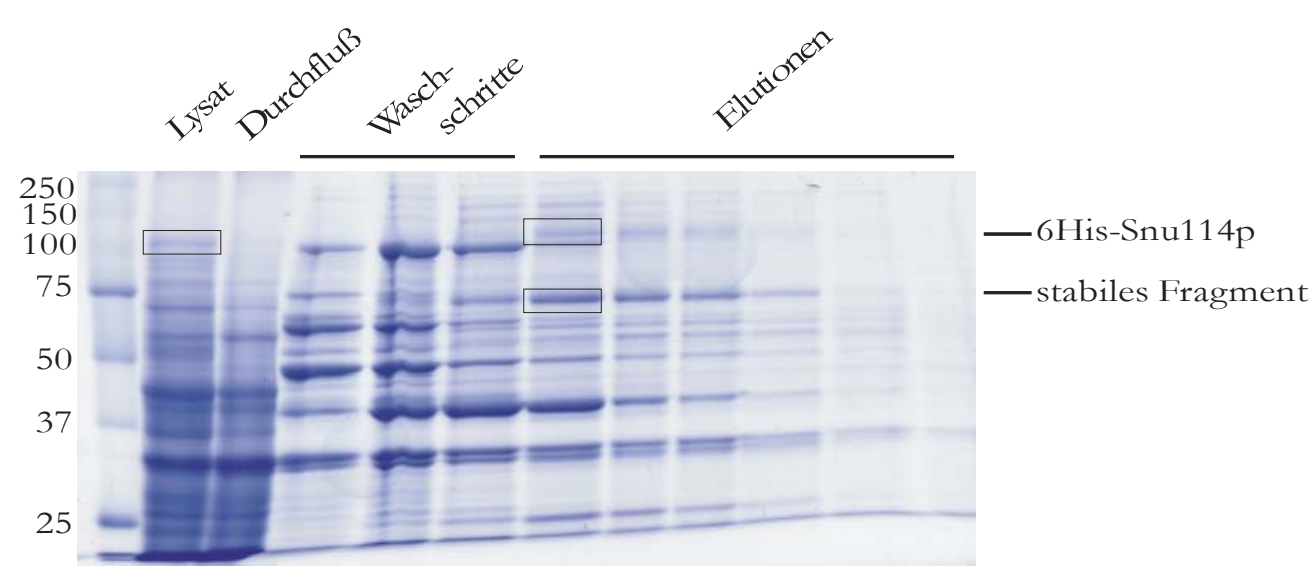

B

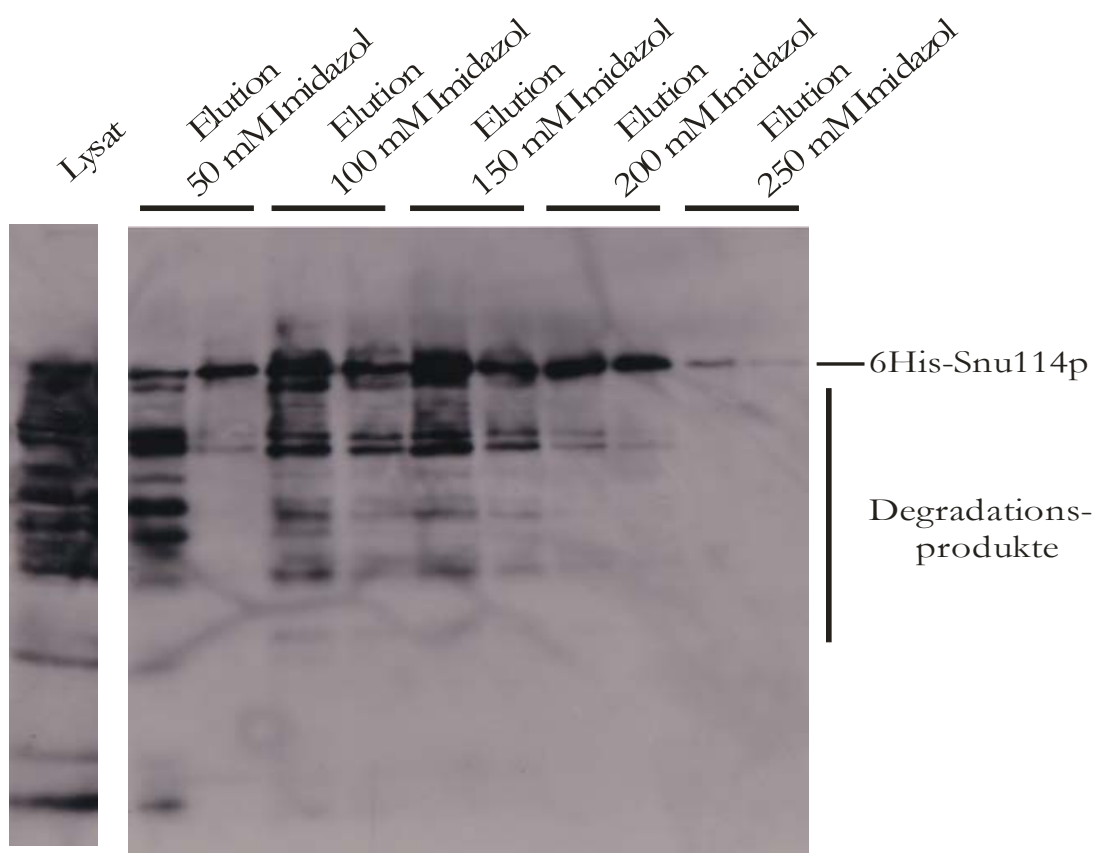

Abbildung 3.15: Proteingel und Western-Blot einer Snu114p Expression. Neben der Zielbande erkennt man deutlich eine etwa $75 \mathrm{kDa}$ große Bande in jeder Bahn. Diese Fragment wird auch nach weiteren Reinigungsschrtten geobachtet. Diese Expression wurde bei einer OD600 von 5.0 geerntet.

Die Zellen wurden anschließend bei vergleichsweise niedrigen Dichten $\left(\mathrm{OD}_{600}\right.$ 3.0-3.3) geerntet. Diese Bedingung sollte der starken Degradation entgegenwirken, die bei nur wenig höheren Dichten $\left(\mathrm{OD}_{600} 5.0\right)$ beobachtet wurde. Es soll betont werden, daß alle Schritte so schnell wie möglich bei $4{ }^{\circ} \mathrm{C}$ und unter Verwendung von Proteinaseinhibitoren durchgeführt worden sind. Die verwendeten Puffer und Inhibitorkonzentrationen werden im Material und Methoden Teil ausführlich 
beschrieben. Im Folgenden werden ein Protein-Gel der verbesserten Reinigung und ein

Western-Blot der anschließenden Ionentauschersäule (Q-Sepharose) gezeigt.

A

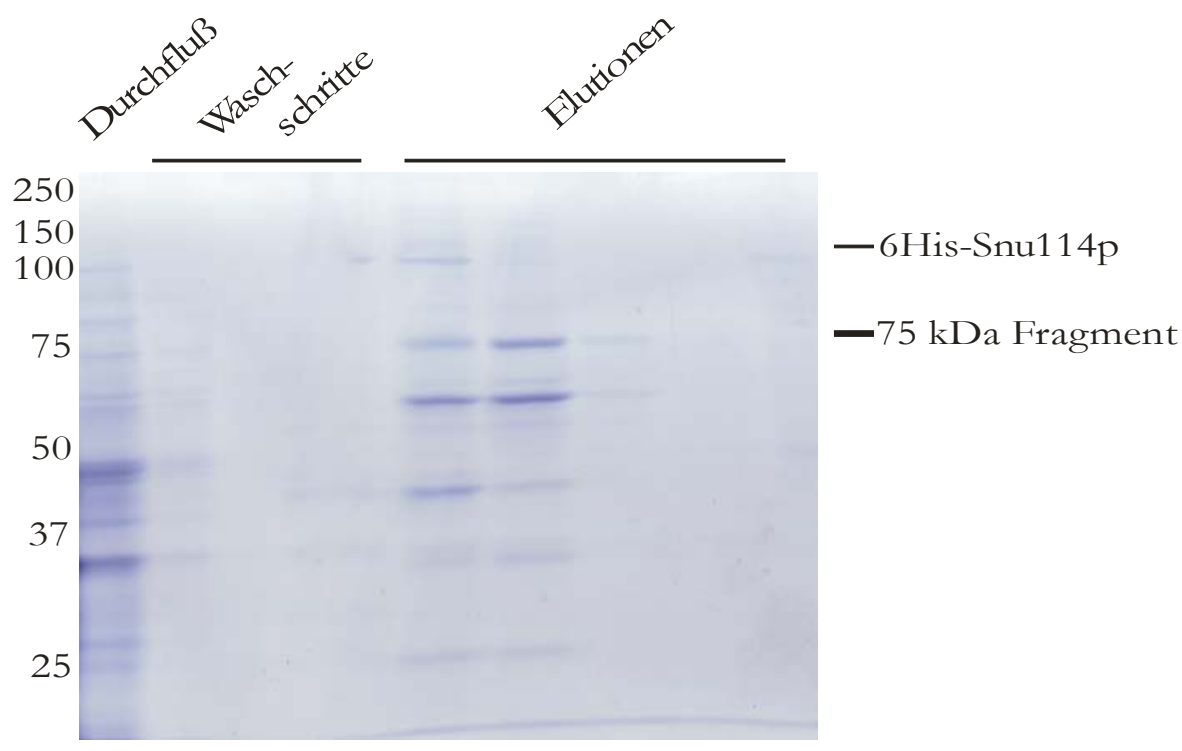

B

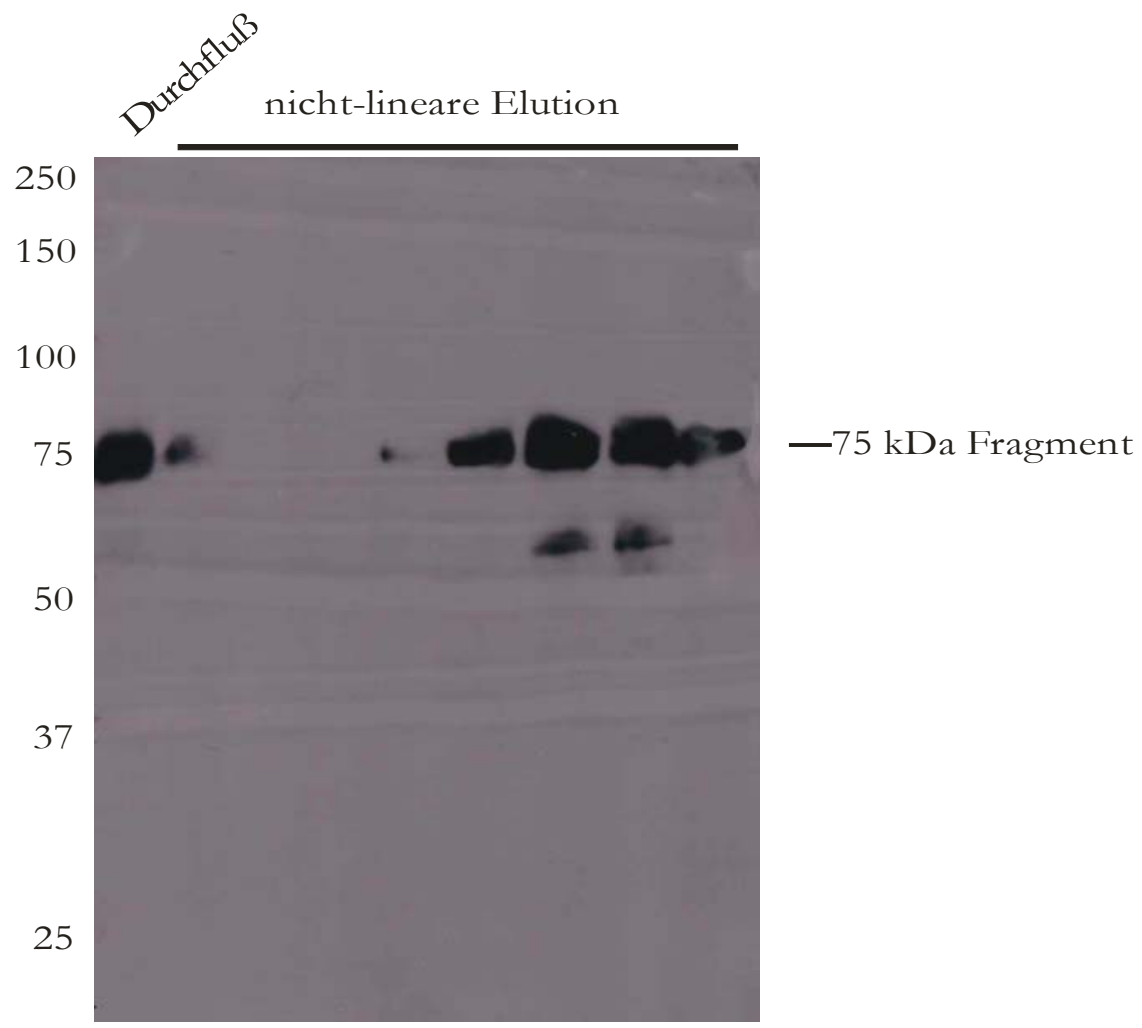

Abbildung 3.16: Verbesserte Affinitätschromatographie (A) und und Western Blot der Ionentauscher-Säule (B). Man erkennt deutlich das Entstehen stabiler Fragmente, vorallem eines von $75 \mathrm{kDa}$, welches sich für eine Subclonierung anbietet. 
Die Abbildungen zeigen, daß das Verringern der Ernte- $\mathrm{OD}_{600}$ die Degradation mindert. Außerdem erkennt man sowohl im Gel als auch im Blot, daß sich ein stabiles $75 \mathrm{kDa}$ großes Fragment bildet. Dieses Fragment ist ein geeignetes Ziel zur Subklonierung und könnte sich durch seine Stabilität und geringere Größe als gut handhabbar erweisen.

\subsection{Zusammenfassung - Snu114p}

Die Expression des endogenen Proteins in Hefe hat nicht zu ausreichenden Mengen undegradiertem Protein geführt. Bei der Aufarbeitung kleinerer Mengen kann der Aktivität der Proteasen leichter entgegen gewirkt werden. Bei den verarbeiteten 161 Kulturvolumen, welche für die Herstellung kristallisierbarer Mengen nötig sind, ist die Degradation mit herkömmlichen Mitteln (Temperaturreduktion und Inhibitoren) nicht weiter einzugrenzen. Interessanterweise kann durch die Reinigung mit Q-Sepharose, einem Ionentauschermaterial, ein stabiles Fragment gereinigt werden. Dieses Fragment ist ein denkbares Ziel für weitere Versuche da es stabil, gut ankonzentrierbar und leicht zu handhaben ist. Daten aus persönlicher Korrespondenz mit P. Fabrizio deuten darauf hin, daß durch die Reinigung mit Q-Sepharose entweder ein in Spuren vorhandenes Regulatorprotein entfernt wird, oder die Konformation des Proteins geändert wird. Nach diesem Reinigungsschritt war keine GTP-Bindung von Snu114p mehr nachzuweisen. Die Grenzen der Domäne müssen durch N-terminale Sequenzierung oder Fingerprinting eruiert werden. 


\subsection{Expression von hSnu114 durch das Baculo-Virus}

\section{Expressions System (BEVS)}

\subsubsection{Allgemein}

Warum wählt man ein solches System? Die Entscheidung zwischen Hefe (wahlweise Pichia pastoris oder Saccharomyces cerevisiae) und Insekten fiel zu Gunsten des BEVS, dem Insekten-System. Hefen modifizieren Proteine, allerdings nicht in dem Maß, wie es höhere Eukaryonten tun. Da die Reinigung rekombinanten Proteins bis zu diesem Zeitpunkt an der Faltung gescheitert war, wurde der höhere Aufwand für Klonierung und Generierung der Klone, sowie Zellkultur in Kauf genommen.

\subsubsection{Generation der Klone und erste Expressionstests}

Es wurden hSnu114 als Volllängenklon und als Deletionsmutante (ohne die ersten 124 Aminosäuren) jeweils mit 8His-Tag generiert. In der folgenden Abbildung sind der verwendete Volllängenklon, die Deletionsmutante und ein GST-Fusionsprotein als Kontrollprotein getestet worden. 
A

$\alpha$ His Antikörper

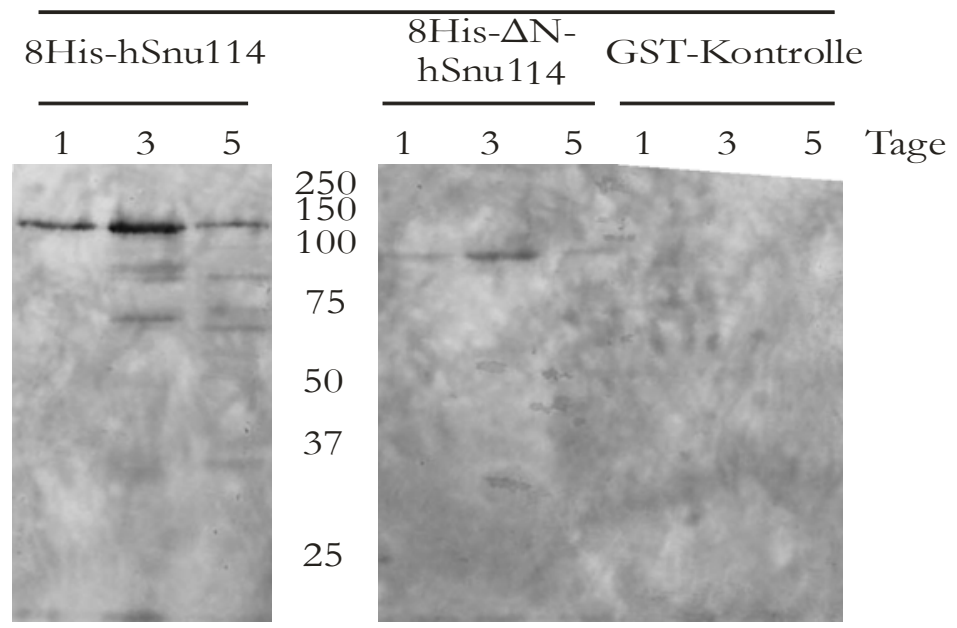

B

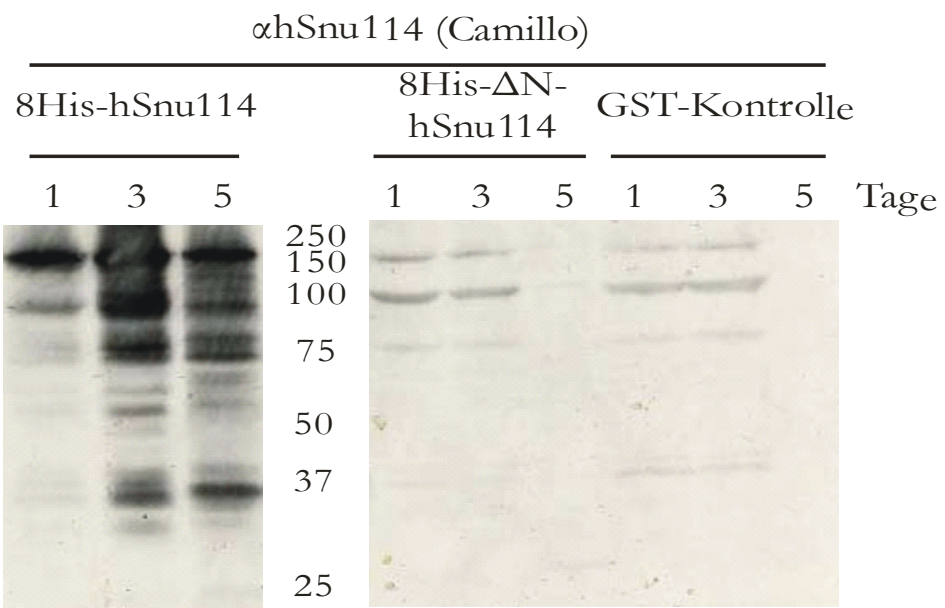

Abbildung 3.17: Blotanalyse der Expression von 8His-hSnu114, 8His- $\Delta \mathrm{N}-\mathrm{hSnu} 114$ und GSTRaver mit (A) einem $\alpha$ His-Antikörper und (B) einem proteinspezifischen Antikörper, der gegen den N-Terminus von hSnu114 gerichtet ist. Alle Kulturen wurden mit gleichen Zelldichten, Volumen und MOI (Multiplicity of Infection) durchgeführt.

Durch die Blotanalyse in (A) kann man deutlich die Expression von beiden Konstrukten sehen. Es gibt spezifische Signale für die erwarteten Größen, wobei in der Kontrolle keine Signale zu sehen sind, daß heißt es gibt kein kreuzreagierendes, histidinhaltiges Protein. Auch die Tatsache, daß mit dem spezifischen Antikörper (B) gegen den N-Terminus von hSnu114 nur Signale in der vollängen Probe zu erkennen sind, entspricht den Erwartungen. Die schwachen Banden in den Proben der Deletionsmutante und der Kontrolle könnten auf das endogene Protein hinweisen. 
Man erkennt deutlich (A), daß die Deletionsmutante schlechtere Ausbeuten verspricht. Das war nach einem starken Verlust der Dichte in der wachsenden, infizierten Kultur zu erwarten. Außerdem sind schon nach $24 \mathrm{~h}$ Infektion starke Degradationsbanden zu erkennen (B, der Volllängenklon).

Deshalb wurde zunächst die Arbeit an der Deletionsmutante vernachlässigt und die Expressionsbedingungen des Volllängenklones optimiert.

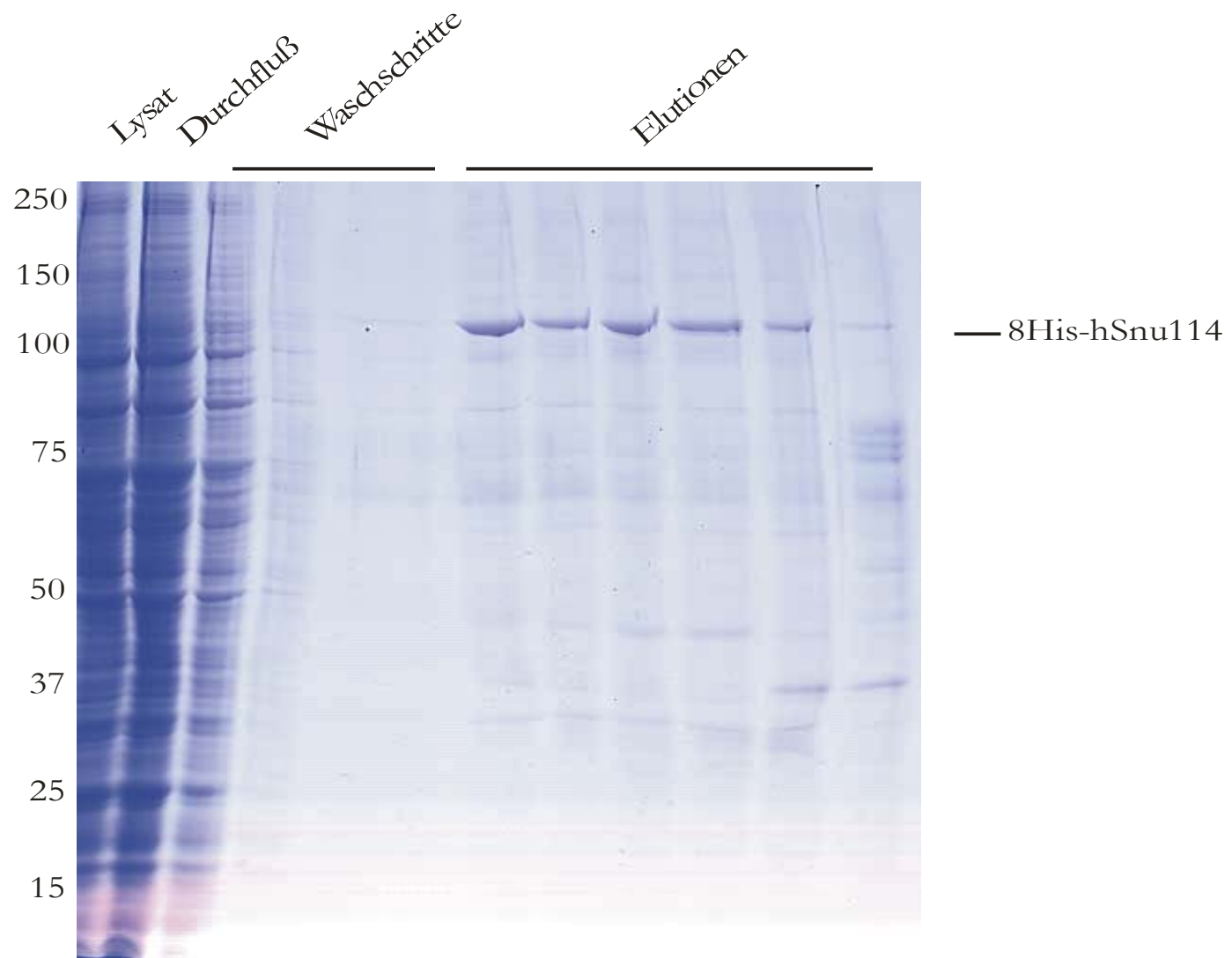

Abbildung 3.18: Optimierte Expression des volllängen Konstruktes. Die Temperatur wurde auf $25^{\circ} \mathrm{C}$ reduziert, die MOI von 10 auf 2 und die Dauer der Infektion von fünf auf zwei Tagen verringert. Bei der Reinigung beinhalteten alle Puffer $0.1 \mathrm{mM}$ GDP.

Die Optimierung der Expression und der Reinigung beinhaltete auch Säulenbindungstests, wobei vielversprechend aussehende Reinigungsschritte, wie eine Hydroxylapatit-Säule im präparativen Maßstab, nicht die nötige Reinheit zur Folge hatten. 
Schließlich wurde die Probe, welche für die den Kristallisationsansatz präpariert wurde, nach der Nickel-Affinitätschromatographie durch einen Gelfitrations-Lauf entsalzt und das Protein auf seine native Faltung hin untersucht.

Das Protein eluierte, zu einem Zeitpunkt, an welchem im Standardlauf ein $44 \mathrm{kDa}$ großes Protein eluierte. Es sollte nun festgestellt werden, ob das Protein unspezifisch an der Matrix adhärierte oder ungefaltet war. Das sollte mittels CDSpektrometrie untersucht werden.

\subsubsection{CD-Spektren von 8His-hSnu114 aus Insektenzellen}

Für die Aufnahme der Spektren wurden Proteinproben eingesetzt, welche unterschiedlich präpariert worden waren. Zum einen wurde die Deletionsmutante untersucht, zum anderen das Volllängenkonstrukt. Letzteres wurde einmal verdaut und einmal unverdaut getestet. Außerdem beinhalteten alle Puffer der Präparationen jeweils 0.1 mM GTP. Laut der Daten von P. Fabrizio (Fabrizio et al., 1997) bindet Snu114p GTP, wobei über die Hydrolyseaktivität keine konkreten Angaben gemacht werden konnten. Das vorhandene GTP sollte die Struktur stabilisieren. Die Messungen wurden normalisiert. 


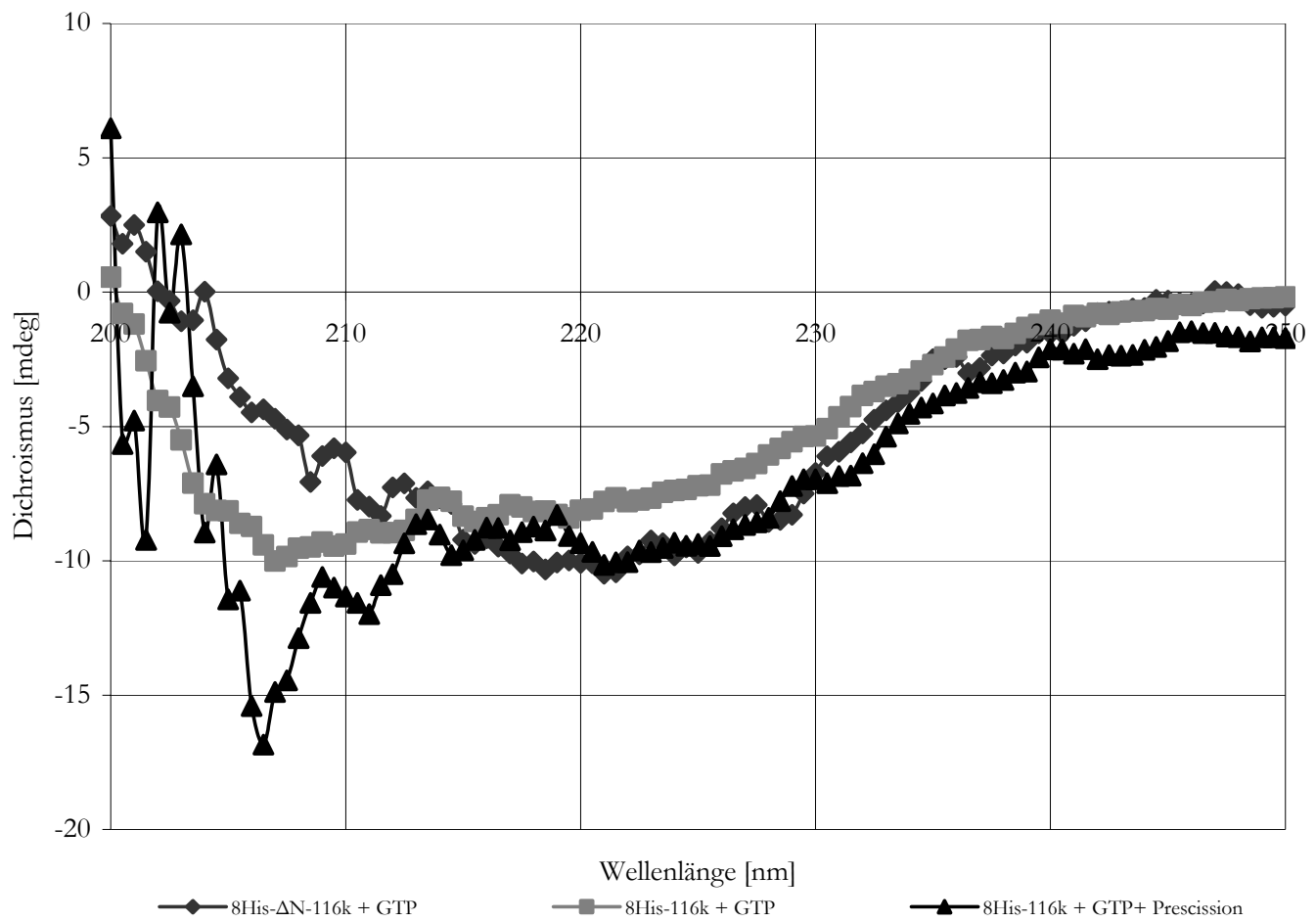

Abbildung 3.19: CD-Spektren von rekombinantem Protein aus Insektenzellen. Eingesetzt wurden $10 \mathrm{mM}$ Protein bei Raumtemperatur. Jedes Spektrum wurde aus 5 Wellenlängenscans gemittelt.

Ein Spektrum eines gefalteten Proteins hat bei $10 \mathrm{mmol}$ eingesetzten Proteins im Schnitt Werte bis zu -80 mdeg. Man erkennte bei ausgebildeten Sekundärstrukturen zwei Minimal bei 202 und 208 nm. Diese Minima sind nur in der Probe mit Prescission ${ }^{\circledR}$ zu erkennen. Da der Unterschied der beiden Volllängenproteinen in den Spuren aktiver, also gefalteter Protease (Prescission) liegt, ist der Nachweis von Sekundärstrukturen, also den angedeuteten Minima bei 202 und 208 nm, in der Protease begründet- auch wenn sie nach einem vorgeschalteten Reinigungsschritt nur noch in Spuren vorhanden ist.

Die Aussage aus diesem Experiment ist, daß das Protein auch aus Insektenzellen nicht in seiner nativen Form vorliegt. Es scheint allerdings so weit modifiziert worden zu sein, daß es in präparierbaren Mengen und löslich gebildet wird. Die Gewinnung von rekombinantem Protein kann nach Ergebnissen von Westermann et al. und Berger et al. (Berger et al., 2004; Westermann et al., 2005) durch die gemeinsame Expression von allen 
Bindungspartnern zu löslichem Protein führen. Zu diesem Zweck wurde die Klonierung aller spezifischen Proteine in das MultiBac System (Berger et al., 2004) begonnen.

\subsubsection{Kristallisation von hSnu114 aus Insektenzellen}

Mit einer Proteinpräparation einer 11 Kultur wurden Kristallisationsansätze pipettiert. Das Protein eluierte wie in den vorhergehenden Test trotz glycerinhaltigem Puffer spät von der Gelfiltrationssäule (etwa im Bereich eines $44 \mathrm{kDa}$ großen Proteins). Nichtsdestotrotz wurden die Fraktionen mit Protein vereinigt und unter Verlusten durch unspezifische Adhäsion an der Membran des Konzentrators auf $2 \mu \mathrm{g} / \mu \mathrm{l}$ ankonzentriert. Die Tropfen der Screens blieben über den beobachteten Zeitraum von drei Monaten klar. Ein erhoffter Kristallisationsprozess der möglicherweise gefalteten Teile hatte nicht eingesetzt.

\subsubsection{Zusammenfassung der Expression in Insektenzellen}

Die Expression in Insektenzellen hat sich als richtungweisend erwiesen. In diesem System konnten zum ersten Mal ausreichende Mengen löslichen Proteins gereinigt werden, welches nicht degradiert vorlag. Der nächste Schritt liegt nun in der Expression aller U5-spezifischen Proteine, oder den interagierenden Domänen, wie sie durch limitierte Proteolysen charakterisiert wurden. Die Klonierung aller Proteine in das MultiBac System hat den Umfang dieser Arbeit überstiegen und wird außerhalb fortgeführt. 


\subsection{Reinigung nativer heterotetramer Komplexe und deren}

\section{Kristallisation}

Die native Reinigung wurde neben der Reinigung der einzelnen rekombinanten Proteine verfolgt. Von Achsel und Kastner (Achsel et al., 1998; Kastner et al., 1998, Kastner et al., 1999) waren Reinigungsprotokolle etabliert worden. Die von C. Bartels adaptierte Reinigung des heterotetrameren Komplexes (siehe Abbildung 3.5) hat sich bei höheren Konzentrationen und größeren Mengen für Kristallisationsexperimente als nicht homogen genug erwiesen. Die Probe ist nur unter hohen Verlusten anzukonzentrieren und es zeigen sich dann Verunreinigungen von reassoziiertem snRNPs.

Die Menge des Subkomplexes gereinigt aus hauptsächlich U5-haltigen Fraktionen nach C. Bartels, war für Kristallisationsexperimente nicht ausreichend. Deshalb sollte eine Methode etabliert werden, mit der größere Mengen gereinigt und/oder ankonzentriert werden können.

In den Gradienten hat sich bei der Arbeitskonzentration und Konzentrationsreduktion des dissoziierenden Agens (NaSCN) teilweise wieder das U5snRNP gebildet. Bei hoher Konzentration ist der heterotetramere Komplex weiter zu einem dimeren Komplex zerfallen. Das Ziel war die Homogenität zu erhöhen, wären die Bedingungen milder wurden. Dazu wurden folgende Überlegungen angestellt:

Für die Kristallisation werden vergleichsweise große Mengen homogenen Materials gebraucht, kann man also eine weitere Quelle neben den vergleichsweise wenigen U5-Fraktionen erschließen, indem man das vorhandene Protokoll an veränderte Volumen adaptiert?

Gibt es eine Möglichkeit reine Präparationen verlustarm anzukonzentrieren? 
Wie kann man die Belastung mindern, die auf die Partikel während der Präparation ausgeübt wird?

Könnte die Magnesium Konzentration das ausdiffundieren des U5-200K verhindern?

Wenn Thiocyanat-Ionen die positiv geladenen Bereiche des Proteins bedecken und so Aggregation und Reassoziation verhindert, können dann weiche Kationen (beispielsweise Guanidinium-Ionen) diesen Effekt weiter verbessern?

Kann eine weitere H20-Säule die Reassoziierten Partikel und/oder snRNP-Cores aus der Präparation entfernen?

Kann man die Reassoziation verhindern indem man die U5-RNA durch den Einsatz von RNAsen soweit verkürzt, daß die Bindungsaffinität des snRNP-Cores an die spezifischen Proteine gemindert wird?

\subsubsection{Konzentrationserhöhung des heterotetrameren Komplexes}

Für Abbildung 3.18 wurde heterotetramerer Komplex wie für Abbildung 3.5 präpariert, allerdings wurde die fünffache Menge auf die Gele aufgetragen. Dabei kann man deutlich erkennen, daß der Hauptpeak des Zielkomplexes, erkennbar an den Proteinen Prp8, U5-200K, hSnu114 und U5-40K in (A) über weite Teile mit den U1spezifischen Proteinen (links daneben) überlappt und mit vollständig assemblierten snRNPs verunreinigt ist. Das erkennt man an dem Vorhandensein von U5-RNA im Peakbereich des Komplexes (B), während man bei einer vollständigen Dissoziation erwartet, daß der leichtere Core-Partikel weiter oben im Gradienten migriert als der Komplex. Außerdem erkennt man durch das planvolle überladen Kontaminationen, welche in den Analysegelen der Präparationen für biochemische Fragestellungen nicht sichtbar waren. In (C), einer elektronenmikroskopischen Aufnahme, erkennt man in den 
schwarzen Kreisen Partikel die in ihren Abmessungen dem Zielpartikel entsprechen. Die Präparation zeigt einige große Partikel (in dem blauen Kreis beispielsweise), bei denen es sich der Größe nach um reassemblierte oder nie vollständig dissoziierte U5-Partikel handelt.

A

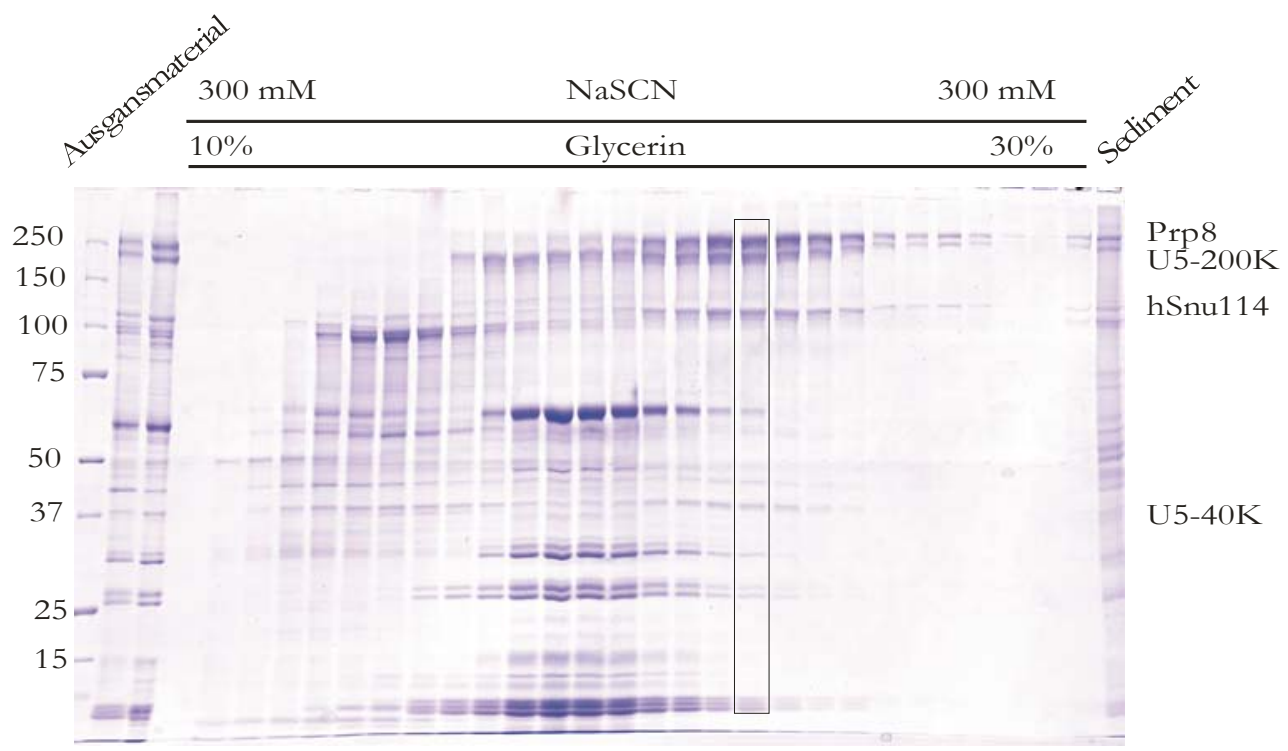

$\mathrm{B}$

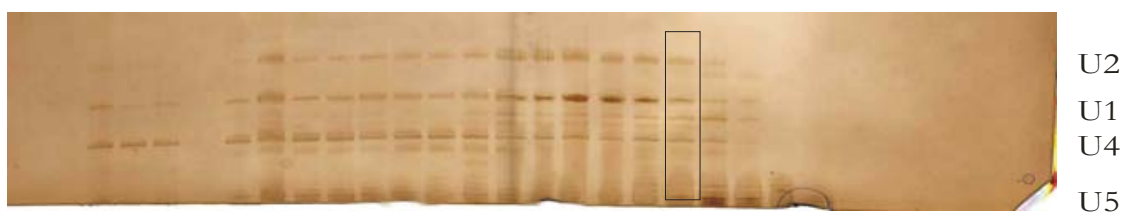

C

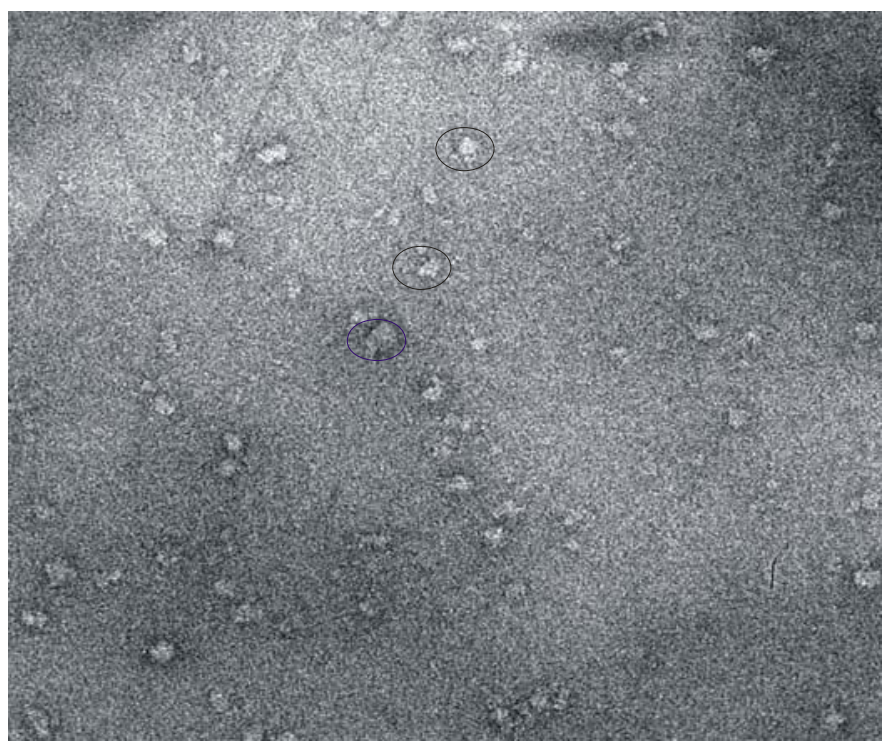

Abbildung 3.20: (A) Proteingel eines Gradient nach C. Bartels präpariert. (B) RNA-Gel desselben Gradienten. (C) EM-Aufnahme der Partikel aus der markierten Fraktion. 


\subsubsection{Einfluß der $\mathrm{Mg}^{2+}$-Konzentration auf den heterotetrameren Komplex}

Das $\mathrm{Mg}^{2+}$-Ion sollte das Ausdiffundieren des U5-200K aus dem heterotetrameren Komplex reduzieren, indem es interagierende Seitenketten stabiler miteinander koordiniert. Nach anfänglichen Hinweisen auf eine verbesserte Bindung durch die Verzehnfachung der $\mathrm{Mg}^{2+}$-Ionen Konzentration, muß das unterschiedliche Verhalten auf Populationsunterschiede zurückgeführt werden. Manche Präparationen verhalten sich besser als andere ohne das die $\mathrm{Mg}^{2+}$-Ionen Konzentration einen Einfluß darauf nimmt. Es bleibt Spekulation, was der Grund dafür ist. Vielleicht durch einen bestimmten Cofaktor, dessen Vorhandensein durch bestimmte Faktoren während der Zellkultur oder der Reinigung bedingt schwankt. Nichtsdestotrotz wurde die zehnfache Konzentration beibehalten, damit die generelle Stabilität des Subkomplexes erhöht wird.

\subsubsection{Guanidinium-Ionen als dissoziierendes Agens}

Die Guanidinium-Ionen waren als Antagonisten zum Thiocyanat-Ion gedacht. DieThiocyanat-Ionen sind groß, weich und schirmen positiv geladene Bereiche an Proteininteraktionsflächen ab, so daß Komplexe zur Dissoziation gebracht werden, bzw. sie nicht aggregieren. Theoretisch haben Guanidinium-Ionen diese Eigenschaften für negativ-geladene Bereiche. In analytischen Gradienten und Gelfiltrationen dissintegrierten die Komplexe vollständig bei einem Zusatz von 20 mM GuanidiniumHydrochlorid, was 5\% der Thiocyanat-Ionen entspricht. Dieser Ansatz wurde nicht weiter verfolgt 


\subsubsection{Präparation aus Randfraktionen und U5-haltigen Fraktionen}

Im direkten Vergleich wird deutlich, daß die Präparation aus U5-haltigen Fraktionen effizienter ist und sich der Komplex besser verhält. Im Versuch wurden relativ kleine Volumen einander gegenübergestellt.

\begin{tabular}{|l|c|c|}
\hline & Randfraktionen & U5-haltige Fraktionen \\
\hline Volumen $[\mathrm{ml}]$ & 54,5 & 39,5 \\
\hline Konzentration $[\mathrm{mg} / \mathrm{ml}]$ & 0,26 & 0,35 \\
\hline eingesetztes Protein $[\mathrm{mg}]$ & 14,17 & 13,83 \\
\hline
\end{tabular}

Tabelle 3.6: Eingesetzte Volumen und Konzentrationen im direkten Vergleich zwischen Randfraktionen und U5-haltigen Fraktionen. Die Pelletierung erfolgte nach den im Methoden Teil beschriebenen Protokoll.

Die Sedimente wurden in gleichen Volumen frischen R400-Puffers gelöst und optisch untersucht. Daraus ergab sich, daß die Präparation aus U5-haltigen Fraktionen farblos und gut löslich ist, während die Präparation aus Randfraktionen sich verhältnismäßig schlecht löst und sich durch eine rotbraune Färbung auszeichnet.

Die Konzentrationen der R400-Pool-Lösungen zeichnen ein noch deutlicheres Bild der Ausbeute:

\begin{tabular}{|l|c|c|}
\hline & Randfraktionen & U5-haltige Fraktionen \\
\hline eingesetztes Protein $[\mathrm{mg}]$ & 14,17 & 13,83 \\
\hline R400 Pool[mg] & 4,505 & 9 \\
\hline Ausbeute [\%] & 31,8 & 65,1 \\
\hline
\end{tabular}

Tabelle 3.7: Vergeleich der Ausbeuten für die Präparation des heterotetrameren Komplexes aus verschiedenen Ausgangsmaterialien bis zum Gradientenauftrag.

Die Präparation aus U5-haltigen Fraktionen hat den Vorteil, daß sich das Material besser handhaben läßt und nur halb so viel Protein verloren geht. Auch die Färbung ausschließlich der Fraktionen die den Komplexes enthalten, spricht für einen Unterschied der Populationen. Es wäre zu untersuchen, ob Proteine anders modifiziert sind, oder andere Cofaktoren in Spuren gebunden haben (Cytochrome), die für die Färbung verantwortlich sind. 
Die Komplexe wurden nach ihrer Präparation $1 \mathrm{~h}$ bei $37^{\circ} \mathrm{C}$ 1:100 mit Trypsin verdaut und die Entstehenden Fragmente durch eine Gelfitrationssäule ihrer Größe nach getrennt. Dies sollte die Unterschiede zwischen den Populationen deutlich machen.

A

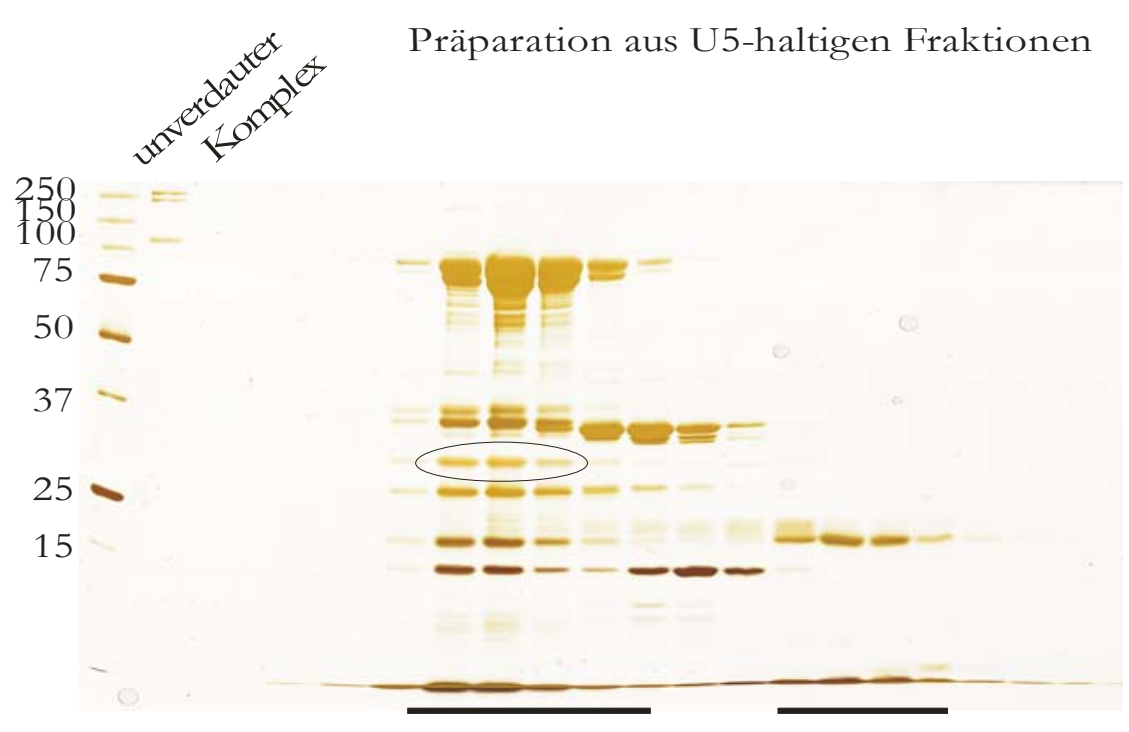

B

Präparation aus Randfraktionen

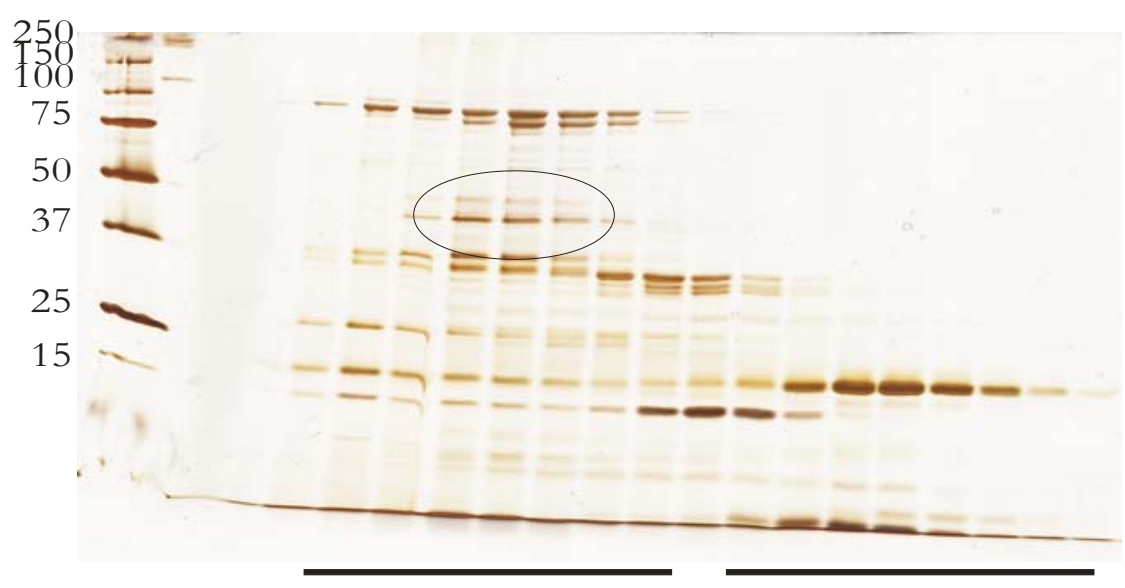

Abbildung 3.21: Vergleichender Verdau und Analyse.

Da es sich bei der Abbildung oben um die Analyse von zwei völlig gleich präparierten Komplexen und deren ebenfalls gleich ausgeführten Verdaue mit Trypsin handelt, liegen Unterschiede im Bandenmuster an den unterschiedlichen Ausgangsmaterialien. Auffällig ist, daß das Elutionsprofil bei dem aus Randfraktionen 
präpariertem Material viel breiter ist. Der Komplex aus U5-haltigen Fraktionen hat viel schärfere Maxima. Die Hauptunterschiede in den Profilen sind eingekreist worden.

\subsubsection{Vergrößerung des Maßstabes bei der Reinigung für kristallisierbare Mengen}

Der Maßstab wurde von wenigen Millilitern auf fast $360 \mathrm{ml}$ eingesetztes Material vergrößert. Das Protokoll ist im Material und Methoden Teil beschrieben. Dazu wurden die hinteren Randfraktionen verwendet, da das Material nur im begrenzten Maße vorlag. In dem oben beschriebenen Vergleichsexperiment wurde der qualitative Unterschied zwischen U5-haltigen Fraktionen und den hinteren Randfraktionen deutlich. Mann kann also mutmaßen, daß die Partikelpopulation aus den U5-haltigen Fraktionen sich durch Cofaktoren oder Modifikationen von der aus den Randfraktionen unterscheidet.

Die Unterschiede zum ursprünglichen Protokoll sind nicht nur in den größeren Volumen zu sehen. Diese verändern natürlich die Geschwindigkeiten und Zeiträume, mit denen die Präparationen durchgeführt werden.

Der Einfluß der $\mathrm{Mg}^{2+}$-Konzentration konnte nicht quantitativ bestimmt werden. Die Konzentrationserhöhung von 1.5 auf $7.5 \mathrm{mM}$ scheint das Ausdiffundieren von U5-200K zu unterbinden. Bivalenten Ionen sollten für die Stabilisierung von Interaktionsflächen vorhanden sein.

Es scheint allerdings auch an dem Ausgangsmaterial zu liegen, da sich jede Präparation minimal unterscheidet. Dies äußert sich in dem Anteil U5-200K, der nicht fest an den heterotetrameren Komplex gebunden ist und ausdiffundiert. Oder an der insgesamt vorhandenen Menge U5-40K. In manchen Präparationen scheint mehr vorhanden zu sein, bzw. sich leichter mit dem Zielkomplex reinigen zu lassen, als in anderen. 
Auch ist das Muster der Kontaminationen von Ausgangsmaterial zu Ausgangsmaterial verschieden.

Um den dissoziierenden Druck zu mindern, welcher auf dem Partikel lastet, wurde mit Zunahme der Glycerinkonzentration die Natriumthiocyanatkonzentration (NaSCN) verringert. Da die Fraktionen, welche den Komplex beinhalten, anschließend ein weiteres Mal sedimentiert werden, sollte die Behandlung des Komplexes so schonend wie möglich erfolgen.

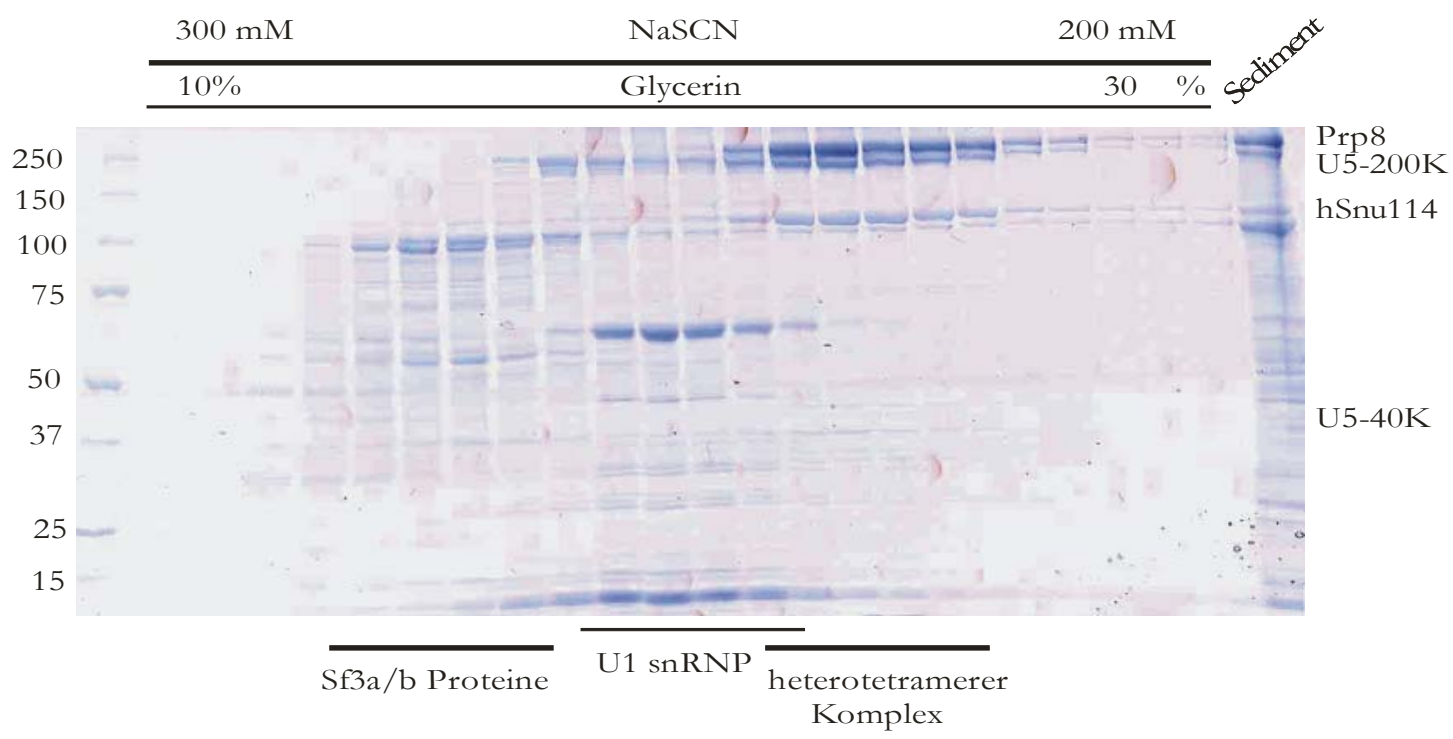

Abbildung 3.22: Analysegel der Dichtegradientenzentrifugation bei der Reinigung des heterotetrameren Komplexes im großen Maßstab.

\begin{tabular}{|l|c|}
\hline Eingesetztes Material (snRNP aus Randfraktionen) [mg] & 20 \\
\hline Auftrag auf die Gradienten (R400-Pool) [mg] & 7 \\
\hline Ausbeute (R400-Pool/eingesetztem Material) [\%] & 35 \\
\hline Heterotetramerer Komplex [mg] & 1,8 \\
\hline Ausbeute (Komplex/eingesetztem Material) [\%] & 9 \\
\hline
\end{tabular}

Tabelle 3.8: Ausbeute bei der Komplexpräparation im großen Maßstab aus Randfraktionen.

Mit diesem Protokoll läßt sich auf schonende Weise der Zielkomplex gewinnen.

Die Ausbeute liegt in einem ähnlichen Rahmen, wie bei dem Vergleichsexperiment. In elektronenmikroskopischen Aufnahmen wurde die Güte des Komplexes nach der 
angepaßten Reinigung für höher befunden, als nach der ursprünglichen Reinigung. Die Homogenität war höher, was für einen niedrigeren Anteil von reassemblierten U5 snRNPs, bzw. Kontaminationen durch U1 snRNPs spricht. Außerdem war der Anteil von aggregiertem Protein und völlig dissoziierten, bestenfalls dimeren Komplexen, geringer (Diskussionen mit B. Kastner, M. Golas, D. Böhringer und N. Fischer).

\subsubsection{Depletion von snRNPs aus der Komplex-Präparation durch eine zweite H20-Säule}

Zunächst sollte untersucht werden, ob man durch eine H20-Säule reassemblierte U5-snRNPs und kontaminierende snRNPs (vor allem das U1-snRNP) aus dem heterotetrameren Komplex entfernen kann. Der Komplex wurde nach dem verbesserten Protokoll präpariert (siehe „Komplex“ in der folgenden Abbildung). Um die Bedingungen, unter der die H20-Säule standardmäßig durchgeführt wird, zu erhalten, mußte der heterotetramere Komplex in Röder-Puffer dialysiert werden. Im Anschluß an die Dialyse wurde die Lösung ankonzentriert, da durch unspezifische Adhäsion Verluste entstanden sind. Die Volumenvergrößerung, welche mit der Dialyse einhergeht, hat auch zu Konzentrationsverlusten geführt. Die an die Dialyse anschließende Konzentrierung war ebenfalls verlustreich, allerdings konnte die ehemalige Konzentration - vor der Dialyse -wieder erreicht werden. 


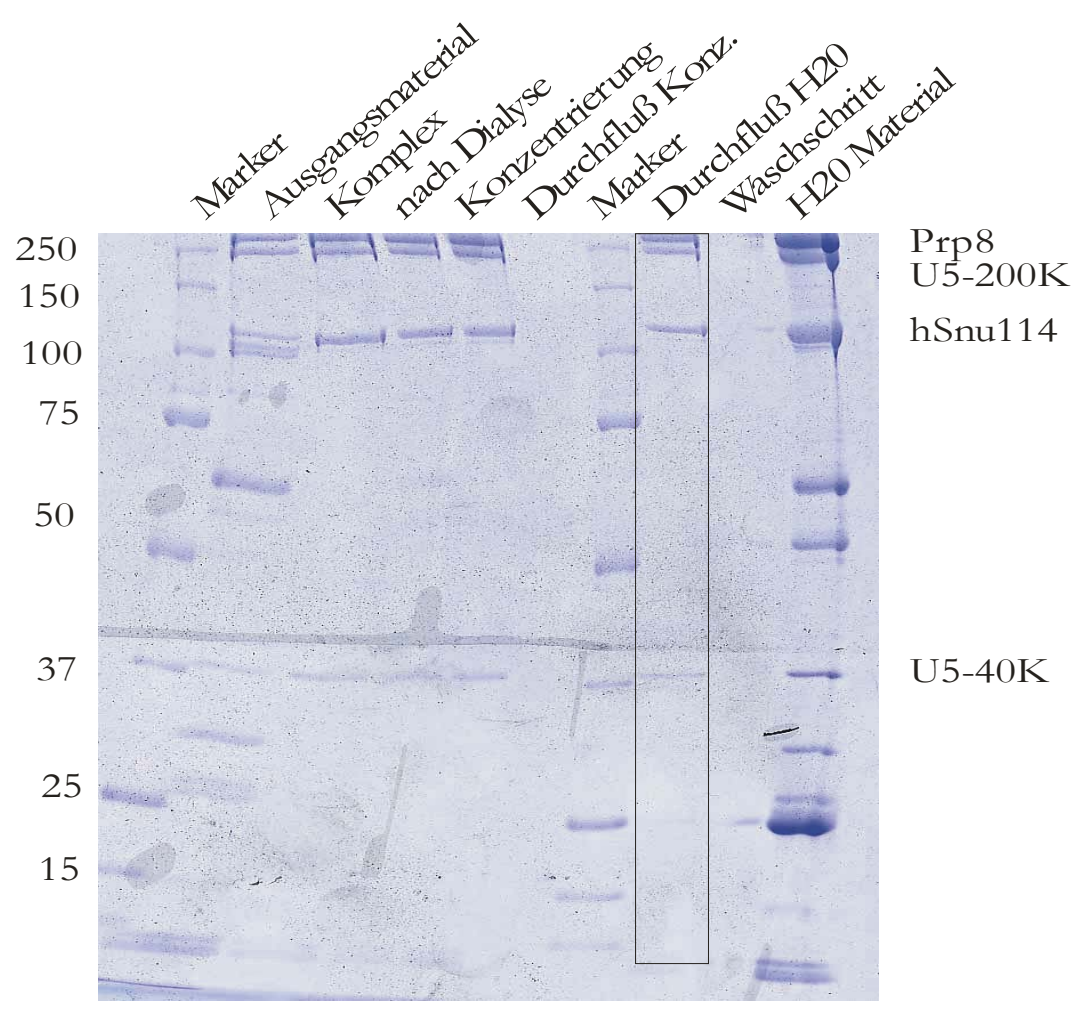

Abbildung 3.23: Depletion von snRNPs durch H20-Affinitätsschritt. Es wurden zur besseren Vergleichbarkeit Volumenäquivalente aufgetragen, wenn nicht anders erwähnt. „Ausgangsmaterial“ ist eine Probe der Lösung, welche zur Sedimentierung eingesetzt wird. „Komplex“ ist heterotetramerer Komplex nach den Gradienten. Die Probe „nach Dialyse“ ist ein Konzentrationsäquivalent. Vom „Durchfluß [der ] Konz[entration]“ wurde soviel wie möglich aufgetragen, um mögliche Verluste sichtbar zu machen. „Durchfluß H20“ ist der snRNP-freie Komplex. Es wurde ein doppelt so großes Volumen wie der „Komplex“ aufgetragen. Vom „Waschschritt“ wurde wieder so viel wie möglich aufgetragen. Bei der Probe „H20 Material“ wurde von $1 \mathrm{ml}$ Säulenmaterial $10 \mu \mathrm{l}$ aufgetragen.

Die Konzentrierung an Membranen ist nicht das Mittel der Wahl bei heterotetramerem Komplex in Röder-Puffer. Die Verluste durch unspezifische Adhäsion sind hoch.

Dafür ist der Komplex, welcher durch die Immundepletion mit dem H20-Antikörper entsteht, frei von Kontaminanten. Es gibt keinerlei Banden für U5-spezifische Proteine (unter der hSnu114 Bande ist bei allen Komplex-Präparationen das Signal von hPrp6 zu sehen), oder U1-spezifische Proteine (kontaminierende Bande bei $70 \mathrm{kDa}$ ) oder Sm-Proteine. Dieser Reinigungsschritt ermöglicht die Herstellung hochreinen Komplexes. 


\subsubsection{Dissoziation von Partikeln durch Behandlung mit RNAsen}

Die Effizienz der Präparationen ließ sich durch die Konzentrationsoptimierung der sich in Lösung befindlichen Komponenten nicht verbessern. Daher stellte sich die Frage, ob man das Gleichgewicht zugunsten der einzelnen Komponenten irreversibel verschieben könnte, beispielsweise durch eine Streptomycinbehandlung der dissoziierten Komponenten oder durch den Einsatz von RNAsen, welche freie, einzelsträngige RNA hydrolysieren und so die Bindungsaffinität zwischen snRNP-Core und Subkomplex weiter schwächen. Prp8 zeigt neben Bindungseigenschaften zum snRNP-Core auch Bindung an die RNA. Wenn man also die Gerüstfunktion des Prp8 umgeht, indem man das Bindemittel, also die RNA, zwischen dem snRNP-Core und dem heterotetrameren Komplex schneidet, sollte die Präparation des Subkomplexes mit höheren Ausbeuten und vorallem homogeneren Ausbeuten möglich sein.

Der Komplex wurde bei $10{ }^{\circ} \mathrm{C}$ mit $1 \mathrm{U}$ T1 RNAse pro $5 \mu \mathrm{g}$ Protein für eine Stunde inkubiert und dann durch Dichtegradientenzentrifugation getrennt. 


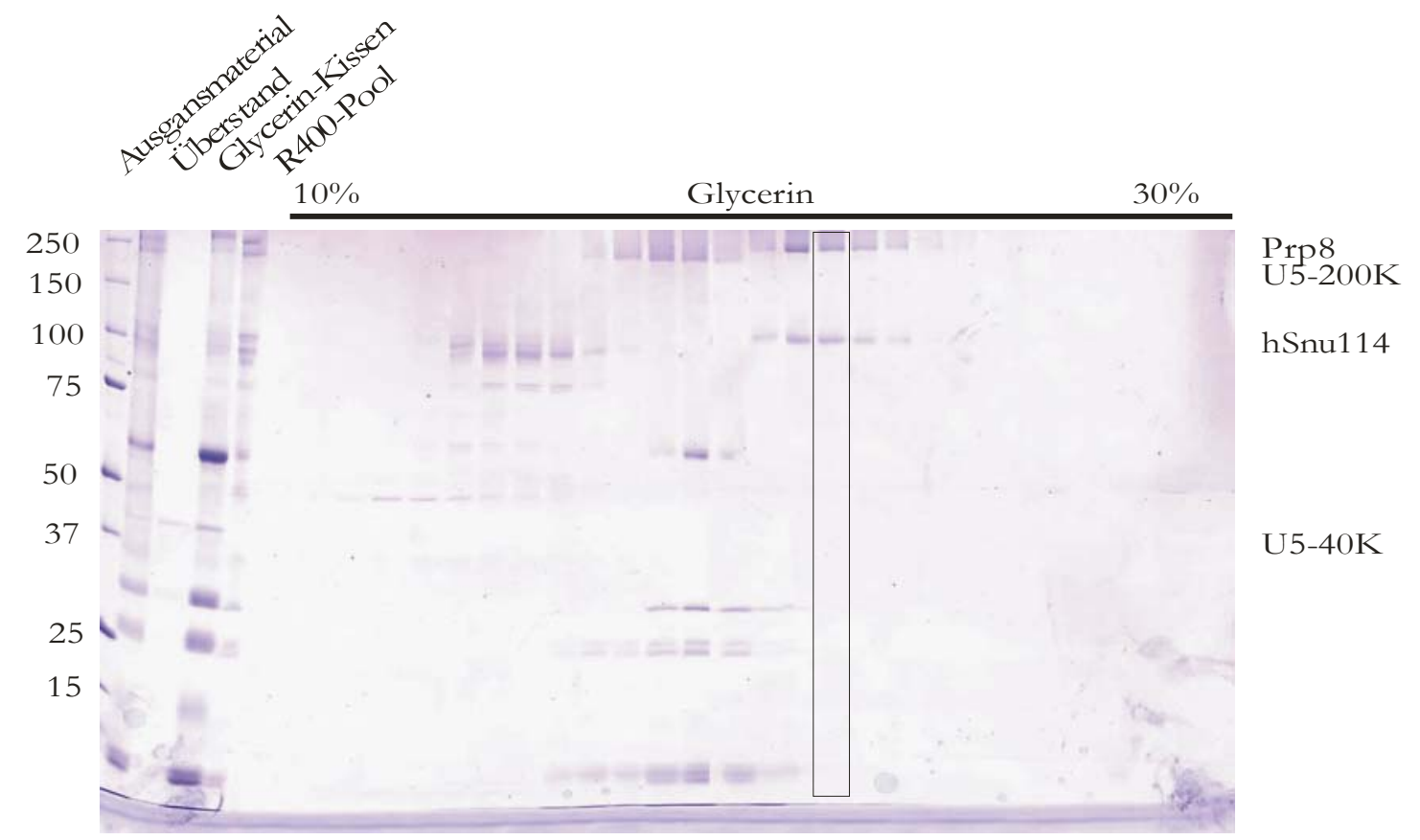

Abbildung 3.24: Proteingel des Subkompleses im Dichtegradienten nach dem Verdau mit T1. In diesem Gel wurde die Wirkung eines Glycerin-Kissens deutlich, da große Mengen des kontaminierenden U1 snRNPs im Kissen bleiben, währen U5 im Sediment, also im R400-Pool, gefunden wird. Man erkennt, daß die RNAse-Behandlung den heterotetrameren Subkomplex zu einem Heterodimer reduziert hat.

Der Subkomplex zerfällt durch die RNAse-Behandlung weiter zu einem Dimer aus Prp8 und hSnu114, welcher bereits bei Achsel et al. (Achsel et al., 1998) unter 400 mM NaSCN beschrieben worden ist. Das Ziel eine effizientere Reinigungsmethode des heterotetrameren Komplexes durch T1-Hydrolyse der RNA zu etablieren wurde nicht erreicht. Man kann allerdings spekulieren, daß der Kontakt zwischen U5-200K und dem Prp8-hSnu114-Dimer, sowie die Affinität des U5-40K an den Dimer auch RNAvermittelt ist. Wenn die Bindung nur durch Protein-Protein-Interaktionen entstünde, würde die RNA-Hydrolyse bei gleichbleibender Konzentration des dissoziierenden Agens keinen Einfluß auf die Komposition des entstehenden Subkomplexes nehmen. 


\subsubsection{Limitierte Proteolyse mit hochkonzentriertem Komplex}

Diese Versuche wurden unternommen, um weitere Hinweise auf den Interaktionsbereich zu erhalten und um das Verhalten der Proteasen bei hohen Proteinkonzentrationen zu untersuchen. Die Bestätigung der bis dahin charakterisierten Interaktionsfläche mit weiteren limitierten Proteolysen war ein untergeordnetes Ziel.

Die Herstellerangaben bezüglich pH-Wert, Temperatur und Konzentrationsverhältnis wurden befolgt, wie im Material und Methoden Teil beschrieben.

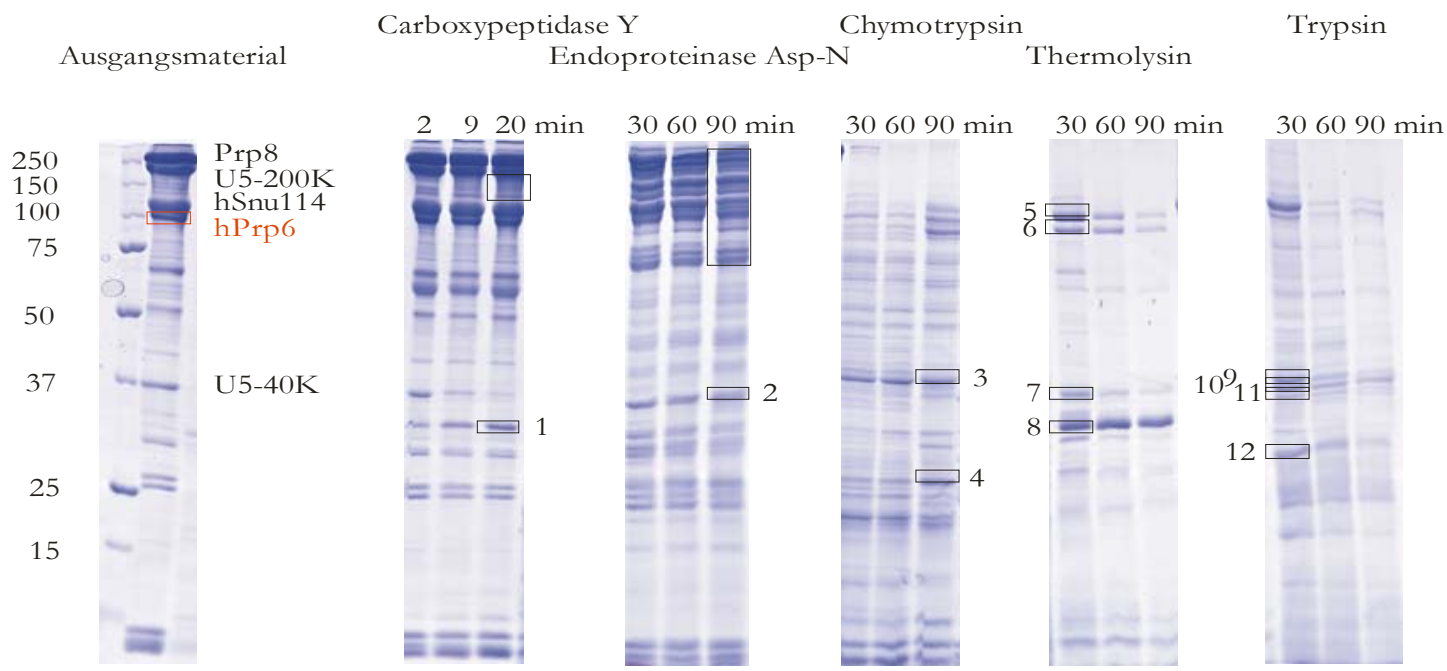

Abbildung 3.25: Limitierte Proteolyse des konzentrierten heterotetrameren Komplexes aus Randfraktionen. Man erkennt am Ausgangsmaterial, daß es sich um stark angereicherten heterotetrameren Komplex handelt, welcher verunreinigt ist. Neben den Zielbanden (in schwarz beschriftet) findet sich eine Hauptkontaminante, bei der es sich erfahrungsgemäß um hPrp6 handelt. Die langen Boxen deuten auf interessante Abbauprodukte hin, welche allerdings nicht im Zielbereich um die 37 kDa (der Größe einzelner Domänen) lagen. 


\begin{tabular}{|c|c|c|c|}
\hline Bande & $\begin{array}{l}\text { Apparentes } \\
\text { Molekulargewic } \\
\text { ht }[\mathrm{kDa}]\end{array}$ & $\begin{array}{l}\text { Identifizierte } \\
\text { Proteine }\end{array}$ & Beobachtungen und Charakteristika \\
\hline \multicolumn{4}{|c|}{ Carboxypeptidase $\mathrm{Y}$} \\
\hline 1 & 32 & Prp8 & $\begin{array}{l}\text { Die Proteolyse muß länger durchgeführt werden, um } \\
\text { mögliche Ziele zu ergeben }\end{array}$ \\
\hline \multicolumn{4}{|c|}{ Endoproteinase Asp-N } \\
\hline 2 & 36 & hSnu114 & $\begin{array}{l}\text { Es handelt sich um das bereits klonierte Fragment D4 } \\
\text { (C-Terminus hSnu114). } \\
\text { Die Wiederholung der Asp-N Proteolyse mit dem } \\
\text { konzentrierten Komplex zeigt deutlich, daß diese } \\
\text { Veränderung eine erneute Optimierung nötig macht }\end{array}$ \\
\hline \multicolumn{4}{|r|}{ Chymotrypsin } \\
\hline 3 & 40 & $\begin{array}{l}\text { Prp8, hPrp6, } \\
\text { hSnu114 \& } \\
\text { U1-70k }\end{array}$ & \multirow{2}{*}{$\begin{array}{l}\text { Eine Optimierung der Bedingung wäre nur dann } \\
\text { sinnvoll, wenn sich eine weitere Reinigung anschließen } \\
\text { würde, welche die einzelnen Proteine voneinander } \\
\text { trennbar macht und eine Gelfiltration, um } \\
\text { interagierende Komponenten zu identifizieren }\end{array}$} \\
\hline 4 & 27 & $\begin{array}{c}\text { Prp8, U5-200K, } \\
\text { hPrp6 }\end{array}$ & \\
\hline \multicolumn{4}{|c|}{ Thermolysin } \\
\hline 5 & 100 & hSnu114 (\& Prp8) & \multirow{2}{*}{$\begin{array}{c}\text { hSnu114 mit Deletion der aziden N-terminalen } \\
\text { Domäne }\end{array}$} \\
\hline 6 & 95 & hSnu114 (\& Prp8) & \\
\hline 7 & 35 & $\begin{array}{l}\text { Prp8, hSnu114, } \\
\text { U5-200K }\end{array}$ & Von der Zusammensetzung ähnlich der Bande \\
\hline 8 & 32 & U5-200K, Prp8 & $\begin{array}{c}\sim 30 \mathrm{kDa} \text { C-Terminus von U5-200K, zweite Hälfte der } \\
\text { Mitte von Prp8 }\end{array}$ \\
\hline \multicolumn{4}{|c|}{ Trypsin } \\
\hline 9 & 39 & $\begin{array}{l}\text { Prp8, U5-200K, } \\
\text { hSnu114 }\end{array}$ & zweite Hälfte der Mitte von Prp8 \\
\hline 10 & 37 & $\begin{array}{l}\text { U5-200K, Prp8, } \\
\text { hSnu114 }\end{array}$ & $\sim 37 \mathrm{kDa}$ C-Terminus von U5-200K \\
\hline 11 & 35 & $\begin{array}{l}\text { hSnu114, Prp8, } \\
\text { U5-200K }\end{array}$ & hSnu114 C-Terminus \\
\hline 12 & 29 & $\begin{array}{l}\text { Prp8, U5-200K, } \\
\text { hSnu114 }\end{array}$ & Prp8 überall \\
\hline
\end{tabular}

Tabelle3. 3.9: Auflistung der untersuchten Banden. Die Größe des Fragmentes wird angegben, sowie die Proteine in absteigender Reihenfolge der Treffer. Wenn sich Areale den Treffern zuweisen ließen wurde dies bioinformatisch analysiert.

Abschließend kann gesagt werden, daß sich durch die Reproduzierbarkeit der Fragmente die Interaktionsfläche biochemisch auf den C-Terminus von U5-200K, den C-Terminus von hSnu114 und einem Bereich ab der Mitte von Prp8 oder dessen MPNDomäne eingrenzen läßt.

Durch die hohe Konzentration wir die Natur des präparierten Komplexes sichtbar. Zum einen ist Prp6 offensichtlich ebenfalls ein Bestandteils des Subkomplexes, wenn er aus den hinteren Randfraktionen gewonnen wird, zum anderen muß bei dieser 
Reinigung ein weiterer Schritt angeschlossen werden um die snRNP-Cores zu entfernen, wie zum Beispiel ein H20-Affinitätsschritt.

\subsubsection{Kristallisation des heterotetrameren Komplexes}

Der gereinigte Subkomplex wurde in einem großen Ansatz von 2300 Bedingungen bei $4{ }^{\circ} \mathrm{C}$ und Raumtemperatur eingesetzt. In den etwa $50 \%$ der Fälle präzipitierte das Protein sofort. In einem Fall wurden Kristalle in Plattenform beobachtet, die sich als Detergenzkristalle erwiesen.

A

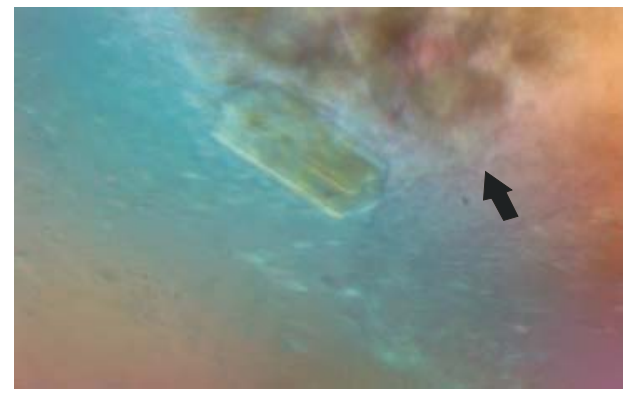

B

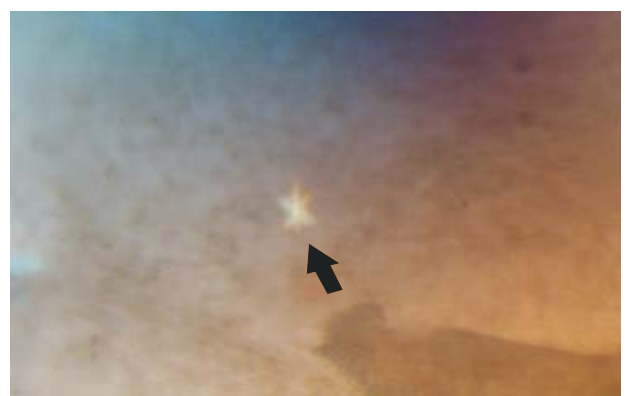

Abbildung 3.26: In (A) erkennt man links neben der Präzipitation (Pfeil) ein Detergenzkristall. In (B) sieht man durch einen Pfeil markiert einen Mikrokristall, der aufgrund seiner Größe nicht getestet werden konnte.

Die sternförmigen Kristalle unterscheiden sich morphologisch stark von den Detergenzkristallen. Die Kristalle ließen sich unter keiner der getesteten Bedingungen vergrößern.

\subsubsection{Zusammenfassung - native Reinigung}

Das Protokoll zur Herstellung des heterotetrameren Komplexes konnte derart angepaßt werden, daß für die Kristallisation ausreichende Mengen hergestellt werden können. Die Wahl des Ausgangsmaterials ist allerdings kritisch und sollte in weiteren Studien zu Gunsten der U5-haltigen Fraktionen getroffen werden. 
Die Verbesserungen des Protokolls finden sich in der Reduktion des dissoziierenden Drucks und der Mehrgabe von bivalenten Ionen. Eine weitere Verbesserung stellt ein zweiter Affinitätsschritt mit H20-Material dar. Auf diese Weise konnte hochreiner heterotetramerer Subkomplex gewonnen werden. Alle weiteren Agenzien haben keinen positiven Effekt auf den Zielkomplex.

Die limitierten Proteolysen mit unterschiedlichen Proteasen und unter verschiedenen Bedingungen haben biochemische Hinweise auf den Kernbereich der interagierenden Domänen geliefert. Dazu zählen der C-Terminus von hSnu114 vermutlich ab Aminosäure 570 - der Sec63-Domäne von U5-200K, sowie einem Bereich von Prp8, der sich auf die zweite Hälfte, bzw. sogar die MPN-Domäne beschränken läßt.

Kristallisationsexperimente mit dem heterotetrameren Komplex aus Randfraktionen haben auf Grund der Inhomogenität keine untersuchbaren Kristalle hervorgebracht. 


\subsection{D-Alignment anhand der Struktur von eEF-2 mit $\Delta \mathrm{N}-$}

\section{hSnu114}

Auf Grund der hohen Sequenzübereinstimmung kann eine 3D-Struktur postuliert werden. Die Konservierung der Sequenzen der G-Proteine in Hefe, nämlich Ef-2 und Snu114p ist nur wenig höher. Snu114ps voraussichtliche 3D-Struktur wurde bei Brenner et al. (Brenner und Guthrie, 2005) durch aufwendige Mutationsstudien unterstützt. Geht man von der strukturellen Konservierung der spleißosomalen Proteine durch die Reiche aus, kann man folgendes Modell wie Brenner vorschlagen:

A

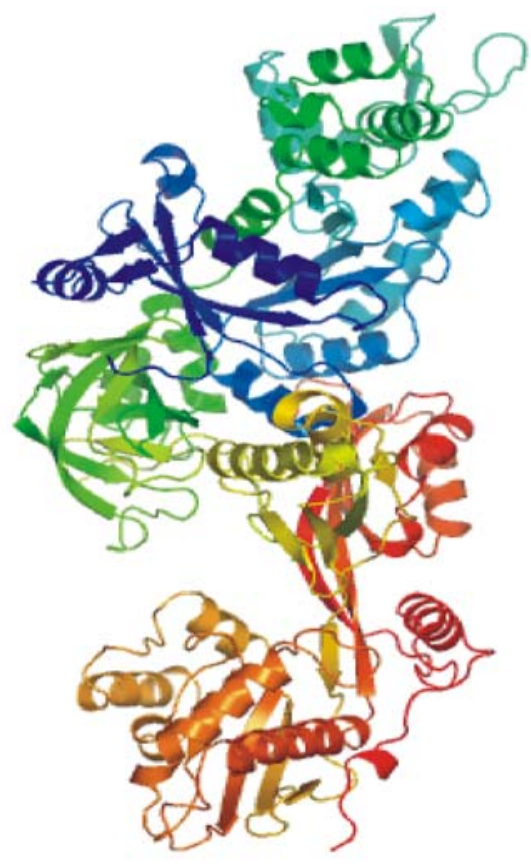

$\mathrm{B}$

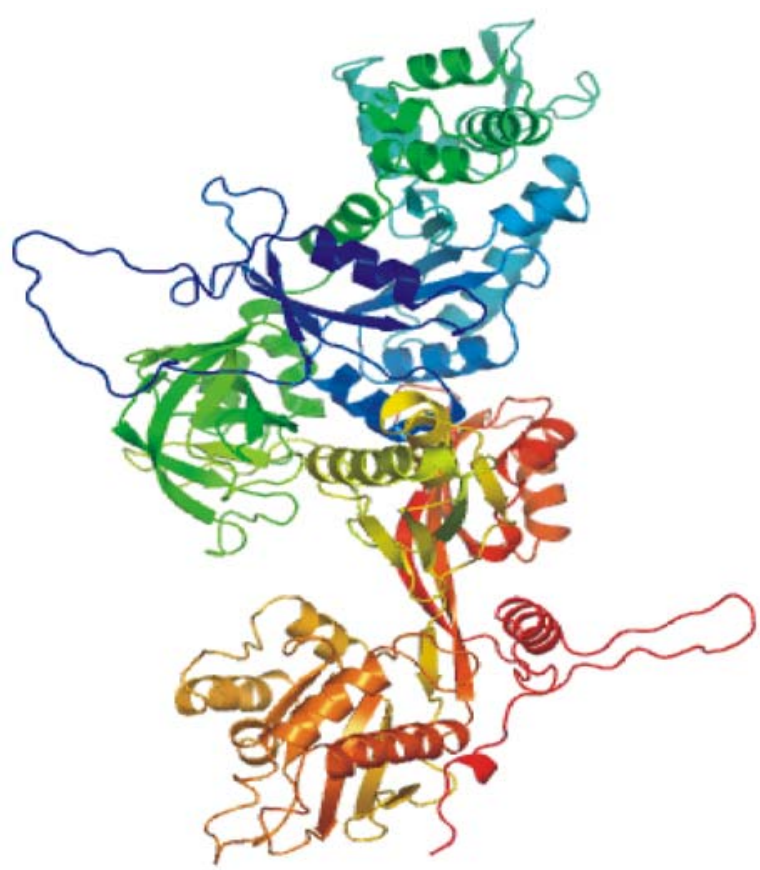

Abbildung 3.x: (A) ist die Struktur von eEF-2 und (B) das 3D-Sequenzalignment von hSnu114. Die Struktur von Joergensen et al., 2003 (Joergensen et al., 2003) hat eine Auflösung von 2.9 Á. Die verwendeten Koordinaten von eEF-2 sind in der Protein Data Bank unter 1NOV ohne Sordarin und 1NOU mit Sordarin hinterlegt. 


\section{Diskussion}

Durch das Spleißosom werden Introns aus der Prä-mRNA entfernt und Exons miteinander verbunden. Bis zum heutigen Tage sind der genaue Mechanismus und die räumliche Anordnung der Komponenten während der einzelnen Schritte nicht bekannt. Man möchte also sowohl über die Anordnung der RNAs als auch der Proteine des Komplexes vor, während und nach der Spleißreaktion Kenntnis erlangen. Die biochemischen Daten deuten darauf hin, daß den Proteinen des U5-Partikels zentrale Rollen zukommen, weshalb die Untersuchung dieser Proteine von großem Interesse ist, zumal dieser Partikel sowohl im majoren als auch im minoren Spleißosom an der Reaktion teilnimmt. Die Rollen der einzelnen Proteine sind noch nicht aufgeklärt, so bleiben also die Fragen offen, welche strukturelle Anordnung und Funktion Prp8 hat, ob hSnu114 die GTP-abhängige Translokase des Spleißosoms ist und wann und wie die ATPase- und Sec63-Domänen des U5-200K an der Spleißreaktion teilnehmen. Um Einsicht über deren Funktion zu erhalten, ist die Kenntnis der Struktur essentiell. In der vorliegenden Arbeit sollte die Produktion der Proteine, deren Reinigung und ihre strukturellen Eigenschaften durch Röntgenkristallographie beschrieben werden.

Die Struktur der Proteine sollte folglich auch Einsichten in den Reaktionsmechanismus des Spleißens liefern. Da sich die Herstellung der rekombinanten Proteine bzw. ihrer Domänen auf herkömmlichem Wege als ausgesprochen schwierig erwiesen hat, konnten Erfolge im Bereich der Expression in Insekten-Zellen erzielt werden, nachdem das gesamte System etabliert worden war.

Die Reinigung des heterotetrameren Subkomplexes aus dem U5-snRNP für kristallographische Fragestellungen konnte ebenfalls realisiert werden, obschon der Subkomplex in zahlreichen Kristallisationsversuchen nicht in untersuchbaren Kristallen resultierte. 
Die Untersuchung des nativen humanen Subkomplexes durch limitierte Proteolysen führte zu Hinweisen auf eine Interaktionsfläche innerhalb des heterotetrameren Subkomplexes.

hSn114 wurde am ausgiebigsten untersucht, und seine Struktur soll anhand eines Homologiemodells postuliert werden.

\subsection{Expression rekombinanten Proteins}

Die Expression und Reinigung mehrerer Milligramm Protein ist einer der ersten Schritte auf dem Weg zur Strukturaufklärung. Die Zielproteine wurden einzeln, domänenweise und in Co-Expressionsversuchen untersucht. Dabei zeigte sich, daß E. coli nicht das System der Wahl für die Expression dieser großen, hochmodifizierten Säugerproteine ist. Bekannte Modifikationen sind beispielsweise unterschiedliche Grade der Phosphorylierung (Changyu et al., 1998; T. Misteli, 1999) und Methylierung (Brahms et al., 2001; Brahms et al., 2000). Modifikationen dienen der Feinabstimmung bei komplizierten zellulären Prozessen wie dem Spleißen. So ist die Bindung von U1-snRNP von dessen Phosphorylierung abhängig, während spätere Schritte der Spleißreaktion von dephosphorylierenden Enzymen abhängig sind.

Auch die Gewinnung des Hefeproteins Snu114p aus Hefe für kristallographische Studien erwies sich als schwierig. Da dieses Projekt nur kurz betrieben wurde, sind die Möglichkeiten mit Sicherheit noch nicht ausgeschöpft. Die größten Fortschritte wurden im Bereich der Baculo-Virus-Expression erzielt.

\subsubsection{Expression in E. coli}

Die Expression von hSnu114, dessen Deletionsmutante (ohne aziden NTerminus) und seiner anhand der EF-2 Proteine klonierten Domänen als einfache 
Expression oder in Kombination mit anderen interagierenden Proteinen hat nicht zu löslichem Protein in seiner nativen Form geführt. Soweit sich Protein exprimieren ließ, präzipitierte dies in Einschlußkörpern und ließ sich auch nicht rückfalten. Das gilt sowohl für hSnu114 als auch für Domänen von U5-200K und Prp8. Diese Ergebnisse werden durch Gelfiltrationsläufe und im Falle des N-Terminus von hSnu114 durch NMR-Daten belegt. Es bleibt Spekulation, ob fehlende Modifikationen oder die Abwesenheit von bestimmten Chaperonen und Membranen oder gar weiterer Proteine der Grund für das ungefaltete Vorliegen sind. Auffällig bei den Coexpressionen der Domänen ist, daß die Kontaminationen größtenteils aus E. coli-Chaperonen bestehen. Die Expression dieser großen und stark modifizierten Proteine in E. coli ist nur unter erheblichem Aufwand möglich und scheint nicht zu gefaltetem Protein zu führen.

\subsubsection{Expression in S. cerevisiae}

Dieses Projekt wurde nur relativ kurz bearbeitet. Daher sind weitere Arbeiten auf dem Gebiet des Hefe-Proteins Snu114p denkbar. Expression und Reinigung sind etabliert. Das Hauptproblem besteht in der Degradation bei großvolumigen Präparationen. Die Proteinmengen, die aus Hefe gewonnen werden können sind klein daher sind große Ansätze unerläßlich.

Ein mögliches Ziel, das dem Abbau durch Proteasen zu widerstehen scheint, ist ein N-terminales Fragment von $75 \mathrm{kDa}$ Größe. Dessen Subklonierung bildet ein offensichtlich relativ stabiles und durch seine geringere Größe besser handhabbares Protein. In dem Zeitrahmen der vorliegenden Dissertation waren die Experimente, welche aus den Ergebnissen resultieren, nicht mehr durchführbar. 


\subsubsection{Expression in F. spodoptera}

In Insektenzellen konnten die größten Erfolge auf dem Gebiet der Expression erzielt werden. Erstmals gelang es, lösliches Protein herzustellen, was sich vermutlich auf Modifikationen zurückführen läßt, welche von Insekten-, nicht hingegen von E. coliZellen an Proteinen vorgenommen werden. Nichtsdestotrotz ist das Protein ungefaltet, wie an CD-Spektren, CD-Schmelzkurven (Daten nicht gezeigt) und Gelfiltrationsläufen erkennbar wurde. Nach den Ergebnissen von Berger et al. (Berger et al., 2004) bleibt zu überprüfen, ob die heterologe Expression aller partikelspezifischen Proteine zu gefaltetem Protein - womöglich als Partikel assembliert - führt.

In Zukunft liegen neue Möglichkeiten in der heterologen Expression der spezifischen Proteine. Im Falle von Prp8 ist eine einfache Expression kaum vorstellbar, da das Protein nur vage Domänen bzw. Bereichen erkennen läßt, die als funktionale Einheiten fungieren (Boon et al., 2006). Es ist denkbar, daß das Protein während seiner Translation durch Chaperone oder Co-Faktoren in einem ungefalteten Stadium gehalten und schrittweise während der Bindung der restlichen U5-Proteine in seine aktive bzw. gefaltete Form überführt wird. Diese These ist mit der Idee, daß Prp8 eine Gerüstfunktion hat (Brown et al., 1992; Boon et al., 2006; Grainger und Beggs, 2005; Collins et al., 1999), zu vereinbaren. Die begonnene Klonierung aller U5-spezifischen Proteine in das MultiBac-System stellt einen großen Schritt in diese Richtung dar. Dieses System ermöglicht die Generierung von verschiedenen Kombinationen.

Das gewonnene Protein wurde zur Kristallisation eingesetzt, was aber nicht in der Bildung von Kristallen resultierte. In den meisten Fällen blieben die Tropfen auch über die beobachteten drei Monate hinaus klar. Unter Punkt 4.2.3 Kristallisationsexperimente der Proteinkomplexe wird diskutiert, weshalb manche Proteine bzw. Proteinkomplexe keine Kristalle bilden. Es bleibt zu hoffen, daß 
funktionelle Einheiten in Insektenzellen zur Expression gebracht und zur Kristallisation eingesetzt werden können.

\subsubsection{Ausblick}

Die bakterielle Expression der U5-spezifischen Proteine ist aufgrund der fehlenden Chaperone, Membranen und Modifikationen keine erfolgversprechende Methode. Die Expression in Hefe ist wegen der geringen Mengen für Kristallisationsexperimente kein Hauptziel. Sie sollte vielmehr, nach der ersten erfolgreichen Expression löslichen Proteins, in Insektenzellen fortgeführt und durch Coexpressionen optimiert werden. Alle nötigen Komponenten für die heterologe Proteinexpression sind vorhanden. Sequenzierte Konstrukte wurden teilweise fertig gestellt; die Rekonstruktion des U5-snRNP in Insektenzellen ist auch vom biochemischen Standpunkt interessant, weil ein Partikel garantiert frei von humanen Proteincofaktoren untersucht werden könnte. Die Frage, ob hSnu114 eine GTPase ist, könnte auf diese Weise geklärt werden.

Außerdem sollten die interagierenden Bereiche aus dem heterotetrameren Subkomplex ebenfalls in das MutliBac-System kloniert werden. Bei den Subdomänen handelt es sich um den kleinsten nötigen Bereich, welcher ohne flexible Bereiche die größten Erfolgsaussichten für das Wachstum hochgeordneter Proteinkristalle hat.

\subsection{Reinigung des nativen Komplexes}

Der Komplex aus HeLa-Zellkultur stellt die einzige Quelle ausreichender Mengen des heterotetrameren Komplexes dar. Die Mengen können durch das Reinigungsprotokoll für große Maßstäbe erreicht werden, vor allem wenn die U5haltigen Fraktionen verwendet werden. Die U5-Populationen aus den hinteren 
Randfraktionen und den U5-haltigen Fraktionen zeigen deutliche Unterschiede auf; allein die Färbung und die schlechtere Löslichkeit der Partikel aus dem erstgenannten Material macht deutlich, daß die Reinigung mit besserem Ausgangsmaterial weiter führt. Ein weiterer Schritt ist die nachgeschaltete H20-Säule, welche zu hochreinem Komplex führt.

\subsubsection{Anpassung des Maßstabes}

Die Vergrößerung des Maßstabes war unerläßlich für die Kristallisationsexperimente, zumal sie die Notwendigkeit einer weitergehenden Reinigung aufgezeigt hat. Für weitere Experimente sollte aber nicht auf die hinteren Randfraktionen zurückgegriffen werden, da die Präparation des Partikels inhomogen und im Unterschied zu dem Partikel aus U5-haltigen Fraktionen weniger effizient herzustellen war, sich schlechter löste und durch eine bräunlich-rote Farbe auffiel.

\subsubsection{Verbesserung der Reinigung}

Die Herstellung des Partikels in großen Mengen zeigte die Notwendigkeit für die Verbesserung der Reinigung auf. Eine Minderung des dissoziierenden Drucks durch Konzentrationsverringerung des Natriumthiocyanats im unteren Teil des Gradienten sowie die Konzentrationserhöhung der bivalenten Ionen im Gradienten erhöhte die Stabilität des Komplexes. Die Einführung eines Glycerinkissens bei der Pelletierung des U5-Partikels führt zu einer frühzeitigen Abtrennung eines großen Teils des kontaminierenden U1-snRNPs.

Der Versuch, das Gleichgewicht von Assoziation und Dissoziation des Subkomplexes mit dem Core-snRNP zu Gunsten der Dissoziation mit GuanidiniumIonen zu verschieben schlug fehl. Allerdings ist die nachgeschaltete H20-Säule das Mittel der Wahl, um an hochreinen Subkomplex zu gelangen. 


\subsubsection{Kristallisationsexperimente der Proteinkomplexe}

Es gibt EM-Daten des U5-snRNP (Kastner, 1998, Springer Lab manual. Springer Verlag Berlin Heidelberg), die einer atomaren Struktur nicht gleichkommen. Das gesamte Partikel kann nur durch Elektronenmikroskopie untersucht werden, weil es mit 0.5 MDa in den Auflösungsbereich der EM fällt. Ein Partikel dieser Größe, Flexibilität und Heterogenität wird keine Kristalle mit einem hochgeordneten Kristallgitter bilden können, was aber wiederum für die Lösung der atomaren Struktur unbedingt Voraussetzung ist. Proteinkristalle sind bereits bei kleineren Molekülen schwer zu erreichen, weil sich sphärische oder ellipsoide Körper mit ungleichmäßigen Oberflächen nur schwerlich in sich wiederholende Einheiten (der Einheitszelle des Kristallgitters) ordnen. Es ist nicht möglich, Proteine oder sogar Proteinkomplexe in einem Kristall angeordnet zu finden, ohne daß sich große mit Flüssigkeit gefüllte Kanäle zwischen den Molekülen befinden. Die Kanäle machen oft $50 \%$ des Kristalls aus, sodaß die Proteine in einem Kristallgitter oft nur an einigen wenigen Regionen, und auch in diesen Fällen nur indirekt miteinander interagieren. Das ist der Grund, aus dem röntgenkristallographische Strukturen in den allermeisten Fällen denen von Proteinen in Lösung entsprechen. Allerdings ist es deshalb auch sehr schwierig, Kristalle zu produzieren, welche die Größe (etwa $0.5 \mathrm{~mm}$ ) und die Ordnung haben, um die Struktur zu lösen. Bei einzelnen Proteinen, die größer sind als $30 \mathrm{kDa}$ ist es schon schwierig, bei Kristalle von Subkomplexen oder gar Partikeln mit der Größe des U5-snRNP mit den heutigen Methoden, unmöglich sie zu erreichen (Branden und Tooze, 1991).

NMR (Nuclear Magnetic Resonance) dient zur Strukturaufklärung auf atomarem Level von Proteinen in Lösung mit einer Größe von bis zu 30 kDa (Branden und Tooze, 1991) und ist auch nicht die Methode für einen Komplex dieser Größe.

Die Größe des Komplexes überschreitet die Obergrenze der NMR bei weitem, also bleibt als einzige Möglichkeit eine atomare Struktur zu erhalten die 
Röntgenkristallographie. Den ersten Schritt stellt die Produktion von Milligrammengen reinen Proteins dar. Die Präparation sollte zu 95\% aus dem Zielprotein bestehen, je höher der Zielproteinanteil, desto besser.

Der nächste Schritt sind sogenannte Initial Screens. Da es noch keine Algorithmen gibt, um die Bedingungen unter denen ein bestimmtes Protein kristallisiert vorherzusagen, werden Proteinkonzentration, $\mathrm{pH}-$ Wert, Temperatur, anwesende Ionen und Präzipitanzen variiert. Des Weiteren ist das Protein selbst entscheidend dafür, ob sich Kristalle bilden (Dale et al., 2003). Es gibt Proteine, die erst durch Modifikationen (Deletionen, Punktmutationen, Cokristallisation, etc. (Braig et al., 1994; Kuge et al., 1997; Martin et al., 2000)) zur Kristallisation gebracht werden konnten.

Rigide Einheiten von Proteinen kristallisieren leichter als Proteine mit flexiblen Bereichen. So wurde eEF2 komplexiert mit einem Sordarin-Molekül sowohl kristallisiert als auch strukturell gelöst. Sordarin ist ein Antibiotikum, welches die Proteinbiosynthese - in hohen Konzentrationen wird auch die Spleißaktivität reduziert - spezifisch unterbindet (Dominguez et al., 2001; Shastry et al., 2001), weil eEF-2 inhibiert wird. Die Inhibition erfolgt durch Bindung des Sordarin-Moleküls in der Scharnierregion der Translokase eEF-2 (Andersen et al., 2003; Jorgensen et al., 2003). Die Flexibilität wird reduziert, bzw. die Translokasebewegung unterbunden. Dadurch wird das Protein rigider. Da die GTP-Bindungseigenschaften von Snu114p (Fabrizio et al., 1997) bekannt waren, wurde die Reinigung in Anwesenheit von GTP durchgeführt. Die Bindung eines GTP-Moleküls sollte die Flexibilität des hSnu114 reduzieren und die Kristallisation ermöglichen. Es muß geprüft werden, ob die Kristallisation eines bestenfalls teilweise gefalteten Proteins ohne seine Bindungspartner überhaupt möglich ist. Daher ist die CoExpression und Co-Reinigung aus Insektenzellen der wesentliche nächste Schritt.

Die Kristallisation des nativen Komplexes hat im Feinscreen zu sechszackigen, sternförmigen Mikrokristallen, der Ansatz der 2300 Bedingungen jedoch nicht zu 
untersuchbaren Kristallen geführt. Da die Proteinlösung in mindestens $50 \%$ der Fälle präzipitierte, sollten die Experimente erneut mit homogenerem Material durchgeführt werden, prinzipiell ist die Herstellung der erforderlichen Mengen jedoch technisch möglich bzw. sogar noch optimierbar.

\subsubsection{Ausblick}

Im Rahmen dieser Arbeit ist es erstmalig gelungen, heterotetrameren Subkomplex aus dem U5-snRNP in den Mengen herzustellen, die für Kristallisationsversuche notwendig sind. Diese Reinigung sollte in Zukunft mit besserem Ausgangsmaterial durchgeführt werden, um effizienter an homogeneres Material zu gelangen. Möglicherweise können die Erfahrungen aus den limitierten Proteolysen genutzt werden, um einen interagierenden Kernpartikel zu gewinnen und zur Kristallisation zu bringen.

\subsection{Limitierte Proteolysen}

Die Untersuchung des heterotetrameren Subkomplexes mit Proteasen stellt einen zentralen Bereich der Arbeit dar. Diese Methode ist für die Kristallographie aus folgendem Grunde von fundamentaler Bedeutung: Je rigider Proteine sind und je weniger flexible Bereiche sie aufweisen, desto wahrscheinlicher bilden sie ein geordnetes Kristallgitter. Mit Proteasen werden durch die Wahl der Verdaudauer nur die flexiblen Bereiche vom interagierenden Kern abgetrennt. Es ist also eine biochemische Methode, um enge Interaktionen in Komplexen oder wenigstens definiert gefaltete Bereiche in Einzelproteinen zu finden und zu charakterisieren. Im Weiteren werden die Regionen, beispielsweise nach Gelfiltrationsläufen, durch Fingerprinting und N-terminale Sequenzierung identifiziert. 


\subsubsection{Interagierende Bereiche}

Durch die Zusammenführung der Daten von Liu et al. (Liu et al., 2006), von Boon et al. und Grainger et al. (Boon et al., 2006; Grainger et al., 2005) und der Ergebnisse dieser Arbeit kann das Modell für eine Interaktionsfläche, siehe Abbildung 4.1, unterstützt werden, welches nur in wenigen Punkten den Daten von Liu et al. widerspricht:

\begin{tabular}{l|l|l|l|l|l|l|l|l|}
\hline \multicolumn{1}{l}{123} \\
\cline { 2 - 6 } hSnu114
\end{tabular}

\begin{tabular}{|c|c|c|c|c|c|c|c|}
\hline & & & & & \\
\hline & & & & & 1600 & 1816 & 2030 \\
\hline U5-200K & DEAD & HelicC & 1. Sec63 & DEAD & & 2. Sec63 & 2138 \\
\hline
\end{tabular}

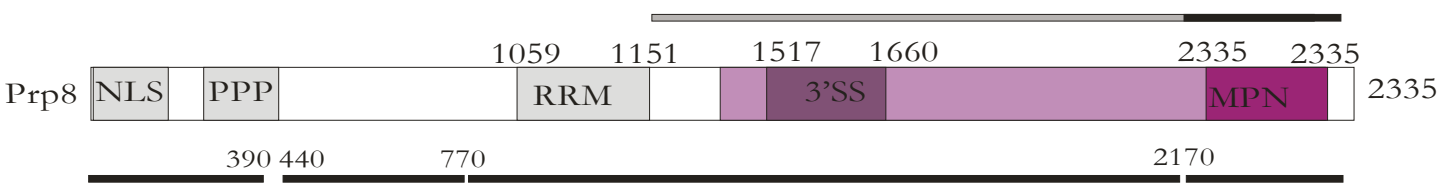

Funktionelle Einheiten nach Grainger et al.

Abbilung 4.1: Identifizierte interagierende Bereiche aus dem präparierten heterotetrameren Komplex. Die interagierenden Bereiche sind durch graue-schwarze Balken über den Proteinen, bzw. farblich dargestellt. Der minimale Interagtionskern ist durch den schwarzen Anteil über den Proteinen dargestellt.

In dieser Arbeit können die von Liu et al. gefundenen Interaktionen biochemisch bestätigt werden. Die geschützten Bereiche der Proteine decken sich mit den durch Two Hybrid-Analysen gefundenen Daten mit Ausnahme der Interaktionen mit dem NTerminus von Prp8 (Prp8-1). Außerdem ist der geschützte Bereich in Prp8 deutlich größer als der Teil, der in Liu et al. mit Prp8-6 nur die MPN-Domäne umfaßt. Im Falle des U5-200K ist der bei Liu et al. beschriebene Bereich mit U5-200K-4 (siehe Abbildung 3.11) nur bedingt zu identifizieren und erstreckt sich über die in U5-200K-5 gefundene Sec63-Domäne. Allerdings wird etwa die Hälfte des U5-200K-4 definierten Fragmentes, nämlich seine zweite Helicase-Domäne bestätigt. Die Aussagen für hSnu114 decken sich gut mit den vorhandenen Daten. Die Bindung erstreckt sich über das gesamte Protein 
mit Ausnahme des N-Terminus. Allerdings sind die minimalen Interaktionsbereiche vor allem in den C-Termini zu finden. Bei Prp8 deckt sich Prp8-6 mit der bei Grainger et al. gefundenen Domäne IV, bzw. der MPN-Domäne. Im Falle von U5-200K ist U5-200K-5 (Sec63-Domäne) nicht in den Two Hybrid-Daten gefunden worden. Die Ergebnisse für hSnu114 stimmen mit den vorhandenen Daten weitestgehend überein und werden auf den Bereich des hSnu114-3, nicht hSnu114-2 und 3, reduziert, was den EF-2-Domänen IV und V bei Liu et al. gleichkommt. Allerdings deuten auch genügend Daten auf eine breite Interaktionsfläche beginnend hinter der aziden N-terminalen Domäne einschließlich des restlichen Proteins. Das würde den Ergebnissen von Liu et al. vollständig entsprechen.

\subsubsection{Ausblick}

Den nächsten wichtigen Schritt für die Definition der Interaktionsplattform des heterotetrameren Komplexes stellt die Rekonstitution aus Fusionsproteinen - am sinnvollsten in Insektenzellen mit dem MultiBac-System - dar.

Im MultiBac-System sind verschiedene Konstrukte unterschiedlicher Länge ohne weiteres generierbar und auch variabel miteinander kombinierbar. Ein so rekonstituierter Partikel wäre nach der Rekonstitution des gesamten Partikels der erste Schritt zur Kristallisation - nach den Einzelproteinen, sollte deren Expression in ihrem nativen Zustand möglich sein. Die Expression, Reinigung und Kristallisation der Proteinbereiche aus dem Interaktionskern stellt das Fundament der Strukturaufklärung des Partikels dar. Aufbauend auf dieser Teilstruktur können die Proteinfragmente immer größer gewählt werden, bis man den größtmöglichen oder sogar aus Vollängenproteinen bestehenden Partikel rekonstituieren kann. 


\subsection{Vorschlag eines Modells}

Beginnend von den Sequenzvergleichen (Fabrizio, 1997) und den bekannten Strukturen (Jorgensen, 2002; Jorgensen, 2003) bzw. den genetischen Untersuchungen (Brenner, 2005), kann man von der Konservierung sowohl von Sequenz, als auch von Funktion und Form der homologen Protein Snu114p in S. cerevisiae und hSnu114 in H. sapiens ausgehen.

Die Sequenzübereinstimmung zwischen eEF-2 und Snu114p in Hefe ist zu 26\% identisch und zu $46 \%$ ähnlich (Brenner, 2005). Auf dieser Übereinstimmung aufbauend wurde mit ClustalW (Thompson, 1994) und MODELLER (Sali, 1993) ein Modell auf der Struktur von eEF-2 (Jorgensen, 2003) erstellt und durch die genetischen Studien von Brenner et al. (Brenner, 2005) überprüft. In dieser Studie wurden hitze- und kältesensitive Mutanten generiert und durch Sequenzierung überprüft. Die Mutationen wurden im Modell identifiziert und ihr Gewicht durch die Untersuchung auf synthetische Wachstumsdefekte mit weiteren U5-Proteinen festgestellt.

Die Sequenzübereinstimmung zwischen hSnu114 und Snu114p beträgt 32\%, die Übereinstimmung von hSnu114 mit dem C. elegans Homolog Caeel-116H sogar 74 \%, bzw. die Ähnlichkeit $86 \%$ (Fabrizio et al., 1997). Die Proteine aus Hefe, Wurm und Mensch besitzen die N-terminale azide Domäne, wobei die Proteine aus Mensch und Hefe bereits zu $28 \%$ identisch sind.

Aufgrund dieser Tatsachen und da Antibiotika aus verschiedenen Gründen Spleißreaktionen inhibieren können (siehe (Hertweck, 2002) und eigene nicht gezeigte Spleiß-Assays mit Fussidinsäure, einem Strukturhomolog des Sordarins), also Antibiotka eine ähnlich Struktur während des Spleißens binden können, wie bei der bakteriellen Translation, kann man folgendes Modell in Übereinstimmung zu Brenner et al. (Brenner, 2005) vorschlagen: 
A

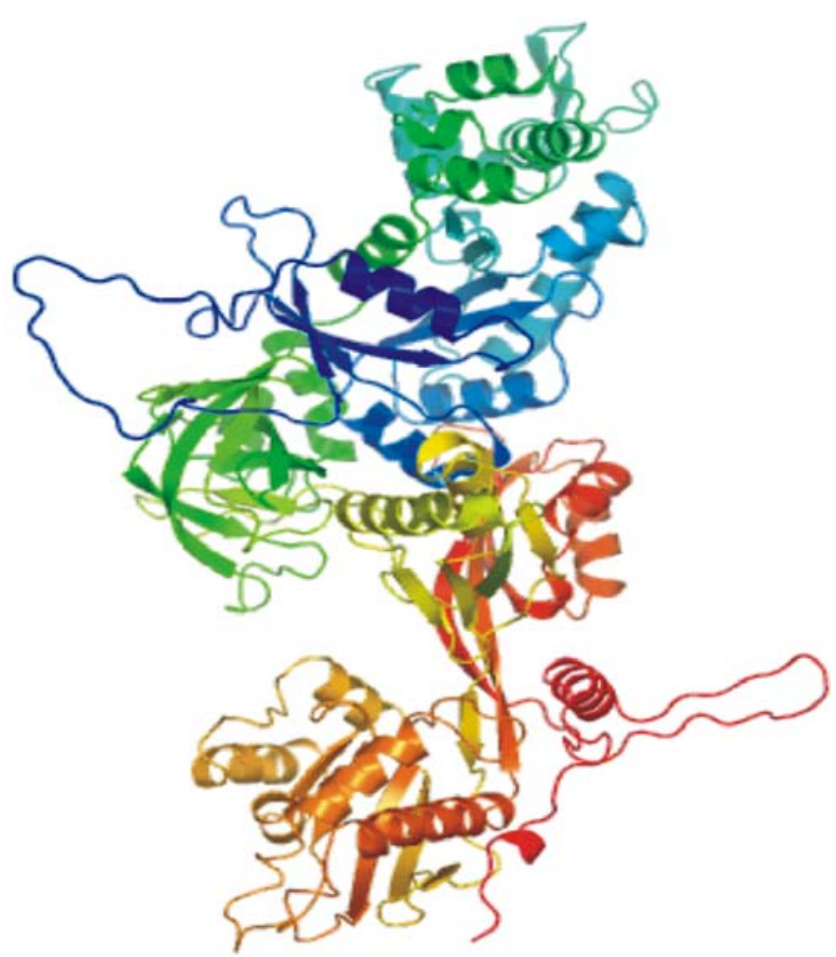

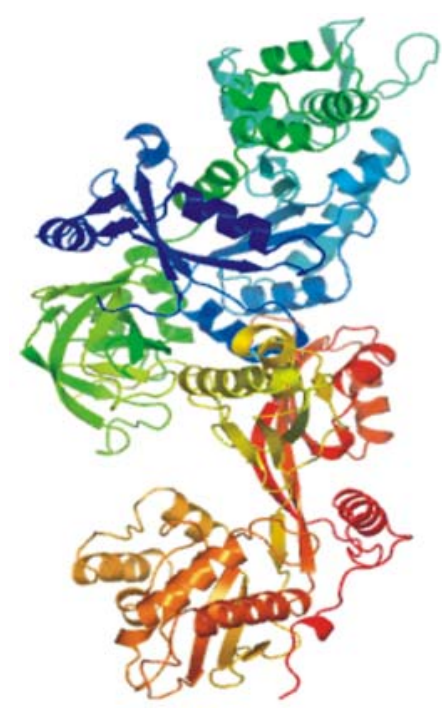

Abbildung 4.2: Strukturmodell von hSnu114 ohne den aziden N-Terminus (A) anhand der Stuktur von eEF-2 (1NOU und 1NOV) (3D-Alignment Server) modelliert. In (B) ist das Modell von eEF-2 ohne Sordarin (Jorgensen, 2003).

Das Ziel für zukünftige Studien ist, Teile bzw. die gesamte Struktur von hSnu114 zu lösen und dieses Modell zu unterstützen und die Bereiche, die im Modell schwach strukturiert dargestellt werden genau abzubilden (roter Loop im unteren rechten Drittel und blauer Loop im oberen linken Viertel). Wegen der hohen Konservation der Sequenz kann man prinzipiell von einer ähnlichen Struktur ausgehen. Die Interaktionsbereiche mit den U5-Proteinen sind interessante Ziele für die Strukturanalysen, weil so die Art und Weise ihres Zusammenspiels verstanden werden kann. Das ist insbesondere bei dem U5-snRNP von großem Interesse, da man zwar weiß, welche Aktivitäten vermittelt werden, aber nicht wie. Grade kürzlich wurde die These eines „power stroke“ aufgebracht (Liu et al., 2006). In diesem Modell wird durch die Hydrolyse eines Triphosphates ein Stoß durch das U5-snRNP übertragen, sodaß die notwendigen strukturellen Umlagerungen stattfinden können. 


\subsection{Abschluß und Ausblick}

Es gelang zwar nicht eine Struktur von einem U5-Protein zu lösen, allerdings konnten Informationen zur Interaktionsfläche der U5-spezifischen Proteine gesammelt werden.

Die Etablierung des Insektenzellsystems und des MultiBac-Systems machen nun Experimente möglich, die bislang nicht denkbar waren, wie beispielsweise die heterologe Expression in Zellinien hoher Eukaryonten. Die Möglichkeit, alle offensichtlich miteinander interagierenden Proteine, bzw. nur die dafür notwenigen Domänen, in diesem eukaryonten Expressionssystem zu exprimieren, war bis zu diesem Zeitpunkt nicht gegeben. Die vorliegenden Ergebnisse ermöglichen die Rekonstitution des interagierenden Kerns und dessen Charakterisierung mit biochemischen und strukturbiologischen Mitteln.

Das Modell von hSnu114, das hier vorgestellt wurde, basiert auf bioinformatischen Analysen und den genetischen Untersuchungen von Brenner et al. (Brenner et al., 2005) Studien in Hefe. 


\section{Anhang}

\subsection{Verwendete Strukturen}

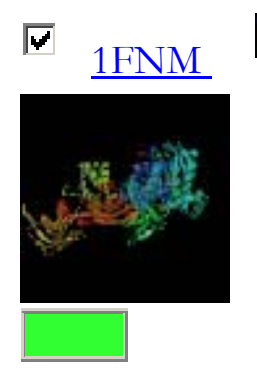

Characteristics

Release Date: 22-Nov-2000 Exp. Method: X Ray Diffraction Resolution: $2.80 \AA$

Classification Translation

Compound Mol. Id: 1 Molecule: Elongation Factor G Mutation: H573A

Authors Laurberg, M., Kristensen, O., Martemyanov, K., Gudkov, A.T., Nagaev, I., Hughes, D., Liljas, A.

\section{1EFG VI THE CRYSTAL STRUCTURE OF ELONGATION FACTOR G COMPLEXED WITH GDP, AT 2.7 ANGSTROMS RESOLUTION}

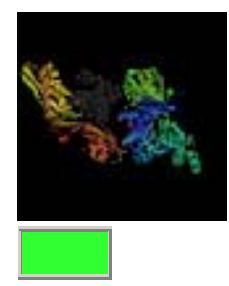

Characteristics

Release Date: 14-Feb-1995 Exp. Method: X Ray Diffraction Resolution: $2.70 \AA$

Classification Elongation Factor

Mol. Id: 1 Molecule: Elongation Factor G Mol. Id: 2

Compound Molecule: Elongation Factor G Mol. Id: 3 Molecule: Elongation Factor $\mathrm{G}$

Authors Czworkowski, J., Wang, J., Steitz, T.A., Moore, P.B.

\section{च 2 EFG VE}

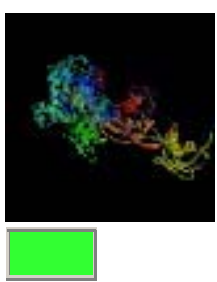

Characteristics

Release Date: 30-Sep-1999 Exp. Method: X Ray Diffraction Resolution: $2.60 \AA$

Classification Protein Binding 
Compound Mol. Id: 1 Molecule: Protein (elongation Factor G) Mol. Id: 2

Molecule: Protein (elongation Factor G Domain 3)

Authors Czworkowski, J., Wang, J., Steitz, T.A., Moore, P.B.

\section{1DAR DE ELONGATION FACTOR G IN COMPLEX WITH GDP}

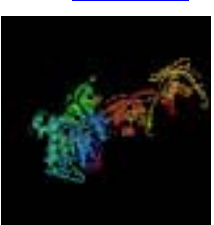

Characteristics

Release Date: 11-Jul-1996 Exp. Method: X Ray Diffraction

Resolution: $2.40 \AA$

Classification Translational Gtpase

Compound Mol. Id: 1 Molecule: Elongation Factor G

Authors

al-Karadaghi, S., Aevarsson, A., Garber, M., Zheltonosova, J., Liljas, A.

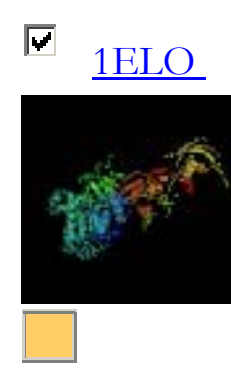

Characteristics

Classification

Compound

Authors
Release Date: 01-Aug-1996 Exp. Method: X Ray Diffraction

Resolution: $2.80 \AA$

Elongation Factor

ELONGATION FACTOR G WITHOUT NUCLEOTIDE

\section{ᄃ 1 KTV Q1 Nucleotide}

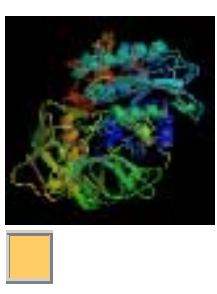

Characteristics

Classification

Compound

Authors
Release Date: 23-Dec-2003 Exp. Method: X Ray Diffraction

Resolution: $3.80 \AA$

Translation

Mol. Id: 1 Molecule: Elongation Factor G

Laurberg, M., Kristensen, O., Su, X.D., Liljas, A.

1N0U VI 


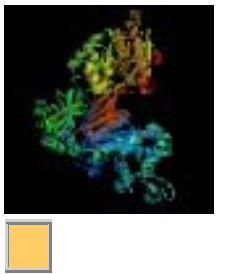

Characteristics Release Date: 11-Feb-2003 Exp. Method: X Ray Diffraction Resolution: $2.12 \AA$

Classification Translation

Compound Mol. Id: 1 Molecule: Elongation Factor 2

Authors Joergensen, R., Ortiz, P.A., Carr-Schmid, A., Nissen, P., Kinzy, T.G., Andersen, G.R.

V $1 \mathrm{~N} 0 \mathrm{~V}$ (1) Crystal structure of elongation factor 2

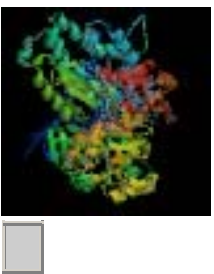

Characteristics

Classification

Compound

Authors
Release Date: 27-Nov-2002 Exp. Method: X Ray Diffraction Resolution: $2.85 \AA$

Translation

Mol. Id: 1 Molecule: Elongation Factor 2

Joergensen, R., Ortiz, P.A., Carr-Schmid, A., Nissen, P., Kinzy, T.G., Andersen, G.R.

\subsection{Tabelle der CD-Spektren}

$\begin{array}{llll} & & & 8 \text { His-116k } \\ \text { nm } & 8 \text { His- } \Delta \text { N-116k }+ \text { GTP } & 8 \text { His-116k }+ \text { GTP } & -1,7102 \\ 250 & -0,50004 & -0,17987 & -1,6816 \\ 249,5 & -0,54753 & -0,21277 & -1,6818 \\ 249 & -0,57664 & -0,22027 & -1,8288 \\ 248,5 & -0,48383 & -0,24446 & -1,6774 \\ 248 & -0,07691 & -0,32042 & -1,6524 \\ 247,5 & -0,00039202 & -0,27095 & -1,5144 \\ 247 & 0,040286 & -0,35682 & -1,5254 \\ 246,5 & -0,42391 & -0,3751 & -1,4556 \\ 246 & -0,42813 & -0,49725 & -1,493 \\ 245,5 & -0,39719 & -0,46312 & -1,82 \\ 245 & -0,31982 & -0,63535 & -2,0409 \\ 244,5 & -0,28753 & -0,61223 & -2,1488 \\ 244 & -0,58497 & -0,69352 & -2,3359 \\ 243,5 & -0,61231 & -0,70129 & -2,3697 \\ 243 & -0,71295 & -0,74168 & -2,3403 \\ 242,5 & -0,72736 & -0,83325 & -2,5006 \\ 242 & -0,7846 & -0,78803 & -2,1261 \\ 241,5 & -1,0852 & -0,92349 & -2,2897 \\ 241 & -1,2527 & -0,86759 & \end{array}$




\begin{tabular}{|c|c|c|c|}
\hline 240,5 & $-1,5244$ & $-1,1533$ & $-2,1385$ \\
\hline 240 & $-1,5493$ & $-1,0443$ & $-2,1279$ \\
\hline 239,5 & $-1,5275$ & $-1,208$ & $-2,423$ \\
\hline 239 & $-1,8804$ & $-1,3168$ & $-2,9563$ \\
\hline 238,5 & $-1,9861$ & $-1,535$ & $-2,9922$ \\
\hline 238 & $-2,2806$ & $-1,7236$ & $-3,2719$ \\
\hline 237,5 & $-2,358$ & $-1,6537$ & $-3,3914$ \\
\hline 237 & $-2,8261$ & $-1,7675$ & $-3,353$ \\
\hline 236,5 & $-3,0122$ & $-1,7992$ & $-3,5603$ \\
\hline 236 & $-2,4091$ & $-2,121$ & $-3,7549$ \\
\hline 235,5 & $-2,4994$ & $-2,4139$ & $-3,851$ \\
\hline 235 & $-2,4941$ & $-2,7004$ & $-4,1428$ \\
\hline 234,5 & $-3,3016$ & $-2,9369$ & $-4,2933$ \\
\hline 234 & $-3,7455$ & $-3,2496$ & $-4,5303$ \\
\hline 233,5 & $-4,089$ & $-3,4078$ & $-4,8806$ \\
\hline 233 & $-4,3988$ & $-3,5037$ & $-5,3781$ \\
\hline 232,5 & $-4,7486$ & $-3,7038$ & $-6,0263$ \\
\hline 232 & $-5,2597$ & $-3,8453$ & $-6,3617$ \\
\hline 231,5 & $-5,5926$ & $-4,2654$ & $-6,8239$ \\
\hline 231 & $-5,9406$ & $-4,6486$ & $-6,8391$ \\
\hline 230,5 & $-6,1092$ & $-5,0817$ & $-7,1134$ \\
\hline 230 & $-6,725$ & $-5,3568$ & $-6,965$ \\
\hline 229,5 & $-7,4905$ & $-5,3725$ & $-6,9642$ \\
\hline 229 & $-8,2849$ & $-5,5672$ & $-7,2196$ \\
\hline 228,5 & $-8,4756$ & $-5,8204$ & $-7,7773$ \\
\hline 228 & $-8,5545$ & $-6,062$ & $-8,3964$ \\
\hline 227,5 & $-7,9231$ & $-6,3813$ & $-8,5649$ \\
\hline 227 & $-8,0011$ & $-6,5682$ & $-8,6622$ \\
\hline 226,5 & $-8,2332$ & $-6,6527$ & $-8,8297$ \\
\hline 226 & $-8,7906$ & $-6,7707$ & $-9,0832$ \\
\hline 225,5 & $-9,2845$ & $-7,1848$ & $-9,4481$ \\
\hline 225 & $-9,704$ & $-7,2099$ & $-9,3735$ \\
\hline 224,5 & $-9,5049$ & $-7,3446$ & $-9,4426$ \\
\hline 224 & $-9,7978$ & $-7,3765$ & $-9,3226$ \\
\hline 223,5 & $-9,3504$ & $-7,4532$ & $-9,5222$ \\
\hline 223 & $-9,2466$ & $-7,6741$ & $-9,6745$ \\
\hline 222,5 & $-9,757$ & $-7,7407$ & $-9,6144$ \\
\hline 222 & $-9,8344$ & $-7,8038$ & $-10,05$ \\
\hline 221,5 & $-10,421$ & $-7,6575$ & $-10,059$ \\
\hline 221 & $-10,476$ & $-7,7919$ & $-10,152$ \\
\hline 220,5 & $-10,087$ & $-8,0687$ & $-9,6629$ \\
\hline 220 & $-10,072$ & $-8,121$ & $-9,3395$ \\
\hline 219,5 & $-9,9811$ & $-8,4018$ & $-9,0761$ \\
\hline 219 & $-10,067$ & $-8,2743$ & $-8,2918$ \\
\hline 218,5 & $-10,314$ & $-8,1523$ & $-8,8669$ \\
\hline 218 & $-10,026$ & $-8,1651$ & $-8,7192$ \\
\hline 217,5 & $-10,101$ & $-7,9966$ & $-8,9333$ \\
\hline 217 & $-9,7291$ & $-7,919$ & $-9,2353$ \\
\hline 216,5 & $-9,4693$ & $-8,2846$ & $-8,7776$ \\
\hline 216 & $-9,1591$ & $-8,3956$ & $-8,7651$ \\
\hline 215,5 & $-9,3759$ & $-8,5381$ & $-9,217$ \\
\hline 215 & $-9,2119$ & $-8,3392$ & $-9,6087$ \\
\hline 214,5 & $-7,8884$ & $-7,7884$ & $-9,787$ \\
\hline 214 & $-7,6693$ & $-7,6377$ & $-9,021$ \\
\hline 213,5 & $-7,4116$ & $-7,7384$ & $-8,4582$ \\
\hline 213 & $-7,6531$ & $-8,4617$ & $-8,6315$ \\
\hline
\end{tabular}




$\begin{array}{llll}212,5 & -7,1196 & -8,8684 & -9,3461 \\ 212 & -7,265 & -8,9502 & -10,5 \\ 211,5 & -8,331 & -8,9576 & -10,905 \\ 211 & -7,9784 & -8,8327 & -11,988 \\ 210,5 & -7,7271 & -8,9373 & -11,566 \\ 210 & -5,9659 & -9,3786 & -11,327 \\ 209,5 & -5,8074 & -9,4554 & -10,996 \\ 209 & -6,0989 & -9,3016 & -10,6 \\ 208,5 & -7,0632 & -9,4844 & -11,564 \\ 208 & -5,3336 & -9,5252 & -12,88 \\ 207,5 & -5,1105 & -9,8441 & -14,45 \\ 207 & -4,7141 & -10,01 & -14,881 \\ 206,5 & -4,3576 & -9,404 & -16,845 \\ 206 & -4,4768 & -8,7201 & -15,404 \\ 205,5 & -3,9047 & -8,6115 & -11,103 \\ 205 & -3,2076 & -8,1463 & -11,428 \\ 204,5 & -1,7692 & -8,1312 & -6,4121 \\ 204 & 0,01472 & -7,8793 & -8,9384 \\ 203,5 & -1,039 & -7,1098 & -3,5061 \\ 203 & -1,0796 & -5,5039 & 2,1448 \\ 202,5 & -0,3251 & -4,2824 & -0,76265 \\ 202 & 0,03383 & -4,0328 & 2,9729 \\ 201,5 & 1,5087 & -2,5552 & -9,2202 \\ 201 & 2,5005 & -1,1869 & -4,78 \\ 200,5 & 1,8013 & -0,79587 & -5,6562 \\ 200 & 2,8334 & 0,55174 & 6,0958\end{array}$

Tabelle der CD-SpektrenTabelle 3.x: Daten der Cd-Spektren gemittelt aus je fünf Messungen und Normalisiert.

\subsection{Verwendete Abkürzungen}

$\begin{array}{ll}\text { ad } & \text { bis } \\ \text { Amp } & \text { Ampicillin } \\ \text { APS } & \text { Ammoniumpersulfat } \\ \text { bp } & \text { Basenpaare } \\ \text { bzw. } & \text { beziehungsweise } \\ { }^{\circ} \mathrm{C} & \text { Grad Celsius } \\ \text { Cam } & \text { Chloramphenicol } \\ \text { cm } & \text { Zentimeter } \\ \text { C-terminal } & \text { carboxyterminal } \\ \text { DNA } & \text { Desoxyribonukleinsäure } \\ \text { dNTP } & \text { Desoxyribonukleotid-5 }{ }^{-} \text {-triphosphat } \\ \text { ds } & \text { doppelsträngig } \\ \text { DTT } & \text { Dithiothreitol } \\ \text { E. } & \text { Escherichia } \\ \text { EDTA } & \text { Ethylendiamintetraacetat, Dinatrium Salz } \\ \text { et al. } & \text { et alteri }\end{array}$


Fa.

x g

GST

h

IMAC

IPTG

Kan

$\mathrm{kb}$

$\mathrm{kDa}$

1

LB

$\log$

m

M

$\mu$

MCS

$\mathrm{M}^{3} \mathrm{G}$

$\mathrm{M}^{7} \mathrm{G}$

$\min$

$\mathrm{ml}$

$\mu \mathrm{M}$

$\mathrm{mM}$

$\mathrm{mm}$

mRNA

n

$\mathrm{N}$-terminal

Ni-NTA

NLS

NMR

OD

$\%$

$\mathrm{OH}$

PAGE

PCR

$\mathrm{pH}$

RNA

prä

SDS
Firma

-fache Erbeschleunigung

Glutathion S-Transferase

Stunde

Immobilisierte Metal Ionen Affinitäts-Chromatographie

Isopropyl- $\beta$-D-thiogalactopyranosid

Kanamycin

Kilobasenpaare

Kilodalton

Liter

Luria Bertani

Logarithmus (dekalischer)

Milli-

Molar

Mikro-

Multiple Cloning Site

2,2,7-Trimethylguanosin

7-Methylguanosin

Minute

Milliliter

Mikromolar

Millimolar

Millimeter

messenger Ribonukleinsäure

Nano-

aminoterminal

Nickelchelat-Nitrilotriacetic Acid

nukleares Lokalisationssignal

Nuclear Magnetic Resonance

Optische Dichte

Prozent

Hydroxy-

Polyacrylamid-Gelelektrophorese

Polymerase-Ketten-Reatkion

negativer dekadischer Logarithmus der Protonenkonzentration

Ribonukleinsäure

vor

Natriumdodecylsulfat 
sn

snRNP

RT

TBE

TEMED

Tet

Tris

$\mathrm{U}$

U

$\mathrm{rpm}$

UV

$\mathrm{V}$

$\mathrm{v} / \mathrm{V}$

Vol.

$\mathrm{w} / \mathrm{v}$ small nuclear

small nuclear ribonucleoprotein particle

Raumtemperatur

Tris-Borat-EDTA

$\mathrm{N}, \mathrm{N}, \mathrm{N}$, N`'Tetramethylethylendiamin

Tetracyclin

Tris-(hydroxymethyl)-aminomethan

(Einheit der Enzymaktivität)

uridin-rich

Umdrehungen pro Minute

Ultraviollet

Volt

Volumen pro Volumen

Volumen

Masse pro Volumen 


\section{Literaturverzeichnis}

Achsel, T., Ahrens, K., Brahms, H., Teigelkamp, S. and Lührmann, R. (1998) The human U5$220 \mathrm{kD}$ protein (hPrp8) forms a stable RNA-free complex with several U5-specific proteins, including an RNA unwindase, a homologue of ribosomal elongation factor EF2, and a novel WD-40 protein. Mol Cell Biol, 18, 6756-6766.

Andersen, G.R., Nissen, P. and Nyborg, J. (2003) Elongation factors in protein biosynthesis. TRENDS in Biochemical Sciences, 28, 434-442.

Bach, M., Winkelmann, G. and Lührmann, R. (1989) 20 S small nuclear ribonucleoprotein U5 shows a surprisingly complex protein composition. Proc Natl Acad Sci US A, 86, 60386042 .

Behrens, S.E., Kastner, B. and Lührmann, R. (1993) Preparation of U small nuclear ribonucleoprotein particles. Academic Press, London

Berger, I., Fitzgerald, D.J. and Richmond, T.J. (2004) Baculovirus expression system for heterologous multiprotein complexes. Nat Biotechnol.

Blum, H., Beier, H. and Gross, H.J. (1987) Improved silver staining of plant proteins, RNA and DNA polyacrylamid gels. Elektrophoresis, 8, 93-99.

Bochnig, P., Reuter, R., Bringmann, P. and Lührmann, R. (1987) A monoclonal antibody against 2,2,7-trimethylguanosine that reacts with intact U1 snRNPs as well as with 7methylguanosine-capped RNAs. Eur. J. Biochem., 168, 461-467.

Boon, K.-L., Norman, C.M., Grainger, R.J., Newman, A. and Beggs, J.D. (2006) Prp8p dissection reveals domain structure and protein interaction sites. $\mathrm{RN} A, 12,1-8$.

Brahms, H., Meheus, L., de Brabandere, V., Fischer, U. and Luhrmann, R. (2001) Symmetrical dimethylation of arginine residues in spliceosomal $\mathrm{Sm}$ protein $\mathrm{B} / \mathrm{B}^{\prime}$ and the Sm-like protein LSm4, and their interaction with the SMN protein. RNA, 7(11), 1531-1542.

Branden, C.T., J. Tooze (1991) Introduktion to Protein Structure. Garland, New York.

Brenner, T.J., Guthrie, C. (2005) Genetic Analysis Reveals a Role for the C Terminus of the Saccharomyces cerevisiae GTPase Snu114 During Spliceosome Activation. genetics, 170, 1063-1080.

Bringmann, P. and Lührmann, R. (1986) Purification of the individual snRNPs U1, U2, U5 and U4/U6 from HeLa cells and characterization of their protein constituents Embo J, 5, 3509-3516.

Bringmann, P., Rinke, J., Appel, B., Reuter, R. and Lührmann, R. (1983) Purification of snRNPs $\mathrm{U} 1, \mathrm{U} 2, \mathrm{U} 4, \mathrm{U} 5$ and U6 with 2,2,7- trimethylguanosine-specific antibody and definition of their constituent proteins reacting with anti-Sm and anti-(U1)RNP antisera. Embo J, 2, $1129-1135$.

Brown, J.D. and Beggs, J.D. (1992) Roles of PRP8 protein in the assembly of splicing complexes. EMBO J 11(10), 3721-3729. 
Burge, C.B., Tuschl, T. and Sharp, P.A. (1999) Splicing of Precursors to mRNAs by the Spliceosomes.

Cech, T.R. (1990) SELF-SPLICING OF GROUP I INTRONS. Annu Rev Biochem, 59, 543-568.

Changyu, W., Chua, K., Seghezzi, W., Lees, E., Gozani, O. and Reed, R. (1998) Phosphorylation of spliceosomal protein SAP 155 coupled with splicing catalysis. genes Dev, 12, 1409-1414.

Collins, C.A. and Guthrie, C. (1999) Allele-specific genetic interactions between Prp8p and RNA active site residues suggest a function for Prp8 at the catalytic core of the spliceosome. Genes Dev, 13, 1970-1982.

Dale, G.E., Oefner, C. and D' Acry, A. (2003) The protein as a variable in protein crystallization. Journal of Structural Biology, 142, 88-97.

Dignam, J.D., Lebovitz, R.M. and Roeder, R.G. (1983) Accurate transcription initiation by RNA polymerase II in a soluble extract from isolated mammalian nuclei. Nucl. Acids. Res., 11, 1475-1489.

Dominguez, J.M. and Martın, J.J. (2001) Identification of a Putative Sordarin Binding Site in Candida albicans Elongation Factor 2 by Photoaffinity Labeling*. Journal ofBiological Chemistry, 276, 31402-31407.

Fabrizio, P., Laggerbauer, B., Lauber, J., Lane, W.S. and Lührmann, R. (1997) An evolutionarily conserved U5 snRNP-specific protein is a GTP-binding factor closely related to the ribosomal translocase EF-2. Embo J, 16, 4092-4106.

GibcoBRL. Guide to Baculovirus Expression Vector Systems and Insect Cell Culture Techniques.

Grainger, R.J. and Beggs, J.D. (2005) Prp8 protein: At the heart of the spliceosome. RNA, 11, 533-557.

Hanahan, D., Jessee, J. and Bloom, F.R. (1985) Plasmid transformation of Escherichia coli and other bacteria. Methods Ensymol, 63-113.

Hausner, T.P.G., L. M.; Weiner, A. M. (1990) Evidence for base-pairing between mammalian U2 and U6 small nuclear ribonucleoprotein particles. Genes Dev, 4, 2146-2156.

Hertweck, M., Hiller, R. and W., M. (2002) Inhibition of nuclear pre-mRNA splicing by antibiotics in vitro. Eur. J. Biochem., 269, 175-183.

Hoffman, B.J., Broadwater, J.A., Johnson, P., Harper, J., Fox, B.G. and Kenealy, W.R. (1995) Lactose fed-batch overexpression of recombinant metalloproteins in Escherichia coli BL21 (DE3): process control yielding high levels of metal-incorporated, soluble protein. Protein Expr Purif, 6, 646-654.

Invitrogen. (2002) Bac-to-Bac Baculovirus Expression System.

Jorgensen, R., Carr-Schmid, A., Ortiz, P.A., Kinzyb, T.G. and Andersena, G.R. (2002) Purification and crystallization of the yeast elongation factor eEF2. Acta Crystallographica Section D, D58, 712-715. 
Jorgensen, R., Ortiz, P.A., Carr-Schmid, A., Nissen, P., Kinzy, T.G. and Andersen, G.R. (2003) Two crystal structures demonstrate large conformational changes in the eukaryotic ribosomal translocase. Nat Struct Biol, 10(5), 379-385.

Kastner, B. (1998) Purification and electron microscopy of spliceosomal snRNPs. In J. Schenkel (Ed.) RNP particles, splicing and Autoimmune Diseases. Springer Lab Manual.

Konarska, M.M., Grabowski, P.J., Padgett, R.A. and Sharp, P. (1985) Characterization of the branch site in lariat RNAs produced by splicing of mRNA precursors. Nature, 313, $552-$ 557.

Kruger, K., Grabowski, P.J., Zaug, A.J., Sands, J., Gottschling, D.E. and Cech, T.R. (1982) Selfsplicing RNA: autoexcision and autocyclization of the ribosomal RNA intervening sequence of Tetrahymena. Cell, 31, 147-157.

Laemmli, U.K. (1970) Cleavage of structural proteins during the assembly of the head of bacteriophage $\lambda$. Nature, 227, 680-685.

Lamond, A.I. (1993a) A glimpse into the spliceosome. Curr Biol, 3, 62-64.

Lamond, A.I. (1993b) The spliceosome. Bioessays, 15, 595-603.

Lin, R.J., Newman, A.J., Cheng, S.C. and Abelson, J. (1985) Yeast mRNA Splicing in vitro. J. Biol. Chem., 260, 14780-14792.

Liu, S., Rauhut, R., Vornlocher, H.P. and Lührmann, R. (2006) The network of protein-protein interactions within the human U4/U6.U5 tri-snRNP. RNA, 12, 1418-1430.

Madhani, H.D. and Guthrie, C. (1992) A novel base-pairing interaction between U2 and U6 sn RNAs suggests a mechanism for the catalytic activation of the spliceosome. Cell, 71, 803817.

Maschhoff, K.L. and Padgett, R.A. (1993) The stereochemical course of the first step of premRNA splicing. Nucleic Acids Res, 21, 5456-5462.

Michel, F. and Ferat, J.-L. (1995) Structure and activities of group II introns. Annu Rev Biochem, 64, 435-461.

Misteli, T. (1999) RNA splicing: What has phosphorylation got to do with it? Curr Biol, 9, 198200.

Moore, M.J. and Sharp, P.A. (1993) Evidence for two active sites in the spliceosome provided by stereochemistry of pre-mRNA splicing. Nature, 365, 364-368.

Mullis, K.B. and Faloona, F.A. (1987) Specific synthesis of DNA in vitro via a polymerasecatalyzed chain reaction. Methods Ensymol, 155, 335-350.

Padgett, R.A., Podar, M., Boulanger, S.C. and Perlman, P.S. (1994) The stereochemical course of group II intron self-splicing. Science, 266, 1685-1688. 
Ponting, C.P. (2000) Proteins of the endoplasmatic-reticulum-associated degradation pathway: domain detection and function prediction. Biochem J, 351, 527-535.

Reed, R. (1989) The organization of 3' splice-site sequences in mammalian introns. Genes Dev, 3, 2113-2123.

Reed, R. and Palandjian, L. (1997) Spliceosome assembly. Oxford IRL Press, Oxford.

Sali, A. and Blundell, T.L. (1993) Comparative protein modelling by satisfaction of spatial restraints. J Mol Biol, 234, 779-815.

Sambrook, J., Fritsch, E.F. and Maniatis, T. (1989) Molecular Cloning - A Laboratory Manual. Cold Spring Harbor Laboratory Press. .

Sharp, P.A. (1985) On the origin of RNA splicing and introns. Cell, 42, 397-400.

Sharp, P.A. (1988) RNA splicing and genes. Jama, 260, 3035-3041.

Shastry, M., Nielsen, J., Ku, T., Hsu, M.-J., Liberator, P., Anderson, J., Schmatz, D. and Justice, M.C. (2001) Species-specific inhibition of fungal protein synthesis by sordarin: identification of a sordarin-specificity region in eukaryotic elongation factor 2 . Microbiology, 147, 383-390.

Sontheimer, E.J., Gordon, P.M. and Piccirilli, J.A. (1999) Metal ion catalysis during group II intron self-splicing: parallels with the spliceosome. Genes Dev, 13, 1729-1741.

Sontheimer, E.J. and Steitz, J.A. (1993) The U5 and U6 small nuclear RNAs as active site components of the spliceosome. Science, 262, 1989-1996.

Sontheimer, E.J., Sun, S. and Piccirilli, J.A. (1997) Metal ion catalysis during splicing of premessenger RNA. Nature, 388, 801-805.

Staley, J.P. and Guthrie, C. (1998) Mechanical devices of the spliceosome: Motors, Clocks, Springs, and Things. Cell, 92, 315-326.

Strauss, E.J. and Guthrie, C. (1991) A cold-sensitive mRNA splicing mutant is a member of the RNA helicase gene family. Genes Dev, 5, 629-641.

Thompson, J.D., Higgins, D.G. and Gibson, T.J. (1994) CLUSTALW: improving the sensitivity of progressive multiple sequence alignment through sequence weighting, position-specific gap penalties and weight matrix choice. Nucleic Acids Res, 22, 4673-4680.

Umen, J.G. and Guthrie, C. (1995) A novel role for a U5 snRNP protein in 3' splice site selection. Genes Dev, 9, 855-868.

Umen, J.G. and Guthrie, C. (1995) Prp16p, Slu7p, and Prp8p interact with the 3' splice site in two distinct stages during the second catalytic step of pre-mRNA splicing. $R N A, \mathbf{1 ( 6 )}$, 584-597.

Weber, K., Pringle, J.R. and Osborne, M. (1972) Measurement of molekular weights by electrophoresis on SDS-acrylamide gel. Methods Enzy 
Westermann, S., Avila-Sakar, A., Wang, H.-W., Niederstrasser, H., Wong, J., Drubin, D.G., Nogales, E. and Barnes, G. (2005) Formation of a Dynamic Kinetochore-Microtubule Interface through Assembly of the Dam1 Ring Complex. Mol Cell, 17, 277-290. 